CORVINUS UNIVERSITY OF BUDAPEST

\title{
EXAMINATION OF PHENOMENA AFFECTING THE DEPRECIATION OF FIXED ASSETS
}

\author{
PhD Dissertation
}

Nándor Kaliczka

Budapest

2013 


\section{Nándor Kaliczka}

Examination of Phenomena Affecting the Depreciation of Fixed Assets 
Department of Managerial Accounting

Supervisors: János Bosnyák Ph.D

Rezső Baricz CSc

Copyright ( Nándor Kaliczka, 2013.

All rights reserved. 


\section{Corvinus University of Budapest}

Management and Business Administration PhD Programme

Examination of Phenomena Affecting the Depreciation of Fixed Assets

(PhD Dissertation)

Nándor Kaliczka

Budapest

2013 


\section{Table of Contents}

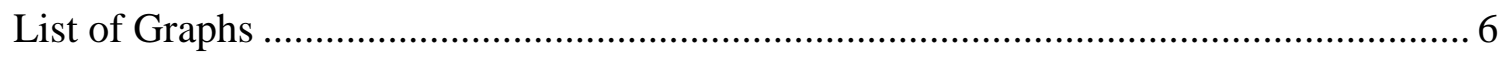

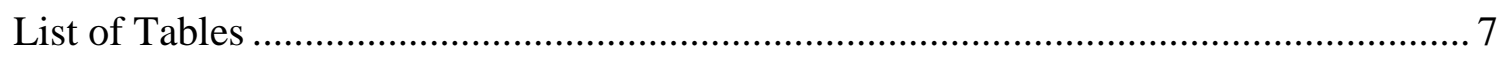

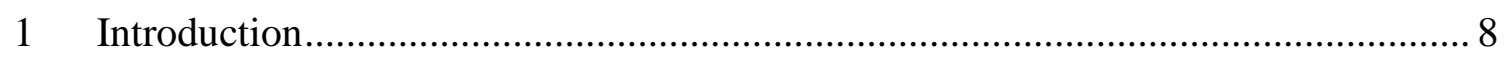

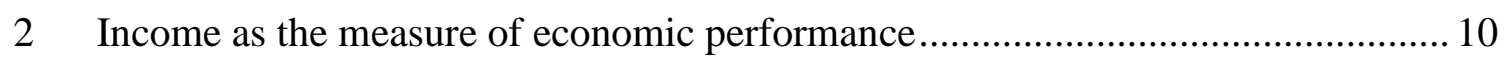

2.1 A brief overview of capital theory and its evolution..................................... 11

2.2 Capital maintenance concepts influencing income ...................................... 15

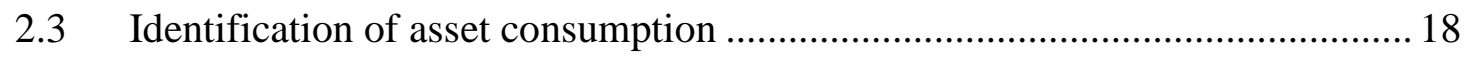

2.3.1 Cost allocation approach in early accounting literature.......................... 21

2.3.2 Reservation for future replacement or the sinking fund approach.............25

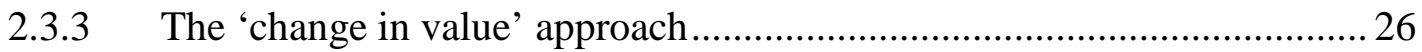

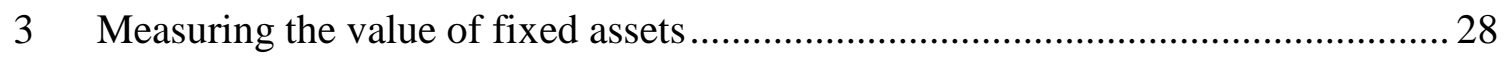

3.1 Methods used to measure asset value........................................................... 30

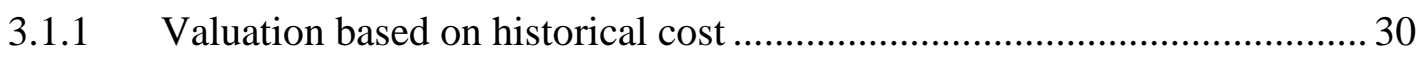

3.1.2 Historical cost adjusted for the effect of inflation ................................... 32

3.1.3 Measurement based on historical cost adjusted for asset specific price

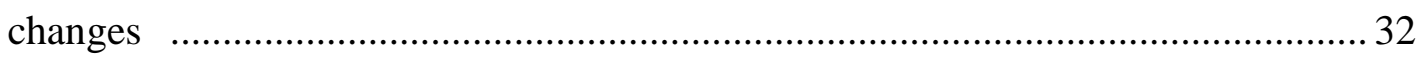

3.1.4 Asset value determination based on the market prices of the assets used.33

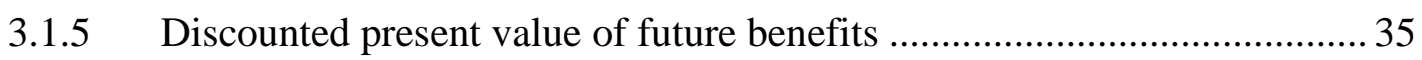

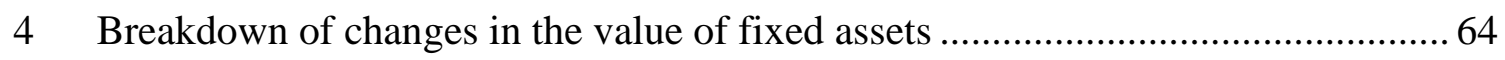

4.1 Change in the value assuming certainty and exact knowledge about the future... .64

4.1.1 Phenomena affecting the cross-section depreciation rate ........................ 71

4.1.2 Summary of the phenomena affecting the time series depreciation rate ... 72

4.2 Change in the value without certainty and exact knowledge about the future.. 74

4.3 The recognition of changes in the value of fixed assets in Hungarian and international accounting practice 
4.3.1 The approach to changes in the value of fixed assets in Hungarian accounting regulations

4.3.2 The approach to changes in the value of fixed assets in the International Financial Reporting Standards (IFRS)

4.4 The role of cross-section and time series depreciation in the determination of the change in the asset value and of the end-of-period asset value 85

4.5 The empirical examination of cross-section depreciation rate.......................... 86

4.5.1 The examination of depreciation rate based on market rentals 87

4.5.2 The empirical examination of cross-section depreciation rate based on second-hand market prices 87

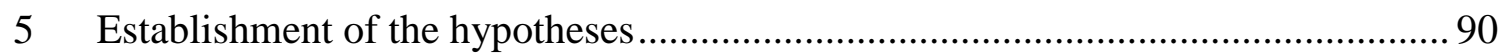

$5.1 \quad$ Research questions behind the hypotheses ............................................... 90

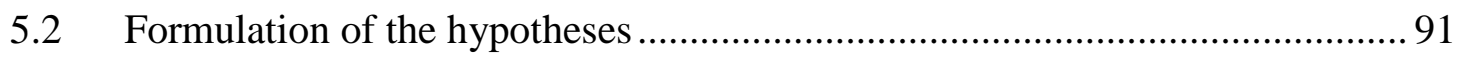

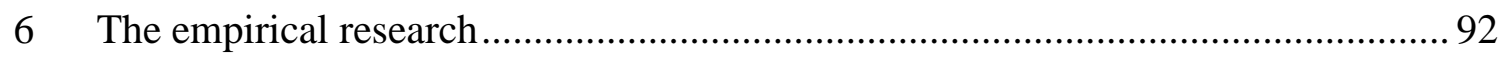

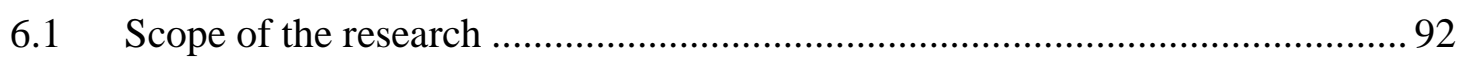

6.2 Preparation of the hypotheses' verification................................................... 93

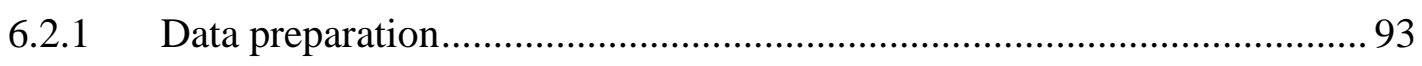

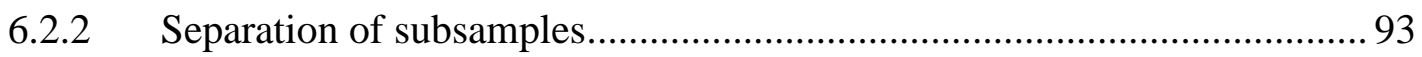

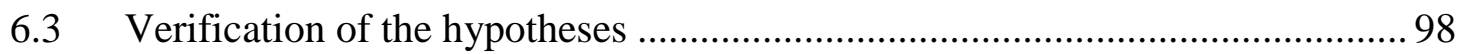

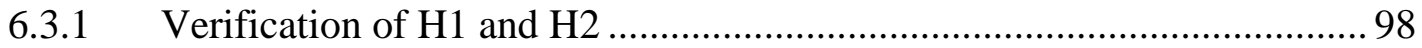

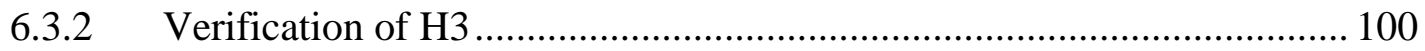

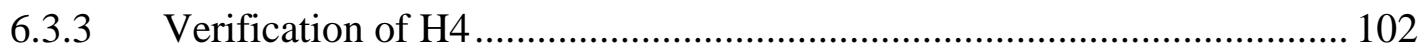

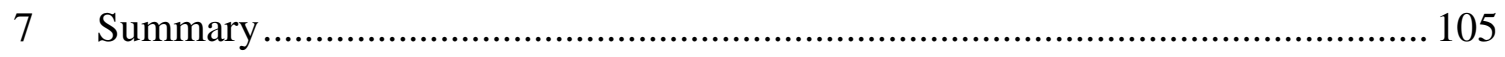

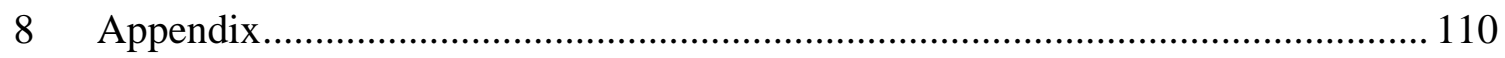

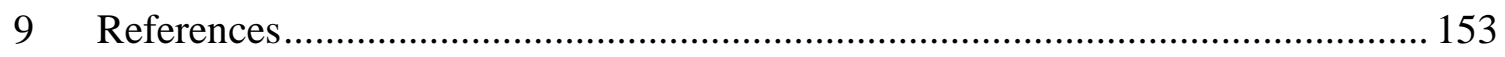

10 Publications of the author in the topic of the thesis ........................................ 159 


\section{List of Graphs}

Graph 1: Different dimensions and concepts of capital. (Source: own elaboration)....... 14

Graph 2: Relationship between the asset values as estimated and calculated using the linear allocation method. (Source: own elaboration).

Graph 3: How the choice of linear allocation or the 'change in the value' method to compute depreciation impacts on income. (Source: own elaboration).

Graph 4: Relationship between services embodied in the assets and periodical capital stock. (Source: own elaboration)

Graph 5: The different asset efficiency patterns as a function of asset age. (Source: own elaboration)

Graph 6: Age-value profiles eventuated by the different efficiency patterns. (Source: own elaboration)

Graph 7: Evolution of service values without and adjusted for disembodied obsolescence throughout the individual periods. (Source: own elaboration)

Graph 8: Evolution of asset values without and adjusted for disembodied obsolescence throughout the individual periods. (Source: own elaboration).

Graph 9: Evolution of service values without and adjusted for embodied obsolescence throughout the individual periods. (Source: own elaboration)

Graph 10: Evolution of asset values without and adjusted for embodied obsolescence throughout the individual periods. (Source: own elaboration)

Graph 11: Breakdown of the change in asset values according to age and time factors.

(Source: based on Hulten and Wykoff [1981a]). 66

Graph 12: Cross-section depreciation, time series depreciation and revaluation. (Source: own elaboration)

Graph 13: Summary of the phenomena affecting the time series depreciation rate.

(Source: own elaboration)

Graph 14: Change in the asset value without certainty and exact knowledge about the future (Source: own elaboration)

Graph 15: Prices of diesel-powered cars plotted against age and mileage. (Source: own elaboration) 93 


\section{List of Tables}

Table 1: Number of observation units in the individual clusters and the individual cluster centres. (Source: own elaboration) 95

Table 2: Estimated parameters of the Box-Cox transformation. (Source: own elaboration) 100

Table 3: Values of the regression based on the variable 'age'. (Source: own elaboration)

Table 4: Negative premiums in the individual clusters, broken down by clusters.

(Source: own elaboration) 103

Table 5: Depreciation rates computed for the individual clusters. (Source: own elaboration) 


\section{Introduction}

The concept of depreciation and the measurement of its value have long been a prominent issue in economic and accounting literature, the relevance of which is demonstrated by the great number of open questions related to the subject. In the last two centuries, several authors (researchers) dealt with the problem of depreciation, which not only contributed to the evolution of depreciation theory, but also gave rise to many new issues. The majority of these newly encountered problems appear to be inextricable, placing the subject in what seems to be an endless horizon.

The concept of depreciation is virtually inseparable from the concepts of capital and income, which appeared as individual measures in the economics literature of the early $20^{\text {th }}$ century. It was not until the $1930 \mathrm{~s}$ that economists began to focus on the interpretation of the concepts of business capital and income. One of the key issues in the determination of capital and income is how to measure the contribution of fixed assets to the corporate operational processes. The primary attribute of these fixed assets is that their service lifetime spans over several reporting periods. Preinreich [1937] differentiates between two main categories of fixed assets on the basis of the services these assets provide. One category encompasses assets providing a limited quantity of services, the other category includes fixed assets that have only limited possibilities to provide services. ${ }^{1}$ However, different approaches are needed to understand the consumption of the two categories of fixed assets; consequently in my dissertation I will only analyse the consumption of assets serving the company's activity during several periods, created by man, with a finite service lifetime, and with quantitative limitations concerning usability (finite number of times of usage). ${ }^{2}$ Asset value consumption may be substantiated in the form of cost allocation, sinking funds or actual changes in value; however of the three, only the 'actual change in value' approach is appropriate to arrive at the correct asset and income values.

\footnotetext{
${ }^{1}$ Examples of this category include patents, brand names, trademarks, licenses among other, as well as elements of knowledge capital.

${ }^{2}$ Hereinafter, these assets will be referred to as "fixed assets".
} 
Depreciation captures a certain part of the changes in the values of fixed assets within a period $;^{3}$ the manner of presenting this concept impacts business income as well as pricing the company's output which needs to include costs related to the consumption of fixed assets, in addition to current costs. Therefore the choice of the method to capture depreciation also influences the company's competitiveness on the capital and commodity markets. As a result, income calculation if faced with the problem of end-ofperiod valuation of fixed assets used (possessed), which is further complicated by the constant changes in prices.

The end-of-period value of fixed assets used may be calculated using the market prices of these assets or on the basis of the discounted present value of their future returns, where the return of the asset is usually identified as its theoretical rental. However, endof-period valuation of assets in both methods is derived from market prices, which is problematic because in reality relevant markets for fixed assets hardly ever exist. As a consequence, the end-of-period asset value is determined using estimated depreciation rates calculated with due regard to the phenomena influencing asset value. In my dissertation, when attempting to determine depreciation, I shall mainly focus on the phenomena of exhaustion, deterioration and obsolescence, and analyse the effects of these using Jorgenson's capital vintage model.

I will perform empirical tests based on supply-side information on the used car market using Box-Cox transformation, showing that passenger cars' depreciation follows a geometric sequence pattern, where age has a stronger explanatory power than mileage. This may be attributed to the fact that obsolescence is asserted in the age variable, as confirmed by the results of the hedonic method and the paired t-test. The results of the empirical tests may also be useful for the determination and application of depreciation rates.

\footnotetext{
${ }^{3}$ For a detailed description, see Chapter 1.
} 


\section{Income as the measure of economic performance}

In economic and accounting literature, income means excess capital generated during a period and available for consumption, always determined from the point of view of a person or a group. However, the way of assigning such excess capital to a person or a group influences the content and the interpretation of the concept of income.

According to Lee [1986], the science of economics considers income as an individual measure; the founder of this personal income theory was Irving Fisher, who identified income as the monetary value of the enjoyment resulting from the consumption of goods and services. His definition does not consider any unconsumed capital increase (i.e. savings) to be part of the income, as he identifies saving as a kind of potential consumption, only resulting in satisfaction when actually consumed (Lee [1986]). However, later economists determined the income of a period $t$ as the sum of consumption $C_{t}$ and saving $S_{t}$, the saving being conceived as the variation of the individual economic capital $K_{t}$ within the period; i.e. $S_{t}=K_{t+1}-K_{t}$. On the basis of the above, individual economic income may be expressed as

(1) $Y_{t}^{e}=C_{t}+K_{t+1}-K_{t}$,

where $K_{t+1}$ and $K_{t}$ means the end-of-period and beginning-of-period capital, respectively (Bélyácz [2002]).

The development of income theory in general is attributed to Hicks, who described his concept of income as follows:

"it would seem we ought to define a man's income as the maximum value which he can consume during a week and still expect to be as well off at the end of the week as he was at the beginning” (Hicks [1978] p. 207).

In the present case, the expression "well off" in Hicks's definition may be identified with wealth or capital, the maintenance of which in its initial state is at the heart of Hicks's income theory. However, several possible approaches exist in relation to the maintenance of capital intact, which I shall analyse in detail hereinafter. 
The economic income concept presented above is also suitable for the measurement of corporate economic performance. Business income expresses the income of the owners of the company resulting from the given enterprise. As owners constitute a group which is homogeneous in respect of the company, the owners' income (i.e. the company's income) may be determined in analogy with individual income (Lee [1986]):

(2) $Y_{t}^{a}=D_{t}+R_{t+1}-R_{t}$.

Business income $Y_{t}^{a}$ is composed of the dividend $D_{t}$ paid or payable to the owners and of the changes in the business capital over the period $R_{t+1}-R_{t}$; this change shall not include the effects of any eventual capital investment or disinvestment effectuated during that period. Dividend $D_{t}$ may be construed as the consumption of business capital $R_{t}$ by the owners, which once paid does not serve the operation of the company's value creating processes any longer, and consequently may be entirely correlated with consumption $C_{t}$ determined in relation to economic income $Y_{t}^{e}$.

Equation (1) and (2) show that the value of the income is principally a function of the difference between the beginning-of-period and end-of-period capital. For an in-depth analysis of this value, in the following chapters I shall give a brief overview of capitalrelated theories as well as of their evolution.

\subsection{A brief overview of capital theory and its evolution}

The conceptual definition of capital is virtually a permanent issue in economic literature, with two principal approaches. Some of the authors define capital starting from its physical quantity, while others use its value as a starting point - it may thus be stated that capital possesses both a quantitative and a value-related dimension. Capital, in its value dimension, made an appearance as early as in classical economics, where land and work were considered to be the primary factors of production, and as a consequence, capital was regarded as the primary representative of work product (Bélyácz [1992]). Since the first half of the last century, capital theory has undergone substantive development due, among others, to Fisher. Fisher [1896] accepted the dominant view of the era considering that capital is constituted of a determined set of wealth categories, so any form of capital needs to include these accepted categories of wealth; this may actually be considered as the materialistic approach to capital value. Fisher criticised 
Adam Smith's thesis according to which a category of wealth may be considered as capital if it is capable to produce a revenue. According to Smith, a merchant ship is capital, whereas a private yacht is not, as it is only suitable for the satisfaction of its owner's individual needs, and thus unable to produce revenue. However Fisher disputed this limitation of the capital concept: he considered that it is possible to identify deriving revenues for every kind of wealth, and through this line of argument he questioned the necessity of breaking down wealth into capital and non-capital elements (Fisher [1896]).

One of the debates on capital in early economic literature concerned the issue of differentiating between capital and income. Following Cannan, Fisher differentiated between capital and income on a time-related basis. In Fisher's opinion, any wealth may be considered in respect of its relationship with time in one of two ways: either as "stocks of wealth" or as "flows of wealth", the inseparability and interrelatedness of which was recognised with the general acceptance of capital value based on future returns. Fisher considers Cannan to be the first to lay the foundations of this relationship between capital and income, as he appears to be the first to have enunciated the precise time relation between these two concepts. According to Fisher [1896], Cannan stated that the wealth of an individual may mean two different things: either his possessions at a given point of time or his receipts for a given length of time. Like Marshall, Cannan conceived of income as a flow of pleasure, but of capital as a stock of things (Fisher [1896]).

Veblen also recognised the sameness of capital value and of the present value of the resulting future benefits (Bélyácz [1992]): he considered that the value of capital is determined by its expected ability to generate benefits. Thus, it has become possible to assess capital as a benefit generation unit, without a need to materialise it. Consequently, we may consider as capital wealth anything that is liable to produce economic benefit in future. With this extension, the concept of capital is no longer limited to tangible assets, which allows for factors identified as elements of the intellectual capital to be considered as part of the capital. ${ }^{4}$ As a result, in case of a capital stock with a complex structure, a vast part of the capital value is constituted by intellectual capital elements, seemingly "invisible" in the material sense, the existence of which is rather difficult to ex ante prove or disprove; and the number of these invisible elements continually grows

\footnotetext{
${ }^{4}$ For a detailed analyses of the elements of intellectual capital, see Juhász [2004].
} 
in parallel with the increasing complexity of capital in the material sense. As a consequence in case of a higher capital complexity, as far as structuration theory is concerned, Veblen's capital value concept may only be concerted with Fisher's materialistic capital concept (considering the individual wealth elements as representatives of the capital value in their physical quality) with a high level of uncertainty. The reconciliation of the two capital value concepts is further complicated by the fact that the above mentioned "invisible", intellectual or human capital elements may only be identified in a subjective way, with a high level of uncertainty. Many tentatives have been (and are currently) made to dissolve the tension between the approaches to capital value as material unit on the one hand and benefit generating unit on the other hand; a common feature of these is that the differences between capital considered as a benefit generating or as a materialised unit are associated with elements which are difficult to observe in the present, such as "employee value" or "client value", definable as wealth only from the benefit generating unit viewpoint, but not in the material sense. These conceptual differences constitute a long disputed issue in accounting theory; as a first step in their reconciliation, after a long process of pondering, certain "invisible" wealth elements, such as business value or corporate value, or the activated value of $R \& D$, have finally been incorporated in the category of wealth elements recognised in accounting, which decreased the difference between the two basic approaches to capital outlined above.

A common feature in the two different capital concepts described hereinabove is that both aim to determine the value dimension of capital. However, an alternative approach to capital exists in economic literature, which examines capital from the point of view of its physical quantity, concentrating on its quantitative dimension, where the concept of capital is supposed to mean the totality of the (physically) productive physical services rendered by the wealth constituting the capital. The quantitative dimension of capital is mainly examined by the branch of economics researching into production theory. In the production theory framework, the physical unit of capital is more important than its value, for production theory revolves around the production function, representing the relationship between the quantities of the output on the one hand, and of the various inputs on the other hand (Griliches [1963]). For the physical dimension of capital, capital goods (or assets) are considered as a pool of potential future (physical) services to be utilised in the value creation processes. Actually, this approach is closely related to 
the "benefit generating unit" concept of capital, as both consider capital to be a pool of potential future services. However in the case of the physical dimension, the analysed factor is the physical unit of the services, whereas in the case of the benefit generating unit concept, it is the value of the services.

The following chart illustrates the relationship between the two currently accepted capital dimensions described above and between their different concepts.

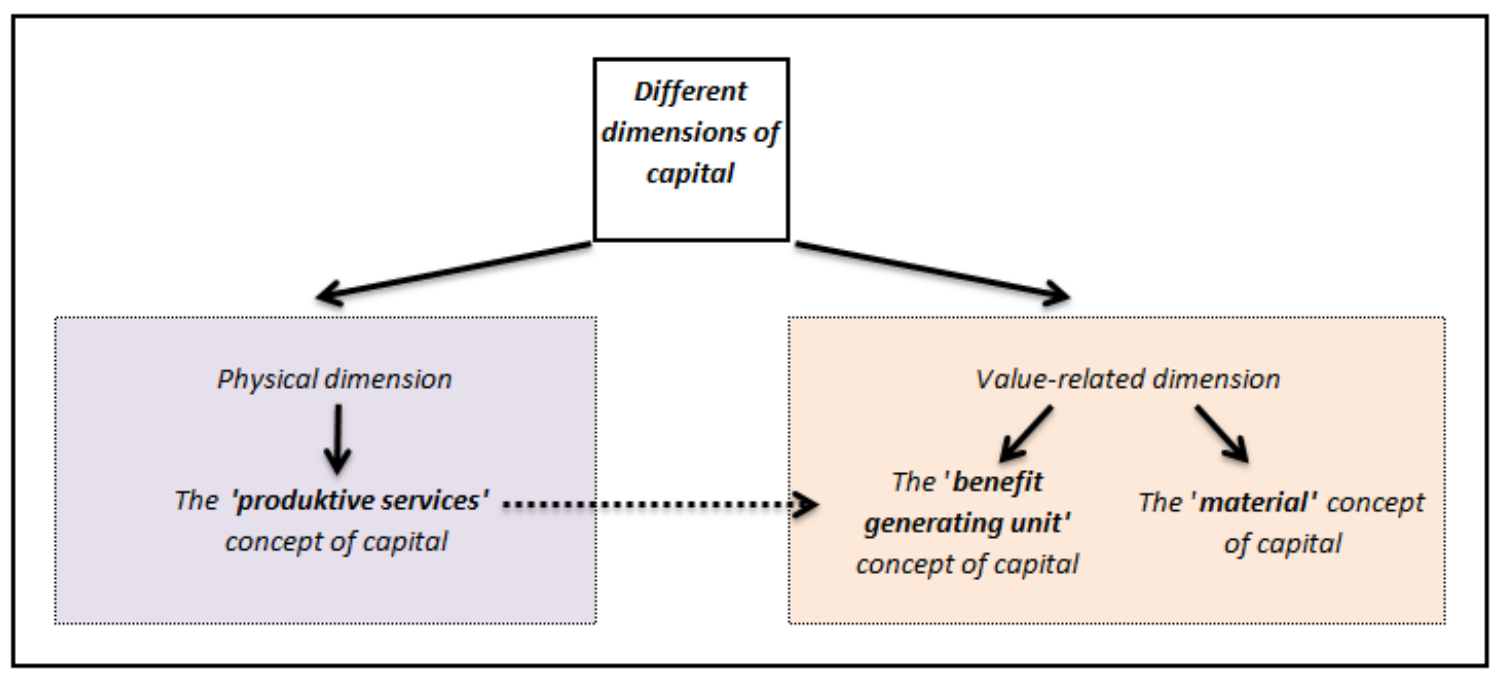

Graph 1: Different dimensions and concepts of capital. (Source: own elaboration)

The issue of measuring and grasping business capital also appears in the practice of business income calculation, the rules pertaining to which are usually set out in the financial reporting standards relevant to the given field. The International Financial Reporting Standards (IFRS) Framework differentiates between the physical and financial dimensions of capital. According to the Framework, the financial dimension of capital is measured in terms of invested money or invested purchasing power, capital being synonymous with the net assets or equity of the entity; whereas the physical dimension of capital regards capital as the productive capacity of the entity. This differentiation between capital dimensions corresponds with the capital dimensions described in the economic literature on capital, on the evolution and present state of which I have hereinabove elaborated.

Many theoretical debates concerning the measurement of capital have been pursued in the history of economics, and in most of the cases, the recognition of the differences stemming from the existence of the double dimension (physical and value) of capital 
contributed to their outcome. An especially heated dispute in this field unfolded in the seventies between Edward Denison and Griliches-Jorgenson; much later Triplett [1996] undertook to resolve this conflict, who considered that the ultimate reason of the difference in the two parties' opinions was the failure to recognise the value and physical dimensions of capital. Evidently these two dimensions of capital imply different capital maintenance concepts, which I will describe in detail in the next chapter.

In equations (1) and (2), the values of economic capital $K_{t}$ and business capital $R_{t}$ as of the beginning of period $t$ both represent the wealth of the owner of the income, the recognition of which in the determination of the income also ensures that any profit arising from economic processes may not be considered as income as long as the capital operators have not undertook to maintain or replace the beginning-of-period capital value $K_{t}$ or $R_{t}$. This guarantees that the intactness of capital is maintained. Several theoretical approaches exist towards this issue, which I will describe in the next chapter.

\subsection{Capital maintenance concepts influencing income}

Virtually all authors discussing capital and income theory agree that the output produced during the operation of the capital provides income to the capital operators, and that out of any output produced in a given period, only that part may be considered as income which is not necessary for the maintenance of the capital at a constant level (Bélyácz [1994a]).

The close relationship between the concepts of capital maintenance and income is also shown by the fact that Hicks built up the three widely accepted categories of incomes around different concepts of capital maintenance: "Income No. 1 is the maximum amount which can be spent during a period if there is to be an expectation of maintaining intact the capital value of prospective receipts (in money terms)" (Hicks [1978] p. 208). The importance of capital maintenance is also apparent in Hicks's two other income categories, where Hicks adjusts his income definition No. 1 by taking into consideration the eventual changes in the interest rates: "We now define income as the maximum amount the individual can spend this week and still expect to be able to spend the same amount in each ensuing week. So long as the interest rate is not expected to change, this definition comes to the same thing as the first; but when the rate of interest is expected to change, they cease to be identical. Income No. 2 is then a closer 
approximation to the central concept than Income No. 1 is" (Hicks [1978] p. 209). In his third income definition, Hicks adjusts his income concept No. 2 by introducing potential changes in prices: "Income No. 3 must be defined as the maximum amount of money which the individual can spend this week and still expect to be able to spend the same amount in real terms in each ensuing week" (Hicks [1978] p. 209).

As capital possesses a physical and a value-related dimension, in the same way, capital maintenance may be regarded from the aspect of both physical and value. The income definitions cited above show that Hicks examines capital from the value aspect, defining its value as the present value of prospective receipts or returns. Furthermore, in his second definition, Hicks determines income on the basis of the criterion related to the conservation of the nominal value of capital, while in income category No. 3 he already considers the conservation of the real value of capital as the central issue of income calculation, identifying the quantity of spendable money in terms of goods.

The issue of maintaining business capital also appears in the practice of business income calculation. Section 108 of the International Financial Reporting Standards (IFRS) Framework defines real and nominal capital maintenance concepts which are entirely consistent with the real and nominal capital conservation concepts derived from Hicks's income concepts, showing the practical applicability of the 'Hicksian' capital maintenance concepts.

Break [1954] discussed several aspects of capital maintenance in detail, identifying four possible ways to maintain capital, and assessing these regarding their clarity and precision and their arbitrary nature. The four possible capital maintenance concepts according to Break are as follows:

- Initial-value capital maintenance, under which all beginning or opening capital values, measured either in money or in real terms, must be held constant.

- Replacement-value capital maintenance, which ignores beginning capital values in favour of holding the current values of identical capital assets constant, instead.

- Initial-physical capital maintenance, which is concerned entirely with the preservation of the beginning physical characteristics of capital assets rather than their monetary values. 
- Prospective-income capital maintenance, designed to equate the current period's income figure to the amount of income expected in each future period (and to maintain the capital in a state that it should be able to ensure such level of income).

Out of the capital maintenance concepts outlined above, Break considered initial-value capital maintenance, determined in an ex post manner, to be the most precise and clearest and the least arbitrary.

Break's capital maintenance concepts are clearly delimited according to their intention to maintain either the quantity or the value of capital. Initial-value capital maintenance, replacement-value capital maintenance, and prospective-income capital maintenance aim to maintain the value of capital; the differences among these concepts result only from the differences in the measurement of this value. However, the declared objective of initial-physical capital maintenance, aiming to maintain the physical quantity of capital, is to maintain the physical attributes of the assets, which may consist in the quantity of the productive services of the assets as described above. A great number of debates have dealt with the applicability of the physical concept of capital maintenance for the purposes of income definition, which largely contributed to the clarification of this theory.

In the capital theory debates of the early 20th century, Pigou represented the idea of measurement of capital on a physical basis (Bélyácz [1994a]). Concerning capital maintenance, several discussions have taken place between Pigou and Hayek, to which also Hicks contributed (Hicks [1942]). Hicks considered Pigou's capital maintenance concept to be incorrect from the viewpoint of capital valuation, and invoked the example of a manufacturer of fashion goods who installs special machinery which may only be used for the production of a given fashion article ${ }^{5}$. The firm uses the machine as long as there is demand for the fashion article in question, then scraps it. According to Hicks, in this case the physical maintenance of the capital is not equal to the maintenance of the capital in the economic sense, as the firm scraps the machinery as fashion changes, long before it would actually wear out in the physical sense. However, despite the physical integrity of the machine, it is necessary that its value should be replaced, as it completely

\footnotetext{
${ }^{5}$ The example assumes that the machine may not be used for any alternative purpose.
} 
loses its value when the goods it produces are out of fashion and do not sell any more. Hicks considers that the definition of capital maintenance should also work in an extreme situation like the one described above, and thinks that Pigou's definition does not meet this criterion.

Although much debated, the physical concept of capital maintenance is applicable in practice even in our days. Section 104b of the IFRS Framework considers physical capital maintenance to be the productive capacity of the entity. Section 109 complements this concept of capital maintenance by taking into account all price changes in the measurement of the capital value of the period, thus evading the weakness of the physical capital maintenance concept outlined by Hicks. However, in line with Section 109, such considered price changes are not treated as part of the company's profit, but appear directly in the capital value: therefore the concept of profit based on physical capital maintenance diverges from the income defined in equation (2). At the same time, the recognition of an "Comprehensive income"-also containing items of a revaluative nature-in the IFRS system restores the capital-income relationship generally accepted in economic science.

The facts described above show that the method of capital maintenance is closely related to the concept of capital, and consequently exerts a fundamental effect on the definition of income itself. It also follows from the diversity prevailing in the field of capital maintenance that there is no single, generally accepted income concept universally suitable for each market player; this is confirmed by the variety of incomes derived for various kinds of persons and groups in line with different capital maintenance concepts.

\subsection{Identification of asset consumption}

As I have already explained in relation to equation (2), changes in the value of capital $R_{t}$ occurring within a period $t$ (excluding any additional capital investment or disinvestment effectuated during that period) constitute a significant part of business income. However, the value of business capital $R_{t}$ is equal to the total of the net assets of the company, i.e. the value of its total assets minus the value of the liabilities of the company. ${ }^{6}$ A certain part of the company's net assets is constituted by the fixed assets, labelled as "fix" because they serve the activity of the business during several periods; as a consequence,

\footnotetext{
${ }^{6}$ This statement is consistent with the provisions of Section 102 of the IFRS Framework.
} 
the physical and price impacts occurring during those periods shall influence the assessment of the asset's future usefulness, i.e. its value. As these physical and price impacts are manifold and exert different impacts on different sets of assets, I shall henceforth only analyse fixed assets created by man, with a finite lifespan and with quantitative limitations concerning usability. Examples of such fixed assets are vehicles, machinery, equipment or buildings used by the company; the recognition of the use of these assets in the company's income is an issue broadly discussed in accounting and economic literature.

Academic opinions on income and capital seem to concur in the view that at the end of each period, a certain portion of the value of the fixed assets as of the beginning of the period should be split up to the debit of the income of the period, for fixed assets get exhausted and deteriorate (or else become obsolete) during the business cycle, and their values expressed in current prices change in line with actual inflation. ${ }^{7}$ These impacts collectively result in the gradual consumption of the asset value; this consumption influences the change in capital $R_{t+1}-R_{t}$ as determined in equation (2), fundamentally affecting business income in the given period.

If the income was not measured for shorter periods but rather in an ex post manner, for the complete service lifetime of the fixed assets, the problems related to the consumption of the fixed assets and the costs incurred in relation to this phenomenon would not arise at all, for in this case the fixed assets would be entirely exhausted by the end of their service lifetimes and, instead of use value, would only possess scrap value, which is considerably easier to establish. In this case actually, the value recognised in the business income would only be the part of the value of the fixed assets - almost entirely consumed during their service lifetimes - which remains after deduction of the scrap value.

Baricz [1994] breaks the lifetime of assets down to physical lifetime and economic lifetime, physical lifetime being the interval during which the asset may be used in line with the relevant technical requirements, while economic lifetime would be the time interval during which the asset may be used in an economical manner. ${ }^{8}$ Baricz observes

\footnotetext{
${ }^{7}$ I will later discuss the impacts of the above mentioned phenomena in detail.

${ }^{8}$ For a detailed historical overview of theories concerning the analysis of economic lifetime, see Bélyácz [1993].
} 
that economic lifetime is usually shorter than physical lifetime, a phenomenon explained by the effects of obsolescence, to be analysed henceforth. For the purpose of the analysis of fixed assets depreciation, it is always the shorter of these two time periods - i.e. service lifetime, the time interval during which the asset is kept in use, as opposed to economic lifetime - that should be taken into consideration.

However the service lifetime of fixed assets is usually very long, which makes it impossible for the company stakeholders (and especially the owners) to only acquire information about the assets and income of the firm at the end of the service lifetime of the fixed assets. Moreover, companies normally operate a great number of fixed assets which tend to be heterogeneous in respect of the length of their service lifetimes as well as the dates of their placing into service. As a consequence, in case of continuous operation it would be impossible to choose a date in time when the ex post identification of the income could be performed; that's why these long operating cycles with different starting dates and extending over different periods are broken down into shorter reporting cycles of one year typically, which corresponds better with the company stakeholders' information needs. However, in this case we need to find a way to establish what part of the value of the fixed assets as of the beginning of the period is consumed during the given period as a result of their use or merely of their ownership. The recognition of the costs stemming from the consumption of fixed assets in the calculation of the income also ensures the intactness of the value of the fixed assets as of the beginning of the period through the fact that the owners' income (profit) may not be established before the costs representing asset consumption appear (and assert their reductive effect) in the income calculation; I elaborated on this capital maintenance function in Chapter 2.2.

Hereinabove I have explained the relationship between capital maintenance and the consumption of fixed assets during production, which also influences the assets and income of the company. Knowledge of these relationships and impacts is indispensable for an income-focussed analysis of fixed asset consumption. The relevant academic literature identifies three fundamental theoretical approaches to recognising the consumption of fixed assets during the reproduction process. Bélyácz [1993] summarises these three approaches as follows: (1) distributing the initial purchase value, reduced by the residual value, in a discretionary proportion along the estimated service lifetime; or 
(2) setting aside a constant amount every year which (together with its accumulating interests) constitutes a fund, segregated from the income, for any replacement due by the end of the lifetime of the asset (sinking fund); or (3) changes in the value of the equipment during the given period. In the following chapter, I will describe these three main trends in the theoretical establishment of asset consumption, and assess to what extent they are suitable for the calculation of the income defined in equation (2).

\subsubsection{Cost allocation approach in early accounting literature}

Accounting literature in its early days considered the contribution of fixed assets to production mainly as the allocation of their initial cost, based in almost every case on the historical cost of the asset. By this time, the relationship between asset consumption and changes in the value of capital was rarely taken into account; consequently, in order to determine the consumption of the assets throughout the given period and their (net) value as of the end of the period, the authors used procedures they considered to be systematic and rational from the aspect of cost allocation (Brief [1967]). Ladelle [1890] regarded cost allocation as a method to determine the contribution of the assets to production, and differentiated between two variants. According to the first one, he proposes to divide the historical cost, reduced by the scrap value, with the number of years of usage: thus in respect of each year, the resulting fraction may be considered as the periodical consumption of the asset. In the second version, he allocates the historical cost of the asset by a constant rate every year for the individual business periods. Ladelle also explains that any capital gain or $\operatorname{loss}^{9}$ resulting from price variations belongs to the entire service lifetime of the asset, and should be allocated as such.

Böhm-Bawerk [1891] also recognised the necessity to gradually allocate goods permanently used in production to the output, as well as the difficulties in doing so, and mentioned that fixed assets provide services in relation to the production of a great number of outputs, and these services are accomplished at different moments in time. He illustrated the problem with a plough which lasts twenty years: he considered that this plough will contribute a twentieth part of its historical cost to the output of each following business period (Böhm-Bawerk [1891]). Böhm-Bawerk's example shows, in

\footnotetext{
${ }^{9}$ In Chapter 4.2 I use a different definition of the concept of capital gain and loss.
} 
addition to the recognition of the problem, that—similarly to Ladelle-he regarded asset consumption as a process of allocation.

In his synthetic work, Diewert [1996] determines asset value consumption from a cost allocation approach as a sequence of $n$ allocations, where $n$ denotes the expected service lifetime of the asset expressed in number of accounting periods. In this case, the rate used to determine the consumption of the asset would be $\delta=1 / \mathrm{n}$. This interpretation is entirely in line with Ladelle's concept. The rate $\delta$ thus determined can be used for the systematic (linear) allocation of the historical (original) cost of the fixed asset to $n$ periods, the totality of these periods representing the service lifetime of the asset in question. Diewert designates the historical cost of the asset, incurred at the beginning of period 0 , as $P^{0}$, and determines its linear allocation as the following sequence of $n$ elements: $(1 / n) P^{0},(1 / n) P^{0}, \ldots,(1 / n) P^{0}$. This method measures the contribution of the asset to production at constant prices in spite of the fact that the revenues and expenses constituting income appear in the periodical income at current prices.

However, Diewert also discusses the possibility of allocating the asset value calculated at current prices. In this case, in the determination of asset consumption, he also takes into account any impacts resulting from the changes in the price of the asset, i.e.: $(1 / n) P^{l},(1 / n) P^{2}, \ldots,(1 / n) P^{n}$, where $P^{t}$ designates the current cost of the asset purchased at the beginning of period 0 at the beginning of the individual periods $t[\mathrm{t}=1,2, \ldots, \mathrm{n}]$.

In addition to linear ('straight-line') cost allocation, several other cost allocation methods are known: of these, Diewert highlights the geometric sequence allocation model, which determines asset consumption using a constant geometric rate $0<\delta<1$. The sequence of historical cost allocations of historical cost $P^{0}$ that this method generates is $\delta P^{0}, \delta(1-\delta)^{2} P^{0}, \delta(1-\delta)^{3} P^{0}, \ldots$. Similarly to linear allocation, geometric sequence based allocation may also be calculated at current prices.

Nevertheless, the methods proposed for the allocation of historical asset costs faced much criticism in academic literature. ${ }^{10}$ Some of the critics censure the arbitrariness of allocation, which in the present case refers to the fact that there is no evident causality between the consumption of the thus computed asset value and the evolution of income in time (Bélyácz [1994b]), which undermines the applicability of allocation in economic

\footnotetext{
${ }^{10}$ See for example: Canning [1929], Bélyácz [1994b].
} 
science, as first pointed out by Hotelling [1925]. Nevertheless, the method is still popular and widely used, owing primarily to the fact that it makes it possible to calculate the consumption of the asset value occurring during the given period at a low cost and with relatively little computing effort - although it does not necessarily closely reflect reality.

Consequently, the simple cost allocation mechanism is quite probably unsuitable to compute the actual end-of-period asset value and, as a result, does not ensure the maintenance of the business capital as outlined in Chapter 2.2 either in the nominal or in the real sense. We may illustrate the problem with the following example: Let us assume that our company purchases a machine for 2.4 units. The company plans to use the machine during 5 periods, its estimated scrap value at the end of period 5 being 0.27 units. However, using the estimation methodology of the machine's scrap value, it is possible to estimate the asset value at the end of each operating period. In the next graph, this asset value function based on our estimates is represented in green.

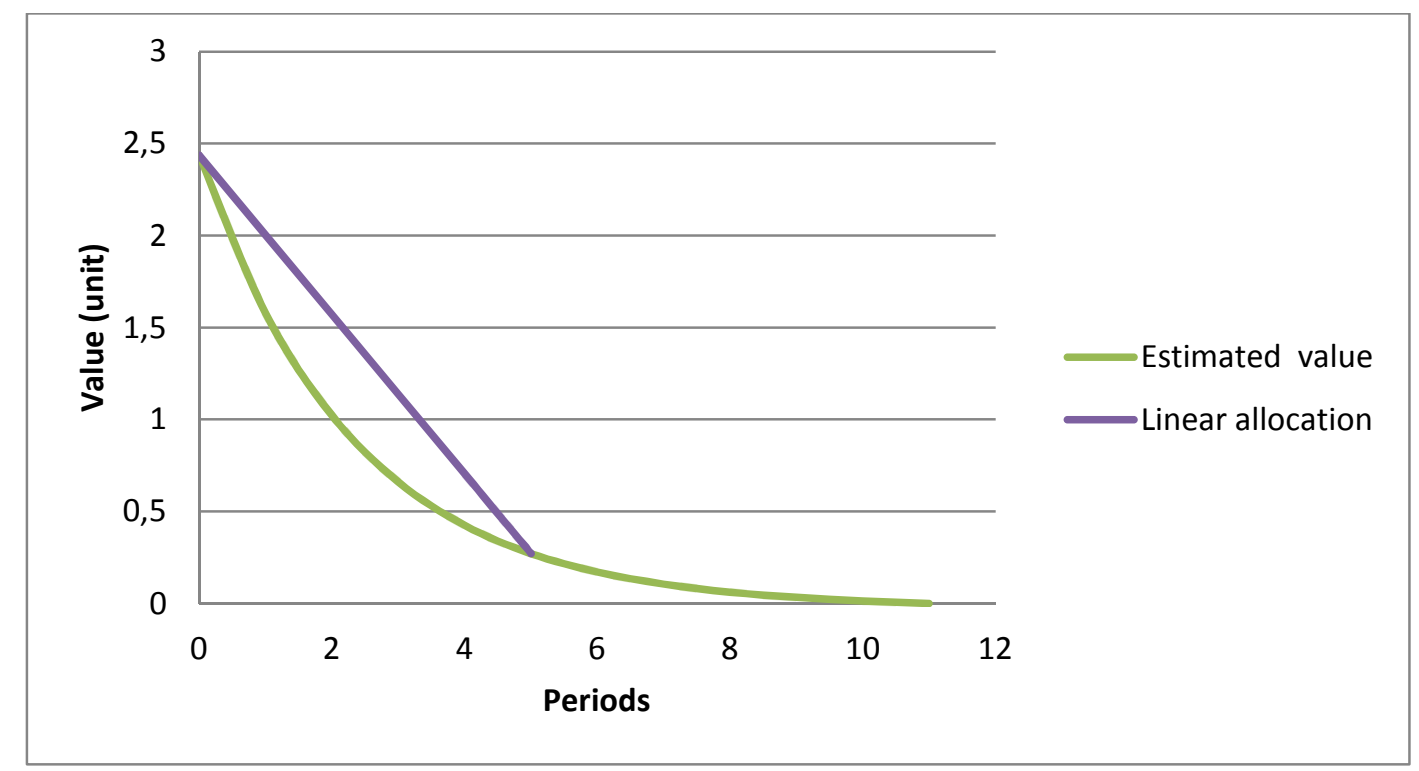

Graph 2: Relationship between the asset values as estimated and calculated using the linear allocation method.

(Source: own elaboration)

The graph also shows the end-of-period net asset values as calculated using the linear cost allocation method: it is evident that the asset value estimates relating to the individual periods and the asset values resulting from linear allocation do not coincide. The asset value calculated by linear allocation gives higher values throughout the operating period of the asset. Consequently, if single line cost allocation does not 
coincide with our estimates of the end-of-period asset values, it evidently distorts the image of the company's financial situation.

The linear allocation concept of the example above does not only influence the end-ofperiod asset value but also impacts on the business income determined in equation (2). This effect is illustrated in the following graph.

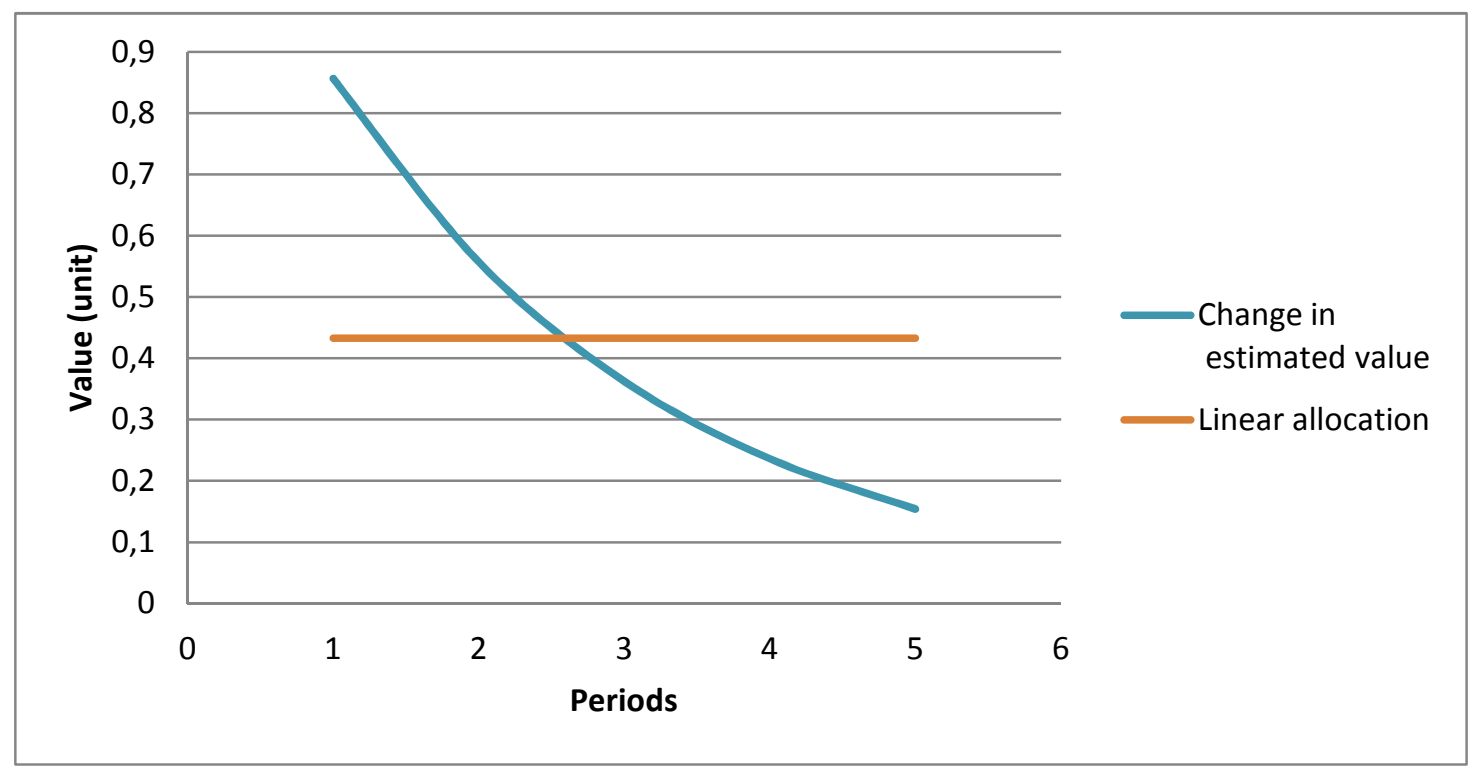

Graph 3: How the choice of linear allocation or the 'change in the value' method to compute depreciation impacts on income. (Source: own elaboration)

The graph shows that in this example, linear allocation used to determine asset consumption first under-, then overrates the depreciation computed on the basis of the estimated change in the asset value, which not only distorts the business income of the individual periods, but is also unable to maintain the value of the beginning-of-period capital either in the nominal or in the real sense.

A frequently cited argument on the side of the systematic allocation of the historical cost points out its objectivity, its independence from the person applying the method. However, the objectivity of allocation methods is undermined by the fact that the usage period and scrap value of the assets are established in an ex ante manner; this estimate is virtually always a result of a subjective judgment, which fundamentally challenges the objectivity of historical cost allocation.

At the same time, the single line allocation of historical asset cost also yields questionable results from the viewpoint of the accounting principles. As the mechanical measurement of asset consumption is very frequently quite out of touch with the actual 
consumption, it does not make it possible to match the appropriate expenditures with the receipts of the period, which infringes the matching principle, and reflects a distorted image of the financial and income situation of the firm.

The cost allocation method actually fails to deliver satisfactory results in determining income (as a means of expressing the company's performance), even in the case of asset value allocation at current cost; as a consequence, I will not consider it as a realistic alternative in the course of my further analyses. Having examined the cost allocation model, I will now continue by introducing the sinking fund approach.

\subsubsection{Reservation for future replacement or the sinking fund approach}

Academic literature outlines another theoretical approach to fixed asset consumption: this method aims to create a monetary fund in the individual periods, which provides for coverage to replace the assets at the end of their service lifetimes. ${ }^{11}$ The idea of approaching asset consumption through a replacement fund model already makes its appearance in Ladelle's early synthetic study. The method consists in setting aside a constant amount throughout the operating periods of the asset which (together with its accumulating interests) provide coverage for the replacement of the asset at the end of its service lifetime (Ladelle [1890]).

As opposed to historical cost allocation, the sinking fund approach considers the issue of consumption from the viewpoint of the replacement value of the asset at the end of its service lifetime. This concept was subject to much criticism in the early decades of the last century on the part of the authors committed to the cost allocation method (Diewert [1996]). Their principal argument against the replacement fund approach was that it is not sure whether the specific asset for the replacement of which a fund had been created during its service lifetime needs to be replaced in order to be able to carry on the business activity. It is thus conceivable that the assets needed for the operation may be superseded by assets with different functions and using new technologies, of which the future purchase value is not related with the future replacement value of the assets currently used. The deliberations concerning these criticisms and the rethinking of the measurement of consumption exerted a stimulating effect on the evolution of the theories. A new formulation was conceived: the representatives of the sinking fund

\footnotetext{
${ }^{11}$ For details, see: Canning [1929], Daniels [1933], Gilman [1939].
} 
approach intended to determine asset consumption by creating a monetary fund which provides for resources to buy a new asset which will probably be needed in production after scrapping the asset currently used. From this point of view, wealth is not conserved in its physical aspect but in its future value, for setting aside a replacement fund from the income makes it possible to buy assets of which the future purchase value reflects potential capital services comparable to those appearing in the value of the currently used asset. Therefore the replacement fund approach regards the present value of the value units of the asset to be purchased in a future period as the asset consumption recognised in the income; in an economic sense, this concept delivers satisfactory results regarding the entire service lifetime of the assets, as it also takes into account the impacts stemming from changes in the exchange rates and in the general price level. However, this does not hold true for the incomes of the individual periods, because asset value consumption will continue to be determined on the basis of an arbitrary allocation, without regard to the possibility of usages of different intensity and to the changes in the value of the assets due to the deterioration of their performance with aging.

Recognising this weakness of the approach, economists began to examine the actual value consumption of the asset values in the individual periods, which I will outline in the next chapter.

\subsubsection{The 'change in value' approach}

The above mentioned weaknesses of straight-line cost allocation and the sinking fund model led to the creation of the theoretical basis, founded by Hotelling and widely accepted today, determining asset consumption in a given period through the difference between the value of the asset at the beginning and end of the period. Hotelling [1925] defined asset consumption over a period as the change in the value of the asset, and considered depreciation as the rate of the decrease of the asset value in a given period. Hotelling turned away from the time-based concept of allocation, used in cost allocation as well as in the replacement fund model.

He defined asset value as the discounted present value of the future rents ('theoretical rentals') and the scrap value of the asset at the end of its service lifetime. He considered the rent of the asset as the value of the maximal quantity of outputs produceable with the 
asset in the given period, calculated at an anticipated sales price, decreased with the operating costs of the asset. Hotelling recognised that depreciation is related to the value of the outputs produced with the asset, deducting operating costs.

In order to avoid any overlapping in the concepts, to describe Hotelling's 'depreciation', in the present study I will use the expression 'time series depreciation'. This may be illustrated using a production equipment, of which the value as of the beginning of period $t$ shall be designated as $P_{0}$, then after a period's usage, its value as of the end of period $t$ shall be $P_{1}$, reflecting the usage of the production equipment throughout a period and the effects of any price changes occurring in the meantime. In this case, the change in the value of the production equipment related to period $t$ (which, assuming precise information and certainty concerning future, is identical with the time series depreciation of the asset) shall be: ${ }^{12}$

(3) $\Delta_{t}=P_{0}-P_{1}$.

On the basis of the above definition, by 'depreciation' Hotelling means the change occurring in the value of the assets from one period to another. Therefore, the determination of depreciation is inseparable from the underlying value theory. In Wright's [1964] formulation: depreciation theory ${ }^{13}$ could not exist without valuation theory.

Consequently, for the determination of changes in asset value, in addition to defining 'asset', it is indispensable to also clarify the definition of 'value' itself. The theoretical basis for doing so is provided by several value theories known to economic science; of these, in the next chapter I will describe the marginalist theory and the labour theory of value, as well as the mutual relationship between these two.

\footnotetext{
${ }^{12}$ I will further discuss the detailed breakdown of the change in the value of the asset in Chapter 1.

${ }^{13}$ Depreciation as defined by Hotelling.
} 


\section{Measuring the value of fixed assets}

"Measurement and observation always presuppose the existence of an underlying theory. The result of the observation and the measured values may only be interpreted on the basis of such a theory." (Bródy [1990] p. 521)

According to the theory above, the measurement of asset value may only be interpreted in the light of the underlying theoretical basis. Theories behind the measurement of fixed asset value at the beginning and the end of the periods are called 'economic value theories'; these have branched, during their evolution, into two distinct and opposed trends, the classical and the neoclassical school, the value theories of which, ostensibly different from one another, became known as the labour theory of value (LTV) and marginalism, respectively. Bródy [1990] considers that as regards measurement, both theories have the fundamental weakness of drawing back their explanations to ultimate factors ("labour quantity" and "utility", respectively) which are very difficult to interpret in practice. LTV is based on an approach of value through the production process; the roots of this go back to primitive societies where natural resources were considered to be 'gifts' of Nature which workers transformed into consumption goods through their work; as a consequence, the value of these goods may solely be equated with the quantity of labour they incorporate, or in other words, labour was regarded as the origin of value (Dooley [2005]). A major representative of LTV was Ricardo, who considered that the value of a commodity depends on the relative quantity of labour which is necessary for its production (Ricardo [1817]). Marx considered the explanation of the equilibrium price of commodities around which "actual prices" fluctuate as one of the functions of LTV (Morishima [1973]), which makes it clear that Marx's value theory founded on socially necessary labour quantity is not a price theory (Sowell [1963]).

Concerning the practical application of the theory, Bródy explains that the quantity of labour was first expressed in labour time; this, however, proved to be inappropriate to grasp the differences in the quality and type of the hours worked, and consequently the concept of wages was introduced to recognise these factors. The value of wages is, in its turn, determined on the basis of an assessment by the labour market, i.e. on society's judgment on the utility of the individual types of labour - as a consequence, the 
concurrent theory, marginalism, is used to solve the problem of measurement in practice (Bródy [1990]).

As opposed to this, the key concept of the marginalist value theory of classical economics is the utility of goods, stating that the market prices of commodities relate to each other in the same way as their utility does, a statement derived from the law of marginal utility. The utility of goods is supposed to be derived from consumers' market preferences. However, preferences are rather hard to harmonise in the case of two persons, lest for the whole of the market. To solve this problem, Debreu overstepped the original interpretation of marginal utility theory and determined the evolution of demand with regard to production procedures, founding his argument on expenditure rather than on the market; in other words, drawing on the reasoning of the labour theory of value (Bródy [1990]).

Bródy's summary outlined above shows clearly that the two ostensibly different value theories are really rooted in one another: "on the one hand, expenditures could only be compared on the basis of their utility, while on the other hand, it was impossible to assess utility without taking into account the related expenditure and outputs." (Bródy [1990] p. 530).

In spite of the equivalent and converging nature of LTV and marginalism, in my study I will primarily rely on the theoretical background of marginalism (also laying down the foundations of the value theory of financial economics) which identifies utility as the returns derived from the goods, and which considers that the value of the goods can be computed as the total of the future returns discounted to present value, a value typically also reflected in market prices. A basic feature of the value theory of financial economics is that in the first step, it does not differentiate between money and real investment, which makes it suitable for a wide range of economic processes (Bosnyák [2003]).

The value theory outlined above provides the theoretical background for the measurement of asset value. The next chapter describes the methods used in practice for the purpose of this measurement. 


\subsection{Methods used to measure asset value}

The issue of the evaluation of fixed asset price at the beginning and the end of the periods is basically rooted in their permanent character, for as a result of their relatively long service lifetime, their value is not only influenced by the changes that may be grasped in the physical sense, but also by several processes occurring in the outside business environment. Therefore, the valuation procedure selected must be suitable for the overall recognition of the above mentioned impacts. In the following subchapters, I will give an overview of the major asset valuation methods and procedures known in economic and accounting literature.

\subsubsection{Valuation based on historical cost}

Historical cost basically allows us to perform a gross or net measurement of asset value. Griliches [1963] considers the measurement of gross asset value to be one of the simplest and at the same time one of the most unclear concept of measurement, which may however only be suitable for the determination of the end-of-period business capital value described in equation (2) in the case of a large group of assets. To measure the gross value of a group of assets, the initial acquisition cost is allocated to the assets until they are scrapped. To illustrate this, following Hulten and Wykoff's [1996] reasoning, we shall take as an example a firm which in the examined period $t$ possesses $n[\mathrm{n}=1,2, \ldots, \mathrm{N}]$ fixed assets of $s[\mathrm{~s}=1,2, \ldots, \mathrm{S}]$ different ages $\left[\mathrm{K}_{\mathrm{t}-\mathrm{s}}^{1}, \mathrm{~K}_{\mathrm{t}-\mathrm{s}}^{2}, \mathrm{~K}_{\mathrm{t}-\mathrm{s}}^{3}, \ldots \mathrm{K}^{\mathrm{N}}{ }_{\mathrm{t}-\mathrm{s}}\right]$. The gross value of the group of assets thus determined, calculated at historical acquisition cost, may be defined as:

(4) $B V_{t}^{K}=P_{t, 0}^{I} \mathrm{~K}_{\mathrm{t}-0}^{\mathrm{n}}+P_{t-1,0}^{I} \mathrm{~K}_{\mathrm{t}-1}^{\mathrm{n}}+\ldots+P_{t-\mathrm{S}, 0}^{I} \mathrm{~K}_{\mathrm{t}-\mathrm{S}}^{\mathrm{n}}$

where $P_{t, O}^{I}$ designates the purchase price of the new asset purchased on day $t$. The equation shows that the value of the gross capital stock is determined as the simple addition of the historical costs of the individual assets. Griliches [1963] introduces two methods by the use of which the value of the asset group determined by equation (4) may be suitable for the expression of the change in capital defined in equation (2). In the case of the first method, assets are scrapped at the end of their anticipated average lifetimes. If these assets have not been purchased at the same time but at different subsequent moments in time, then the value of the group of assets at the beginning and 
the end of the period may be calculated as the moving total of past investments, where the value of the group of assets is primarily determined by the average lifetime of the assets. In this case, the difference in the individual lifetimes of the assets does not influence the value of the group of assets, which raises the problem that after the end of the average lifetime, half ${ }^{14}$ of the assets are actually still operational.

The second method proposed by Griliches takes into account the individual lifetimes characterising the given types of assets, determining capital value on a so-called 'mortality sequence'.

Griliches explains that neither of the two methods considers the possibility that two assets of the same type may have different service lifetimes. To solve this problem, he proposes to take into account the lifetimes of each asset separately; this is called the 'adjusted gross stock method'.

The use of historical acquisition costs also makes it possible to determine the net asset value: due to its simple nature, this measurement method is very popular in accounting practice (Daines [1929]), despite the fact that it is rather imprecise. In the case of this method, asset value is determined period by period using the allocation rates described in Chapter 2.3.1. ${ }^{15}$ By applying this rate, the acquisition cost of the asset is allocated to its different operating periods, and the end-of-period asset value is determined as the difference of the initial acquisition cost and the part of it allocated until the given moment in time.

The main drawback of the method is that it fails to consider the variations in the values of the assets operating during several periods due to the exhaustion, deterioration and obsolescence of the asset as well as to variations in the price levels; as a consequence, the asset value calculated for the end of the period is bound to be far remote from the actual market value, or the alternative cost of the asset. Therefore not only does this method convey a false picture of the company finances, but its result also fails to correspond with the asset value defined in Chapter 2.3.3 which is necessary for the determination of the period income calculated at current prices as described in Chapter

\section{2 .}

\footnotetext{
${ }^{14}$ As follows from the concept of 'average'.

${ }^{15}$ This rate is known in accounting practice as 'depreciation rate'; however this only partially corresponds with the concept of 'depreciation rate' as used in the present study and further analysed below.
} 
The historical cost of assets may thus be considered as a past characteristic which-in a changing business and technological environment-is irrelevant for the determination of economic value.

\subsubsection{Historical cost adjusted for the effect of inflation}

Diewert [1996] introduces the method of historical cost adjusted for the effect of inflation as a potential method to determine asset value, which differs from the method described in the chapter above insomuch as at the determination of the asset value at the end of the period, any inflation-related influence is also taken into account. Inflation is calculated as the fraction of the beginning-of-period and end-of-period general price levels, which is however different from the asset specific price change; therefore the calculated price of the asset deviates from its actual market value, which is considered to be a weakness in this method.

The advantage of the method as opposed to the simple historical cost model, on the other hand, is that the asset value already contains the effect of general price change, therefore it allows a much more precise determination of the end-of-period asset value in an inflation-laden business environment. The measurement of general price change presents, however, a problem in the practical application of this model, raising a number of questions still unanswered by economic science. ${ }^{16}$

An additional drawback of this method is that it still fails to consider the variations in the asset values due to the exhaustion, deterioration and obsolescence of the asset; therefore the asset value calculated using this model is not liable to concur with the actual value of the asset.

\subsubsection{Measurement based on historical cost adjusted for asset specific price changes}

Asset value determination based on historical cost adjusted for asset specific price changes is almost identical with the method described in the previous chapter, with the mere difference that in this case the historical cost of the asset is corrected by the asset specific price change (characteristic of the asset itself) instead of the changes in the general price levels. This way the calculated value of the asset may be determined more

\footnotetext{
${ }^{16}$ For further details concerning the theoretical and practical issues related to the measurement of inflation, see: Diewert [1995], Diewert [2001] and Andrle [2003].
} 
precisely than with the use of the changes in the average price levels as explained above. According to Diewert [1996] the challenge in the practical application of the method lies in the determination of the rate expressing the appropriate asset specific price change, complicated by the extreme heterogeneity of the assets, the differences in time between the rates eventually determined for a given period and the time limits of the accounting periods, and the potential acquisition of assets at different times within an accounting period.

In addition to the difficulties of practical application, another disadvantage of the method is that the effects of the exhaustion, deterioration and obsolescence of the assets due to their actual use still fail to be recognised in the end-of-period asset values; therefore the use of this model is liable to convey a distorted image of the company's finances and income.

\subsubsection{Asset value determination based on the market prices of the assets used}

Both accounting and economic literature mention the possibility of determining asset value on the basis of market information; this method is related to the marginalist value theory through the underlying assumption that the relative market prices of assets reflect the marginal utility derived from their consumption, and consequently, the market price is appropriate for the measurement of asset value. The market is able to measure value by way of the trading price shaped by supply and demand, where the asset price is supposed to reflect the value judgment of the presumably well-informed sellers and buyers. Hicks explains that if a second-hand commodity market exists, then the market value of the assets, also reflecting their deterioration, may be determined on the basis of market information (Hicks [1978]); this market value will reflect the effects of the asset specific inflation described in the previous chapter as well as any value changes resulting from the deterioration, obsolescence and exhaustion of the assets. The asset value thus calculated is finally suitable for the measurement of the change in capital needed for the calculation of income as defined in equation (2).

To illustrate this method, following Hulten and Wykoff's [1996] reasoning, we shall take as an example a firm which at an examined moment in time $t$ possesses $n[\mathrm{n}=1,2, \ldots, \mathrm{N}]$ fixed assets of $s[\mathrm{~s}=1,2, \ldots, \mathrm{S}]$ different ages $\left[\mathrm{K}_{\mathrm{t}-\mathrm{s}}^{1}, \mathrm{~K}_{\mathrm{t}-\mathrm{s}}^{2}, \mathrm{~K}_{\mathrm{t}-\mathrm{s}}^{3}, \ldots \mathrm{K}_{\mathrm{t}-\mathrm{s}}^{\mathrm{N}}\right]$. The value of these assets at present market prices shall then be determined as follows: 
(5) $\mathrm{V}_{\mathrm{t}}^{\mathrm{K}}=\mathrm{P}_{\mathrm{t}, 0}^{\mathrm{I}} \mathrm{K}_{\mathrm{t}-0}^{\mathrm{n}}+\mathrm{P}_{\mathrm{t}, 1}^{\mathrm{I}} \mathrm{K}_{\mathrm{t}-1}^{\mathrm{n}}+\ldots+\mathrm{P}_{\mathrm{t}, \mathrm{S}}^{\mathrm{I}} \mathrm{K}_{\mathrm{t}-\mathrm{S}}^{\mathrm{n}}$,

where the market price of an asset of age $s$ at a moment in time $t$ is denoted by $P_{t, s}^{I}$. Hulten and Wykoff [1996] consider that the price $P_{t, s}^{I}$ assigned to the used assets corresponds with the amount that a rational investor would be willing to pay for the given used asset; this should at the same time reflect the present value of the future returns the asset is presumed to produce. However, academic literature discussing asset valuation criticises the results of this method on numerous points.

Part of these criticisms doubt the existence of an active second-hand market, asserting that in actual fact, second-hand market is rather sporadic and dominated by dealers (Hulten and Wykoff [1996]). The effect of these factors is liable to deter market price from the value reflecting the utility of the asset as explained in Chapter 3.1.4. Should such markets exist, as a result of the great heterogeneity of fixed assets it is still questionable whether another identical asset with an identical extent of usage could be found on the market in order to compare its price with the end-of-period value of our asset.

Another criticism frequently raised in connection with market price based asset valuation concerns the information asymmetry on the market, formulated by Akerlof [1970] using a "market for lemons" model. Akerlof assumes that owners primarily sell their assets in less good condition on the second-hand market, and go on using the better quality ones: in consequence, market price will be suitable for the measurement of the value of assets of a poorer quality, and as a result, the assets resold on second-hand markets are not representative of all the underlying population of assets (Akerlof [1970]), and so the suitability of market asset prices for the valuation of assets in use is rather limited.

A practical issue concerning valuation based on the market prices of used assets is that markets are not transparent, i.e. the trading prices may not be observed. For this reason, market value is frequently operationalised using realisable value or substitution/replacement value. Realisable value corresponds to the potential sales price, while replacement value is the total of the potential purchase price plus transaction costs; this signifies that the realisable value is presumably lower than the replacement value. In practice, realisable value is rather used for the measurement of the wealth of 
business units, while substitution value tends to be used for the measurement of national wealth and income (Diewert [1996]).

\subsubsection{Discounted present value of future benefits}

It is an approach widely accepted in mainstream literature discussing the determination of asset value that an asset is considered to be a pool of potential future services to be used in the operation of the company. This approach is also applied by accounting practice. The IAS 16 standard (of the IFRS system) clearly formulates in its section 49 and 50 that it regards fixed assets as a pool of potential future benefits, which future economic benefits are expected to flow to the entity.

Therefore, the theory behind the valuation method connects the flow of the future services rendered by the asset with the present stock of the asset. Böhm-Bawerk [1891] (cited by Diewert and Wykoff [2006]) recognised this relationship very early, and considered asset value to be the discounted present value of the future services to be rendered by the asset. It is a generally accepted view in pertaining literature to identify the value of the services rendered by the asset within one period with the theoretical rentals of the asset on an efficient rental market, named "quasi rent" by Hicks [1942, p. 176]. Theoretical rentals reflect the value judgment of the users of these services, and as such, any marginal utility derived from the consumption of further units of service. As a result, valuation based on the discounted present value of future services builds on the foundations of marginalist value theory.

\subsubsection{Stock-flow relationship between asset value and the value of the future services rendered by the asset}

Following Hulten's [1990] and Diewert-Wykoff's [2006] chain of thought, ${ }^{17}$ I designate by $P_{t, s}^{K}$ the value of the service of an asset of age $s$ for period $t$. In this case, the stock value $P_{t, s}^{I}$ of the asset of an age $s$ for period $t^{18}$ may be calculated as the net present value of its future services:

(6) $P_{t, S}^{I}=P_{t, s}^{K}+\frac{P_{t+1, S+1}^{K}}{1+r_{t, 1}}+\frac{P_{t+2, s+2}^{K}}{\left(1+r_{t, 1}\right)\left(1+r_{t, 2}\right)}+\cdots+\frac{P_{t+S_{t}-s, S_{t}}^{K}}{\left(1+r_{t, 1}\right)\left(1+r_{t, 2}\right) \cdots\left(1+r_{t, S_{t}-s}\right)}$,

\footnotetext{
${ }^{17}$ As well as Hulten's [1990] designation system.

${ }^{18} t$ also designates the beginning of the period.
} 
where $S_{t}$ designates the end of the service lifetime $\left[s=1,2,3 \ldots, S_{t}\right]$ of the asset as estimated at moment $t$, and where $r_{t, \tau}$ is the nominal interest rate valid in future periods $\tau=1,2, \ldots$ as estimated at moment $t$, also expressing the alternative cost of the initial value of the asset. Diewert [1996] describes the following approaches for the determination of the applied nominal interest rate $r_{t, \tau}$ :

- The use of a discounted cash flow rate

- The use of a rate determined with the Capital Asset Pricing Model

- The use of the ex post return method

- The use of the weighted average of past ex post returns

- The use of an exogenous market interest rate

- The use of an official rate of return.

Due to limitations in volume, I shall not be able to discuss the issue of the determination of the applied nominal interest rate $r_{t, \tau}$, but will take it for granted for the purposes of the analysis. Diewert and Wykoff [2006] make the simplifying assumption concerning the interest rate that the interest rates $r_{t, \tau}$ applied in each future period $\tau$ are constant:

(7) $r_{t, \tau}=r_{t} ; \tau=1,2, \ldots$

Following this assumption, equation (6) shall be formulated as follows: ${ }^{19}$

(8) $P_{t, s}^{I}=\sum_{\tau=0}^{S_{t}-s} P_{t+\tau, s+\tau}^{K} /\left(1+r_{t}\right)^{\tau}$.

Academic literature proposes several different approaches for the determination of value $P_{t, s}^{K}$ of the services, which I will describe in the following chapters.

\subsubsection{The value of the services}

To determine the value of the assets, according to equation (8) we need to know the value of the services, which represents the return on the operation of the assets in the individual periods. Therefore the value $P_{t, s}^{K}$ of the service of the asset for a period may be expressed as a market fee that the user pays for nothing but the use of the asset

\footnotetext{
${ }^{19}$ This differs from Hulten's as well as from Hulten and Wykoff's definition inasmuch as they interpret the value of the services as returns at the end of the examined periods, as a result of which the index of the discount factor will contain $\tau+1$.
} 
during a period; the value of the inputs (e.g. fuel) necessary for the operation of the asset are not comprised in this fee; as a consequence, the value of the service also depends on he efficiency of the use of the inputs necessary for the operation of the asset. The one-period value of the services of an asset may be best identified with the theoretical rental produced on the market, which Böhm-Bawerk [1891] recognised very early in his theoretical work. Let us take the active rental market of vehicles as an illustration, where the physical services rendered by cars act as perfect replacement for one another; and let us assume that vehicles only need fuel to render their services, yet the vehicles appearing on the market use this fuel with different levels of efficiency (consumption), that is, the cars need different quantities of fuel to run a certain distance. In this case, presuming that market players take their decisions in a rational manner (striving to minimise costs), it is evident that the theoretical rental of the cars with higher fuel consumptions will be lower; it is clear, then, that the service value (identified with theoretical rental) is only a fee paid for the use of the vehicle, which is substantially influenced by the input and output efficiency characteristics of the asset. I will later discuss the wider interpretation of asset efficiency and its effect on the asset value in detail.

From the above definition of return on the use of the assets it is apparent that by service value I do not mean the residual amount remaining from the company receipts after deduction of current expenditure; therefore, asset value is not influenced by the "individual" profitability (or lack of profitability) of the firm. Actually, the creation of a residual amount from the company receipts after deduction of current expenditure is not only due to the operation of the fixed assets, but much rather to certain elements intangible and inseparable from the whole of the company, ${ }^{20}$ such as the value of continuous operation, of the client base, of the employees etc. It is understood that when a house is built, the added value (or decrease in value) between the construction cost and the value of the building should not be attributed to the last brick, but much rather to the intangible elements mentioned above. Therefore, this surplus value may not be attributed to the company's fixed assets exclusively.

Anticipated market rentals are thus suitable for the expression of the value of services; however, certain problems arise in this connection, the major one being that fixed assets

\footnotetext{
${ }^{20}$ For a detailed description of the components of company value, see: Juhász [2004].
} 
do not have rental markets, for most of the assets are used by their owners. For this reason, other approaches to service value are experimented with in academic literature.

Hotelling [1925] defined the service value of an asset on the basis of the gross return produced by the asset in the given period, which corresponds to the difference between the value of the outputs produced by the asset, calculated at theoretical sales prices, and the operating costs of the asset in that period. The 'gross return' definition therefore approaches the service value from the side of the maximal amount of rental a tenant would agree to pay, presuming that all market players are perfectly informed as to output price and operating costs. Hotelling also assumes that the asset produces at full capacity in the given period, and that the outputs may be sold at the anticipated sales price. Preinreich [1938]—following Hotelling — also identified the service value of an asset with the gross return it produces. However, the definition of service value as the residuum of the company receipts decreased by operating costs is unable to measure fixed asset value independently from the given company, unless the above conditions are met. As a result, a theoretical approach somewhat deviating from Hotelling's ideas gained ground in academic literature to grasp service value.

The foundations of this different approach were laid down by Lutz, Haavelmo, Jorgenson et al in connection with the measurement of the net capital stock, ${ }^{21}$ where the value $P_{t, s}^{K}$ of the services is considered to be the ex post user cost $\omega_{t, s}$ of an asset of age $s$ for period $t$, determined by the end of the period, i.e. at moment $t+1$. Ex post user cost $\omega_{t, s}$ may be regarded as an opportunity cost which the owners waive when they decide to lease their own assets instead of using them (Hulten and Wykoff [1996]).

Diewert [1996] defines the ex post user cost of an asset as the difference of the values of the asset at the beginning of the period and after one period of usage, as determined at the end of the period but discounted for the beginning of the period:

$$
\text { (9) } \omega_{t, s}=P_{t, s}^{I}-P_{t+1, s+1}^{I} /\left(1+r_{t}\right)=\left[r_{t} P_{t, s}^{I}+\left(P_{t, s}^{I}-P_{t+1, s+1}^{I}\right)\right] /\left(1+r_{t}\right) \text {. }
$$

\footnotetext{
${ }^{21}$ For details, see: Lutz and Lutz [1951], Haavelmo [1960], Hall and Jorgenson, [1967], Jorgenson [1963], Jorgenson, Hunter and Nadiri [1970], Jorgenson and Stephenson [1967].
} 
According to Diewert's interpretation, in the expression on the right side of equation (9), $r_{t} P_{t, s}^{I}$ expresses the expected return (or otherwise the alternative cost) related to the asset in question, while the formula $\left(P_{t, s}^{I}-P_{t+1, s+1}^{I}\right)$ designates the change in the asset value.

Diewert's [1996] definition of user cost differs from the concept of user costas defined by Hulten and Wykoff [1996] and Triplett [1996] inasmuch as the latter calculated the ex post user cost for the end of the period, i.e. for moment $t+1$; however in this case the discount factor $\left(1+r_{t}\right)$ would not appear at the end of equation (9).

It is thus clear that the user cost of the assets represents an ex post cost relating to one period, while theoretical rental may be considered as an ex ante fee granting a right to the services provided by the asset for one period (Hulten and Wykoff [1996]). Supposing full use of the assets and a perfectly informed rental market, the theoretical rental and ex post user cost of a same asset of age $s$ for a period $t$ shall be identical:

$$
\omega_{t, s}=P_{t, s}^{K}
$$

However as a result of uncertainties of use and information asymmetry, this condition is hardly ever fulfilled (Hulten and Wykoff [1996]). The difference resulting from the ex post nature of user cost and the ex ante character of theoretical rental was also recognised by Diewert [1996] who regards theoretical rental as an ex ante user cost. Diewert [1996] describes the difference between the ex post and ex ante user cost for a moment $t$ in detail; this difference shall give a part of the difference between the actual end-of-period asset value $P_{t+1, s+1}^{I}$ and its value $P_{t+1, s+1}^{I}(t)$ estimated at moment $t$, considered to be a realised part of an unexpected or "windfall" profit or loss by Bélyácz [2002] and Lee [1986]. ${ }^{22}$

To determine the user cost, we need either the beginning-of-period or the end-of-period value of the assets. This valuation may be performed on the basis of market information concerning the assets used; however, as I have mentioned before, used assets hardly have an efficient and operational market.

\footnotetext{
${ }^{22}$ In Chapter 4.2 this problem will be further discussed in detail.
} 
Therefore academic literature tries to determine the value of the assets for a given moment in time by grasping the processes and phenomena influencing the change of the asset value. I will describe these processes and phenomena in the following subchapter.

\subsubsection{Phenomena affecting asset value}

It is clear that the value of used assets is shaped by the physical and economic phenomena occurring in them and in their surroundings. Griliches [1963] defines these phenomena and processes in the following way:

- Exhaustion: with aging, there follows a decline in the life expectancy of the asset; that is, at the end of the period in question, the expected service lifetime of the asset will be shorter than at the beginning of that period.

- Deterioration: with aging, there is a decline in the physical productivity of the asset within the individual periods; i.e. the services rendered by the asset become poorer by the end of the period than they were at the beginning.

- Obsolescence: as a result of technological progress, the services provided by assets using an older technology will be worth less than those of assets with the most recent technology: this represents a decline in the relative market return for the productivity of these assets, also influenced by other relative price changes.

Triplett [1996] regarded the concept of exhaustion as defined by Griliches as the last phase of deterioration; nevertheless, Triplett considered it expedient to differentiate between the two effects. ${ }^{23}$ Another reason why it is subservient to differentiate between the two phenomena is that exhaustion is directly connected with value $P_{t, s}^{I}$ of the asset, i.e. it does not affect asset value $P_{t, s}^{K}$, but the elements of the addition in equation (8) will decrease by one by the end of the period. Therefore, the effect of exhaustion is relatively easy to visualise and to understand, as a result of which fact it is a factor constantly (although not always expressedly) taken into account in studies on depreciation.

\footnotetext{
${ }^{23}$ To illustrate the difference between exhaustion and deterioration, let us take the example of a coal mine, where the service provided by the mine is the quantity of coal mined in a given period. Let us furthermore assume that the heating value of the coal situated in the lower layers is lower than that of the coal in the upper layers. In this case, by the end of a period, the coal stock remaining in the mine will be smaller than it was at the beginning of the period: according to the terminology above, this represents the "exhaustion" of the mine. However, in the subsequent periods, coal is extracted from lower and lower layers, which (in line with our assumption) will yield coal of ever lower heating value; this means that period after period, the services rendered by the mine will become poorer and poorer, corresponding to "deterioration" in the above outlined nomenclature.
} 
On the other hand, deterioration is connected with the value $P_{t, s}^{K}$ of the service rendered by the asset, which decreases insomuch as the older asset is only able to provide poorer or less service in the subsequent periods than it could when it was younger.

Jorgenson [1971] considers the above definition of the phenomenon of deterioration as a mortality sequence, and Triplett [1996] explains it with two additional factors, the decay and retirement of the assets. Triplett considers decay as the decrease in the productive efficiency of the surviving capital services, while he defines retirement as the loss of capital services. In Triplett's [1996] opinion, as a consequence of decay, the efficiency of the asset decreases as its age increases, so that it can render ever less or poorer service in the periods to come. The phenomenon of decay may also be examined from the aspect of input and output; Feldstein and Rothschild [1974] establish the difference between these two phenomena very clearly. In their understanding, input decay means that as it grows older, an asset uses more input to render an identical capital service than a newer unit. On the other hand, output decay means that as it gains in age, an asset will be able to render less and less capital service in each future period. The essence of decay may be illustrated with a lorry, where input decay would consist in the fact that as the vehicle gets older, its fuel consumption will steadily grow; while output decay would mean that as a result of the ever more frequent breakdowns and time spent in the garage, the lorry will be able to provide less and less capital service (for example, run less kilometres) in the subsequent periods.

As a second component of deterioration, Triplett [1996] identifies the loss of service resulting from the retirement of the assets; which however may only be construed for a group of assets only, for in the case of one asset, retirement (reaching the end of usability) also entails the end of the valuation. In the case of a single asset, retirement as the loss of a certain part of the services corresponds to output decay as outlined above. For this reason, in the present study I shall not perform a separate analysis of retirement.

The next phenomenon influencing the changes in asset value is obsolescence, also mentioned by Griliches. When a new asset using a new, more developed technology appears on the market, the value of the existing assets using a less developed technology will decrease as a result: Hulten and Wykoff [1996] call this decrease obsolescence. The phenomenon of obsolescence appears primarily as a result of the intensive innovation and technological development characteristic of capitalism, a phenomenon which in the 
economic sense was baptised "creative destruction" by Kornai [2010], in the wake of Schumpeter. In connection with the above mentioned technological advance, Hall [1968] recognises two further phenomena: embodied and disembodied technological progress, a phenomenon also identified earlier by Jorgenson [1966]. In the case of embodied technological progress, the new, more developed technology is embodied in a specific asset which becomes available to market players. Contrarily, in the case of disembodied technological progress, no asset of a more developed condition appears, but the services of the existing asset lose value as a result of the general development of other technologies: in other words, the change occurs in the exchange rate of the asset. Building on the findings of Jorgenson and Hall, following the pattern of technological progress, Diewert and Wykoff [2006] differentiate between embodied and disembodied obsolescence:

- Disembodied obsolescence: where there are no new and improved models introduced on the market, but the value of the capital service of the asset declines over time due to shifts in demand or other exogenous factors;

- Embodied obsolescence: where new and improved models of the capital good appear on the market over time, as a result of which-under the assumption of Hulten and Wykoff [1996] — the value of the asset with the older technology will decrease.

The phenomenon of embodied obsolescence is clearly recognisable in the first half of Griliches's [1963] definition of obsolescence, while the reference to "other relative price changes" may be identified with the phenomenon of disembodied obsolescence.

With the exception of exhaustion, the phenomena outlined above all affect the value $P_{t, s}^{K}$ of the services rendered by the asset, which however may be further analysed to establish whether the given phenomenon modifies the asset service value through the unit value or through the quantity of the service provided by the asset.

Actually for an in-depth analysis of the effects of these phenomena, it is necessary to differentiate between services on a quantitative and value-related basis. It holds true for a major part of fixed assets that as their age grows, the services they provide will typically decrease and get poorer in the physical sense; and these changes are also reflected in the value of the services. 


\subsubsection{The quantity of services embodied in the asset}

For a quantitative measurement of the services embodied in the assets, it is always necessary to determine a unit of measurement which may be different for each asset but always refers to the activity performed by the asset in the production process. The unit of measurement of the asset service may be machine hour for a production machine or kilometre for a vehicle. These measurement units also make it possible to express the asset itself in quantitative terms. Physics provide the theoretical and conceptual background, as well as the generally accepted measurement methods, necessary for the observation and determination of services expressed in quantity units; whereas economic science is responsible for the theoretical background of connecting measurement units with the production processes (I will discuss this aspect in detail further on).

The quantitative determination of assets enters into the field of the branch of classical economics studying production theory. As I mentioned earlier in Chapter 2.1 on capital, production theory revolves around the production function, representing the relationship between the quantities of the output on the one hand, and of the various inputs needed for its production on the other hand - according to the definition widely accepted in economics (Griliches [1963]). Part of the inputs necessary for the production process of the examined period are provided by the fixed assets (vehicles, equipment, buildings) used by the company: academic literature calls these inputs the capital service provided by the fixed assets in the given period, or in short, service. ${ }^{24}$ In the quantitative analysis of the potential services relating to a period, the vintage and age of a fixed asset-as explanatory variables - are connected with the (surviving) quantity of services in the asset, and with its efficiency. The vintage of an asset (i.e. its date of fabrication) may determine the initial quantity of service in that asset, the gradual decrease of the former, as well as the service lifetime of the asset, in case there is a difference between the technological standards of the assets manufactured at different moments in time. On the other hand, the age of the asset shows the quantity of surviving services embodied in the asset, and refers to its potential efficiency in the individual periods to come. The facts outlined above can be very easily visualised through a simple example. An older beast of burden will evidently be able to provide less service ${ }^{25}$ in a given period than a younger

\footnotetext{
${ }^{24}$ Used in this sense by Hulten [1990], Triplett [1996], Hulten and Wykoff [1996], Diewert [1996], Diewert and Wykoff [2006], Jorgenson [1991].

${ }^{25}$ Assuming use of identical intensity.
} 
animal: the reason for this difference lies in the phenomena of deterioration and decay outlined in the previous chapter. We may then say that the services of the younger animal are more efficient; and as the younger animal may be expected to live longer than the older one, it may be anticipated that the quantity of services for the rest of its life is also superior; consequently, the younger animal's services will be exhausted later than those of the older one. However, the quantity and the efficiency of the remaining services of two assets of the same age may also differ if the assets are of different vintages, ${ }^{26}$ provided that there are deviations in the qualities of the various vintages. On the basis of the above, it may be established that the services of the assets of different ages and vintages constitute the (physical) capital stock of the company, also expressing the extent of the productive capacity of the firm.

To grasp the relationship between the totality of the services provided by the asset and capital stock, let us consider a company operating several fixed assets of the same type but of different ages $s[\mathrm{~s}=0,1,2, \ldots, \mathrm{S}]$ at a given moment in time $t$. The fixed assets of age $s$ used by the company are able to deliver capital service $k_{t, s}$ in period $t$ in order to contribute to the company's operation, i.e. to produce output. The totality of the capital services $k_{t, s}$ at the disposition of the company at moment $t$ constitute the capital stock $K_{t}^{A}$ of the company. This relationship is illustrated by the graph below:

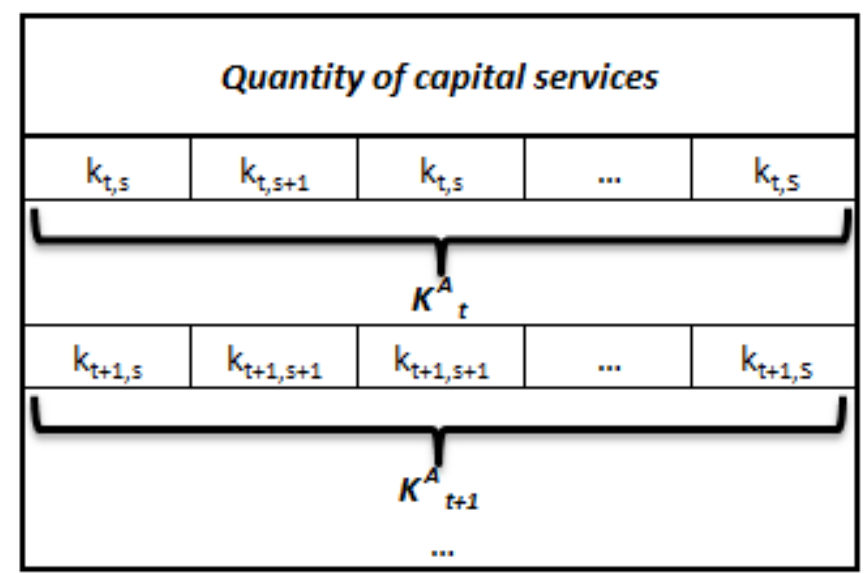

Graph 4: Relationship between services embodied in the assets and periodical capital stock. (Source: own elaboration)

The capital services $k_{t, s}$ of the fixed assets last until the period $[t, t+1, t+2, \ldots]$ where at one moment $t$ the asset reaches the end $S$ of its service lifetime $[\mathrm{s}=0,1,2, \ldots, \mathrm{S}]$.

\footnotetext{
${ }^{26}$ Examined at different moments in time.
} 
Therefore, in a period $t$, fixed assets of different ages, possessed by the company, provide capital service for the production process, and the totality of these capital services may be considered as the capital stock $K_{t}^{A}$ for period $t .^{27}$ This may be expressed as follows:

(11) $\quad K_{t}^{A}=\left[k_{t, 0}, k_{t, 1}, \ldots, k_{t, S}\right]$.

Capital stock $K_{t}^{A}$ thus ensures the operation of the company's activities in the individual operating periods $[t, t+1, t+2, \ldots]$ of the company. For this purpose, the company needs to provide for the replacement of any decrease in the capital stock as compared to its stock in the previous period: this represents essentially the maintenance of the intactness of capital in the physical sense, described in detail in Chapter 2.2.

\subsubsection{Determining the capital stock of a given period by the use of the perpetual inventory method}

Hulten [1990] explains that the quantity $k_{t, 0}$ of capital services the company acquires through the purchase of new assets in the given period is comparatively easy to summarise; however, the services of the fixed assets already in use cannot be added up because of the differences in the rate of deterioration, i.e. in efficiency. This actually constitutes the major problem in the determination of capital stock $K_{t}^{A}$ according to equation (11). Many economists eliminate this problem by the use of the perpetual inventory method, making it possible to add up services with different efficiencies using efficiency weights. The method may only be applied on the condition that the assets of different ages and their services are perfectly replaceable between themselves (Hulten [1990]). For the examination of this model, let us first assume that the assets of different ages represent identical levels of technological advance, ${ }^{28}$ where the difference between the services of the assets of different ages results exclusively from the phenomenon of deterioration (described in Chapter 3.1.5.3). Following Hulten's train of thought, the quantity $k_{t, s}$ of the services of assets with same levels of technology but of different ages in period $t$ may be expressed from service $k_{t, 0}$ of the 'new' asset through the association of a relative efficiency weight $0 \leq \varphi_{s} \leq 1$, where $[\mathrm{s}=0,1,2, \ldots, \mathrm{S}]$ designates

\footnotetext{
${ }^{27}$ This definition corresponds with the concept of "capital stock" as used by Hulten [1990], Triplett [1996], Hulten and Wykoff [1996].

${ }^{28}$ I will later relieve this assumption in Chapter 3.1.5.8.
} 
the age of the asset, that is, the number of periods during which the given fixed asset had been previously used. If we consider the new assets to be the most efficient in the individual periods $t$, then efficiency weight $\varphi_{0}=1$ will be assigned to those. Using the relative efficiency weights thus determined, equation (11) may be formulated in the following way: ${ }^{29}$

$$
K_{t}^{A}=\varphi_{0} k_{t, 0}+\varphi_{1} k_{t, 0}+\cdots+\varphi_{S} k_{t, 0}
$$

The perpetual inventory method may also be interpreted as applied to the entire service lifetime $[\mathrm{s}=0,1,2, \ldots, \mathrm{S}]$ of an asset, where the different service quantities $k_{t, s}$ and service values $P_{t, s}^{K}$ corresponding to the different ages $s$ of the asset may be expressed, through the use of efficiency weights, from the quantity of service $k_{t, 0}$ and the service value $P_{t, 0}^{K}$ of the new asset. This was first recognised by Christensen and Jorgenson [1973] and has since been baptised 'asset vintage model' or 'capital vintage model' in academic literature.

\subsubsection{The capital vintage model}

As mentioned earlier, the perpetual inventory method made it possible to express the services of the assets of different ages $s$ from each other using efficiency weights $\varphi_{s}$. To this analogy, Christensen and Jorgenson [1973] proposed a simplified procedure for the model described in equation (8). The essence of this simplification is that the services $\varphi_{t, s}$ of different efficiencies provided by the asset at its different ages $s$ as estimated at moment $t$ may be expressed from each other through the use of relative efficiency weights. For a better oversight of the model, let us assume that there is no technological progress in the given business environment, so that the differences between the services rendered by the assets of different ages are only attributable to deterioration as defined in Chapter 3.1.5.3. In this case, assuming competitive market conditions, the following equation may be considered to be valid (Diewert and Wykoff [2006]):

$$
P_{t, s}^{K}=\varphi_{t, s} P_{t, 0}^{K}
$$

where $\varphi_{t, s}$ is the relative efficiency of an asset of age $s$ compared to that of a new asset of age $s=0$, this efficiency weight being, for a new asset of age $s=0, \varphi_{t, 0}=1$. Diewert

\footnotetext{
${ }^{29}$ Following the reasoning of Hulten [1990], Triplett [1996], Hulten and Wykoff [1996].
} 
and Wykoff [2006] note concerning equation (13) that it is only true in case the new assets and the assets of age s are perfectly replaceable between themselves. In this case, using equation (13), equation (8) may be formulated as follows:

$$
P_{t, s}^{I}=\sum_{\tau=0}^{S-s} \varphi_{t, s+\tau} P_{t+\tau, 0}^{K} /\left(1+r_{t}\right)^{\tau}
$$

In equation (14), the service values $P_{t, s}^{K}$ of the different assets of ages $s$ may thus be expressed using relative efficiency weight $\varphi_{t, s}$ from the value $P_{t+\tau, 0}^{K}$ of the services provided by the new asset of age $s=0$ at the individual moments $t+\tau$.

Following Diewert and Wykoff's [2006] reasoning, assuming a business environment characterised with price changes, I will differentiate, regarding assets of the same age, between the service values observable at a given moment $t$ and the expected service values at the beginning of the individual future periods. I will assume that the following relationship exists between the service values of assets of different ages at given moments $t$ :

$$
\begin{gathered}
P_{t, s}^{K} *\left(1+i_{t, 0}\right)=P_{t, s}^{K} ; P_{t, s}^{K} *\left(1+i_{t, 1}\right)= \\
P_{t+1, s}^{K} ; P_{t, s}^{K} *\left(1+i_{t, 1}\right)\left(1+i_{t, 2}\right)=P_{t+2, s}^{K} ; \ldots
\end{gathered}
$$

where $1+i_{t, \tau}$ designates the variation factor of the service value which expresses the expected future change $[\tau=1,2,3 \ldots]$ in the service value of the asset estimated at moment $t$, regardless of the deterioration of the asset. In another approach, factor $1+i_{t, \tau}$ expresses the nominal price change in one service unit of the asset from a future moment $t+\tau$ until the next moment $t+\tau+1$, as estimated at moment $t$.

To simplify matters, Diewert and Wykoff [2006] assume that the rate $i_{t, \tau}$ influencing the price of the service units of the assets is constant within the examined future periods $=1,2,3 \ldots$ :

$$
i_{t, \tau}=i_{t} ; \tau=1,2,3, \ldots
$$

In this case, equation (14) relating value $P_{t, s}^{I}$ of the asset as calculated at moment $t$ with value $P_{t, s}^{K}$ of the future services may be formulated using equations (15) and (16) as follows: 


$$
P_{t, s}^{I}=\sum_{\tau=0}^{S_{t}-s}\left(1+i_{t}\right)^{\tau} \varphi_{t, s+\tau} P_{t, 0}^{K} /\left(1+r_{t}\right)^{\tau}
$$

On the right side of equation (17), service values $\varphi_{t, s+\tau} P_{t, 0}^{K}$ expressing the deterioration of the different assets of age $s$ at moment $t$ may be transformed, through the use of factor $\left(1+i_{t}\right)^{\tau}$, into service values valid at moment $t+\tau$ :

$$
\left(1+i_{t}\right)^{\tau} \varphi_{t, s+\tau} P_{t, 0}^{K}=P_{t+\tau, s+\tau}^{K} ; \tau=0,1,2, \ldots
$$

where if $\tau=0$ then $\left(1+i_{t}\right)^{\tau}=1$.

We may conclude that the use of the model defined in equation (17) necessitates the knowledge of efficiency weights $\varphi_{t, s+\tau}$ and of price variation factor $\left(1+i_{t}\right)^{\tau}$. In the next chapter, I will first analyse the possible ways of determining efficiency weights, still excluding technological progress, then I will continue with the examination of phenomena causing price change $i_{t}$, this time taking technological progress duly into account.

\subsubsection{Determining relative efficiency weights}

As at present I am analysing value $P_{t, s}^{I}$ of the assets of different ages in an environment excluding technological progress, the existence of a difference between the values of the assets of different ages may only be attributed to the deterioration and the exhaustion of these assets, which effects I described in Chapter 3.1.5.3. The deterioration of the assets of different ages, i.e. the difference in their efficiency, is reflected in service value $P_{t, s}^{K}$; the mutual correlation between the service values of these assets of different ages, as defined in equation (13), considerably simplifies the model outlined in equation (8), as shown by equation (14). The expression from one another of the values $P_{t, s}^{K}$ of the services belonging to assets of different ages is important because fixed assets do not have rental markets the existence of which could provide information about the values of the services rendered by the assets of different ages. However, through the estimation of efficiency weights, we acquire a usable model; this estimation needs to be performed with due regard to the quality standards, use intensity and technical maintenance of the asset. Consequently, the value of the services provided by assets of different ages may be expressed after the analysis of various features of the asset, by relating the relative efficiency $\varphi_{t, s}$ of the used asset to the efficiency $\varphi_{t, 0}=1$ of a new asset at a moment $t$. 
Therefore, assets of different ages $s$ will have different relative efficiency weights $\varphi_{t, s}$, which at the same time should also express the proportions of their service values, valid at the given moment in time, as described in equation (13).

Numerous approaches are described in literature for the determination and estimation of efficiency weights. Hulten [1990], Hulten and Wykoff [1996] and Triplett [1996] outline three major methods for the determination of efficiency weights $\varphi_{t, s}$. The first approach assumes that the change of any physical attribute of the assets is related with the decrease of the efficiency of that asset. The second approach identifies the decrease in the efficiency of the asset with a related change in the marginal product; while the third approach assumes that the decrease in the efficiency of assets follows a certain pattern characteristic of the given asset and of its method and intensity of use.

\subsection{The relationship between the efficiency and the physical attributes of an asset}

The approach intending to determine the loss of relative efficiency on the basis of physical attributes is founded on the assumption that the change in any physical characteristic of an asset entails a change in the relative productive efficiency of the asset. Hulten [1990] illustrates this approach with the example of soap and dry ice, where he identifies relative efficiency weights $\varphi_{t, s}$ with the surface areas of new and used blocks of dry ice or bars of soap. Hulten explains, however, that in the case of most assets, this approach to the determination of efficiencies and their correlation with physical attributes is not applicable, because there are assets in the case of which the decrease in efficiency does not show correlation with any decrease in the physical attributes of the assets. Triplett [1996] argues against the possibility to determine efficiency weights in this manner, supporting his argumentation with the example of an eraser: he says that during erasing, a rubber may lose several millimetres of its surface or may remain virtually unchanged, despite the fact that the operation performed was exactly the same, i.e. the eraser provided the same service both times. Therefore the suitability of this method for the determination of the loss of relative efficiency of an asset is very limited and restricted to a certain kind of assets, even on a theoretical plane. 


\subsection{Determining asset efficiency from the proportion of the marginal product of two} periods

Following the reasoning of Hulten [1990] and Hulten and Wykoff [1996], another possible way of determining relative efficiency weights $\varphi_{t, s}$ is to express them from the production process itself. In this case, we may consider relative efficiency weights $\varphi_{t, s}$ as the proportion of the relative marginal products of the assets of ages $s=0$ (new) and $s+1$; this approach dissolves the apparent contradiction in Triplett's eraser case by recognising that the differences in the usage and the intensity of use of the assets also impact on the evolution of relative efficiency weights $\varphi_{t, s}$.

Nevertheless, when determining efficiency weights by calculation from the proportion of relative marginal products, we face the challenge of having to aggregate the services of assets of different vintages; as a consequence, marginal product may only be determined as an aggregate of the individual production functions of homogeneous capital stocks (Hulten [1990]). The relationship between the service and the output of homogeneous assets of age $s$ is expressed by production function $f^{s}$ :

$$
Q_{t, s}=f^{s}\left(k_{t, s}, L_{t, s}\right),
$$

where $Q_{t, s}$ designates the output quantity that the asset is able to produce in period $t$ using service $k_{t, s}$ provided by the asset of age $s$ and quantity of labour $L_{t, s}$ corresponding to this service. After aggregating outputs $Q_{t, s}$ produced using the services of homogeneous assets of different vintages, we get the aggregate production function of period $t$, which we may express on the basis of Hulten [1990] and Triplett [1996] as follows:

$$
Q_{t}=\sum_{s=0} Q_{t, s}=\sum_{s=0} F^{s}\left(k_{t, s}, L_{t, s}\right)
$$

Expressing the aggregation of the services of assets of different vintages in period $t$ in a different way, we get the following equation:

$$
Q_{t}^{*}=F\left(\left(k_{t, 0}, k_{t, 1}, \ldots, k_{t, S}\right), L_{t}\right)
$$

where $Q_{t}^{*}$ designates the maximal output of the assets of different ages realisable in period $t$, where aggregate $L_{t, s}$ of the necessary quantities of labour $L_{t}$ connected with 
the individual services is available. In this context, Hulten [1990] explains that ensuing from Leontief's results, it is a necessary and sufficient condition of the aggregation of the services comprised in equation (21) that the marginal rate of substitution of any input pair in an aggregate group should be independent of any inputs outside the aggregation. ${ }^{30}$ From this condition it also ensues that technologies $F^{s}$ corresponding to the assets of different vintages contained in the aggregation need to be identical.

Having regard to the necessary conditions of aggregation, the relative efficiency of homogeneous assets may be expressed on the basis of knowledge available at moment $t$ as follows:

$$
\frac{\partial Q^{*} / \partial k_{t, s}^{n}}{\partial Q^{*} / \partial k_{t, 0}^{n}}=\varphi_{t, s} s=0,1,2, \ldots, S_{t}
$$

However, in practice, it is rather cumbersome to calculate efficiency weights from variations in marginal product. Diewert [1996] mentions two main issues regarding this method. The first problem is that it only works in extremely aggregate models and for a small number of outputs. The other issue is the condition relating to the additionability of the services of assets of different vintages that the services of such assets need to perfectly replace one another. This condition is very rarely fulfilled in reality.

\subsection{Determining the decrease in the efficiency of fixed assets on the basis of patterns}

Due to the above outlined limitations of the determination of the relative efficiency weights connected with fixed assets, economic literature tends to assume that the loss of efficiency of an asset follows a certain pattern characteristic of the given asset. This pattern is usually assigned to the given asset on the basis of observation or assumption. The pattern of the decay of the efficiency with age may vary for the different assets, depending on the individual quality, the usage and the intensity of use, as well as the level of maintenance of the asset. Despite the many varieties of use and other circumstances, academic literature typically differentiates between three basic patterns (constant, linear and geometric) on the basis of the evolution of the relative efficiencies. Hulten [1990] and Hulten and Wykoff [1996] describe these patterns in detail. The following graph illustrates the constant, linear and geometric patterns of relative

\footnotetext{
${ }^{30}$ This condition is not fulfilled in the case of input decay as outlined above; therefore this method is only applicable with limitations for the determination of decrease in efficiency resulting from input decay.
} 
efficiency decrease as the function of the age of the asset, showing the evolution of the efficiency of an asset with a service lifetime of 10 years according to the different patterns.

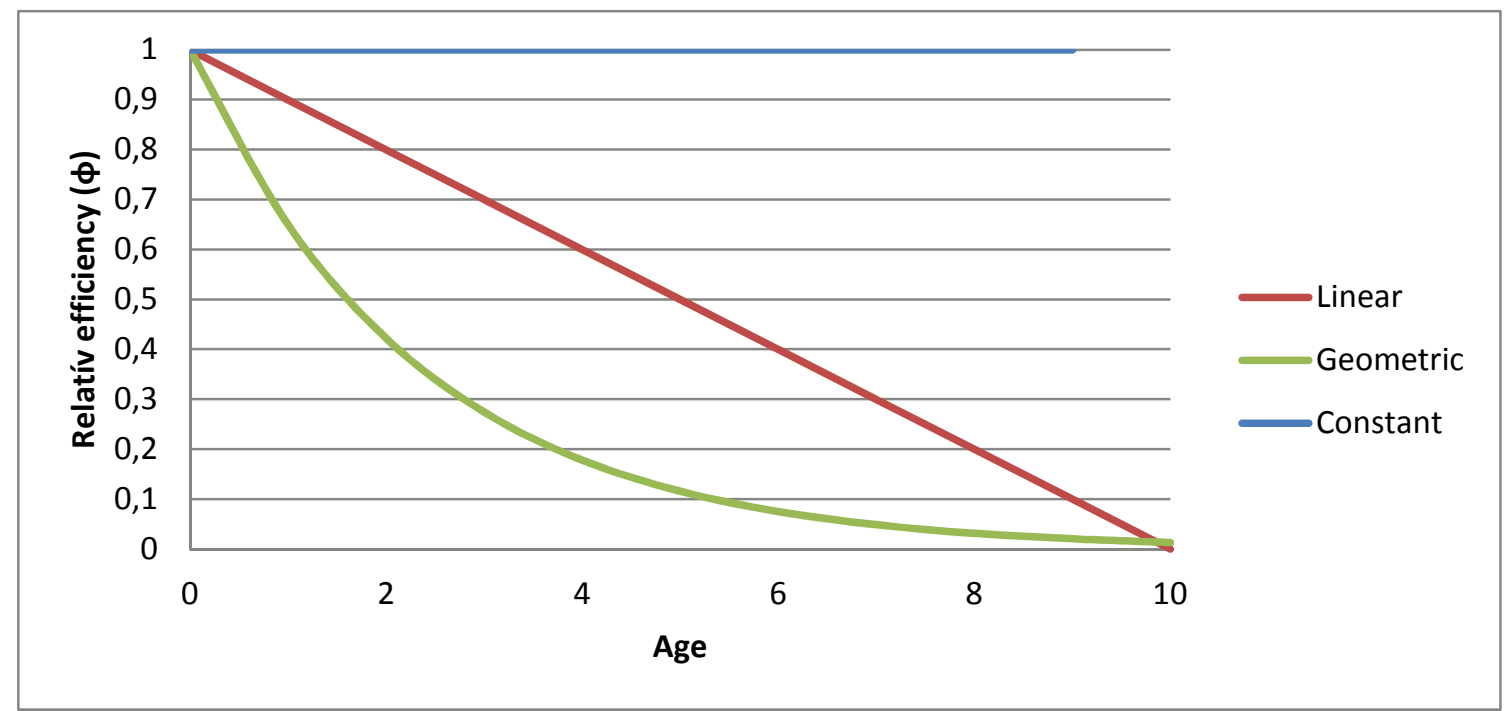

Graph 5: The different asset efficiency patterns as a function of asset age. (Source: own elaboration)

The first and the simplest of the patterns introduced by Hulten [1990] and Hulten and Wykoff [1996] is the 'constant efficiency pattern', also called 'one-hoss shay' ${ }^{31}$ or 'light bulb' efficiency pattern. The pattern assuming constant efficiency is founded on the observation that some assets are able to provide services of a constant efficiency throughout their service lifetime, independently of their time of use and their age. The most frequently cited example of an asset with this type of efficiency is the light bulb, which shines with a typically constant 'efficiency' through all the periods of its service lifetime up to the end of its lifetime, when it finally burns out, i.e. its efficiency decreases to zero. Hulten [1990] expresses the above outlined age-constant efficiency with the following formula:

$$
\varphi_{t, 0}=\varphi_{t, 1}=\cdots=\varphi_{t, S_{t}-1}=1, \varphi_{t, S_{t}+\tau}=0, \tau=0,1,2, \ldots
$$

To determine the efficiency of an asset following a constant efficiency pattern, it suffices to estimate the end $S_{t}$ of the service lifetime of the asset at moment $t$ to be able to use the efficiency weights $\varphi_{t, s}$ corresponding to the individual periods.

\footnotetext{
${ }^{31}$ After the 'wonderful shay' appearing in the poem entitled The wonderful one-hoss shay by O. W. Holmes.
} 
The second, also simple, pattern of efficiency decrease outlined by Hulten [1990] and Hulten and Wykoff [1996] is linear: in this case it is assumed that the relative efficiency of the asset decreases in a linear fashion with age, right until the end $S_{t}$ of its service lifetime:

$$
\varphi_{t, 0}=1, \varphi_{t, 1}=1-\frac{1}{s_{t}}, \varphi_{t, 2}=1-\frac{2}{s_{t}}, \ldots, \varphi_{t, S_{t}-1}=1-\frac{s_{t}-1}{s_{t}}, \varphi_{t, S_{t}+\tau}=
$$

$0 ; \tau=0,1,2, \ldots$

From the above definition it is clear that in the linear pattern, the efficiency of the asset decreases by a constant part by the end of each period:

$$
\varphi_{t, s-1}-\varphi_{t, s}=\frac{1}{s_{t}}, s=0,1,2, \ldots, S_{t}
$$

To determine the decrease in the efficiency of the asset, here again it is sufficient to estimate the end $S_{t}$ of the service lifetime of the asset to establish the individual efficiency weights.

The third pattern of efficiency decrease described by Hulten [1990] and Hulten and Wykoff [1996] is the geometric pattern, in which the decrease in the efficiency of the asset is expressed by a constant rate $\delta_{t}$ estimated at a moment $t$ :

$$
\frac{\left(\varphi_{t, s-1}-\varphi_{t, s}\right)}{\varphi_{t, s-1}}=\delta_{t}
$$

Using this rate $\delta_{t}$, the efficiency decrease pattern may be defined as follows:

$$
\varphi_{t, 0}=1, \varphi_{t, 1}=\left(1-\delta_{t}\right)^{1}, \varphi_{t, 2}=\left(1-\delta_{t}\right)^{2}, \varphi_{t, s}=\left(1-\delta_{t}\right)^{s}, \ldots
$$

This means that in the geometric pattern of decrease in efficiency, the efficiency of the asset may be determined using a simple constant rate $\delta_{t}$; the simple nature of this method makes it quite popular in empirical studies on depreciation. Beyond its simplicity, this pattern is also widely used because, ensuing from the nature of geometric sequences, relative efficiency weight $\varphi_{t, s}$ expressing the value of the services $P_{t, s}^{K}$ and the rate expressing the decrease in the value $P_{t, s}^{I}$ of the asset may be mutually correlated by generalising equation (27): 


$$
\varphi_{t, s}=\left(1-\delta_{t}\right)^{s}
$$

where rate $\delta_{t}$ is constant throughout the service lifetime of the asset:

$$
\delta_{t}=\delta_{t, s} ; s=0,1,2, \ldots, S_{t} .
$$

Substituting the expression on the right hand side of equation (28) into equation (17), we obtain the following definition of service value:

$$
P_{t, s}^{I}=\sum_{\tau=0}^{\infty}\left(1+i_{t}\right)^{\tau}\left(1-\delta_{t}\right)^{s+\tau} P_{t, 0}^{K} /\left(1+r_{t}\right)^{\tau}
$$

In this case, if $i_{t}=r_{t}$ and $\left(1-\delta_{t}\right)<0$, the expression on the right side of equation (30) may be regarded as a geometric sequence in which the rate of totals $P_{t, 0}^{I}$ and $P_{t, s}^{I}$ will be:

$$
\frac{P_{t, s}^{I}}{P_{t, 0}^{I}}=\left(1-\delta_{t}\right)^{s}=\varphi_{t, s}
$$

Nevertheless, this pattern based on a geometric sequence is frequently criticised, despite its advantages described above, because of the fact that the relative efficiency $\varphi_{t, s}$ and value $P_{t, s}^{I}$ of the asset only approximate zero but never reach it, which assumption is unrealistic in the case of fixed assets. This phenomenon may be conveniently observed in Graph 5. Another subject of criticism follows from the nature itself of the geometric sequence generated using a constant rate, where the geometric pattern of efficiency decrease eventuates a greater degree of efficiency decrease at the beginning of the service lifetime of the asset. However, despite its ostensibly unrealistic features, it is not at all uncommon that a geometric pattern is identified in the empirical analysis of the relative efficiency decrease and depreciation of assets. ${ }^{32}$

On the basis of the relationship defined in equation (17), the above presented patterns of efficiency decrease impact on value $P_{t, s}^{I}$ of the asset, the evolution of which with age (if $\left.i_{t}=0 ; r_{t}=0,1\right)$ is illustrated by the following graph: ${ }^{33}$

\footnotetext{
${ }^{32}$ See for example: Hulten and Wykoff [1981a], Storchmann [2004].

${ }^{33}$ Hulten and Wykoff [1996] and [1981a] call this attribute the 'age-price profile'. As in the present study I consider the market price of the assets to be equal to their value as determined following the principle of marginalism, I will henceforth use the term 'age-value profile' for this effect.
} 


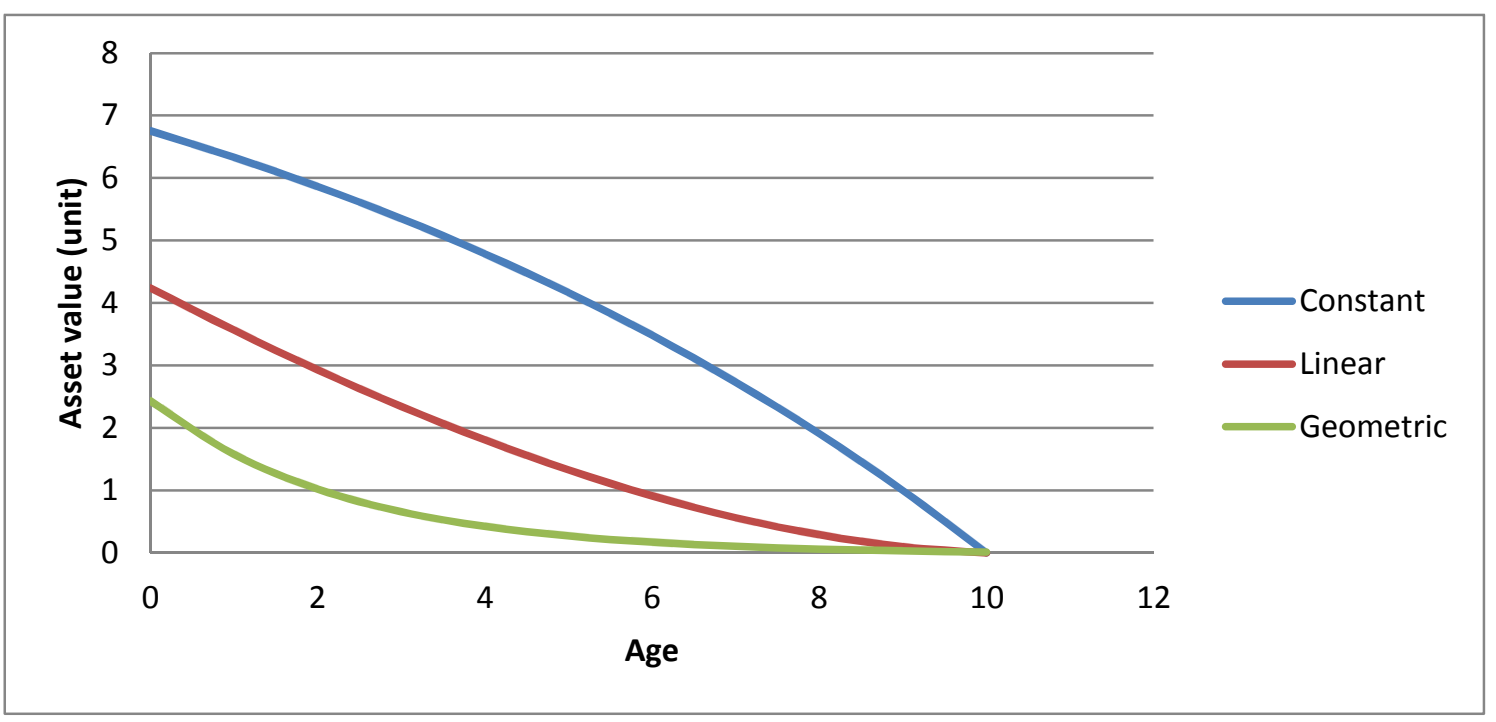

Graph 6: Age-value profiles eventuated by the different efficiency patterns. (Source: own elaboration)

In this chapter I have described a model frequently used for the aggregation of the future service values of assets, where the expression of the relative efficiency of the asset creates the link between the service values corresponding to the different ages of the asset, of which the discounted present value is actually identical with the value of the asset. For the sake of clarity, up to this point I examined the model in an environment where I entirely excluded the possibility of technical progress. In the next chapter I will relieve this restriction.

\subsubsection{Technological progress and obsolescence}

Throughout my analysis of asset value, until the present point I assumed the existence of a business environment without technological progress. Following the reasoning of Jorgenson [1966], Hall [1968], Hulten [1990] and Diewert and Wykoff [2006], I will hereinafter assume a business environment where technological advances do exist, as a result of which the assets manufactured become more and more developed and able to satisfy new needs compared to earlier times. In the context of technological progress, Hall [1968] differentiates between embodied technological progress and disembodied technological progress, both of which may result in the decrease in the value of the less advanced asset; ${ }^{34}$ Hulten and Wykoff [1996] call this decrease 'obsolescence'. Following

\footnotetext{
${ }^{34}$ Wykoff [2003] considers that Griliches doubts the truth of this statement. According to Wykoff, Griliches considers that technological progress increases the value of the more advanced asset, but this does not affect the value of the less developed assets already in use.
} 
the pattern of the differentiation made in the case of technological progress, Diewert and Wykoff [2006] differentiate between embodied and disembodied obsolescence.

\subsection{Disembodied technological progress and obsolescence}

Disembodied technological progress is an assumed technical advancement which is not 'embodied' in new assets providing the given service but in the development of assets providing different services. As a result of this, the demand for the asset in question decreases, and so does the value $P_{t, s}^{K}$ of its service. ${ }^{35}$ If the future decrease of the service value may be anticipated, then on the basis of the relationship defined in equation (17), this will also trigger a decrease in value $P_{t, s}^{I}$ of the asset itself; ${ }^{36}$ Diewert and Wykoff [2006] call this decrease 'disembodied obsolescence'.

In connection with equation (15), I determined the asset specific nominal price variation factor $\left(1+i_{t, \tau}\right)$ of asset value $P_{t, s}^{K}$ as estimated at moment $t$ and valid for future periods $t+\tau$, about which I assumed in equation (16) (for the sake of the clarity of the model) that its value remains constant in every future period $t+\tau$ beginning with moment $t$. Diewert and Wykoff [2006] break down the nominal asset specific price change rate $i_{t}$ as estimated at moment $t$ into two parts, to real asset specific price change rate $i_{t}^{*}$ and general price change rate, i.e. inflation. ${ }^{37}$ I will designate the inflation rate estimated at moment $t$ and valid for future periods $t+\tau$ with $\rho_{t, \tau}$. For the sake of clarity, let us assume, however, that inflation rate $\rho_{t, \tau}$ remains constant for all future periods $t+\tau$ beginning with moment $t$ :

$$
\rho_{t, \tau}=\rho_{t} ; \tau=1,2,3, \ldots
$$

In this case, the relationship between inflation $\rho_{t}$ and asset specific real $i_{t}^{*}$ and nominal $i_{t}$ price change rates will be:

$$
1+i_{t}^{*}=\frac{1+i_{t}}{1+\rho_{t}}
$$

\footnotetext{
${ }^{35}$ For instance, the general progress made in plastics industry, opening up the possibility of fabricating synthetic waterpipes, clearly decreased the demand for machinery used to manufacture the lead pipes widely used before. Consequently, the price of machines producing lead pipes decreased as a result of the development of plastics industry: we construe this decrease as disembodied obsolescence.

${ }^{36}$ This decrease in the asset value is greatly influenced by its alternative usability for other purposes.

${ }^{37}$ Diewert [2005] discusses the potential methods and issues of determining inflation rate in practice in detail.
} 
Following Diewert and Wykoff's [2006] reasoning, however, the general price change rate $\rho_{t}$ does not only affect service values but also the nominal interest rate $r_{t}$ defined in connection with equations (6) and (7), which again may be broken down into two parts, general price change $\rho_{t}$ and real interest rate $r_{t}^{*}$. This relationship is reflected by the following equation:

$$
\text { (34) } 1+r_{t}^{*}=\frac{1+r_{t}}{1+\rho_{t}}
$$

If we substitute the real rates expressed in equations (33) and (34) into equation (17) and simplify the expression on the right hand side with the average price change factor $1+\rho_{t}$, then we obtain the following definition for asset value:

$$
P_{t, s}^{I}=\sum_{\tau=0}^{S_{t}-s}\left(1+i_{t}^{*}\right)^{\tau} \varphi_{t, s+\tau} P_{t, 0}^{K} /\left(1+r_{t}^{*}\right)^{\tau}
$$

Therefore, according to this model, asset value is not influenced by the anticipated future average price change rate $\rho_{t}$.

When the future value of the services provided by the asset decrease as a result of disembodied technological progress, the asset specific real price change rate $i_{t}^{*}$ defined above will have a negative value, which will appear throughout the entire service lifetime of the asset beginning with moment $t$. In other words, disembodied obsolescence resulting from disembodied technological progress pushes the function of asset value $P_{t, s}^{K}$, as examined in the light of future periods, "lower" in the graph, as illustrated below: 


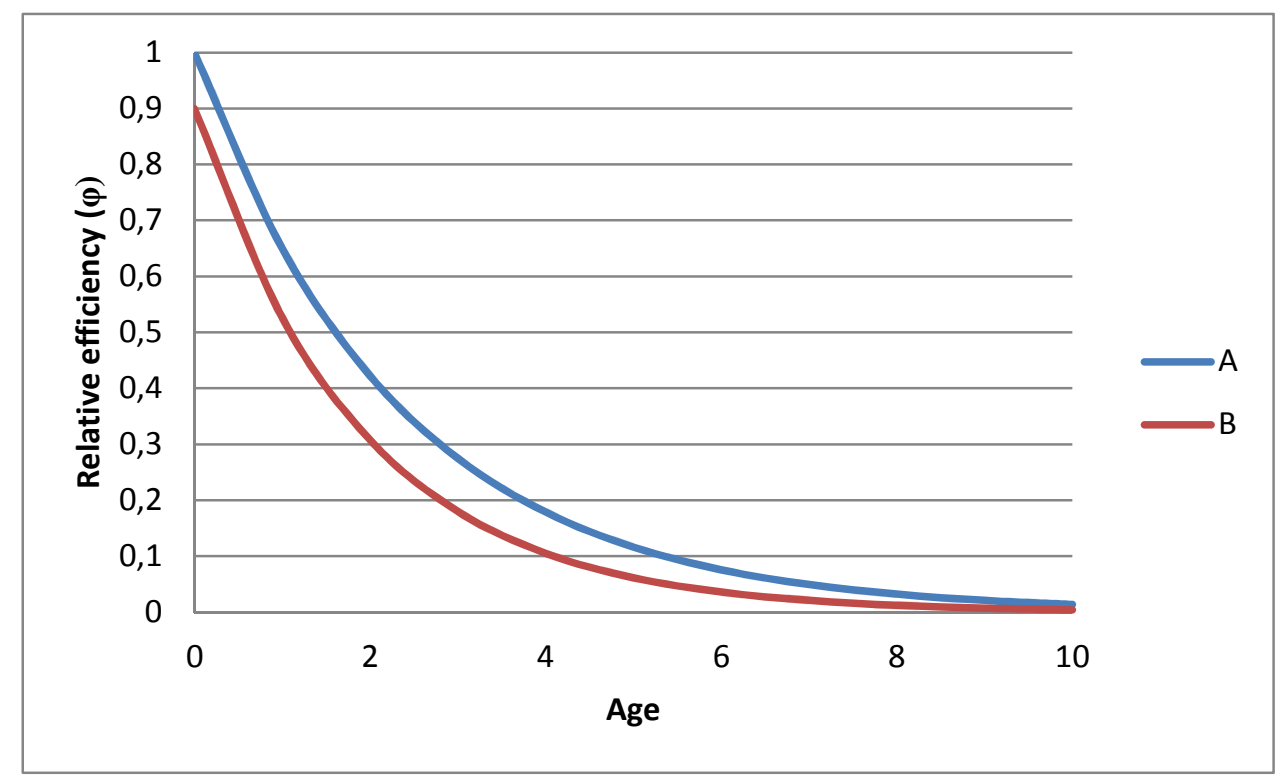

Graph 7: Evolution of service values without and adjusted for disembodied obsolescence throughout the individual periods. (Source: own elaboration)

In Graph 7 I indicated with an 'A' the initial, 'non-obsolete' function of asset values $P_{t, s}^{K}$ in the future periods; when determining this function, I assumed a service lifetime of 10 years and a service decrease pattern of the geometric sequence type. Function ' $B$ ' is the variant of function ' $A$ ' adjusted with asset specific price change rate $i_{t}^{*}=-0,1$, which demonstrates the effect of disembodied obsolescence. Graph 7 clearly shows that under the effect of disembodied obsolescence, the value of the service provided by the asset decreases in the present as well as in each future period.

According to the relationship defined in equation (35), the disembodied obsolescence affecting service values $P_{t, s}^{K}$ also impact on the value of the assets themselves; the following graph illustrates this effect. 


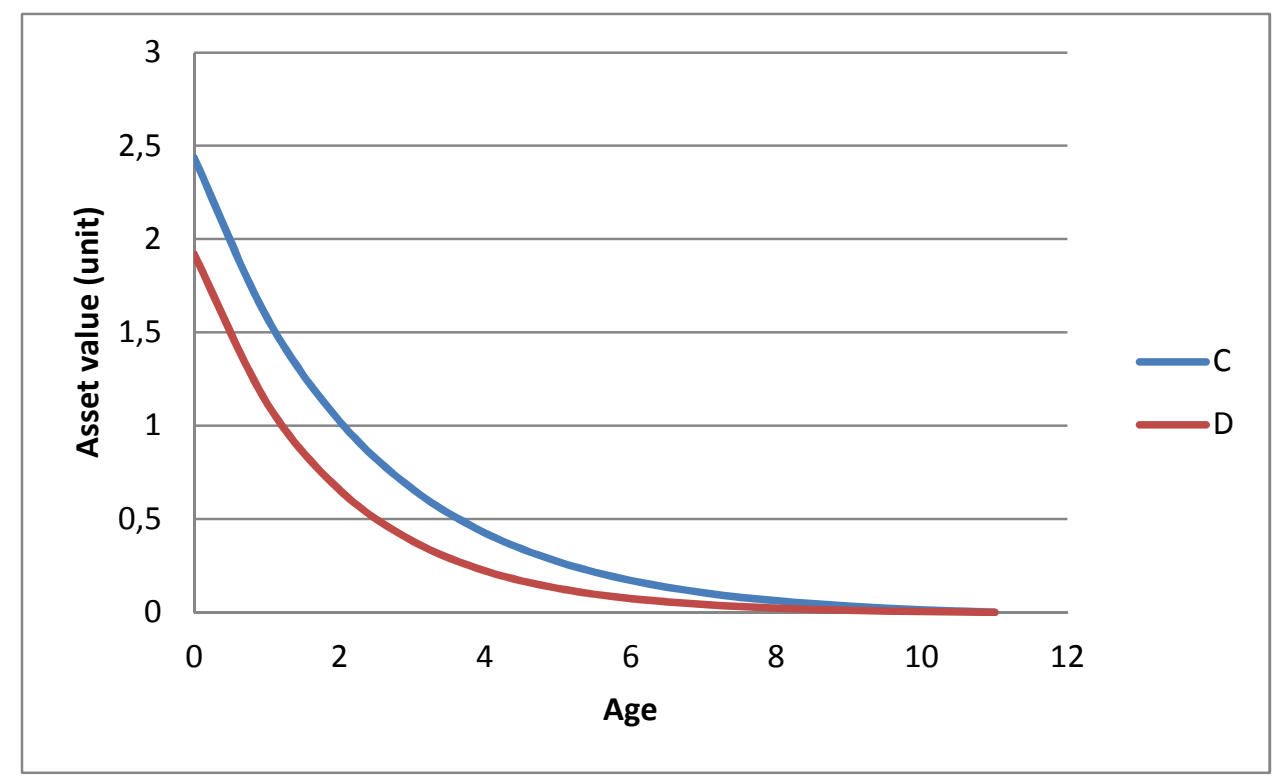

Graph 8: Evolution of asset values without and adjusted for disembodied obsolescence throughout the individual periods. (Source: own elaboration)

I indicated with a ' $\mathrm{C}$ ' the function of asset value $P_{t, s}^{I}$ calculated from services values indicated with an ' $\mathrm{A}$ ' in Graph 7 using real interest rate $r_{t}^{*}=0,1$, and with a ' $\mathrm{D}$ ' the function of asset value $P_{t, s}^{I}$ calculated from the service value indicated with a 'B', also using real interest rate $r_{t}^{*}=0,1$.

It is therefore apparent in the case of both Graph 7 and 8 that the estimated disembodied obsolescence affects the present and future values of the service provided by the asset, and in this manner also influences the value of the asset itself, as well as its evolution.

\subsection{Embodied technological progress and obsolescence}

As opposed to the above, we call 'embodied technological progress' the appearance on the market of a more recent, technologically more advanced asset which, however, provides the same service and is suitable to replace the previous one. The higher level of technological progress of an asset may be apparent in a longer service lifetime or a higher productive efficiency. The increase of the lifespan and productive efficiency of the more advanced asset may be considered as the opposite of exhaustion and deterioration described in Chapter 3.1.5.3, deterioration being equivalent to the phenomenon of decay in the case of an individual asset. If the expected service lifetime of a more advanced asset is longer than that of a less advanced asset, then the exhaustion of the more advanced asset takes longer, which influences the value $P_{t, s}^{K}$ of the service of 
the less advanced asset (provided that their efficiency decrease patterns are identical) only if an installation cost is incurred in relation to the operation of the asset. Installation costs occur more frequently in the case of less advanced assets, and this surplus cost may decrease value $P_{t, s}^{K}$ of the services of the less advanced asset.

Similarly to decay, the improvement of productive efficiency resulting from embodied technological progress may be interpreted both from the input and the output side. The improvement of output efficiency means that compared with a less advanced asset, the asset will be able to produce more output with the same quantity of input in the periods to come. On the other hand, the improvement of input efficiency means that the more advanced asset will use less input to produce the same quantity of output than a less advanced one. In this case, as a result of the efficiency improvement resulting from progress, value $P_{t, s}^{K}$ of the services provided by the less advanced assets will decrease due to the advantages of using the more advanced asset. The decrease in value $P_{t, s}^{I}$ of the less developed assets entailed by technological progress embodied in the improvement of efficiency and in the increase of service lifetime is called 'embodied obsolescence' by Diewert and Wykoff [2006].

Consequently, the relative efficiency weights $\varphi_{t, s}$ defined in equation (13) not only express the effects of deterioration but also that of embodied obsolescence, for in this case service value $P_{t, 0}^{K}$ of the new asset of age $s=0$ belongs to an asset with a more developed technology. Therefore in the case of embodied technological progress, the efficiency of an asset of age $s$ is not inferior to that of a new asset only because of its deterioration but also because the new asset represents a more advanced level of technology.

The obsolescence generated by embodied technological progress will thus decrease value $P_{t, s}^{K}$ of the service provided by the asset in addition to the effects of deterioration, i.e. the evolution of service value with age becomes steeper, as illustrated in the following graph: 


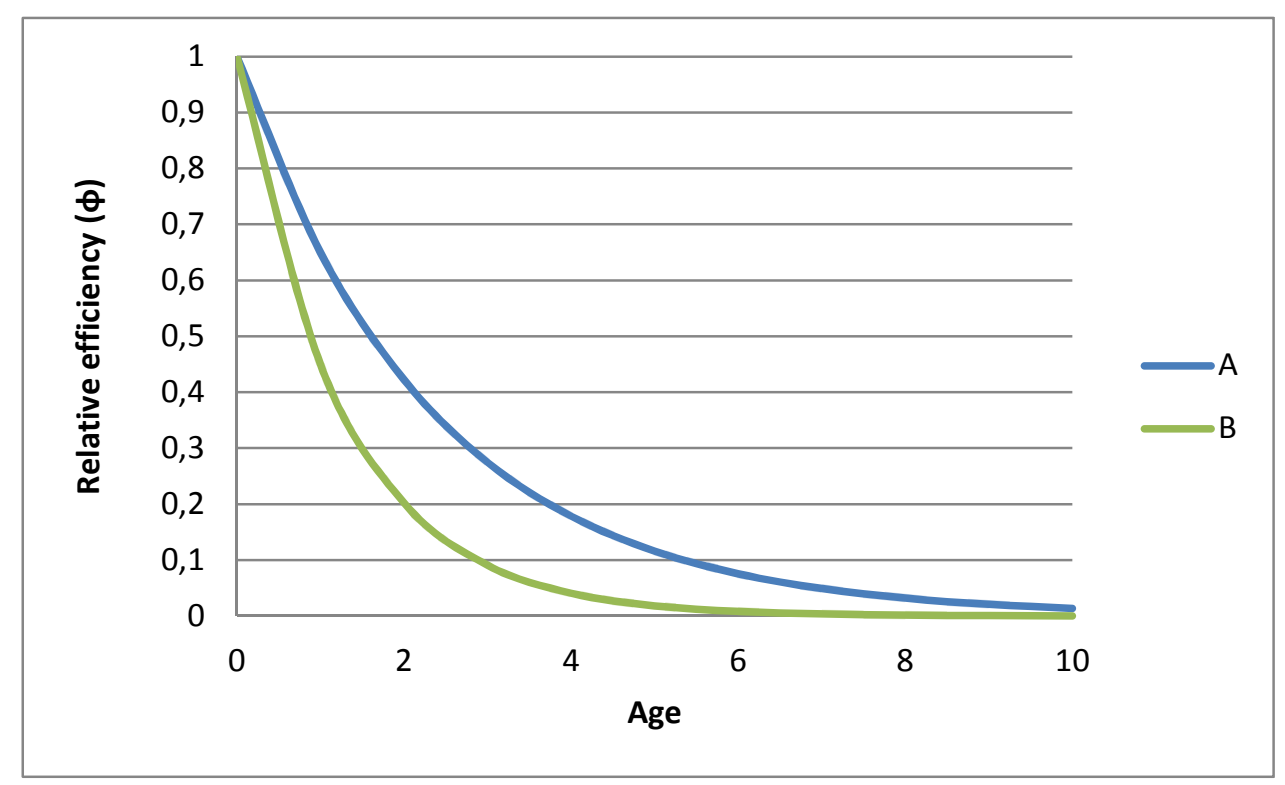

Graph 9: Evolution of service values without and adjusted for embodied obsolescence throughout the individual periods. (Source: own elaboration)

In Graph 9 I indicated with an 'A' the initial, 'non-obsolete' function of asset values $P_{t, s}^{K}$ in individual periods; when determining this function, I assumed a service lifetime of 10 years and a deterioration pattern $\left(1-\delta_{t}\right)=0,35$ of the geometric sequence type. Function ' $\mathrm{B}$ ' is the variant of function ' $\mathrm{A}$ ' adjusted with embodied obsolescence, for which I increased the efficiency decrease rate $\left(1-\delta_{t}\right)=0,35$, expressing deterioration, with 0.2 , i.e. the decrease in efficiency occurring as a result of the anticipated embodied obsolescence. The efficiency decrease rate also including the effect of embodied obsolescence will therefore be: ${ }^{38}\left(1-\delta_{t}\right)=0,35+0,2=0,55$. Graph 9 thus clearly shows that under the effect of embodied obsolescence, the value of the service provided by the asset decreases in each future period.

According to the relationship defined in equation (35), the embodied obsolescence affecting service values $P_{t, s}^{K}(35)$ also impact on the value of the assets themselves; Graph 10 illustrates this effect.

\footnotetext{
${ }^{38}$ On the basis of equation (28).
} 


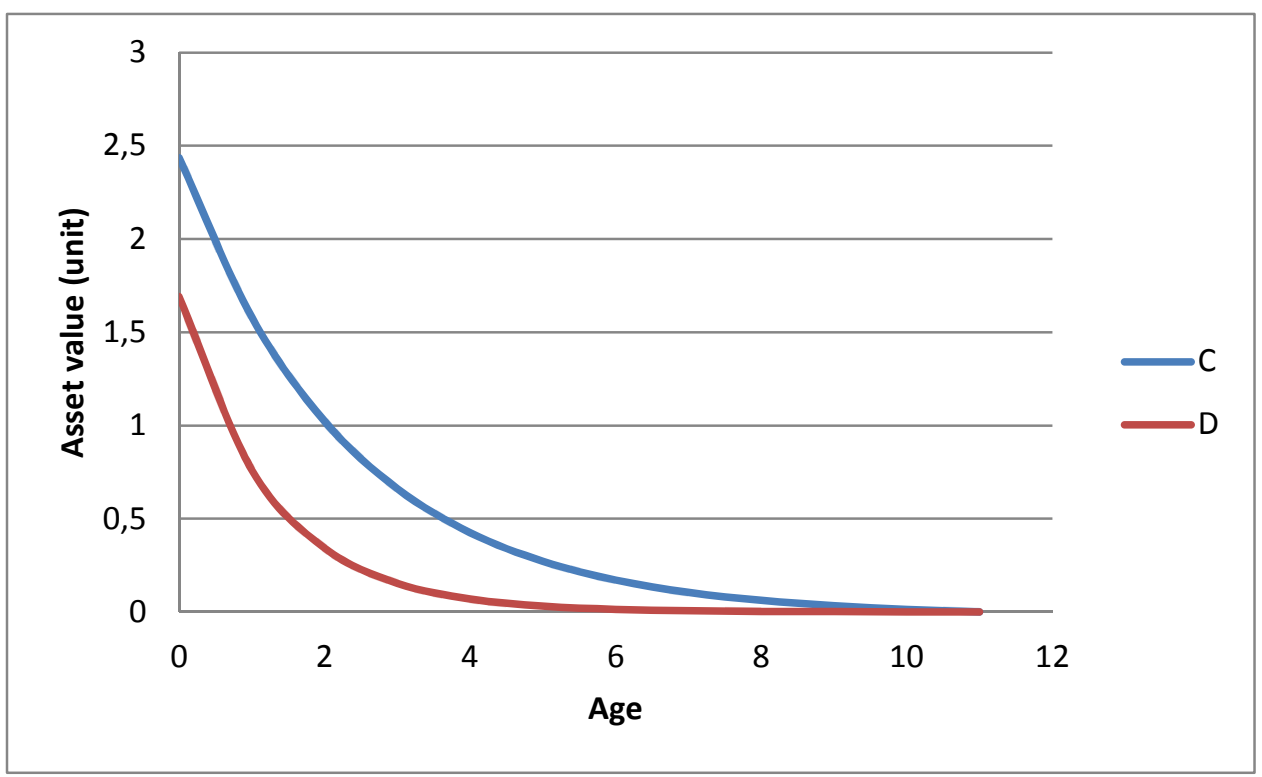

Graph 10: Evolution of asset values without and adjusted for embodied obsolescence throughout the individual periods. (Source: own elaboration)

In Graph $10 \mathrm{I}$ indicated with a ' $\mathrm{C}$ ' the function of asset value $P_{t, s}^{I}$ calculated from the service values determined by function ' $\mathrm{A}$ ' of Graph 9 using real interest rate $r_{t}^{*}=0,1$, and with a ' $\mathrm{D}$ ' the function of asset value $P_{t, s}^{I}$ calculated from the service values determined by function 'B' of Graph 9, also using real interest rate $r_{t}^{*}=0,1$.

It is therefore apparent from Graphs 9 and 10 that through affecting the future values of the service provided by the asset, the estimated embodied obsolescence also influences the value of the asset itself in the different periods.

\subsubsection{Age and date effects exerted by phenomena influencing changes in the asset value}

In this chapter, I have described the effects of the phenomena of exhaustion, deterioration and embodied as well as disembodied obsolescence on the asset value at a given moment $t$ and on its evolution with age. These effects influence the income defined in equation (2) through the fact that fixed assets are part of beginning-of-period and end-of-period capital values $R_{t}$ and $R_{t+1}$.

If the above mentioned phenomena exert an influence on the value of the asset, this influence also needs to appear in the market value of the asset. However, as I mentioned before, relatively few used assets have an active competitive market which could 
provide information serving as a basis to determine the end-of-period value of the asset in use.

Therefore we need to estimate the change in the value of the asset in use on the basis of the phenomena affecting the asset value as of the beginning and the end of the period; a possible model to do so was presented in equation (35).

The impacts of exhaustion, deterioration and obsolescence, estimated in the future, change not only with the age of the asset, thus influencing the current value of the asset, but also because we perform our estimations for the future at different moments in time, i.e. at different dates, and the change in the date of the estimation also impacts on the asset value. According to the organisation described above, these effects are called 'age and time effect' in academic literature. As, however, age effect is primarily based on time, I will hereinafter designate the phenomenon identified by academic literature as time effect by the term of 'date effect'. In the next chapter, I will analyse the breakdown of changes in the asset value according to age and date effect, respectively, and examine how the possession or lack of exact knowledge of future conditions influences these effects. 


\section{Breakdown of changes in the value of fixed assets}

In academic literature discussing changes in asset value it is a generally accepted view that the change (typically decrease) in the value of an asset from moment $t$ to moment $t+1$ is explained by the aging of the asset and by the change in the moment of valuation. ${ }^{39}$ For the above mentioned breakdown of the change in value, we need to consider the change in the value $P_{t, s}^{I}$ of the asset of age $s$ from moment $t$ to moment $t+1$, which may be formulated as follows:

(36) $\Delta_{t, s}=P_{t, s}^{I}-P_{t+1, s+1}^{I}$.

Substituting the asset values $P_{t, s}^{I}$ defined in equation (35) into equation (36) for moments $t$ and $t+1$, we obtain the following equation:

$$
\begin{gathered}
\Delta_{t, s}=P_{t, s}^{I}-P_{t+1, s+1}^{I}= \\
\sum_{\tau=0}^{S_{t}-s} \frac{\left(1+i_{t}^{*}\right)^{\tau} \varphi_{t, s+\tau} P_{t, 0}^{K}}{\left(1+r_{t}^{*}\right)^{\tau}}-\sum_{\tau=0}^{S_{t+1}-(s+1)} \frac{\left(1+i_{t+1}^{*}\right)^{\tau} \varphi_{t+1, s+1+\tau} P_{t+1,0}^{K}}{\left(1+r_{t+1}^{*}\right)^{\tau}}
\end{gathered}
$$

The change in the value $\Delta_{t, s}$ thus defined may be examined in respect of the change in the service value $P_{t, 0}^{K}$ of the new asset as well as in the light of assumptions concerning certainty and exact knowledge about the future. The research aims to clearly differentiate, in the theoretical sense, between any age effects appearing in the changes in the value of the assets on the one hand, and the elements related to revaluation and capital gain/loss constituting date effect, on the other hand.

\subsection{Change in the value assuming certainty and exact knowledge about the future}

I will first analyse the change in the value $\Delta_{t, s}$ of the asset as defined in equation (37), assuming certainty and exact knowledge about the future concerning the real changes $i_{t}^{*}$ in the service values $P_{t, 0}^{K}$ of the new asset, the relative efficiency $\varphi_{t, s}$ of the asset, the duration $S_{t}$ of its service lifetime, the real interest rate $r_{t}^{*}$ and the inflation rate $\rho_{t}$. In this

\footnotetext{
${ }^{39}$ See for example: Hulten and Wykoff [1981b] and [1996], Jorgenson [1996], Diewert [1996], Triplett [1996], Wykoff [2003], Diewert and Wykoff [2006].
} 
case, the asset value determined at different moments in time (at different dates) is not influenced by uncertainties in the estimation of the parameters valid at future moments $t$ :

$$
S_{t}=S ; i_{t}^{*}=i^{*} ; r_{t}^{*}=r^{*} ; \varphi_{t, s}=\varphi_{s} ; \rho_{t}=\rho ; t=1,2,3, \ldots
$$

In this case, based on the conditions expressed in equation (38), equation (37) may be formulated as follows:

$$
\begin{gathered}
\text { (39) } \Delta_{t, s}=\Delta P_{t, s}^{I}=P_{t, s}^{I}-P_{t+1, s+1}^{I}= \\
\sum_{\tau=0}^{S-S} \frac{\left(1+i^{*}\right)^{\tau} \varphi_{s+\tau} P_{t, 0}^{K}}{\left(1+r^{*}\right)^{\tau}}-\sum_{\tau=0}^{S-(s+1)} \frac{\left(1+i^{*}\right)^{\tau} \varphi_{s+1+\tau} P_{t+1,0}^{K}}{\left(1+r^{*}\right)^{\tau}}
\end{gathered}
$$

It is apparent from equation (39) that the changes in the values in question result partly from the alteration of the moment $t$ of valuation and partly from the fact that the asset becomes a period older, i.e. its age grows from $s$ to $s+1$. These two effects together cause the change in value $\Delta P_{t, s}^{I}$ — called 'time series depreciation' by Hill [1999] in the event of certainty and exact knowledge of future conditions ${ }^{40}$ — which I will hereinafter designate with $\Delta P_{t, s}^{I}$. Hulten and Wykoff [1981a] illustrate the discrete system of value change as outlined in equation (39) with a matrix providing a separate display of asset values $P_{t, s}^{I}$ according to the date of valuation (columns) and the increase in the age (rows).

\footnotetext{
${ }^{40}$ This corresponds to the concept of 'depreciation' as defined by Hotelling. Hotelling also defined depreciation on the condition of certainty and exact knowledge about the future (Hotelling [1925] p. 343).
} 


\begin{tabular}{|l|l|l|l|l}
\hline $\boldsymbol{t}=$ & $\boldsymbol{1}$ & $\mathbf{2}$ & $\mathbf{3}$ & $\cdots$ \\
\hline $\boldsymbol{s}=\mathbf{0}$ & $P_{1,0}^{I}$ & $P_{2,0}^{I}$ & $P_{3,0}^{I}$ & $\cdots$ \\
\hline $\boldsymbol{1}$ & $P_{1,1}^{I}$ & $P_{2,1}^{I}$ & $P_{3,1}^{I}$ & $\cdots$ \\
\hline $\mathbf{2}$ & $P_{1,2}^{I}$ & $P_{2,2}^{I}$ & $P_{3,2}^{I}$ & $\cdots$ \\
\hline $\mathbf{3}$ & $P_{1,3}^{I}$ & $P_{2,3}^{I}$ & $P_{3,3}^{I}$ & $\cdots$ \\
\hline$\cdots$ & $\cdots$ & $\cdots$ & $\cdots$ & $\cdots$ \\
\hline
\end{tabular}

Graph 11: Breakdown of the change in asset values according to age and time factors. (Source: based on Hulten and Wykoff [1981a])

Graph 11 shows that if asset values are represented in the dimensions of the date of valuation and age, the time series depreciation defined in equation (39) may be interpreted in the present matrix as the difference of two cells which represent a transversal movement to the right. This diagonal shift in the matrix expresses a collective change in the age of the asset and in the date of valuation; therefore the time series depreciation expressed in equation (39) may be construed as the root of the change in these two factors, which we may identify as age effect and date effect. Following Diewert and Wykoff's [2006] train of thought, time series depreciation may be broken down to age effect and date effect in two different ways depending on the order of the shift in the matrix: i.e. first to the right and then down, or first down and then to the right. Therefore age and date effect may be expressed according to the different orders of the shifts as follows:

$$
\begin{aligned}
& \text { (40) } \Delta P_{t, s}^{I}=\left[P_{t, s}^{I}-P_{t+1, s}^{I}\right]+\left[P_{t+1, s}^{I}-P_{t+1, s+1}^{I}\right]=G_{t, s}+D_{t+1, s} \\
& \text { (41) } \Delta P_{t, s}^{I}=\left[P_{t+1, s}^{I}-P_{t+1, s+1}^{I}\right]+\left[P_{t, s+1}^{I}-P_{t+1, s+1}^{I}\right]=D_{t, s}+G_{t, s+1},
\end{aligned}
$$

where $D_{t, s}$ and $D_{t+1, s}$ designate the changes in the value resulting from the increase in the age $s$ of the asset at moments $t$ and $t+1$, i.e. the age effects; whereas $G_{t, s}$ and $G_{t, s+1}$ represent the changes in the value of assets of ages $s$ and $s+1$ due to the change in the moment $t$ of valuation, i.e. the date effects ${ }^{41}$. Hill [1999] uses the term 'revaluation effect' to designate the change in the value resulting from a change in the date of valuation, assuming certainty and exact knowledge about the future.

\footnotetext{
${ }^{41}$ Hulten and Wykoff [1981a] use the term 'discrete time effect' to designate the effect thus defined. Discrete time effect, or date effect, represents the difference between the value of a three-year-old asset as of 31 December 2010 and the value of a similarly three-year-old asset as of 31 December 2011.
} 
Formulas $D_{t, s}$ and $D_{t+1, s}$ incorporating age effect, express the difference between the values of two assets of ages $s$ and $s+1$ at a given moment $t$ or $t+1 .{ }^{42}$ To designate this effect, Hulten and Wykoff [1996] use the term '(economic) depreciation' and Hill [1999] uses the expression 'cross-section depreciation'.

Substituting the formulas on the right hand side of equation (39) into the corresponding cells of the matrix in Graph 11, the difference of the individual cells will yield the definitions of cross-section depreciation and revaluation, situated on the right-hand side of equations (40) and (41), as illustrated by the following graph:

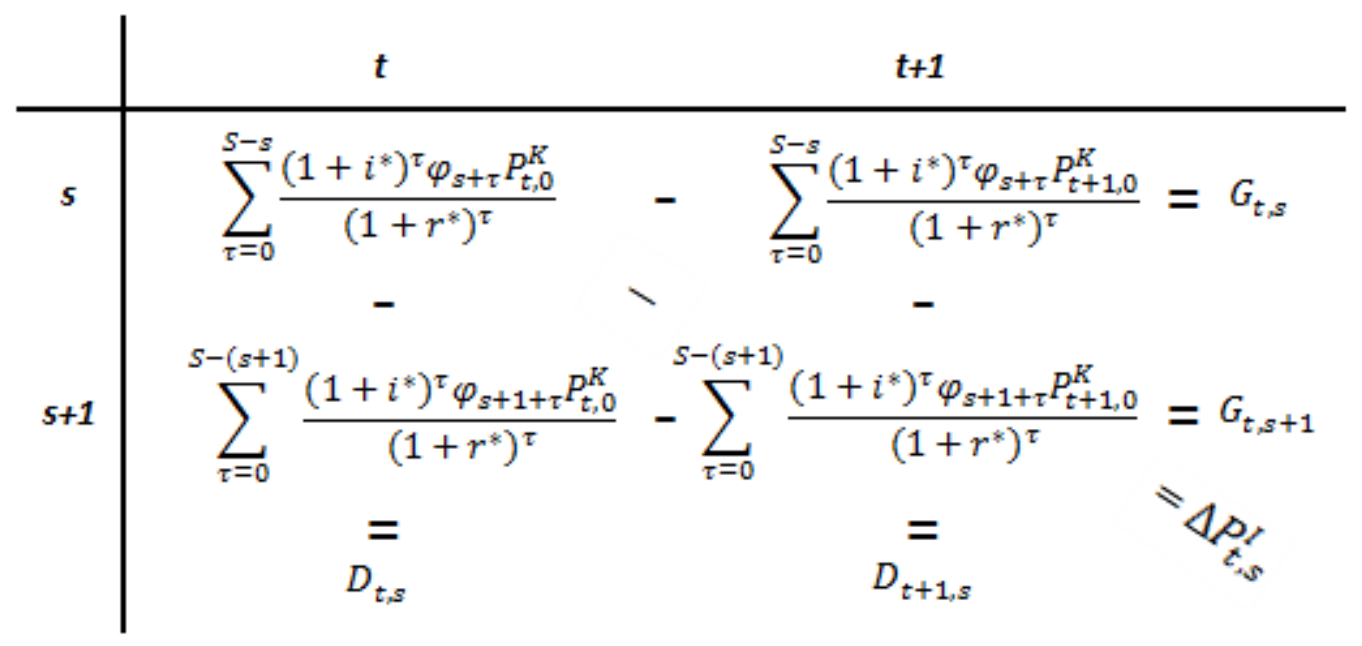

Graph 12: Cross-section depreciation, time series depreciation and revaluation. (Source: own elaboration)

It is clear from Graph 12 that the overall change in the asset value (assuming certainty and exact knowledge about the future), i.e. time series depreciation $\Delta P_{t, s}^{I}$ is not affected by the order of the 'directions' of computing. As a result, the order of calculating crosssection depreciation and revaluation is based on tradition and conventions. Cross-section depreciation and $D_{t+1, s}$ and $D_{t, s}$ (as illustrated in Graph 12) may also be expressed using a cross-section depreciation rate:

$$
\begin{aligned}
& \text { (42) } \delta_{t+1, s}^{C}=1-\left(P_{t+1, s+1}^{I} / P_{t+1, s}^{I}\right)=D_{t+1, s} / P_{t+1, s}^{I} \text {; where } P_{t+1, s}^{I} \neq 0 \\
& \text { (43) } \delta_{t, s}^{C}=1-\left(P_{t, s+1}^{I} / P_{t, s}^{I}\right)=D_{t, s} / P_{t, s}^{I} ; \text { where } P_{t, s}^{I} \neq 0 .
\end{aligned}
$$

\footnotetext{
${ }^{42}$ Hulten and Wykoff [1981a] use the term 'discrete age effect' to designate the effect thus defined. Discrete age effect represents for instance the difference between the value of a three-year-old asset as of 31 December 2011 and the value of a four-year-old asset as of 31 December 2011.
} 
Following the same logic, the revaluation rates $\theta_{t, s}$ and $\theta_{t, s+1}$ corresponding to revaluations $G_{t, s}$ and $G_{t, s+1}$ of assets of age $s$ and $s+1$ may be expressed as follows:

$$
\begin{aligned}
& \text { (44) } \theta_{t, s}=1-\left(P_{t+1, s}^{I} / P_{t, s}^{I}\right)=G_{t, s} / P_{t, s}^{I} \text {; where } P_{t, s}^{I} \neq 0 \\
& \text { (45) } \theta_{t, s+1}=1-\left(P_{t+1, s+1}^{I} / P_{t, s+1}^{I}\right)=G_{t, s+1} / P_{t, s+1}^{I} ; \text { where } P_{t, s}^{I} \neq 0 .
\end{aligned}
$$

Using the above defined cross-section depreciation and revaluation rates, the time series depreciation rate $\delta_{t, s}^{T}$ of an asset of age $s$ for period $t$ may be expressed as follows:

$$
\begin{aligned}
& \text { (46) } \delta_{t, s}^{T}=1-\left(P_{t+1, s+1}^{I} / P_{t, s}^{I}\right)=1-\left(1-\theta_{t, s}\right)\left(1-\delta_{t+1, s}^{C}\right)=1- \\
& \left(1-\delta_{t, s}^{C}\right)\left(1-\theta_{t, s+1}\right) ; \text { where } P_{t, s}^{I} \neq 0 .
\end{aligned}
$$

Substituting the expressions used in Graph 12 into the corresponding asset values $P_{t, S}^{I}$ of equations (44) and (45), we obtain the following definition of revaluation rates $\theta_{t, s}$ and $\theta_{t, s+1}$ :

$$
\begin{aligned}
& \text { (47) } \theta_{t, s}=1-\left(P_{t+1, s}^{I} / P_{t, s}^{I}\right)= \\
& 1-\left(\sum_{\tau=0}^{S-S} \frac{\left(1+i^{*}\right)^{\tau} \varphi_{S+\tau} P_{t+1,0}^{K}}{\left(1+r^{*}\right)^{\tau}} / \sum_{\tau=0}^{S-S} \frac{\left(1+i^{*}\right)^{\tau} \varphi_{S+\tau} P_{t, 0}^{K}}{\left(1+r^{*}\right)^{\tau}}\right) ; \text { where } P_{t, s}^{I} \neq 0 \\
& \text { (48) } . \theta_{t, s+1}=1-\left(\frac{P_{t+1, s+1}^{I}}{P_{t, s+1}^{I}}\right)= \\
& 1-\left(\sum_{\tau=0}^{S-(s+1)} \frac{\left(1+i^{*}\right)^{\tau} \varphi_{s+1+\tau^{2}} P_{t+1,0}^{K}}{\left(1+r^{*}\right)^{\tau}} / \sum_{\tau=0}^{S-(s+1)} \frac{\left(1+i^{*}\right)^{\tau} \varphi_{s+1+\tau} P_{t, 0}^{K}}{\left(1+r^{*}\right)^{\tau}}\right) ; \text { where } P_{t, s}^{I} \neq 0
\end{aligned}
$$

Respecting equation (38), I assumed certainty and exact knowledge about future at every future moment $t+\tau$ concerning the real changes $i^{*}$ in the service values $P_{t, 0}^{K}$ of new assets, the relative productive efficiency $\varphi_{S}$ of the assets, the duration $S$ of the service lifetime, as well as the real interest rate $r^{*}$, in every future period $t+\tau$. Therefore any difference between revaluations $G_{t, s}$ and $G_{t, s+1}$ as calculated "from different directions" only results from the nominal change in the service value $P_{t, 0}^{K}$ of the new asset. This change is expressed by the asset specific real price change rate $i^{*}$ of the asset service and by the inflation $\rho$ valid for period $t .^{43}$ This may be formulated as follows:

$$
\left(1+i^{*}\right)(1+\rho) P_{t, 0}^{K}=P_{t+1,0}^{K}
$$

\footnotetext{
${ }^{43}$ As follows from equations (15), (16), (32), (33)and(38).
} 
Substituting the formula on the left hand side of equation (49) into formulas $P_{t+1,0}^{K}$ of equations (47) and (48), revaluation rates $\theta_{t, s}$ and $\theta_{t, s+1}$ are simplified to the following form:

$$
\begin{aligned}
& \text { (50) } \theta_{\mathrm{t}, \mathrm{s}}=1-\left(\mathrm{P}_{\mathrm{t}+1, \mathrm{~s}}^{\mathrm{I}} / \mathrm{P}_{\mathrm{t}, \mathrm{s}}^{\mathrm{I}}\right)=1-\left[\left(1+\mathrm{i}^{*}\right)(1+\rho)\right] \text {; where } \mathrm{P}_{\mathrm{t}, \mathrm{s}}^{\mathrm{I}} \neq 0 \\
& \text { (51) } \theta_{t, s+1}=1-\left(P_{t+1, s+1}^{I} / P_{t, s+1}^{I}\right)=1-\left[\left(1+i^{*}\right)(1+\rho)\right] \text {; where } P_{t, s+1}^{I} \neq 0 .
\end{aligned}
$$

These formulas clearly show that the revaluation rates $\theta_{t, s}$ and $\theta_{t, s+1}$ of assets of age $s$ and $s+1$ at individual moments $t$ are identical; i.e.:

$$
\theta_{\mathrm{t}, \mathrm{s}}=\theta_{\mathrm{t}, \mathrm{s}+1}=\theta_{\mathrm{t}} ; s=1,2,3
$$

This shows that the increase in age $s$ of the asset does not affect the revaluation rate $\theta_{\mathrm{t}}$ for period $t$. Departing from this fact, the equation on the right hand side of equation (46) may be formulated as follows:

$$
1-\left(1-\theta_{t}\right)\left(1-\delta_{t+1, s}^{C}\right)=1-\left(1-\delta_{t, s}^{C}\right)\left(1-\theta_{t}\right)
$$

Simplifying this equation with the revaluation rate we obtain the result that the crosssection depreciation rates $\delta_{t+1, s}^{C}$ and $\delta_{t, s}^{C}$ of assets of age $s$ are also identical for moments $t$ and $t+1$ :

$$
\delta_{t+1, s}^{C}=\delta_{t, s}^{C}=\delta_{s}^{C} ; t=1,2,3 \ldots
$$

In this case, the time series depreciation rate $\delta_{t, s}^{T}$ defined in equation (46) may be expressed using equations (52) and (54) as follows:

$$
\delta_{t, s}^{T}=1-\left(P_{t+1, s+1}^{I} / P_{t, s}^{I}\right)=1-\left(1-\theta_{t}\right)\left(1-\delta_{s}^{C}\right)
$$

Substituting the formula on the right hand side of equation (50) for the revaluation rate $\theta_{t}$ in equation (55), ${ }^{44}$ we obtain the nominal definition of the time series depreciation rate $\delta_{t, s}^{T}$ :

$$
\delta_{t, s}^{T}=1-\left(1+i^{*}\right)(1+\rho)\left(1-\delta_{s}^{C}\right)
$$

\footnotetext{
${ }^{44}$ Using simplification (52).
} 
In the event of $\rho=0$, Diewert [2005] calls the time series depreciation rate $\delta_{t, s}^{T}$ 'real time series depreciation rate'; this real time series depreciation rate $\bar{\delta}_{t, s}^{T}$ may be formulated as follows:

$$
\bar{\delta}_{t, s}^{T}=1-\left(1+i^{*}\right)\left(1-\delta_{s}^{C}\right)
$$

However in the event of inflation, only nominal time series depreciation rate $\delta_{t, s}^{T}$ is able to produce the asset value $P_{t+1, s+1}^{I}$ calculated at current prices for end-of-period moment $t+1$, which at the same time ensures the nominal capital maintenance defined in Paragraph 2.2. Therefore, the income $Y_{t}^{a}$ defined in equation (2) is a nominal income, and the difference between this and the income $Y_{t}^{a}$ calculated on the basis of real capital maintenance is exactly equal to the inflation $\rho P_{t, s}^{I}$ corresponding to beginning-of-period asset value $P_{t, s}^{I}$. Meanwhile, this ostensible additional income $\rho P_{t, s}^{I}$ distorts the truthful image of the company's performance, as it is not created as a result of effective economic activity. In the practice of business income calculation, however, companies seek to present the nominal income computed on the basis of nominal capital maintenance (except for extreme cases of inflation); therefore, in the remaining part of my study, I will examine the nominal time series depreciation rate $\delta_{t, s}^{T}$.

We can thus establish that the nominal time series depreciation rate $\delta_{t, s}^{T}$ of the analysed fixed assets as defined in equation (56) clearly consists of three main parts: asset specific real price change rate $i^{*}$ and inflation $\rho$ valid for period $t$, and the cross-section depreciation rate $\delta_{s}^{C}$ of the asset. The asset specific real price change rate $i^{*}$ expresses the change in the price of a service unit of the asset. In Chapter 3.1.5.8.1, following the reasoning of Diewert and Wykoff [2006], I attributed this change to the effect of disembodied obsolescence. However, disembodied obsolescence does not only appear as the difference in the time series depreciation rate $\delta_{t, s}^{T}$ and cross-section depreciation rate $\delta_{s}^{C}$ of the asset of age $s$ for period $t$, but it also influences the service values $t+\tau$ of the new assets for the future periods $P_{t+\tau, 0}^{I}$. Therefore, disembodied obsolescence as estimated in the future also constitutes a decisive part of the cross-section depreciation rate $\delta_{S}^{C}$ of the asset, in conjunction with the phenomena of exhaustion, deterioration and embodied obsolescence described in Chapter 3.1.5.3. I will explain the relationship between these factors in the next chapter. 


\subsubsection{Phenomena affecting the cross-section depreciation rate}

The phenomena of exhaustion, deterioration and embodied as well as disembodied obsolescence described in Chapter 3.1.5.3 impact on the change in the value of the aging asset. This change in value may be formulated as cross-section depreciation rate $\delta_{s}^{C}$ using equations (43) and (54) as well as the asset value definitions described in Graph 12 as follows:

$$
\delta_{S}^{C}=1-\left[\left(\sum_{\tau=0}^{S-(s+1)} \frac{\left(1+i^{*}\right)^{\tau} \varphi_{S+1+\tau} P_{t, 0}^{K}}{\left(1+r^{*}\right)^{\tau}}\right) /\left(\sum_{\tau=0}^{S-S} \frac{\left(1+i^{*}\right)^{\tau} \varphi_{S+\tau} P_{t, 0}^{K}}{\left(1+r^{*}\right)^{\tau}}\right)\right]
$$

The component of the cross-section depreciation rate $\delta_{S}^{C}$ thus formulated to be discussed first is exhaustion. As I stated before, as a result of exhaustion, an asset of age $s+1$ has one future operational period less left than an asset of age $s$, which may be expressed as $S-s>S-(s+1)$, consequently we may say that the asset becomes ever more exhausted as it gets on in years, and the effect of this evidently also shows in the crosssection depreciation rate $\delta_{s}^{C}$ of the asset, as demonstrated by equation (58).

As the asset advances in age, not only the number of its remaining operational periods decreases but so does the operating efficiency the asset will be able to deliver in the individual periods left. This operating efficiency is determined by the deterioration of the asset as well as by embodied obsolescence. The deterioration of the asset thus consists in the fact that its services become poorer and less valuable as compared to its former 'self'; on the other hand, embodied technological progress means that (in addition to deterioration) the services of the asset become less valuable and more obsolete as compared to the services rendered by a more developed asset. ${ }^{45}$ As I explained before, these effects are expressed by efficiency weights $\varphi_{s+\tau}$. We may consequently state that as a result of deterioration and embodied obsolescence, the value of the services of an asset of age $s+1$ possesses an efficiency weight which is lower than that corresponding to a more developed asset of age $s: \varphi_{s}>\varphi_{s+1}$. Therefore, by way of the difference between relative efficiency weights $\varphi_{s}$ and $\varphi_{s+1}$, the effects of

\footnotetext{
${ }^{45}$ That is to say that I assume that it is not the services provided by the asset with the more recent technology that become more valuable compared to those of an asset of the same age but from an earlier period; on the contrary, it is the asset with the older technology that loses value. I described this assumption and the pertaining circumstances in detail in Chapter 3.1.5.8.2.
} 
deterioration and embodied obsolescence also appear in the cross-section depreciation rate $\delta_{s}^{C}$ of the asset, as it is apparent from equation (58).

As I demonstrated in Chapter 3.1.5.8.1, through the asset specific real price change rate $i^{*}$ the phenomenon of disembodied obsolescence impacts on the service values $P_{t+\tau, 0}^{K}$ of the new assets in the remaining periods; as a result, disembodied obsolescence also affects the cross-section depreciation rate $\delta_{s}^{C}$ of the asset, as also shown by equation (58).

\subsubsection{Summary of the phenomena affecting the time series depreciation rate}

In the previous chapter I described the phenomena impacting on the cross-section depreciation rate $\delta_{s}^{C}$ of an asset of age $s$ as well as on its revaluation rate $\theta_{t}$ for period $t$, assuming that the condition of certainty and exact knowledge about the future is fulfilled; these phenomena together determine the time series depreciation rate $\delta_{t, s}^{T}$ of the asset of age $s$ valid for period $t$. The relationships of these factors and the phenomena affecting them are illustrated in the following graph. 


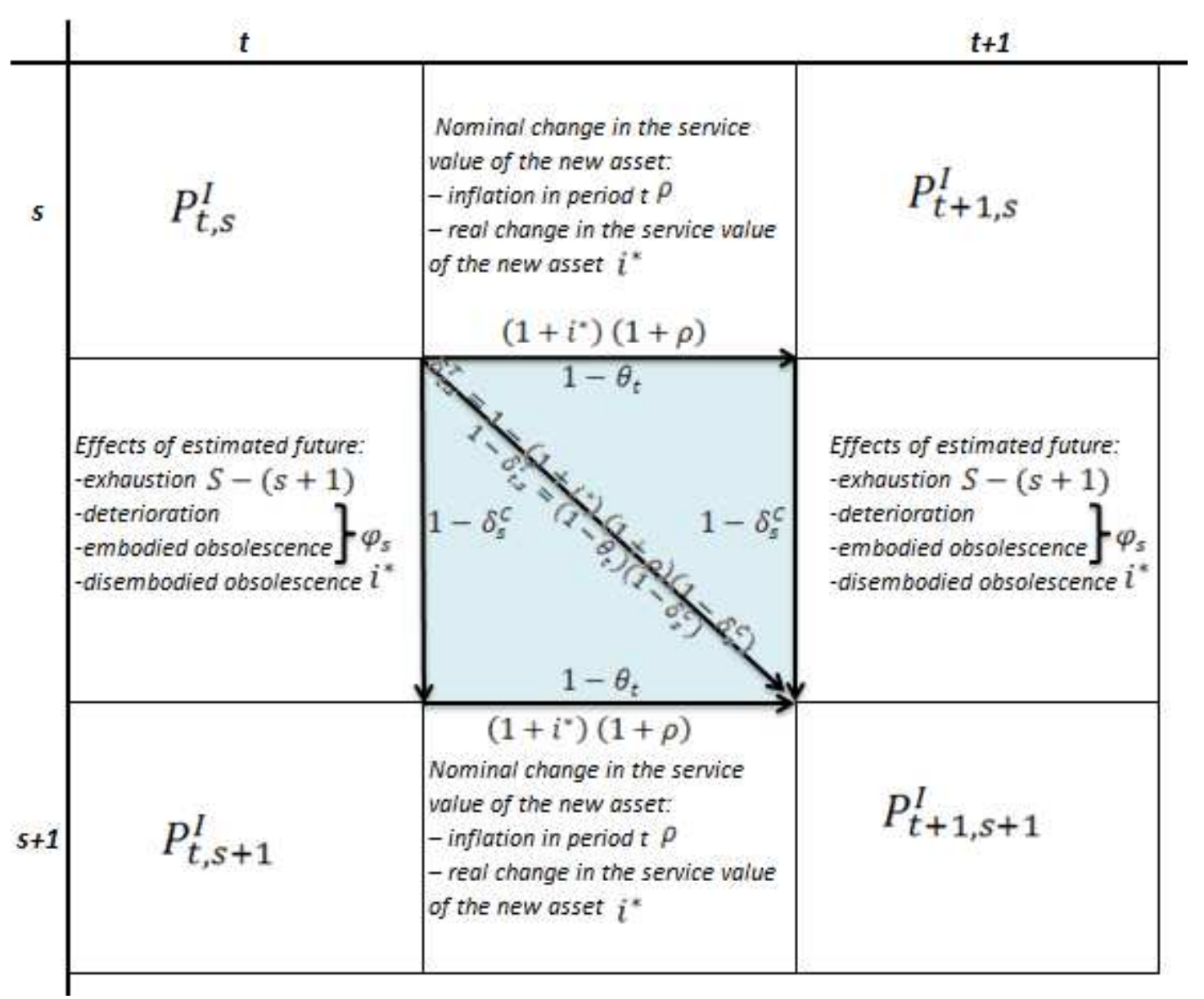

Graph 13: Summary of the phenomena affecting the time series depreciation rate. (Source: own elaboration)

The graph shows that (under the condition of certainty and exact knowledge about the future) the time series depreciation rate $\delta_{t, s}^{T}$ of the asset of age $s$ for period $t$ is shaped by exhaustion, deterioration, embodied and disembodied obsolescence, as well as phenomena related with inflation; therefore the asset value, observable at different moments in time, changes as a result of these effects. It is very difficult to delimit these various effects in the changes in the asset value; however, it is absolutely necessary to take them into account when estimating the time series depreciation rate of the asset.

In Wykoff's [2003] opinion, cross-section depreciation as defined above is in line with the provisions of the US Tax Code, stipulating that depreciation is a result of "wear, tear and obsolescence'; nevertheless, also real time series depreciation fulfills this criterion, if the effect of the real asset specific price change rate is attributed to disembodied obsolescence. 
Consequently, the knowledge of the phenomena affecting asset value is important for the determination of time series depreciation for two main reasons. First, very few used assets have a market which would be able to provide information that could serve as a basis for the end-of-period asset valuation. Secondly, for the purposes of the pricing of the company's output, it is important to know right at the beginning of a period the extent of asset consumption-that is, its time series depreciation-anticipated for the given period, because, beside the various current costs, output price also needs to provide coverage for the periodic cross-section depreciation and for the effect of revaluation in order to maintain the initial capital intact (I elaborated on the issue of capital maintenance in detail in Chapter 2.2).

When examining the change in the asset value, I have so far departed from the assumption of certainty and exact knowledge about the future. In the next chapter, however, I will analyse the change in the asset value, defined in equation (36), without maintaining this assumption, in the expectation that this method will be more suitable for the practical issues related to changes in asset values.

\subsection{Change in the value without certainty and exact knowledge about the future}

Given uncertainty and lack of exact knowledge about future, the asset values measured at different moments $t$ differ from each other partly as a result of the phenomena described above, but also because our estimates made at earlier moments $\mathrm{t}$ may deviate from the actual realised values on the one hand, and from our estimates for the future based on more recent knowledge, on the other hand. As a result, realised or unrealised 'windfall' profits or losses are incurred ${ }^{46}$ (Bélyácz [2002]), which Hill [1999] considers to be capital gains or losses and definitely isolates from revaluation effect $G_{t, s}$ and $G_{t, s+1}$, ensuing from the nominal change in the value of the new asset or in the service value of the asset, as discussed earlier. In the absence of exact knowledge concerning the future, the change in the asset value, and the value of an asset of age $s$ at moment $t$, may be established with less uncertainty on the basis of information available at moment $t+1$ than it could be on the basis of information available at moment $t$. In

\footnotetext{
${ }^{46}$ To which I have made reference earlier, in Chapter 3.1.5.2, in connection with the ex post and ex ante determination of service values $P_{t, s}^{K}$.
} 
retrospective, possessing all the information available at moment $t+1$, the value $\ddot{P}_{t, s}^{I}$ of the asset of age $s$ at moment $t$ may be defined as follows:

$$
\text { (59) } \quad \ddot{P}_{t, s}^{I}=\sum_{\tau=0}^{S_{t+1}-s} \frac{\left(1+i_{t+1}^{*}\right)^{\tau} \varphi_{t+1, s+\tau} \ddot{P}_{t, 0}^{K}}{\left(1+r_{t+1}^{*}\right)^{\tau}} \text {. }
$$

$\ddot{P}_{t, 0}^{K}$ being the value, determined in an ex post manner, of the service of the new asset in period $t$, regarding which it is true that:

$$
\text { (60) } \ddot{P}_{t, 0}^{K}\left(1+\ddot{i}_{t}^{*}\right)\left(1+\ddot{\rho}_{t}\right)=P_{t+1,0}^{K}
$$

where $i_{t}^{*}$ is the ex post real price change rate of the service of the new asset as established for period $t$ at moment $t+1$, equal in the present case (as a result of the simplification in equation (16)) with the real price change rate expected for every future period, and where $\ddot{\rho}_{t}$ designates the ex post inflation rate for period $t$.

In this case, based on information available at moment $t+1$, the time series depreciation rate defined in equation (39) shall be defined as follows:

$$
\begin{aligned}
& \text { (61) } \quad \Delta P_{t, s}^{I}=\ddot{P}_{t, s}^{I}-P_{t+1, s+1}^{I}= \\
& \sum_{\tau=0}^{S_{t+1}-s} \frac{\left(1+i_{t+1}^{*}\right)^{\tau} \varphi_{t+1, s+\tau} \ddot{P}_{t, 0}^{K}}{\left(1+r_{t+1}^{*}\right)^{\tau}}-\sum_{\tau=0}^{S_{t+1}-(s+1)} \frac{\left(1+i_{t+1}^{*}\right)^{\tau} \varphi_{t+1, s+1+\tau} P_{t+1,0}^{K}}{\left(1+r_{t+1}^{*}\right)^{\tau}}
\end{aligned}
$$

Hicks [1978] defined the change in value $\Delta P_{t, s}^{I}$ expressed in equation (61) as the ex post calculation of depreciation, the term 'ex post' meaning in this case that the beginning-ofperiod and end-of period asset values $\ddot{P}_{t, s}^{I}$ and $P_{t+1, s}^{I}$, respectively, are determined on the basis of information available at the end of the period, i.e. at moment $t+1$. However, the determination of these values does not rely solely on ex post events and information, for at moment $t+1$ we use the estimate of the ex ante flow of asset services to calculate the value of the asset; Bélyácz [2002] points out this ostensible contradiction in connection with the determination of income.

In this case, the change in the value defined in equation (37) may be expressed by separating the ex post time series depreciation expressed in equation (61) as follows: 


$$
\begin{aligned}
& \Delta_{t, s}=P_{t, s}^{I}-P_{t+1, s+1}^{I}=\Delta P_{t, s}^{I}+\varepsilon_{t, s}=\sum_{\tau=0}^{S_{t}-s} \frac{\left(1+i_{t}^{*}\right)^{\tau} \varphi_{t, s+\tau} P_{t, 0}^{K}}{\left(1+r_{t}^{*}\right)^{\tau}}- \\
& \sum_{\tau=0}^{S_{t+1}-(s+1)} \frac{\left(1+i_{t+1}^{*}\right)^{\tau} \varphi_{t+1, s+1+\tau} P_{t+1,0}^{K}}{\left(1+r_{t+1}^{*}\right)^{\tau}}
\end{aligned}
$$

where $\varepsilon_{t, s}$ is the part of the change in the asset value which is attributable to differences between the information available at moments $t$ and $t+1$ and to the uncertainty of the estimation. Therefore $\varepsilon_{t, s}$ represents what Hill [1999] considers to be capital gain/loss and Bélyácz [2002] calls 'windfall' gain/loss. ${ }^{47}$ This may be expressed as follows:

$$
\varepsilon_{t, s}=P_{t, s}^{I}-\ddot{P}_{t, s}^{I}=\sum_{\tau=0}^{S_{t}-s} \frac{\left(1+i_{t}^{*}\right)^{\tau} \varphi_{t, s+\tau} P_{t, 0}^{K}}{\left(1+r_{t}^{*}\right)^{\tau}}-\sum_{\tau=0}^{S_{t+1}-s} \frac{\left(1+i_{t+1}^{*}\right)^{\tau} \varphi_{t+1, s+\tau} \ddot{P}_{t, 0}^{K}}{\left(1+r_{t+1}^{*}\right)^{\tau}}
$$

It is clear that capital gain/loss $\varepsilon_{t, s}$ expressed in equation (63) is derived from the information gap between moments $t$ and $t+1,{ }^{48}$ therefore it should be considered as a part of the change in the value resulting from the difference in the estimation uncertainties. The changes in the information concerning the future as available at moments $t$ and $t+1$ may be reasonably explained by the fact that moment $t+1$ is closer in time to the end $S_{t+1}$ of the service lifetime of the asset, and the information concerning the remaining service lifetime $S_{t+1}-s$ of the asset may thus be estimated with more precision at moment $t+1$ than at moment $t$. However, part of the capital gain/loss $\varepsilon_{t, s}$ defined in equation (63) does not only result from the difference between the estimates made at moments $t$ and $t+1$ concerning the future, but also from the difference between the elements estimated at moment $t$ and realised by moment $t+1$ : consequently, the capital gain/loss may be broken down to a realised and an unrealised part. Nevertheless, for reasons of limitations regarding the volume of this work, I will not be able to examine this aspect in detail, and I will hereinafter consider the capital gain/loss as resulting simply from the information gap between moments $t$ and $t+1$.

The first such information gap influencing the asset value concerns the duration $S_{t}$ of the service lifetime of the asset, which affects the value of the asset through the phenomenon of exhaustion, presented in Chapter 3.1.5.3; therefore, the difference

\footnotetext{
${ }^{47}$ Bélyácz [2002] also notes that according to Hicks, this term comes from Keynes.

${ }^{48}$ Concerning the real change $i_{t}^{*}$ in the service values $P_{t, 0}^{K}$ of the new assets, the relative productive efficiency $\varphi_{t, s}$, the duration $S_{t}$ of the service lifetime, the real interest rate $r_{t}^{*}$, and the inflation rate $\rho_{t}$.
} 
between the durations $S_{t}$ and $S_{t+1}$ estimated at moment $t$ and $t+1$ affects the capital gain/loss $\varepsilon_{t, s}$ defined in equation (63).

The difference between the information concerning the future available at moments $t$ and $t+1$ may also become apparent in the real change of the value of one service unit of the asset. This change is expressed in equation (63) by rates $i_{t}^{*}$ and $i_{t+1}^{*}$. In connection with equation (33), we defined $i_{t}^{*}$ as an asset specific real price change rate reflecting the effects of disembodied obsolescence resulting from disembodied technological progress, as outlined in Chapter 3.1.5.8.1. Therefore, the difference between $i_{t}^{*}$ and $i_{t+1}^{*}$ shows the difference in the estimates concerning the future disembodied obsolescence of the asset services, also affecting the capital gain/loss $\varepsilon_{t, s}$ expressed in equation (63).

For the sake of clarity, I assume, respecting definition (16), that the asset specific nominal price change rate $i_{t}$ is constant in every future period estimated at moment $t$; pursuing from equation (33), this assumption of constant rate shall also be true for the asset specific real price change rate $i_{t}^{*}$. In reality however, the price of the services of the new assets does not vary according to a constant rate, for disembodied technological progress might appear in the business environment at rather unpredictable intervals. This would, in its turn, result in an unpredictable rhythm of variations in the service unit values estimated at moments $t$ and $t+1$, i.e. in the service values of the new asset, and the deviations due to this fact may also impact on the capital gain/loss $\varepsilon_{t, s}$ defined in equation (63).

Capital gain/loss $\varepsilon_{t, s}$ is also affected, beside the factors described above, by the differences in the functions of the relative efficiency weights $\varphi_{t, s}$ and $\varphi_{t+1, s}$ estimated at moments $t$ and $t+1$, respectively, expressing the effects of the deterioration and embodied obsolescence of the assets. This difference evidently results from the fact that the relative efficiency weights $\varphi_{t, s}$ may undoubtedly be estimated with more precision at moment $t+1$, closer to the end of the service lifetime of the asset, than at an earlier moment $t$. This difference between the estimates concerning the future relative efficiency made at moments $t$ and $t+1$ also contributes to the capital gain/loss $\varepsilon_{t, s}$ defined in equation (63). 
Consequently, the effects asserted in the capital gain/loss $\varepsilon_{t, s}$ expressed in equation (63) result from the fact that the value of the asset at moment $t$ may be determined with much more certainty on the basis of information available at moment $t+1$ than based on information available at moment $\mathrm{t}$.

By isolating the capital gain/loss $\varepsilon_{t, s}$ for period $t$, the ex post value $\ddot{G}_{t, s}$ of the revaluation $G_{t, s}$ defined in Graph 12 as calculated on the basis of information available at moment $t+1$ may be determined using the ex post service value $\ddot{P}_{t, 0}^{K}$ of period $t$, contained in equation (60), as follows:

$$
\begin{aligned}
& \text { (64) } \ddot{G}_{t, s}=\ddot{P}_{t, s}^{I}-P_{t+1, s}^{I}= \\
& \sum_{\tau=0}^{S_{t+1}-s} \frac{\left(1+i_{t+1}^{*}\right)^{\tau} \varphi_{t+1, s+\tau} \ddot{P}_{t, 0}^{K}}{\left(1+r_{t+1}^{*}\right)^{\tau}}-\sum_{\tau=0}^{S_{t+1}-s} \frac{\left(1+i_{t+1}^{*}\right)^{\tau} \varphi_{t+1, s+\tau} P_{t+1,0}^{K}}{\left(1+r_{t+1}^{*}\right)^{\tau}}
\end{aligned}
$$

Substituting the expression on the left hand side of equation (60) into the service value $P_{t+1,0}^{K}$ of the new asset as of moment $t+1$ in the addition on the right hand side of equation (64), the ex post revaluation $\ddot{G}_{t, s}$ for period $t$ may be expressed as follows:

$$
\begin{aligned}
& \ddot{G}_{t, s}=\ddot{P}_{t, s}^{I}-P_{t+1, s}^{I}= \\
& \sum_{\tau=0}^{S_{t+1}-s} \frac{\left(1+i_{t+1}^{*}\right)^{\tau} \varphi_{t+1, s+\tau} \ddot{P}_{t, 0}^{K}}{\left(1+r_{t+1}^{*}\right)^{\tau}}-\sum_{\tau=0}^{S_{t+1}-s} \frac{\left(1+i_{t+1}^{*}\right)^{\tau} \varphi_{t+1, s+\tau} \ddot{P}_{t, 0}^{K}\left(1+\ddot{i}_{t}^{*}\right)\left(1+\ddot{\rho}_{t}\right)}{\left(1+r_{t+1}^{*}\right)^{\tau}}= \\
& \ddot{P}_{t, s}^{I}-\ddot{P}_{t, s}^{I}\left(1+\ddot{i}_{t}^{*}\right)\left(1+\ddot{\rho}_{t}\right) .
\end{aligned}
$$

This makes it possible to express the revaluation rate $\theta_{t}$, defined in equations (50) and(52), in an ex post manner; this ex post revaluation rate $\ddot{\theta}_{t, s}$ shall be computed as follows:

$$
\begin{gathered}
\text { (66) } \ddot{\theta}_{t}=1-\left(\ddot{P}_{t, s}^{I}\left(1+\ddot{\imath}_{t}^{*}\right)\left(1+\ddot{\rho}_{t}\right) / \ddot{P}_{t, s}^{I}\right)= \\
1-\left[\left(1+\ddot{\imath}_{t}^{*}\right)\left(1+\ddot{\rho}_{t}\right)\right] ; \text { where } \ddot{P}_{t, s}^{I} \neq 0
\end{gathered}
$$

It also ensues from this argumentation that the time series depreciation rate $\delta_{t, s}^{T}$ for period $t$ as defined in equation (56) may be determined with more precision at moment $t+1$ than at moment $t$. Therefore, the ex post depreciation rate $\ddot{\rho}_{t}$ of an asset of age $s$ for period $t$ in the 'Hicksian' sense may be expressed at moment $t+1$ as follows, using the cross-section depreciation rate $\delta_{t, s}^{T}$ determined at moment $t+1$ according to 
equation (42), the ex post asset specific real price change rate $\delta_{t+1, s}^{C}$ defined in equation (60) and the ex post inflation rate $\ddot{i}_{t}^{*}$ for period $t$ :

$$
\delta_{t, S}^{T}=1-\left(1+\ddot{i}_{t}^{*}\right)\left(1+\ddot{\rho}_{t}\right)\left(1-\delta_{t+1, s}^{C}\right)
$$

The above outlined relationship between the ex post time series depreciation rate $\delta_{t, s}^{T}$ and capital gain/loss $\varepsilon_{t, s}$ is illustrated in the following graph.

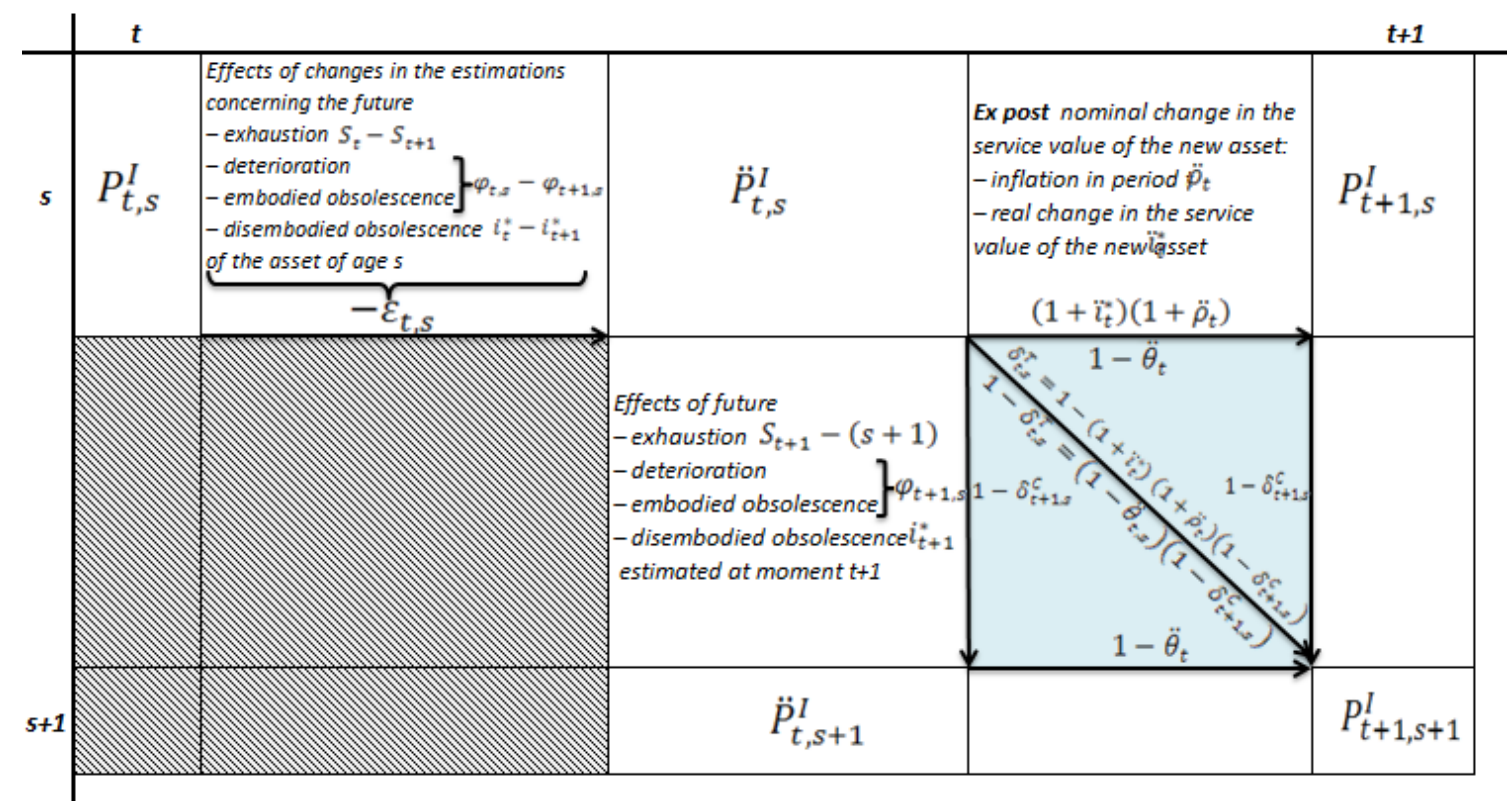

Graph 14: Change in the asset value without certainty and exact knowledge about the future (Source: own elaboration)

The graph shows that in case of uncertainty about future circumstances, the time series depreciation rate is delimited from the effects of capital gain/loss $\varepsilon_{t, s}$ corresponding to period $t$, as defined in equation (63). Meanwhile the capital gain/loss $\varepsilon_{t, s}$ may not, by definition, constitute part of the time series depreciation rate $\delta_{t, s}^{T}$ of the asset of age $s$ in period $t$, for if the future causes and effects of capital gains/losses $\varepsilon_{t, s}$ were known, they should be incorporated into the time series depreciation rate $\delta_{t, s}^{T}$.

Consequently, the time series depreciation rate $\delta_{t, s}^{T}$ of an asset of age $s$ for period $t$ may be determined using the cross-section depreciation rate determined at moment $t+1$, the ex post asset specific real price change rate for period $t$, and the ex post inflation rate. 


\subsection{The recognition of changes in the value of fixed assets in Hungarian and international accounting practice}

The issue of the determination of the depreciation of fixed assets also emerges in the practice of business income calculation. In the next chapter therefore, I will outline the provisions pertaining to the calculation of depreciation set out by the International Financial Reporting Standards (IFRS) Framework and by Act C of 2000 on accounting (the Accounting Act) providing the regulatory framework for accounting in Hungary.

\subsubsection{The approach to changes in the value of fixed assets in Hungarian accounting regulations}

The Accounting Act uses the concepts of ordinary and accelerated depreciation and of value adjustment to grasp the changes in the value of fixed assets I examined hereinabove.

In Section 52(1), the Act defines ordinary depreciation as the cost value (purchase or production value) of the assets less the residual value estimated for the end of the useful economic life of the asset, distributed over the number of years in which such assets are expected to be used. According to Section 52(2), this distribution should take into account "the expected use and the useful economic life of the individual asset, its physical wearing out and market obsolescence"-these effects are identical with the effects of exhaustion, deterioration and embodied and disembodied obsolescence discussed hereinabove. The Act offers several methods for the distribution of the cost value of the asset, reduced by the residual value; theoretically, these distribution models make it possible to express the time series depreciation defined in equation (61), ${ }^{49}$ although the Act does not express such intention in connection with ordinary depreciation. However in absence of such intention, ordinary depreciation is unable to ensure the maintenance of the beginning-of-period capital defined in Chapter 2.2, and depicts a distorted image of the financial and income situation of the company (I have elaborated on these issues in detail in Chapter 2.3.1).

As opposed to this, the Act stipulates that accelerated depreciation needs to be recognised if the net value of the asset, reduced by ordinary depreciation, is permanently and significantly higher than its market value. Pursuant to Section 53(2) of the Act,

\footnotetext{
${ }^{49}$ Provided that their values do not exceed their cost values.
} 
accelerated depreciation shall be effected to an extent that the assets "be shown in the balance sheet at the known market value [...] prevailing at the balance sheet preparation date" ${ }^{50}$ It is therefore apparent from the formulation that accelerated depreciation aims at an ex post determination of the end-of-period market value of the asset, and ordinary and accelerated depreciation aim to grasp the changes in the 'market value' of the asset from one period to another, provided that this value decreases. If the asset value, calculated at current prices, increases from one period to another, then the law provides possibility to reverse any accelerated depreciation accounted earlier, up to the net asset value determined using ordinary depreciation. If, on the other hand, the asset price at current prices increases from period to period to an extent that exceeds its net value calculated using ordinary depreciation, the Accounting Act also makes it possible to recognise this through the institution of value adjustment; at the same time, the part of the asset value resulting from value adjustment shall not be incorporated in the ordinary depreciation.

Consequently we may state that the provisions of the Accounting Act provide a possibility to recognise the changes in the asset value in circumstances of uncertainty and lack of knowledge about future, as described in Chapter 4.2; therefore the Act is able to ensure nominal capital maintenance as discussed in Chapter 2.2, and makes it possible to exactly determine the end-of-period asset value. However, the concepts used by the Act may not be clearly matched with the elements of cross-section depreciation $D_{t+1, s}$, revaluation $\ddot{G}_{t, s}$ and capital gain/loss $\varepsilon_{t, s}$ discussed earlier in the context of the change in the asset value.

\subsubsection{The approach to changes in the value of fixed assets in the International Financial Reporting Standards (IFRS)}

The valuation of fixed assets, constituting the subject matter of my study, is regulated within the IFRS Framework by Standard IAS 16. A key element of this valuation is fixed asset depreciation. In its definitions, the Standard defines depreciation as "the systematic allocation of the depreciable amount of an asset over its useful life", the

\footnotetext{
${ }^{50}$ The formulation may not be entirely clear in the respect that assuming continuous operation from the balance sheet date to the closing date of the balance sheet, the assets of the company are in use, and therefore their "known" market values "prevailing" at (and reflecting their state as of) the closing date of the balance sheet will evidently be lower than their market value as of the balance sheet date, as a result of use and obsolescence between these two dates. However, these elements are recognised as changes in the value pertaining to the next year. It would consequently be more expedient to use the formulation "[based on information] that became known before the balance sheet preparation date", as occurring on several occasions in the text of the Act.
} 
depreciable amount being "the cost of an asset, or other amount substituted for cost, less its residual value".

It is clear from the definition of depreciation used by the IAS 16 that in order to calculate depreciation, in addition to the historical cost of the asset, we also need to estimate its useful life and its residual value after its expected use; on the basis of these elements, the depreciable value may be allocated over the useful life of the asset. The Standard considers residual value to be the estimated amount that an entity would currently obtain from disposal of the asset, after deducting the estimated costs of disposal, if the asset were already of the age and in the condition expected at the end of its useful life. Therefore the definition of residual value in the IAS 16 substantially differs from its definition articulated in the Hungarian Accounting Act, which provides that the residual value should be determined with regard to the future date where its use ends, instead of the present date.

Section 56 of the IAS 16 Standard makes it clear that it regards the asset as a pool of future benefits embodied in it; I presented the theoretical roots of this view in Chapter 3.1.5. At the same time, the Standard fails to clarify what it means by 'future economic benefits embodied in an asset'. There are two basic ways to define this concept. One of them is the definition of 'value in use' offered by Standard IAS 36 on the Impairment of Assets, which identifies future benefits as "cash flows expected to be derived from an asset". However, grasping the future economic benefit of an asset through the cash flows derived from the asset aims, by definition, to determine the company-specific value of the asset, which makes it difficult to measure asset value independently from the given company and from the other assets. The other possibility is to use the income approach defined in IFRS 13 Fair Value Measurement, for which section B14 clarifies that future cash flows should reflect the assumptions used by market participants during asset pricing, which is a clear intention to determine the company-independent value. This method of determining future benefits (cash flows) consequently is equivalent to the theoretical rental (or user cost) concept discussed in Chapter 3.1.5.2, which-ensuing from the independent value judgement of the rental and second-hand markets-theoretically makes it possible to measure the value of the benefits independently from the company and its other assets.

Section 56 of the IAS 16 Standard provides that the future economic benefits, or services, embodied in the asset are principally consumed by the entity; the consumption of the services is fundamentally due to the use of the asset and to technological and 
market obsolescence. This view is entirely consistent with the consideration of the effects of exhaustion, deterioration and embodied and disembodied obsolescence as explained in Chapter 3.1.5.3, where I discussed the effects of the use of the asset broken down to exhaustion and deterioration.

Section 60 of the Standard provides that the systematic allocation of the depreciable value of the asset should be performed in a way that it reflects the pattern in which the asset's future economic benefits are expected to be consumed by the entity. Now in equation (6), I identified the value of future benefits (i.e. of the service value) discounted to present value with the asset value itself; therefore, the depreciation of the asset may derive from the consumption of the service values, which in this case means that in equation (6) we addition the service values for one future period less, so that the asset value will decrease with exactly the value we consumed in the present period. The depreciation determined on the basis of the pattern according to which the services are consumed may be correlated with the change in the asset value as measured at a given moment in time, expressed by the cross-section depreciation rate defined in equation (42). However, in order to grasp the entire change in the asset value, in addition to the determination of the end-of-period cross-section depreciation we also need the ex post revaluation $\ddot{G}_{t, s}$ defined in equation (64) and the capital gain/loss $\varepsilon_{t, s}$ expressed in equation (63) corresponding to the period. The recognition of the above mentioned elements of the ex post changes in the asset value may differ from the concept of depreciation as defined in the Standard, depending on whether the entity chooses to use the revaluation or the historical cost model for the valuation of the examined fixed assets.

The revaluation model aims to ensure that the asset is recognised in the balance sheet at its 'fair' value (real value) at the end of the period. The IFRS 13 Standard stipulates that fair value is „,... the price that would be received to sell an asset or paid to transfer a liability in an orderly transaction between market participants at the measurement date." The formulation makes it clear that the periodical change in the asset value corresponds, in the revaluation model, with the change in value defined in equation (36). Section 34 of the Standard provides guidance respecting the frequency of asset revaluations, which should depend upon the frequency of the changes in fair values of the items concerned. Pursuant to the section, when the fair value of a revalued asset differs materially from its carrying amount, a further revaluation is required. In the case of those assets, however, which experience significant and volatile changes in fair value, 
such frequent revaluations are unnecessary for assets with only insignificant deviations between the fair value and the book value. Instead, it may be necessary to revalue these items only every three or five years.

The analysis of the regulation framework points to the fact that the role of the depreciation, as defined in the Standard, in the determination of the end-of-period asset value is not clarified in either approach to the fair value used in the revaluation model. Furthermore, it cannot be established which of the constituents of the change in the asset value, such as cross-section depreciation, ex post revaluation or capital gains/losses, identified on the condition of uncertainty, the Standard considers to be part of the depreciation or of the revaluation, ${ }^{51}$ respectively.

In the event of the choice of the cost model, the changes in asset value in a given period are determined partly on the basis of depreciation as defined in the Standard, and partly on the basis of impairment loss and reversal as defined in the IAS 36 Standard. If the depreciation reflects, in line with the provisions of Section 60 of the IAS 16 Standard, the consumption pattern of the future benefits of the asset, then-taking the periodical nominal and real price changes into account - it needs to be equivalent to the time series depreciation defined in equation (61), provided that the end-of-period asset value does not exceed the carrying amount of the beginning of the period. The choice of the cost model may be justified in practice by the fact that the fair value of the asset cannot be reliably measured at the end of the individual periods. Nevertheless, it is still necessary to 'revise' the asset value resulting from the recognition of depreciation; this is ensured by the provisions of the IAS 36 Standard concerning impairment loss and its reversal. The recognition of impairment loss aims to ensure that the end-of-period asset value should not exceed its realisable value, i.e. the higher of the real value less the sales costs of the asset and the value in use of the asset. The IAS 36 Standard defines 'value in use' as the present value of the future cash flows expected to be derived from an asset. Therefore, the definition of value in use in the IAS 36 Standard may not be considered to be a value that is independent from the given entity, in contrast with fair value, which by definition aims to provide an interpretation of asset value which is independent from the company. If, then, the end-of-period asset value determined according to the cost model is equal to a value in use which is higher than the fair value, this shows that the concept of asset value is different from the end-of-period value defined in equation (36). If, after

\footnotetext{
${ }^{51}$ Revaluation in the interpretation of the Standard.
} 
the recognition of the impairment loss or its reversal, the end-of-period asset value is equal to its fair value, this means that the impairment or reversal recognised in the given period is equivalent with the capital gain/loss $\varepsilon_{t, s}$ defined in equation (63), although this relationship does not clearly ensue from the text of the Standard.

Section 13 of the IAS 16 Standard provides that if the service lifetime of certain parts of the examined fixed assets differs from the service lifetime of the asset itself, then these main parts may be recognised by the entity as independent assets if their cost value may be measured reliably and if they are expected to proffer future economic benefits. If such main parts of fixed assets, with service lifetimes different from those of the assets themselves, may be identified and interpreted as independent assets, it also allows for a more precise estimation of the depreciation of the asset itself. This estimation is influenced by the phenomena of exhaustion, deterioration and embodied and disembodied obsolescence as described before. Hungarian accounting rules, on the other hand, do not contain provisions on the independent recognition of parts of fixed assets having a service lifetime different from that of the asset itself; however, this approach may be helpful in the determination of the depreciation rate.

Consequently we may state that the change in value of the examined fixed assets as established in line with the revaluation model provided in the IAS 16 Standard is consistent with the change in value described in Chapter 4.2, and as such, this method ensures nominal capital maintenance as discussed in Chapter 2.2, and makes it possible to exactly determine the end-of-period asset value.

\subsection{The role of cross-section and time series depreciation in the determination of the change in the asset value and of the end-of-period asset value}

It is therefore apparent from the accounting interpretation of the change in value of fixed assets as described in Chapter 4.3.1 and 4.3.2 that accounting primarily intends to grasp the changes in the market value of fixed assets, and identifies the end-of-period asset value with the market value of the asset by the end of the period. However, as I indicated in Chapter 3.1.4, the fixed assets used by companies hardly ever have an active and transparent market which would enable us to measure the end-of-period value of the assets. Therefore, in practice, the values of fixed assets used by companies are established using depreciation rates which need to correspond with the time series 
depreciation rate $\delta_{t, s}^{T}$ as specified in equation (67), constituted of the ex post real change $\dddot{\imath}_{t}^{*}$ of the service value of the new asset in the given period, the ex post periodical inflation $\ddot{\rho}_{t}$, and the cross-section depreciation rate $\delta_{t+1, s}^{C}$ of the asset as determined at the end of the period:

$$
\delta_{t, S}^{T}=1-\left(1+\ddot{i}_{t}^{*}\right)\left(1+\ddot{\rho}_{t}\right)\left(1-\delta_{t+1, s}^{C}\right)
$$

The real price change rate $\ddot{i}_{t}^{*}$ and the periodical ex post inflation $\ddot{\rho}_{t}$ may be established in an ex post manner based on the changes occurring within period $t$ (i.e. at moment $t+1$ ) in the service values $P_{t, 0}^{I}$ of new assets available on the market and perfectly replacing the given assets or in the service values $P_{t, 0}^{K}$ of the new assets. In order to determine the cross-section depreciation rate $\delta_{t+1, s}^{C}$ of the asset, however, it is necessary to estimate its exhaustion, deterioration and embodied and disembodied obsolescence occurring in period $t$ and anticipated for the future (in Chapter 4.1.1, I described the relationship between these phenomena and the cross-section depreciation rate in detail). At the same time, these effects are substantially influenced by the specific features, usage and maintenance characteristics of the asset, as well as by a number of further circumstances related to its use.

In certain cases it is possible to determine the cross-section depreciation rate using an empirical method, which also provides a useful testing for the cross-section depreciation rate used. These empirical examinations are almost in every case based on market prices: consequently, they not only reflect embodied and disembodied obsolescence but also the 'average' condition (wear) of the asset, which-although not likely to correspond to the cross-section depreciation of the individual asset-provides guidance for the determination of that rate. In the next chapter, I will describe different approaches to the empirical determination of the cross-section depreciation rate and function, which may help to calculate the time series depreciation functions and rates of the various assets in a way that the results better approximate reality.

\subsection{The empirical examination of cross-section depreciation rate}

The empirical measurement of cross-section depreciation rate $\delta_{t+1, s}^{C}$ as defined in equation (42) is typically performed on the basis of second-hand market prices and the 
theoretical rentals prevailing on the rental market of the assets. In the present chapter, I will elaborate on the approaches used in these calculations.

\subsubsection{The examination of depreciation rate based on market rentals}

If a rental market exists for the given fixed assets, the cross-section depreciation rate $\delta_{t+1, s}^{C}$ defined in equation (42), corresponding to moment $t+1$, may be calculated by observing the rents $P_{t, s}^{K}$ of the assets of different ages $s$. If we substitute the expression on the right hand side of equation (8) for the asset values $P_{t+1, s}^{I}$ and $P_{t+1, s+1}^{I}$ on the right hand side of equation (42), we may calculate the cross-section depreciation rate $\delta_{t+1, s}^{C}$ using the observed rents as follows:

$$
\begin{gathered}
\text { (69) } \delta_{t+1, s}^{C}=1-\left[P_{t+1, s+1}^{I} / P_{t+1, s}^{I}\right]= \\
1-\left[\sum_{\tau=0}^{S_{t+1}-(s+1)} \frac{P_{t+1+\tau, s+1+\tau}^{K}}{\left(1+r_{t+1}\right)^{\tau}} / \sum_{\tau=0}^{S_{t+1}-s} \frac{P_{t+1+\tau, s+\tau}^{K}}{\left(1+r_{t+1}\right)^{\tau}}\right] .
\end{gathered}
$$

The main problem concerning this approach is that fixed assets typically do not have a transparent and active rental market which would make it possible to observe the services values (i.e. the rents) of assets of different ages. Respecting this method, Diewert [1996] explains that even if such a rental market existed, we probably would not be able to estimate cross-section depreciation in a precise way, because that would also necessitate an estimate of the future changes in rents and the discount rates to be used, which, however, entails much uncertainty. Jorgenson [1996] considers this method to be an alternative for the examination of cross-section depreciation on the basis of secondhand market prices, but notes that relatively few empirical studies have been made using this approach. As a result of the difficulties and uncertainties described above, it is not probable that information from the rental market could be effectively used for the empirical determination of the cross-section depreciation rate (Diewert [1996]).

\subsubsection{The empirical examination of cross-section depreciation rate based on second-hand market prices}

Mainstream literature discussing the empirical determination of depreciation rates often uses second-hand market asset prices to estimate the cross-section depreciation rate $\delta_{t+1, s}^{C}$ corresponding to moment $t+1$, defined in equation(42). Asset values $P_{t+1, s}^{I}$ and $P_{t+1, s+1}^{I}$ are in this case identified with the second-hand market prices of 
assets of age $s$ and $s+1$ observed at moment $t+1$, from the proportion of which it is possible to estimate the cross-section depreciation rate $\delta_{t+1, s}^{C}$ of an asset of age $s$.

In Chapter 3.1.4, I have already discussed the critical observations usually made concerning the use of second-hand market prices; these also apply to the determination of the cross-section depreciation rate $\delta_{t+1, s}^{C}$. Beside the points already mentioned, the cross-section depreciation values thus computed are also distorted by the fact that the assets found on the second-hand market are all 'surviving assets', a problem first addressed by Hulten and Wykoff [1981a] in their empirical research.

\subsubsection{The distorting effect of surviving assets}

In their empirical research, Hulten and Wykoff [1981a] consider the assets appearing on the second-hand market and thus included in the sample to be 'surviving assets', not including those assets which had been scrapped earlier. Diewert and Wykoff [2006] think it probable that Schmalenbach [1959] was the first to recognise that failing to take into account the distortion of surviving assets in the calculation of the depreciation rate is liable to lead to serious problems. In the context of the distortion caused by surviving assets, Hulten and Wykoff [1981a] explain that the authors of earlier studies on depreciation implicitly assumed that the assets have identical service lifetimes, i.e. they are scrapped at the same age. However, this assumption is not realistic; this is conveniently illustrated by the fact that, evidently, there will be a smaller number of 20year-old assets in 1990 than 10-year-old assets in 1980, for in the meantime, some of the assets will have reached the end of their service lifetimes and will have been scrapped. These scrapped assets will not be represented on the second-hand market, and will therefore be excluded from the analysed sample, which distorts the determination of depreciation rate on the basis of second-hand market prices. To formulate the problem in another way: a surviving asset of a given vintage present on the second-hand market will not be representative of the 'average' asset of that vintage but of the 'surviving' assets of the vintage in question. At the same time, 'average' assets are more relevant to the measurement of asset value than the assets of the given vintage which 'survive' for the longest time (Hulten and Wykoff [1981a]). In order to be able to take into account the deviating scrapping dates of the various assets, i.e. to exclude the distorting effect of the surviving assets, Hulten and Wykoff [1981a] 'censure' the sample of surviving assets 
using a retirement distribution characteristic of the given asset. ${ }^{52}$ Jorgenson [1996] regards the retirement distribution characteristic of the various assets as the probability that an asset of age $s$ should survive the given period. Multiplying the market price of the surviving asset with this probability, we obtain the value of the average asset of the given vintage, on the assumption that the value of the assets already scrapped is zero.

Of all the empirical analysis methods of depreciation, Diewert [1996] considers the approach based on second-hand market prices to be the most satisfactory in every respect, on the condition that a second-hand market relevant to the given asset exists. I will therefore use the cross-section analysis of the second-hand market to test my hypotheses formulated below.

\footnotetext{
${ }^{52}$ Analysing the depreciation of office buildings, Hulten and Wykoff [1981a] used Winfrey $\mathrm{L}_{0}$ distribution to take the differences in retirement date into account.
} 


\section{Establishment of the hypotheses}

\subsection{Research questions behind the hypotheses}

In the chapters above I have explained that I will analyse the consumption of fixed assets using the 'change in value' approach founded by Hotelling. Part of this change in value is the value-age profile elaborated by Jorgenson and his followers. The cross-section depreciation rate calculated on the basis of this profile may be regarded as the consumption pattern of the future services of the asset calculated at present prices; therefore this profile also constitutes a determining element of the time series depreciation rate described in equation (68).

In my study, I have restricted the scope of depreciation analysis to fixed assets created by man, with a finite service lifetime and limited services; therefore the fixed assets used for the empirical analysis of the hypotheses should also bear these features. Such fixed assets include passenger cars, for it may be established without any doubt that their service lifetime and their services are finite and that they are man-made. Certainly, many other fixed assets beside cars fulfill these criteria; yet cars typically have a market extensive and (presumably) active enough to suit my purpose, as this fact allows me to observe the characteristics of the assets appearing on the market to an extent that makes it possible to test my hypotheses. ${ }^{53}$ Such observable characteristics are the second-hand market prices, the vintages and the ages of cars. In Chapter 1, I considered asset age as an explanatory variable of depreciation expressing the exhaustion, deterioration and obsolescence of assets. In the case of cars, another factor to observe is mileage, which I assume to be an independent explanatory variable of the 'average' deterioration and exhaustion of cars in the calculation of depreciation.

In Hungarian accounting practice, the cost allocation model described in Chapter 2.3.1 (and especially the linear allocation method) prevails in the calculation of depreciation. Linear cost allocation is, however, probably unable to reproduce the change in the asset value, which not only reflects a distorted image of the company's financial and income situation, but also leads to the incorrect pricing of the company output. Therefore, it is particularly important that the depreciation model used by companies should not fail to consider the effects of exhaustion, deterioration and obsolescence, presented in

\footnotetext{
${ }^{53}$ Account taken of the criticisms outlined in Chapter 3.1.4.
} 
Chapter 3.1.5.3; these effects also determine the shape of the depreciation function, constituting the subject matter of my Hypotheses 1 and 2 .

In Chapter 4.1.1, I traced back the cross-section depreciation of fixed asset to four major phenomena: exhaustion, deterioration, and embodied and disembodied obsolescence. Virtually all researchers discussing depreciation agree in their views concerning the impacts of exhaustion and deterioration on the asset value; as opposed to this, the effects of embodied and disembodied obsolescence on the asset value constitute a widely discussed issue in academic literature on depreciation, and therefore these are not always taken into account in the calculation of the cross-section depreciation rate, which also results in distorted finance and income figures, and impacts on the pricing of the company output. Therefore, my Hypotheses 3 and 4 relate to the recognition of the phenomena of embodied and disembodied obsolescence in cross-section depreciation.

\subsection{Formulation of the hypotheses}

Based on the considerations described above, I establish the following hypotheses:

H1: The cross-section depreciation of used passenger cars of the same category follows a geometric pattern according to the age of the cars.

H2: The cross-section depreciation of used passenger cars of the same category follows a geometric pattern according to the mileage of the cars.

H3: Age has more explanatory power than mileage in the cross-section depreciation of used passenger cars of the same category.

H4: Among used passenger cars of the same category and with identical mileages, the value of older specimens is inferior to the value of younger specimens. 


\section{The empirical research}

\subsection{Scope of the research}

I will analyse the hypotheses using quantitative research methods, on the basis of information from the second-hand car market. As cars do not have a transparent market which would make it possible to observe both the characteristics of the cars and the strike prices, I will conduct my research by observing the market supply of second-hand cars. The second-hand car market supply is available through numerous online selling portals, the individual supplies of which may be contracted using a procedure called 'crawling'. Considering the opinions of several professional players of the second-hand passenger car market, I will use the Belgian car supply for the purpose of my study, for it is the market where it is the less probable that the mileage of the cars should be manipulated. Lack of manipulation is a very important factor in the present research because I consider mileage as an independent variable expressing the exhaustion and deterioration of the cars. For the testing of my hypotheses, I will use the supply data of one of the major Belgian selling sites, www.autoscout24.be, using the entire supply of the portal as of 1 March 2011. The entire supply consists of 75614 observation units, i.e. cars of different ages and mileages offered for sale: this will serve as a basis for the creation of the database used for the verification of the hypotheses.

As I explained before, a condition of the application of the capital vintage model is that the assets of different ages should be perfectly replaceable between themselves: this means that I need to limit my observation to cars using the same kind of fuel. Therefore I will only use the sample of diesel-powered passenger cars-amounting to a sample of 43114 items over the entire database- to test my hypotheses. ${ }^{54}$

The individual cars offered for sale-i.e. the observation units-are articulated around the following variables: brand, supply price, model, year of fabrication, mileage (in kilometres), and engine power (in kilowatts). It should therefore be noted that in the observations, 'market price' does not signify strike price but supply price. In my research, however, I assume that the surplus manifested in the supply prices as compared to the realised strike prices is constant for all vintages and does not affect the validity of the research conclusions.

\footnotetext{
${ }^{54}$ For an analysis of a sample of gasoline-powered cars, see Kaliczka [2012].
} 


\subsection{Preparation of the hypotheses' verification}

\subsubsection{Data preparation}

I began data preparation by reviewing the descriptive statistics of the various variables, which greatly contributed to the exclusion of the distorting effect of outlier values.

In the case of certain observation units, the variables of power or price seemed to take zero value, probably as a result of a recording error. In order to avoid distortion, I omitted from the database all of the observation units with any variables the value of which may be regarded as a recording error.

As the application of the capital vintage model is conditional on the perfect replaceability of the examined assets and their services between each other, I omitted from the observation units those cars which I presumed to be damaged or otherwise in a state that makes them unfit for the normal use typical of passenger cars.

The prices of the cars in the database thus cleared are displayed, according to age and mileage, in the following graph.

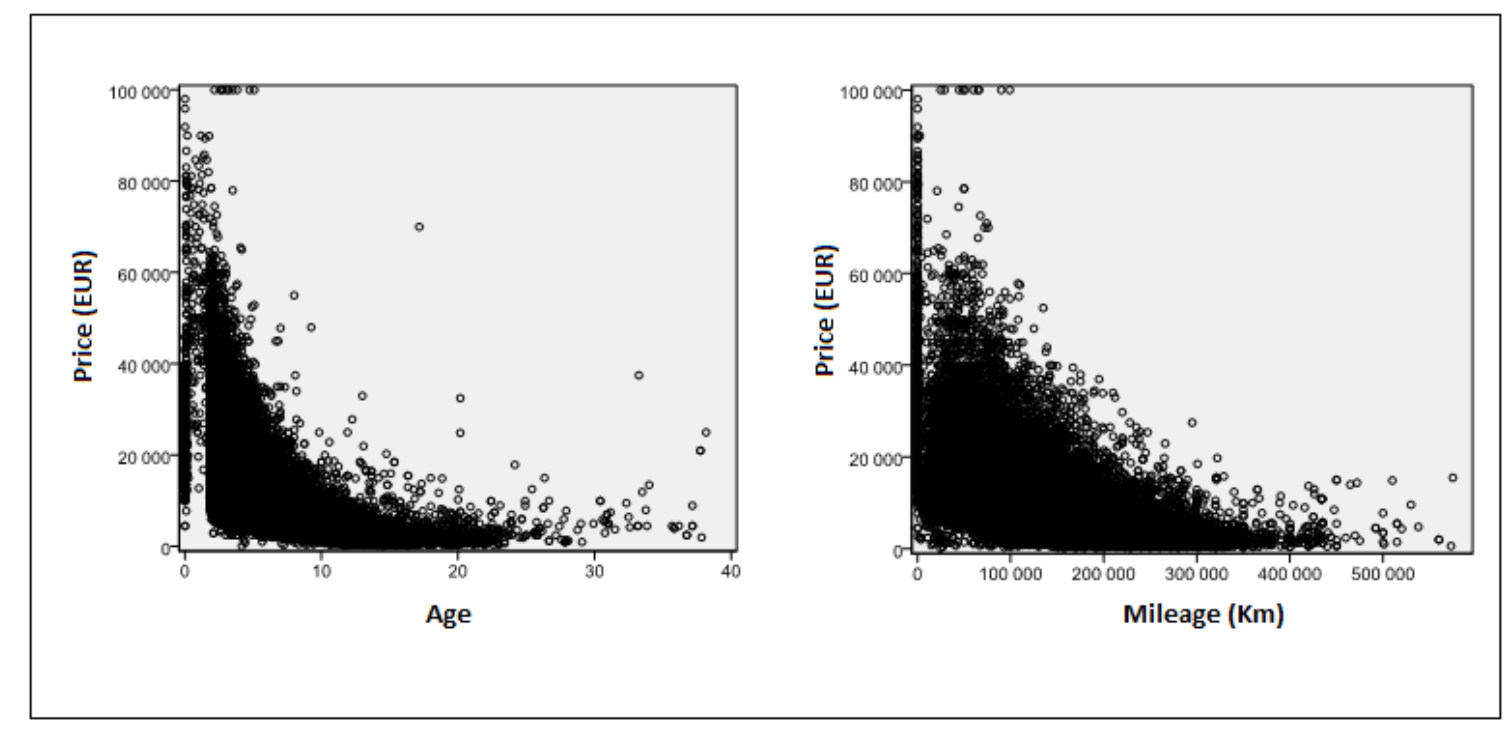

Graph 15: Prices of diesel-powered cars plotted against age and mileage. (Source: own elaboration)

\subsubsection{Separation of subsamples}

The database of observation units thus created is still unsuitable for the testing of the hypotheses, as it represents several 'layers' of cars with quite different efficiencies, 
service lifetimes and purposes of use; this is to say that the entire lot of observation units comprises luxury, lower-class and middle-class cars, although neither these vehicles themselves, nor their services could be regarded as perfect replacements for one another. Consequently, the cross-section depreciation rates need to be established for each of the layers unveiled in the observation sample separately, and to be able to do so, subsamples should be isolated. The hypotheses may then be tested separately on each of these isolated samples (clusters).

One way to sort out these subsamples is to proceed on the basis of their make: yet this solution is not likely to yield good results, as the individual brands usually trade in several categories, and the specimens belonging to different categories are not perfectly replaceable between themselves; moreover, their depreciation function may also differ substantially as a result of the differences in their constructions. ${ }^{55}$ Therefore, in order to separate the subsamples, I would also need to take the individual models within the brands into account. In this case however it would be reasonable to classify the individual models of the different brands into homogeneous categories, which would be hard work for two car makes, but next to impossible for the 55 brands represented in my observations. The ostensibly unfeasible task of clustering according to makes and models is further complicated by the fact that the models issued by the individual brands tend to vary from one vintage to another, so that the samples created on the basis of brands and models will not be stable from one period to another.

As a result of the above mentioned difficulties, I used the 'power' variable to establish the subsamples; i.e. I assumed that cars with similar engine powers make up homogeneous groups regarding their services. The histogram of the power variable for the cars in the database shows a multimodal property which further supports the existence of several subsamples and justifies my intention to separate them. I began to do so by applying the method of hierarchical clustering, ${ }^{56}$ as I did not have any presumptions regarding the number of homogeneous groups I would be able to make up on the basis of the 'power' variable. Due to the computing limitations of the software package used for the analysis, ${ }^{57}$ it was impossible to directly cluster the entire database

\footnotetext{
${ }^{55}$ As an example, I would mention the brand Mercedes-Benz, where the depreciation functions of A-class and S-class specimens are likely to differ substantially.

${ }^{56}$ Ward's method using squared Euclidean distance, without standardisation.

${ }^{57}$ SPSS Inc. PASW Statistics 18.
} 
of diesel cars comprising 43040 items; therefore I selected a sample of 1300 units by random sampling, sufficiently small for me to perform the clustering operation on. Cutting the resulting dendrogram at relative distance 5, 4 clusters are formed, which serve as a pointer for the k-centre clustering. I performed the k-centre clustering on the entire database; the procedure performed 11 iterations. The following table shows the result of the clustering and the individual cluster centres.

\begin{tabular}{|c|c|c||}
\hline Cluster & $\begin{array}{c}\text { Observations } \\
(\text { no) }\end{array}$ & $\begin{array}{c}\text { Final cluster centres } \\
\text { (kilowatt) }\end{array}$ \\
\hline \hline 1 & 17171 & 99 \\
\hline 2 & 2635 & 147 \\
\hline 3 & 298 & 217 \\
\hline 4 & 22915 & 65 \\
\hline \hline Total: & 43040 & -- \\
\hline
\end{tabular}

Table 1: Number of observation units in the individual clusters and the individual cluster centres. (Source: own elaboration)

Having accomplished the clustering, the prices of the cars belonging to the different clusters with respect to their ages and mileages are positioned as shown by the following diagram:
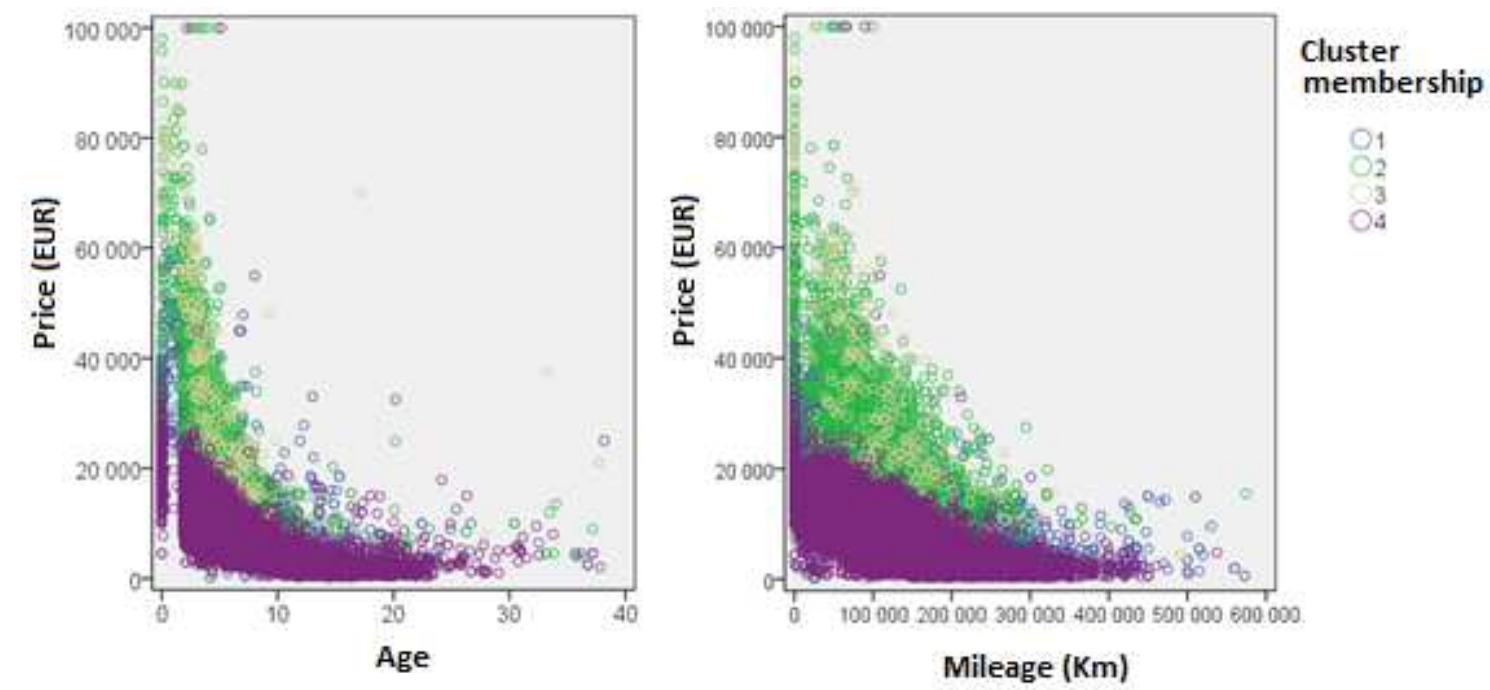

Graph 16: Position of clusters in the price, age and mileage space (Source: own elaboration)

Graph Graph 16 shows that the individual clusters are situated in layers: this confirms my preliminary assumption that the groups of cars broken down according to their 
engine power form distinct layers in the database, and that the depreciation of the cars belonging to these groups may only be examined separately. I will therefore perform the tests separately for the individual clusters. The prices of the cars belonging to the individual clusters with respect to their ages and mileages are positioned as shown by the following diagrams: 


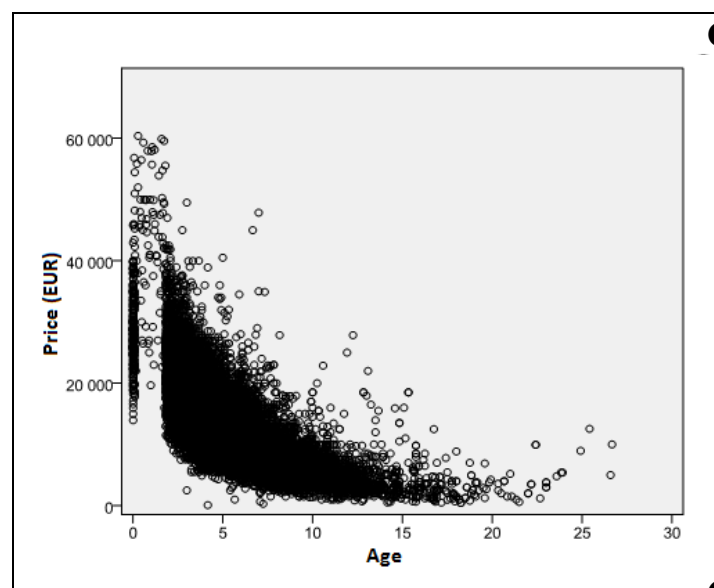

\section{Cluster 1}

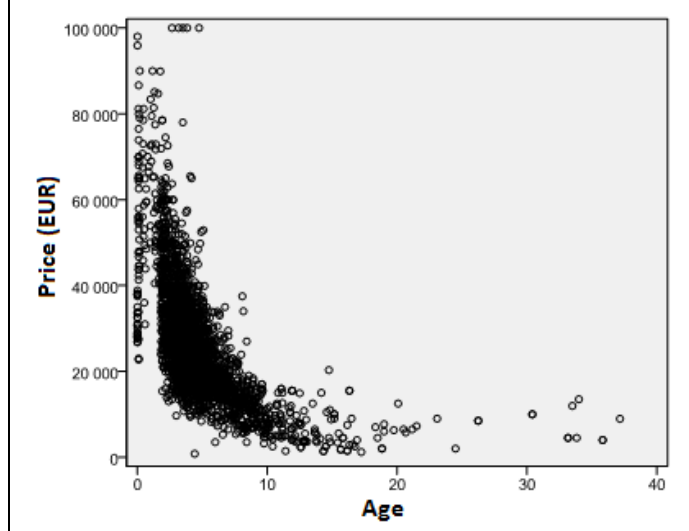

Cluster 2
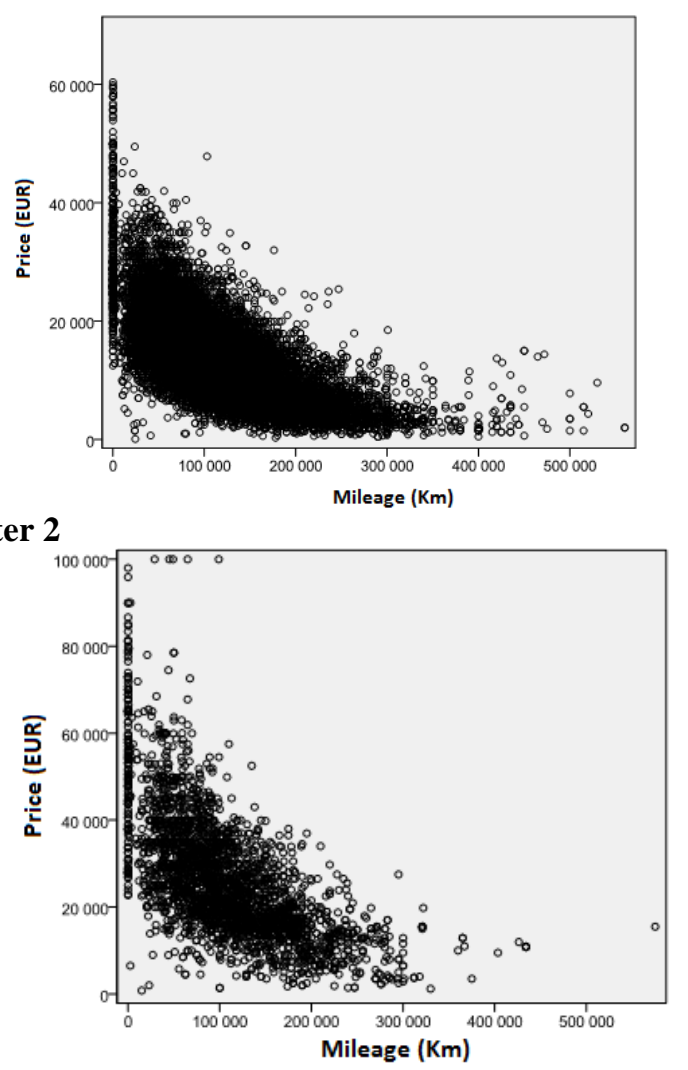

Cluster 3
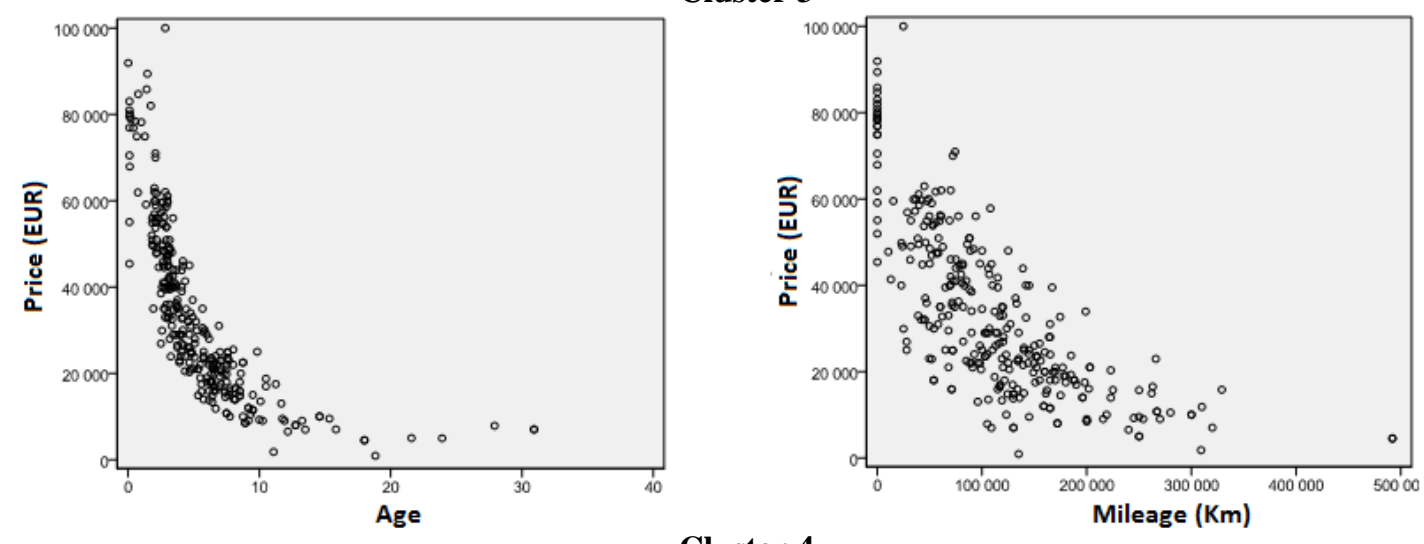

Cluster 4
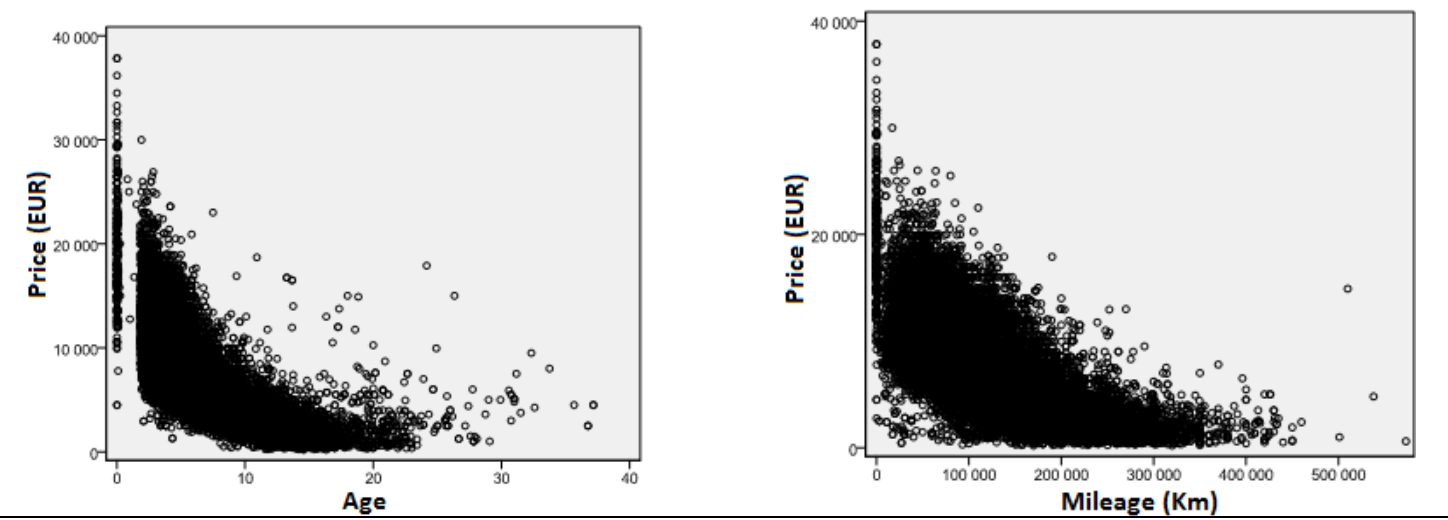

Graph 17: Prices in the individual car clusters plotted against age and mileage. 
Graph 17 clearly shows that the depreciation of the cars belonging to the individual clusters, plotted against age and mileage, is not linear in either of the clusters; therefore in order to determine the depreciation function, we need a method that is able to work for functions with non-linear shapes.

Furthermore we may observe in Graph 17 that the decrease in the value of used cars is halted, in each cluster, sometime about the age of 25 years, and subsequently an increase follows, due, presumably, to the fact that the cars in question reach veteran status. However, this so-called 'veteran effect' is not asserted in the case of the same cluster plotted against mileage, which shows that the veteran effect is characteristic of cars older than 25 years but with comparatively low mileages.

The elements of the subsets created through clustering may be considered to be replaceable with each other, and so the clusters are suitable for the differentiated testing of the hypotheses.

\subsection{Verification of the hypotheses}

\subsubsection{Verification of $\mathrm{H} 1$ and $\mathrm{H} 2$}

I used the Box-Cox transformation by Hulten and Wykoff [1981a] for the verification of hypotheses $\mathrm{H} 1$ and $\mathrm{H} 2$, as the flexibility of the function shape it yields makes it possible to identify the most current shapes of cross-section depreciation function (geometric, linear, 'one-hoss shay', as described in Chapter 6).

The Box-Cox transformation used to identify the shape of the cross-section depreciation function shall be a specifically transformed version of the linear regression function, i.e.:

$$
\text { (70) } \frac{Y^{\lambda_{1}}-1}{\lambda_{1}}=\alpha+\beta \frac{X^{\lambda_{2}}-1}{\lambda_{2}}+u \text {. }
$$

It may be demonstrated that if $\lambda_{1}, \lambda_{2} \rightarrow 0$ then the model is simplified to the log-log form $\ln Y=\alpha+\beta \ln X+u$. If $\lambda_{1}=\lambda_{2}=1$, we obtain the linear form $Y-1=\alpha+$ $\beta(X-1)+u$, whereas if $\lambda_{1} \rightarrow 0$ and $\lambda_{2}=1$, the model gives the semi-logarithmic form $\ln Y=\alpha+\beta(X-1)+u$ (Ramanathan [2002]); this semi-logarithmic function shape is identical with the depreciation function following a geometric pattern. Therefore, the different values taken by $\lambda$ make it possible to determine the shape of the depreciation function and, consequently, the depreciation pattern of passenger cars. 
The regression equation adjusted for the Box-Cox transformation may be formulated for the analysis of the cross-section depreciation as follows:

$$
\text { (71) } \frac{P_{i}^{\lambda_{1}}-1}{\lambda_{1}}=\alpha+\beta \frac{s_{i}^{\lambda_{2}}-1}{\lambda_{2}}+u_{i}, i=1, \ldots, N
$$

where $P$ designates the supply price and $s$ designates age as an independent variable.

If the independent variable of the analysis is not the age but the mileage of the car, then the regression equation formulated with the Box-Cox transformation shall be:

$$
\text { (72) } \frac{P_{i}^{\lambda_{1}}-1}{\lambda_{1}}=\alpha+\beta \frac{m_{i}^{\lambda_{2}}-1}{\lambda_{2}}+u_{i}, i=1, \ldots, N \text {, }
$$

where $P$ designates the supply price and $m$ designates mileage as an independent variable.

Following Ramanathan's [2002] method of determining the definition of $\lambda_{1}$ and $\lambda_{2}$ allowing the best covariance, I first formulated the following new variables from the dependent and independent elements of equations (71) and (72): $P_{i}^{*}=\frac{P_{i}^{\lambda_{1}}-1}{\lambda_{1}} ; s_{i}^{*}=$ $\frac{s_{i}^{\lambda_{2}}-1}{\lambda_{2}} ; m_{i}^{*}=\frac{m_{i}^{\lambda_{2}}-1}{\lambda_{2}}$.

Subsequently, I identified the values of $\lambda_{1}$ and $\lambda_{2}$ which yield a minimal sum of squares for the residua of linear regressions (73) and (74), i.e. which show the best covariance.

$$
\begin{aligned}
& \text { (73) } P_{i}^{*}=\alpha+\beta s_{i}^{*}+u_{i}, i=1, \ldots, N \\
& \text { (74) } \quad P_{i}^{*}=\alpha+\beta m_{i}^{*}+u_{i}, i=1, \ldots, N
\end{aligned}
$$

The following table summarises, broken down to clusters, the values of $\lambda_{1}$ and $\lambda_{2}$ thus obtained. 


\begin{tabular}{|c|c|c|c|c|c|c|c|}
\hline Cluster & $\begin{array}{c}\text { Cluster centre } \\
\text { (kilowatt) }\end{array}$ & $\begin{array}{c}\text { Independent } \\
\text { variable }\end{array}$ & $\lambda_{1}$ & $\lambda_{2}$ & $\beta$ & $\alpha$ & $R^{2}$ \\
\hline \multirow{2}{*}{1.} & \multirow{2}{*}{99} & Age & 0.000 & 0.766 & -0.240 & 10.191 & 0.619 \\
\hline & & Mileage & 0.000 & 0.826 & 0.000 & 10.268 & 0.507 \\
\hline \multirow{2}{*}{2.} & \multirow{2}{*}{147} & Age & 0.000 & 0.800 & -0.229 & 10.722 & 0.624 \\
\hline & & Mileage & 0.000 & 0.783 & 0.000 & 10.815 & 0.458 \\
\hline \multirow{2}{*}{3.} & \multirow{2}{*}{217} & Age & 0.000 & 0.658 & -0.303 & 11.086 & 0.822 \\
\hline & & Mileage & 0.000 & 0.761 & 0.000 & 11.193 & 0.677 \\
\hline \multirow{2}{*}{4.} & \multirow{2}{*}{65} & Age & 0.000 & 0.756 & -0.244 & 9.698 & 0.687 \\
\hline & & Mileage & 0.000 & 0.863 & 0.000 & 9.761 & 0.543 \\
\hline
\end{tabular}

Table 2: Estimated parameters of the Box-Cox transformation. (Source: own elaboration)

Table Table 2 clearly shows that the values of $\lambda_{1}$ are quite close to zero for both age and mileage, and the values of $\lambda_{2}$ approximate 1 . This shows that the depreciation function of cars is semi-logarithmic in respect of both age and mileage, which means that the depreciation function follows a geometric pattern in both cases. Based on this fact, I accept hypotheses $\mathrm{H} 1$ and $\mathrm{H} 2$.

The effective cross-section depreciation of fixed assets therefore follows a geometric sequence pattern both in respect of age and of the physical performance variable, from which fact it ensues that the linear cost allocation model used in practice exerts, in the case of comparable fixed assets, a distorting effect on the image of the company's financial and income situation.

\subsubsection{Verification of $\mathrm{H3}$}

As the results of the Box-Cox transformation show that the depreciation function of the examined cars is semi-logarithmic and follows a geometric pattern, therefore by logarithmising the supply prices, the depreciation function may also be expressed as follows:

$$
\text { (75) } \ln P_{i}=\alpha+\beta s_{i}+u_{i}, i=1, \ldots, N \text {. }
$$

By logarithmising prices, I have therefore defined a new variable $\ln P_{i}$ for the regression; the following graph shows the position of prices, broken down to categories, plotted against age and mileage. 

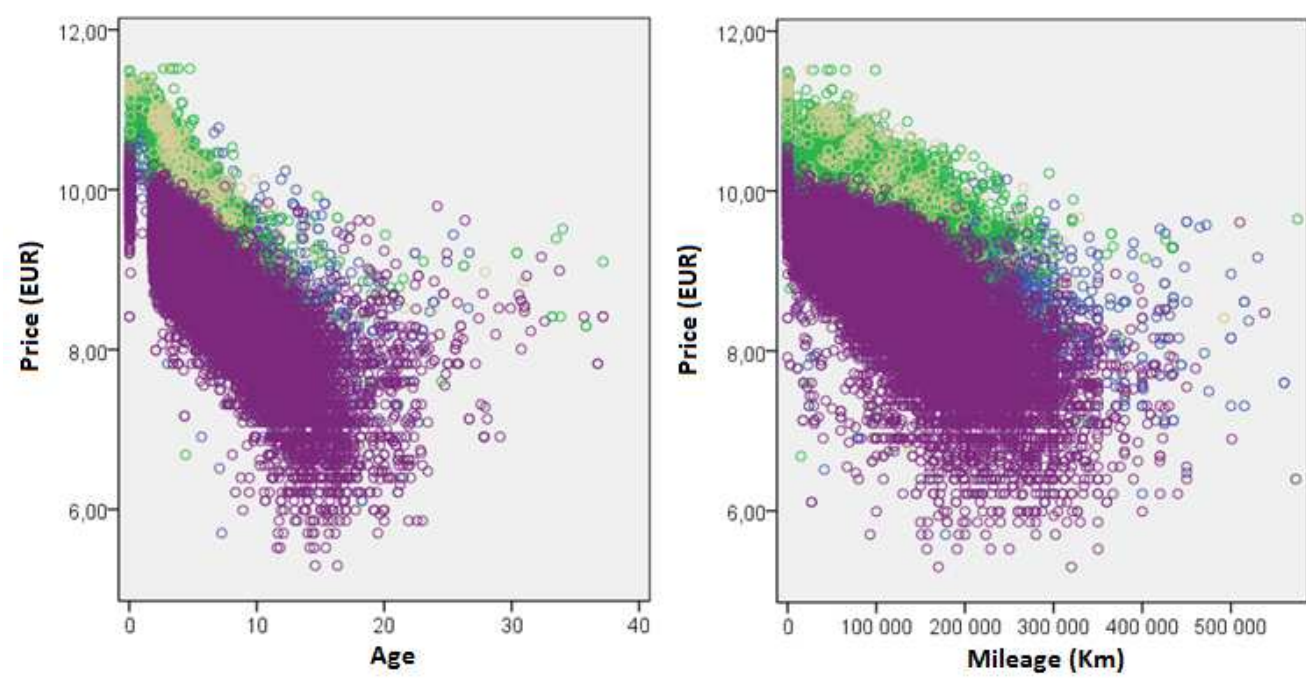

Cluster

membership

Graph 18: Logarithmised supply prices plotted against age and mileage. (Source: own elaboration)

Graph18 shows that after logarithmising prices, the observations approximate the linear pattern: therefore for the purpose of testing hypothesis $\mathrm{H} 3$, I used logarithmised prices as the dependent variable.

I ran the regression by clusters, including the independent variables of age and mileage, using the 'stepwise' method. The results of this run are presented in Appendix 1. Reviewing the descriptive statistics, it appears that the relative deviation of the variables does not exceed 2 in either of the clusters; this means that they are not excessively heterogeneous, and may thus be involved in the model. The correlation matrices show that the independent variables of age and mileage strongly correlate with the logarithmised price variable. We also see a strong correlation between the independent variables of age and mileage in each cluster; this multicollinearity evidently follows from the nature of the variables. In all four clusters, the first variable to enter the regression is age, and no variable exits it in either of the clusters. The value of $\mathrm{R}^{2}$ only weakly improves with the entry of the mileage variable in the case of clusters 1 and 4 with a higher number of elements: this is a consequence of the strong multicollinearity between the independent variables. In the case of clusters 2 and 3 containing less elements, the multicollinearity between the independent variables is weaker; here the value of $\mathrm{R}^{2}$ improves by 0.1 with the entry of the mileage variable.

The following table shows the values obtained as a result of the calculation of regression as defined in equation (75) for the individual clusters, with age as the only independent variable: 


\begin{tabular}{|c|r|r|r|r|}
\hline Cluster & $\begin{array}{r}\text { Cluster centre } \\
\text { (kilowatt) }\end{array}$ & $\alpha$ & $\beta$ & $R^{2}$ \\
\hline 1. & 99 & 10.228 & -0.155 & 0.614 \\
\hline 2. & 147 & 10.641 & -0.126 & 0.526 \\
\hline 3. & 217 & 10.946 & -0.131 & 0.690 \\
\hline 4. & 65 & 9.650 & -0.141 & 0.650 \\
\hline
\end{tabular}

Table 3: Values of the regression based on the variable 'age'. (Source: own elaboration)

It is therefore clear that the covariance of the regression function is nearly identical with the covariance of the equation determined using the Box-Cox transformation as shown in Table 2.

The histogram of the standardised residuals shows a quasi normal distribution for the four clusters. In the normal probability plot, the points sometimes deviate from the $45^{\circ}$ straight line, but there are no major deviations: this shows that the results of the regressions run are suitable for the verification of the hypotheses.

The results show that the independent variable of age has a higher explanatory power than mileage in each cluster; therefore, based on the above results, I accept hypothesis $\mathbf{H 3}$.

It seems demonstrated, therefore, that whereas the physical performance variable of fixed assets as such only comports the phenomena of exhaustion and deterioration, the age of passenger cars also incorporates the phenomenon of obsolescence, in addition to exhaustion and average deterioration. Consequently, the calculated value of depreciation will be more precise if the age of the asset is taken into account in the calculation.

\subsubsection{Verification of $\mathrm{H4}$}

To verify hypothesis H4 I used the 'hedonic' method parting from the assumption that the supply price of the examined cars is a result of the characteristics of the individual cars, these characteristics being in the present case the exhaustion and deterioration resulting from use, and the embodied and disembodied obsolescence resulting from the technological progress. I constructed the hedonic method used for the testing of hypothesis $\mathrm{H} 4$ by classifying the observation units in the individual clusters into 10 groups on the basis of the deciles of the 'mileage' variable, with the result that the 
observation units belonging to the individual groups would have approximately similar mileages. Subsequently, I defined a new variable from the quotient of the age and the mileage, denoted by 'age/mileage'. In the case of new cars, I changed the value of mileage from 0 to 1 so as to be able to perform the division for the calculation of the 'age/mileage' variable. Next, I divided the observation units into another three groups on the basis of the $33^{\text {rd }}$ and $66^{\text {th }}$ percentiles of the 'age/mileage' variable, assigning the units with low age/km values to Group 1 and those with high age/mileage values to Group 3. If the value of the 'age/mileage' variable is low, it means that it took a comparatively short time for the given car to perform a distance of a kilometre; if this value is high, then the car took longer to run the same distance. Subsequently I computed the difference of the average prices of Groups 1 and 3 constituted on the basis of the variable 'age/mileage' for each of the 10 mileage groups, in order to be able to say whether among cars with the same mileage, the price of the older cars contains the negative premium due to obsolescence.

\begin{tabular}{|c|r|c|c|c|}
\hline \multirow{2}{*}{$\begin{array}{c}\text { Percentiles } \\
\text { according } \\
\text { mileage }\end{array}$} & \multicolumn{4}{|c|}{ Negative premiums } \\
by clusters (EUR) \\
\cline { 2 - 5 } & 1. & 2. & 3. & 4. \\
\hline 1. & -14861.2 & - & - & -1442.2 \\
\hline 2. & -5541.3 & -11722.2 & -9930.8 & -2812.0 \\
\hline 3. & -6122.6 & -14635.8 & -33893.6 & -3157.0 \\
\hline 4. & -6089.6 & -8659.2 & -24033.7 & -3524.0 \\
\hline 5. & -5346.6 & -10790.5 & -23959.9 & -3728.8 \\
\hline 6. & -5778.8 & -11687.9 & -17208.8 & -4034.3 \\
\hline 7. & -5688.9 & -9021.8 & -16387.5 & -4225.3 \\
\hline 8. & -5641.0 & -11680.0 & -18092.0 & -3747.5 \\
\hline 9. & -4565.5 & -12914.2 & -13849.0 & -2615.3 \\
\hline 10. & -3691.5 & -7118.0 & -6933.3 & -1098.6 \\
\hline
\end{tabular}

Table 4: Negative premiums in the individual clusters, broken down by clusters. (Source: own elaboration)

Table 4 clearly shows that in almost each of the groups created on the basis of mileage, a negative premium may be identified in the supply prices of the older cars, which I attribute to the effect of obsolescence. Clusters 2 and 3 did not contain any observation units belonging to Group 1 (among the groups constituted on the basis of the 'age/mileage' variable), probably due to the small number of elements in these clusters. 
To demonstrate the existence of the identified negative premium, I also performed a paired t-test on the whole database. The subject of the paired t-test were the supply prices of the observation units in Groups 1 and 3 of the database broken down into three groups based on the $33^{\text {rd }}$ and $66^{\text {th }}$ percentiles of the 'age/mileage' variable. The results of the paired t-test are presented in Appendix 2. The results clearly show that the value of the F-test is significant, therefore the null hypothesis for the F-test needs to be rejected; the variances of the supply prices of the cars belonging to Groups 1 and 3 are different, which means that the results of the Welch's t-test should be considered as relevant. The results of the Welch's t-test are significant: therefore, by rejecting the null hypothesis, I have demonstrated that the averages of the supply prices of the cars belonging to Groups 1 and 3 are not identical.

\section{Based on the results of the hedonic method and of the paired t-test, I accept hypothesis $\mathbf{H 4}$.}

Therefore, the depreciation of fixed assets is affected by the embodied and disembodied obsolescence of the services of the asset, in addition to its exhaustion and deterioration; consequently, it is necessary to take these phenomena into account in the calculation of fixed asset depreciation. 


\section{Summary}

In my dissertation, examining fixed asset depreciation from the aspect of business income, I have unequivocally established that the theoretical background of depreciation goes far beyond the simple cost allocation approach; indeed, the calculation of depreciation should rather be regarded as an issue of asset valuation. Through the endof-period capital value of the company, the calculation of depreciation impacts on the income of the business, which at the same time guarantees the intactness of the capital as of the beginning of the period. It also follows from the various concepts of capital maintenance described that there is no single, generally accepted income concept universally suitable for each market player; this is confirmed by the existence of a variety of incomes derived in line with different capital maintenance concepts. The value of business capital is equal to the totality of the net assets of the company, i.e. the value of its total assets, less the value of the company's liabilities; certain part of the company's thus determined net assets is constituted by the fixed assets, labelled as "fix" because they serve the activity of the business during several periods; as a consequence, the physical and price impacts occurring during those periods shall influence the assessment of the asset's future usefulness, i.e. its value. International literature explains the changes in asset values with the phenomena of exhaustion, deterioration, and embodied and disembodied obsolescence; consequently, these phenomena also influence asset depreciation.

The change in the asset value, assuming that the condition of certainty and exact knowledge about the future is fulfilled, is called 'time series depreciation' in academic literature: this may be further broken down to two elements, cross-section depreciation and revaluation. Cross-section depreciation expresses the change in the asset value due to aging at a given moment in time; whereas revaluation represents the difference between the values of an asset of a given age measured at two different moments. These effects may also be regarded as age and date effect. In absence of certainty and exact knowledge about the future, the change in the asset value is complemented by the differences in the estimates made at different moments in time, called 'capital gains or losses' in academic literature. 
Cross-section depreciation therefore constitutes an inherent part of the change in the asset value occurring between two (reporting) dates; this change in value-and consequently the calculated value of cross-section depreciation itself-is a fundamental element in the determination of the business income and of the unit cost of the company output. As a result, the way of determining the change in value also impacts on the competitiveness of the company on the commodity and capital markets.

It is apparent from the above outlined interpretation of the change in fixed asset value that the calculation of business income recognises the change in the market value of the fixed assets; however, the fixed assets used by companies hardly ever have an active and transparent market which would enable us to measure the end-of-period value of the assets. Therefore, in practice, the values of fixed assets used by companies are established using depreciation rates which need to correspond with the time series depreciation rate, constituted of the ex post real change in the price of the asset services, the ex post periodical inflation, and the cross-section depreciation rate of the asset as determined at the end of the period. The real price change rate and the periodical ex post inflation may be established in an ex post manner, at the end of the period, based on the changes occurring within the period in the service values of new assets available on the market and perfectly replacing the given assets, or in the service values of the new assets. In order to determine the cross-section depreciation of the asset, however, it is necessary to estimate its exhaustion, deterioration and embodied and disembodied obsolescence occurring in the given period and anticipated for the future; these phenomena will determine the depreciation pattern characteristic of the given asset and of its usage. The cross-section depreciation patterns of the assets may be calculated using Jorgenson's capital vintage model, on the basis of information derived from the second-hand asset market; the results of this calculation are instrumental in the computing of the depreciation of the individual assets. Consequently, when performing the empirical verification of the hypotheses, I examined the depreciation of second-hand passenger cars using the theoretical base of the capital vintage model; the results of the Box-Cox transformation used for the verification of hypotheses $\mathrm{H} 1$ and $\mathrm{H} 2$ have shown that passenger car depreciation follows a geometric sequence pattern, where-as is apparent from the testing of hypothesis $\mathrm{H} 3$ - the age of the cars has a stronger explanatory power than their mileage. This result is explained by the phenomenon of 
obsolescence, present in the 'age' variable as demonstrated by the acceptance of hypothesis $\mathrm{H} 4$.

To illustrate the results, by substituting equation (75) into equation (43) the depreciation rate estimated on the basis of regression may be expressed as follows:

$$
\text { (76) } \delta_{t, s}^{C}=1-\left[P_{t+1, s+1}^{I} / P_{t+1, s}^{I}\right]=1-\left[e^{\alpha+\beta(s+1)} / e^{\alpha+\beta s}\right]=1-e^{\beta} \text {. }
$$

When determining the depreciation rate, I assume that the duration of the service lifetimes of the different cars examined differs due to external impacts such as accidents or crashes, which impacts I do not consider to form part of the cross-section depreciation of passenger cars. Therefore I do not adjust the definition of the cross-section depreciation function for the distribution described in Subchapter 4.5.2.1.

The following table shows the depreciation rates calculated using the regression values $\beta$ presented in Table 3 .

\begin{tabular}{|c|r|r|}
\hline Cluster & \multicolumn{1}{|c|}{$\delta_{t, s}^{C}$} & $1-\delta_{t, s}^{C}$ \\
\hline 1. & 0.144 & 0.856 \\
\hline 2. & 0.118 & 0.882 \\
\hline 3. & 0.123 & 0.877 \\
\hline 4. & 0.132 & 0.868 \\
\hline
\end{tabular}

Table 5: Depreciation rates computed for the individual clusters. (Source: own elaboration)

Table 5 shows that there are only minor differences in the depreciation rates of the individual clusters. The following graph presents the value functions determined for the individual clusters using the computed depreciation rates for a period of 40 years. 


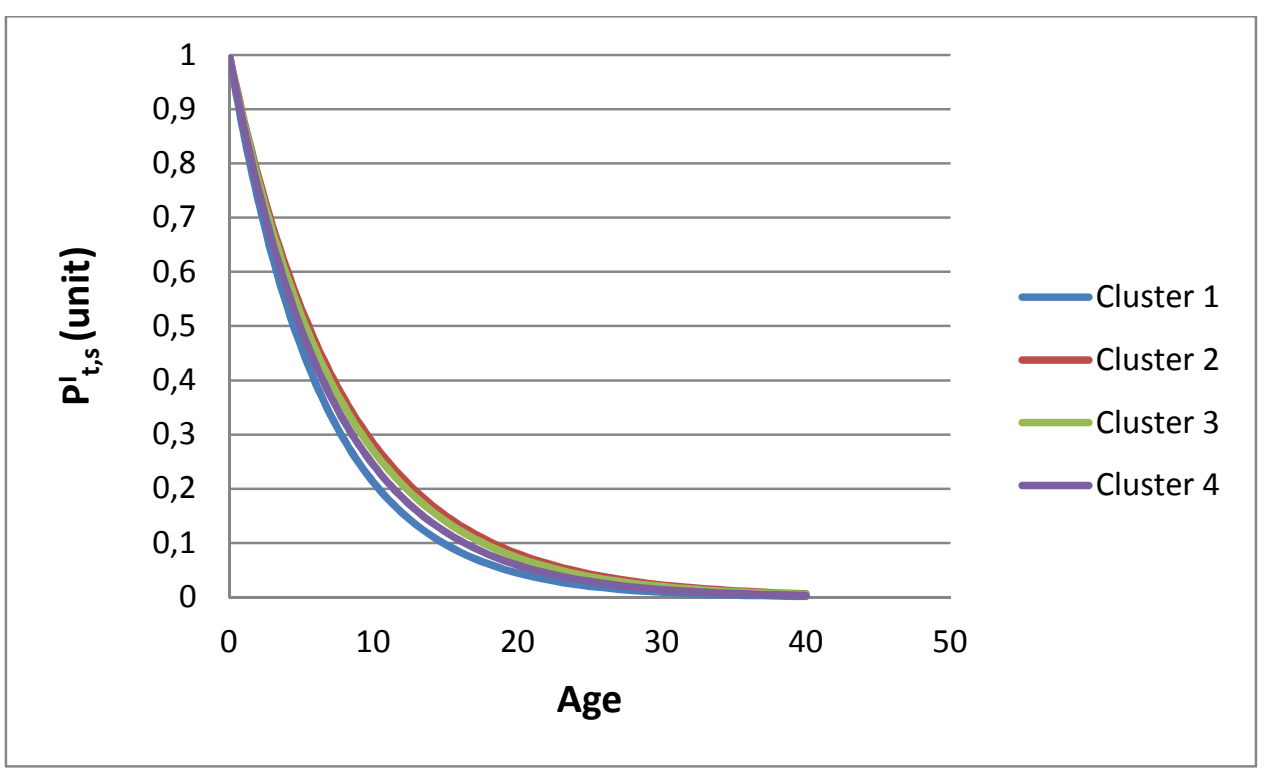

Graph 19: Depreciation patterns computed for the individual clusters. (Source: own elaboration)

The graph shows that the estimated depreciation of the examined cars follows a geometric sequence pattern, shaped-according to theory-by the exhaustion, deterioration and obsolescence of the cars.

The identification of the geometric sequence pattern is a prominently important finding because in Hungarian accounting practice, asset depreciation is typically determined using the linear cost allocation model, which entails-in the light of my present empirical research results - that through the use of the linear cost allocation method, cars become overvalued in the balance sheet. It also follows from the above facts that the depreciation write-offs corresponding to the individual periods are overestimated in the initial periods and underestimated in the later periods. This distorts the image of the company's income situation and (through the allocated depreciation) the unit cost of the company output, which affects the competitiveness of the company on the commodity and capital markets. 


\section{Acknowledgments}

The completion of a doctoral dissertation is not solely the merit of any single person, but also of those who have supported the author throughout. I wish to extend my gratitude to all those who supported me, first to my supervisors, the late János Bosnyák, and Rezső Baricz, for their continued guidance. I am also very grateful to Professor Iván Bélyácz, for helping set out the course of my research and for suggestions of academic works that eventually formed the basis of this dissertation's literature. I also thank György Boda for his enriching suggestions.

Finally, I owe gratefulness to my family members, who have shared the human burden of writing this dissertation, and provided the necessary environment that helped me finish writing. 


\section{Appendix}

Appendix 1: The results of the regression analysis of each cluster.

\section{Regression 1}

\section{Descriptive Statistics}

\begin{tabular}{|l|r|r|r|}
\hline & \multicolumn{1}{|c|}{ Mean } & Std. Deviation & N \\
\hline Ln price (EUR) & 9,3721 &, 58723 & 17171 \\
Age & 5,5088 & 2,95995 & 17171 \\
Mileage $(\mathrm{Km})$ & 119288,05 & 66610,643 & 17171 \\
\hline
\end{tabular}

\section{Correlations}

\begin{tabular}{|c|c|c|c|c|}
\hline & & $\begin{array}{c}\text { Ln price } \\
\text { (EUR) }\end{array}$ & Age & Mileage $(\mathrm{Km})$ \\
\hline \multirow[t]{3}{*}{ Pearson Correlation } & Ln price (EUR) & 1,000 &,- 783 &,- 712 \\
\hline & Age &,- 783 & 1,000 & ,707 \\
\hline & Mileage (Km) &,- 712 & ,707 & 1,000 \\
\hline \multirow[t]{3}{*}{ Sig. (1-tailed) } & Ln price (EUR) & &, 000 & ,000 \\
\hline & Age &, 000 & &, 000 \\
\hline & Mileage (Km) & ,000 &, 000 & . \\
\hline \multirow[t]{3}{*}{$\mathrm{N}$} & Ln price (EUR) & 17171 & 17171 & 17171 \\
\hline & Age & 17171 & 17171 & 17171 \\
\hline & Mileage (Km) & 17171 & 17171 & 17171 \\
\hline
\end{tabular}


Variables Entered/Removed ${ }^{\text {a }}$

\begin{tabular}{|c|c|c|c|}
\hline Model & $\begin{array}{l}\text { Variables } \\
\text { Entered }\end{array}$ & $\begin{array}{l}\text { Variables } \\
\text { Removed }\end{array}$ & Method \\
\hline$\overline{1}$ & Age & & $\begin{array}{l}\text { Stepwise } \\
\text { (Criteria: } \\
\text { Probability-of-F- } \\
\text { to-enter <= } \\
\text {,050, } \\
\text { Probability-of-F- } \\
\text { to-remove >= } \\
, 100) \text {. }\end{array}$ \\
\hline 2 & Mileage $(\mathrm{Km})$ & & $\begin{array}{l}\text { Stepwise } \\
\text { (Criteria: } \\
\text { Probability-of-F- } \\
\text { to-enter <= } \\
, 050, \\
\text { Probability-of-F- } \\
\text { to-remove >= } \\
\text {,100). }\end{array}$ \\
\hline
\end{tabular}

a. Dependent Variable: Ln price (EUR)

Model Summaryc

\begin{tabular}{|l|r|r|r|r|}
\hline Model & $\mathrm{R}$ & R Square & \multicolumn{1}{|c|}{$\begin{array}{c}\text { Adjusted R } \\
\text { Square }\end{array}$} & $\begin{array}{c}\text { Std. Error of the } \\
\text { Estimate }\end{array}$ \\
\hline 1 &, $783^{\mathrm{a}}$ &, 614 &, 614 &, 36499 \\
2 &, $814^{\mathrm{b}}$ &, 663 &, 663 &, 34074 \\
\hline
\end{tabular}
a. Predictors: (Constant), Age
b. Predictors: (Constant), Age, Mileage (Km)
c. Dependent Variable: Ln price (EUR) 
Model Summaryc

\begin{tabular}{|c|c|c|c|c|c|c|}
\hline \multirow[t]{2}{*}{ Model } & \multicolumn{5}{|c|}{ Change Statistics } & \multirow[b]{2}{*}{ Durbin-Watson } \\
\hline & $\begin{array}{c}\text { R Square } \\
\text { Change }\end{array}$ & F Change & $\mathrm{df1}$ & df2 & Sig. F Change & \\
\hline 1 & ,614 & 27276,007 & $\overline{1}$ & 17169 & ,000 & \\
\hline 2 & ,050 & 2531,604 & 1 & 17168 & ,000 & ,498 \\
\hline
\end{tabular}

c. Dependent Variable: Ln price (EUR)

ANOVA $^{c}$

\begin{tabular}{|rl|r|r|r|r|r|}
\hline Model & & Sum of Squares & \multicolumn{1}{c|}{ df } & Mean Square & F & Sig. \\
\hline 1 & Regression & 3633,626 & 1 & 3633,626 & 27276,007 &, $000^{\mathrm{a}}$ \\
& Residual & 2287,201 & 17169 &, 133 & & \\
& Total & 5920,827 & 17170 & & & \\
& Regression & 3927,555 & 2 & 1963,777 & 16913,962 &, $000^{\circ}$ \\
& Residual & 1993,272 & 17168 &, 116 & & \\
& Total & 5920,827 & 17170 & & & \\
\end{tabular}

a. Predictors: (Constant), Age

b. Predictors: (Constant), Age, Mileage (Km)

c. Dependent Variable: Ln price (EUR)

Coefficients $^{\mathrm{a}}$

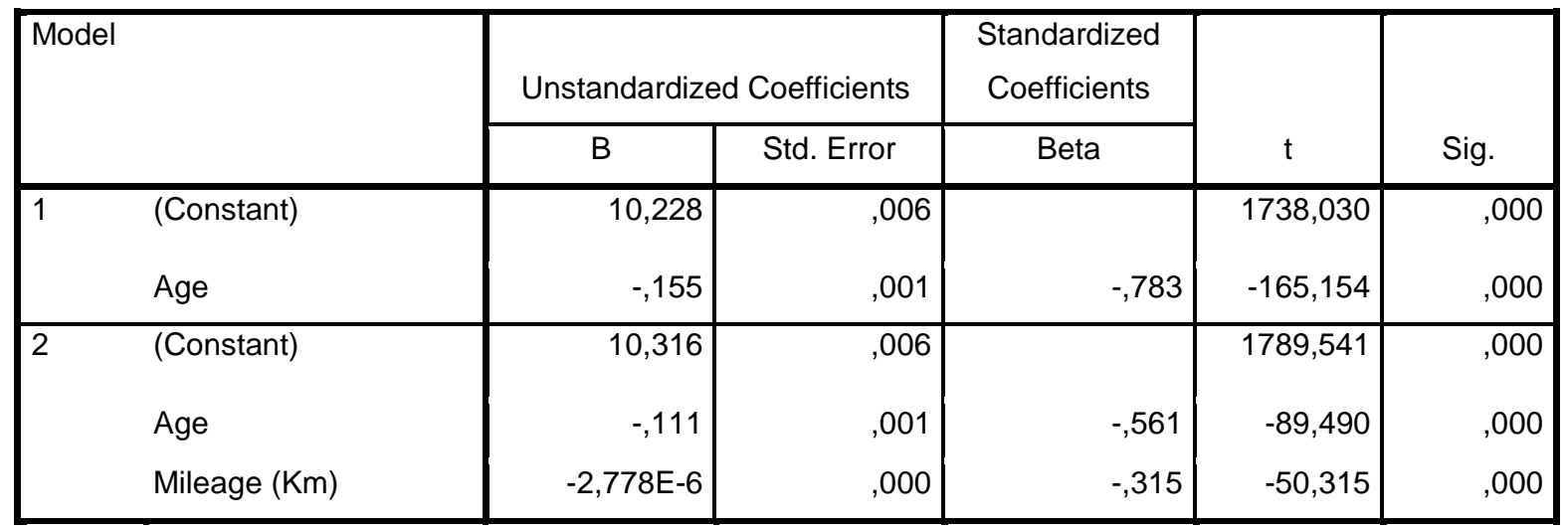

a. Dependent Variable: Ln price (EUR) 


\section{Coefficients $^{\mathrm{a}}$}

\begin{tabular}{|ll|r|r|r|r|r|}
\hline Model & \multicolumn{2}{|c|}{$95,0 \%$ Confidence Interval for B } & \multicolumn{3}{|c|}{ Correlations } \\
\cline { 3 - 7 } & & Lower Bound & Upper Bound & Zero-order & Partial & Part \\
\hline 1 & (Constant) & 10,217 & 10,240 & & & \\
& Age &,- 157 &,- 154 &,- 783 &,- 783 &,- 783 \\
\hline 2 & (Constant) & 10,305 & 10,327 & & & \\
& Age &,- 114 &,- 109 &,- 783 &,- 564 &,- 396 \\
& Mileage $(\mathrm{Km})$ &, 000 &, 000 &,- 712 &,- 358 &,- 223 \\
\hline
\end{tabular}

a. Dependent Variable: Ln price (EUR)

\section{Coefficients $^{\mathrm{a}}$}

\begin{tabular}{|ll|r|c|}
\hline \multicolumn{2}{|l|}{ Model } & \multicolumn{2}{|c|}{ Collinearity Statistics } \\
\cline { 3 - 4 } & & Tolerance & \multicolumn{1}{c|}{ VIF } \\
\hline 1 & (Constant) & & \\
& Age & 1,000 & 1,000 \\
\hline $2 \quad$ & (Constant) & & \\
& Age &, 500 & 2,001 \\
& Mileage $(\mathrm{Km})$ &, 500 & 2,001 \\
\hline
\end{tabular}

a. Dependent Variable: Ln price (EUR)

\section{Excluded Variables ${ }^{\mathrm{D}}$}

\begin{tabular}{|c|c|c|c|c|}
\hline Model & Beta In & $t$ & Sig. & $\begin{array}{c}\text { Partial } \\
\text { Correlation }\end{array}$ \\
\hline $1 \quad$ Mileage $(\mathrm{Km})$ &,$- 315^{\mathrm{a}}$ & $-50,315$ &, 000 &,- 358 \\
\hline
\end{tabular}

a. Predictors in the Model: (Constant), Age

b. Dependent Variable: Ln price (EUR)

Excluded Variables $^{\mathrm{D}}$

\begin{tabular}{|c|c|c|c|}
\hline \multirow[t]{2}{*}{ Model } & \multicolumn{3}{|c|}{ Collinearity Statistics } \\
\hline & Tolerance & VIF & $\begin{array}{l}\text { Minimum } \\
\text { Tolerance }\end{array}$ \\
\hline Mileage $(\mathrm{Km})$ &, 500 & 2,001 &, 500 \\
\hline
\end{tabular}

b. Dependent Variable: Ln price (EUR) 


\section{Coefficient Correlations $^{\mathrm{a}}$}

\begin{tabular}{|lll|r|r|}
\hline Model & & \multicolumn{1}{|c|}{ Age } & \multicolumn{1}{c|}{ Mileage $(\mathrm{Km})$} \\
\hline 1 & Correlations & Age & 1,000 & \\
\cline { 2 - 5 } & Covariances & Age & $8,856 \mathrm{E}-7$ & \\
\hline 2 & Correlations & Age & 1,000 &,- 707 \\
& & Mileage $(\mathrm{Km})$ &,- 707 & 1,000 \\
& & Age & $1,544 \mathrm{E}-6$ & $-4,852 \mathrm{E}-11$ \\
& Covariances & $-4,852 \mathrm{E}-11$ & $3,049 \mathrm{E}-15$ \\
& & Mileage $(\mathrm{Km})$ & & \\
\end{tabular}

a. Dependent Variable: Ln price (EUR)

Collinearity Diagnostics ${ }^{a}$

\begin{tabular}{|c|c|c|c|c|c|c|}
\hline \multirow[t]{2}{*}{ Model } & \multirow[t]{2}{*}{ Dimension } & \multirow[b]{2}{*}{ Eigenvalue } & \multirow[b]{2}{*}{ Condition Index } & \multicolumn{3}{|c|}{ Variance Proportions } \\
\hline & & & & (Constant) & Age & Mileage $(\mathrm{Km})$ \\
\hline \multirow[t]{2}{*}{$\overline{1}$} & 1 & 1,881 & 1,000 & ,06 & ,06 & \\
\hline & 2 & ,119 & 3,974 & 94 & ,94 & \\
\hline \multirow[t]{3}{*}{2} & 1 & 2,791 & 1,000 & 02 & 01 & 01 \\
\hline & -2 & ,141 & 4,442 & ,97 &, 10 & , 17 \\
\hline & 3 & ,067 & 6,435 & 01 & ,88 & ,82 \\
\hline
\end{tabular}

a. Dependent Variable: Ln price (EUR) 
Casewise Diagnostics $^{\mathrm{a}}$

\begin{tabular}{|c|c|c|c|c|}
\hline Case Number & Std. Residual & $\begin{array}{c}\text { Ln price } \\
\text { (EUR) }\end{array}$ & Predicted Value & Residual \\
\hline 9 & $-9,719$ & 5,70 & 9,0153 & $-3,31154$ \\
\hline 56 & $-4,026$ & 6,11 & 7,4809 & $-1,37170$ \\
\hline 57 & $-4,026$ & 6,11 & 7,4809 & $-1,37170$ \\
\hline 71 & $-4,070$ & 6,21 & 7,6014 & $-1,38680$ \\
\hline 72 & $-4,152$ & 6,21 & 7,6294 & $-1,41480$ \\
\hline 124 & $-3,148$ & 6,40 & 7,4696 & $-1,07267$ \\
\hline 125 & $-5,030$ & 6,40 & 8,1110 & $-1,71403$ \\
\hline 174 & $-3,722$ & 6,48 & 7,7451 & $-1,26808$ \\
\hline 199 & $-8,508$ & 6,51 & 9,4138 & $-2,89906$ \\
\hline 202 & $-3,314$ & 6,55 & 7,6803 & $-1,12926$ \\
\hline 203 & $-4,496$ & 6,55 & 8,0831 & $-1,53201$ \\
\hline 204 & $-4,116$ & 6,55 & 7,9536 & $-1,40256$ \\
\hline 239 & $-3,750$ & 6,62 & 7,8980 & $-1,27789$ \\
\hline 345 & $-3,821$ & 6,75 & 8,0472 & $-1,30197$ \\
\hline 455 & $-4,049$ & 6,90 & 8,2825 & $-1,37977$ \\
\hline 468 & $-3,695$ & 6,91 & 8,1666 & $-1,25888$ \\
\hline 469 & $-3,695$ & 6,91 & 8,1666 & $-1,25888$ \\
\hline-470 & $-5,021$ & 6,91 & 8,6187 & $-1,71091$ \\
\hline 471 & $-4,211$ & 6,91 & 8,3427 & $-1,43496$ \\
\hline 472 & $-5,937$ & 6,91 & 8,9308 & $-2,02307$ \\
\hline 473 & $-7,501$ & 6,91 & 9,4637 & $-2,55591$ \\
\hline 631 & $-3,741$ & 7,00 & 8,2779 & $-1,27479$ \\
\hline 692 & $-4,100$ & 7,09 & 8,4872 & $-1,39708$ \\
\hline 693 & $-4,280$ & 7,09 & 8,5483 & $-1,45825$ \\
\hline 815 & $-4,182$ & 7,13 & 8,5557 & $-1,42482$ \\
\hline 816 & $-4,182$ & 7,13 & 8,5557 & $-1,42482$ \\
\hline 908 & $-3,523$ & 7,17 & 8,3704 & $-1,20028$ \\
\hline 909 & $-3,105$ & 7,17 & 8,2280 & $-1,05791$ \\
\hline 958 & $-3,284$ & 7,21 & 8,3269 & $-1,11909$ \\
\hline 959 & $-4,209$ & 7,21 & 8,6419 & $-1,43407$ \\
\hline 996 & $-4,050$ & 7,24 & 8,6206 & $-1,37997$ \\
\hline 1083 & $-4,519$ & 7,31 & 8,8523 & $-1,53975$ \\
\hline 1116 & $-3,799$ & 7,31 & 8,6076 & $-1,29442$ \\
\hline 1117 & $-3,919$ & 7,31 & 8,6484 & $-1,33521$ \\
\hline 1118 & $-5,598$ & 7,31 & 9,2208 & $-1,90756$ \\
\hline
\end{tabular}




\begin{tabular}{|c|c|c|c|c|}
\hline 1119 & $-5,598$ & 7,31 & 9,2208 & $-1,90756$ \\
\hline 1120 & $-4,571$ & 7,31 & 8,8708 & $-1,55755$ \\
\hline 1466 & $-3,415$ & 7,44 & 8,6021 & $-1,16368$ \\
\hline 1467 & $-3,415$ & 7,44 & 8,6021 & $-1,16368$ \\
\hline 1468 & $-4,000$ & 7,44 & 8,8012 & $-1,36284$ \\
\hline 1611 & $-3,385$ & 7,49 & 8,6484 & $-1,15345$ \\
\hline 1788 & $-3,271$ & 7,55 & 8,6642 & $-1,11462$ \\
\hline 1979 & $-3,319$ & 7,60 & 8,7318 & $-1,13088$ \\
\hline 1980 & $-3,319$ & 7,60 & 8,7318 & $-1,13088$ \\
\hline 1982 & $-3,596$ & 7,60 & 8,8263 & $-1,22536$ \\
\hline 1983 & $-3,596$ & 7,60 & 8,8263 & $-1,22536$ \\
\hline 2190 & $-3,342$ & 7,63 & 8,7644 & $-1,13877$ \\
\hline 2191 & $-3,342$ & 7,63 & 8,7644 & $-1,13877$ \\
\hline 2192 & $-3,204$ & 7,64 & 8,7308 & $-1,09167$ \\
\hline 2196 & $-3,412$ & 7,65 & 8,8124 & $-1,16275$ \\
\hline 2238 & $-3,416$ & 7,67 & 8,8373 & $-1,16410$ \\
\hline 2275 & $-3,963$ & 7,70 & 9,0467 & $-1,35052$ \\
\hline 2513 & $-3,214$ & 7,74 & 8,8359 & $-1,09522$ \\
\hline 2514 & $-3,803$ & 7,74 & 9,0366 & $-1,29590$ \\
\hline 2515 & $-4,024$ & 7,74 & 9,1116 & $-1,37099$ \\
\hline 2662 & $-3,287$ & 7,78 & 8,9032 & $-1,12002$ \\
\hline 2768 & $-3,192$ & 7,82 & 8,9078 & $-1,08773$ \\
\hline 2853 & $-3,126$ & 7,82 & 8,8893 & $-1,06529$ \\
\hline 2854 & $-4,763$ & 7,82 & 9,4470 & $-1,62297$ \\
\hline 2855 & $-5,287$ & 7,82 & 9,6255 & $-1,80141$ \\
\hline 3370 & $-3,162$ & 7,90 & 8,9782 & $-1,07755$ \\
\hline 3470 & $-3,145$ & 7,92 & 8,9911 & $-1,07172$ \\
\hline 3471 & $-3,145$ & 7,92 & 8,9911 & $-1,07172$ \\
\hline 3745 & $-4,814$ & 7,97 & 9,6128 & $-1,64031$ \\
\hline 3948 & $-3,485$ & 8,00 & 9,1904 & $-1,18733$ \\
\hline 4018 & 3,581 & 8,01 & 6,7860 & 1,22033 \\
\hline 4019 & 3,581 & 8,01 & 6,7860 & 1,22033 \\
\hline 4090 & $-3,216$ & 8,01 & 9,1023 & $-1,09593$ \\
\hline 4091 & $-3,216$ & 8,01 & 9,1023 & $-1,09593$ \\
\hline 4099 & $-3,162$ & 8,01 & 9,0838 & $-1,07748$ \\
\hline 4367 & $-3,462$ & 8,07 & 9,2507 & $-1,17976$ \\
\hline 4530 & $-3,145$ & 8,09 & 9,1579 & $-1,07154$ \\
\hline 4531 & $-3,036$ & 8,09 & 9,1209 & $-1,03452$ \\
\hline 4961 & 3,558 & 8,16 & 6,9482 & 1,21235 \\
\hline
\end{tabular}




\begin{tabular}{|c|c|c|c|c|}
\hline 4962 & 3,558 & 8,16 & 6,9482 & 1,21235 \\
\hline 5363 & $-3,047$ & 8,17 & 9,2131 & $-1,03835$ \\
\hline 5401 & $-3,103$ & 8,19 & 9,2460 & $-1,05730$ \\
\hline 5561 & $-3,157$ & 8,22 & 9,2918 & $-1,07575$ \\
\hline 6332 & 3,199 & 8,29 & 7,2040 & 1,09002 \\
\hline 6333 & 3,199 & 8,29 & 7,2040 & 1,09002 \\
\hline 6981 & 4,263 & 8,38 & 6,9253 & 1,45259 \\
\hline 7937 & 4,213 & 8,48 & 7,0407 & 1,43570 \\
\hline 8707 & 5,108 & 8,52 & 6,7765 & 1,74066 \\
\hline 9086 & 3,540 & 8,56 & 7,3502 & 1,20624 \\
\hline 9467 & 6,299 & 8,59 & 6,4480 & 2,14620 \\
\hline 9468 & 6,271 & 8,59 & 6,4572 & 2,13693 \\
\hline 9639 & $-3,251$ & 8,61 & 9,7185 & $-1,10783$ \\
\hline 9694 & 3,959 & 8,61 & 7,2636 & 1,34893 \\
\hline 9695 & 3,959 & 8,61 & 7,2636 & 1,34893 \\
\hline 13529 & 3,810 & 8,84 & 7,5410 & 1,29823 \\
\hline 14314 & 3,164 & 8,85 & 7,7754 & 1,07826 \\
\hline 15152 & 3,343 & 8,92 & 7,7769 & 1,13909 \\
\hline 16380 & 4,033 & 8,96 & 7,5875 & 1,37438 \\
\hline 16388 & 3,230 & 8,96 & 7,8613 & 1,10063 \\
\hline 16964 & 3,309 & 8,98 & 7,8534 & 1,12752 \\
\hline 18558 & 5,230 & 9,05 & 7,2658 & 1,78205 \\
\hline 19692 & 4,252 & 9,09 & 7,6393 & 1,44885 \\
\hline 20089 & 6,844 & 9,10 & 6,7674 & 2,33202 \\
\hline 22830 & 5,588 & 9,21 & 7,3013 & 1,90406 \\
\hline 22831 & 5,588 & 9,21 & 7,3013 & 1,90406 \\
\hline 23516 & 6,681 & 9,21 & 6,9340 & 2,27638 \\
\hline 23517 & 3,405 & 9,21 & 8,0500 & 1,16029 \\
\hline 24146 & 4,185 & 9,26 & 7,8331 & 1,42603 \\
\hline 24718 & 3,121 & 9,28 & 8,2193 & 1,06336 \\
\hline 27275 & 4,174 & 9,39 & 7,9697 & 1,42216 \\
\hline 28149 & 3,692 & 9,43 & 8,1756 & 1,25787 \\
\hline 28623 & 5,985 & 9,44 & 7,3980 & 2,03946 \\
\hline 30021 & 3,506 & 9,51 & 8,3160 & 1,19448 \\
\hline 30022 & 3,506 & 9,51 & 8,3160 & 1,19448 \\
\hline 30981 & 4,494 & 9,54 & 8,0119 & 1,53131 \\
\hline 31357 & 3,681 & 9,55 & 8,2927 & 1,25413 \\
\hline 33444 & 3,317 & 9,65 & 8,5185 & 1,13011 \\
\hline 33940 & 3,903 & 9,67 & 8,3443 & 1,32976 \\
\hline
\end{tabular}




\begin{tabular}{|c|c|c|c|c|}
\hline 34461 & 4,687 & 9,68 & 8,0831 & 1,59722 \\
\hline 34855 & 3,527 & 9,71 & 8,5093 & 1,20186 \\
\hline 36565 & 4,867 & 9,80 & 8,1370 & 1,65836 \\
\hline 37037 & 4,673 & 9,83 & 8,2331 & 1,59239 \\
\hline 37038 & 4,673 & 9,83 & 8,2331 & 1,59239 \\
\hline 37039 & 4,379 & 9,83 & 8,3333 & 1,49220 \\
\hline 37040 & 4,379 & 9,83 & 8,3333 & 1,49220 \\
\hline 37043 & 3,623 & 9,83 & 8,5909 & 1,23463 \\
\hline 39212 & 3,498 & 10,00 & 8,8070 & 1,19185 \\
\hline 39510 & 4,553 & 10,04 & 8,4863 & 1,55125 \\
\hline 40084 & 3,128 & 10,09 & 9,0284 & 1,06574 \\
\hline 40437 & 3,838 & 10,13 & 8,8189 & 1,30769 \\
\hline 41162 & 3,843 & 10,23 & 8,9247 & 1,30955 \\
\hline 41163 & 3,204 & 10,23 & 9,1428 & 1,09177 \\
\hline 41808 & 3,346 & 10,37 & 9,2335 & 1,14003 \\
\hline 42070 & 3,860 & 10,46 & 9,1450 & 1,31527 \\
\hline 42127 & 3,045 & 10,46 & 9,4256 & 1,03755 \\
\hline 42486 & 3,144 & 10,61 & 9,5378 & 1,07126 \\
\hline 42624 & 3,525 & 10,71 & 9,5133 & 1,20094 \\
\hline 42700 & 4,474 & 10,78 & 9,2515 & 1,52433 \\
\hline
\end{tabular}

a. Dependent Variable: Ln price (EUR)

Residuals Statistics ${ }^{a}$

\begin{tabular}{|l|r|r|r|r|r|}
\hline & Minimum & Maximum & Mean & Std. Deviation & N \\
\hline Predicted Value & 6,4480 & 10,3154 & 9,3721 &, 47827 & 17171 \\
Residual & $-3,31154$ & 2,33202 &, 00000 &, 34072 & 17171 \\
Std. Predicted Value & $-6,114$ & 1,972 &, 000 & 1,000 & 17171 \\
Std. Residual & $-9,719$ & 6,844 &, 000 & 1,000 & 17171 \\
\hline
\end{tabular}

a. Dependent Variable: Ln price (EUR) 


\section{Charts}

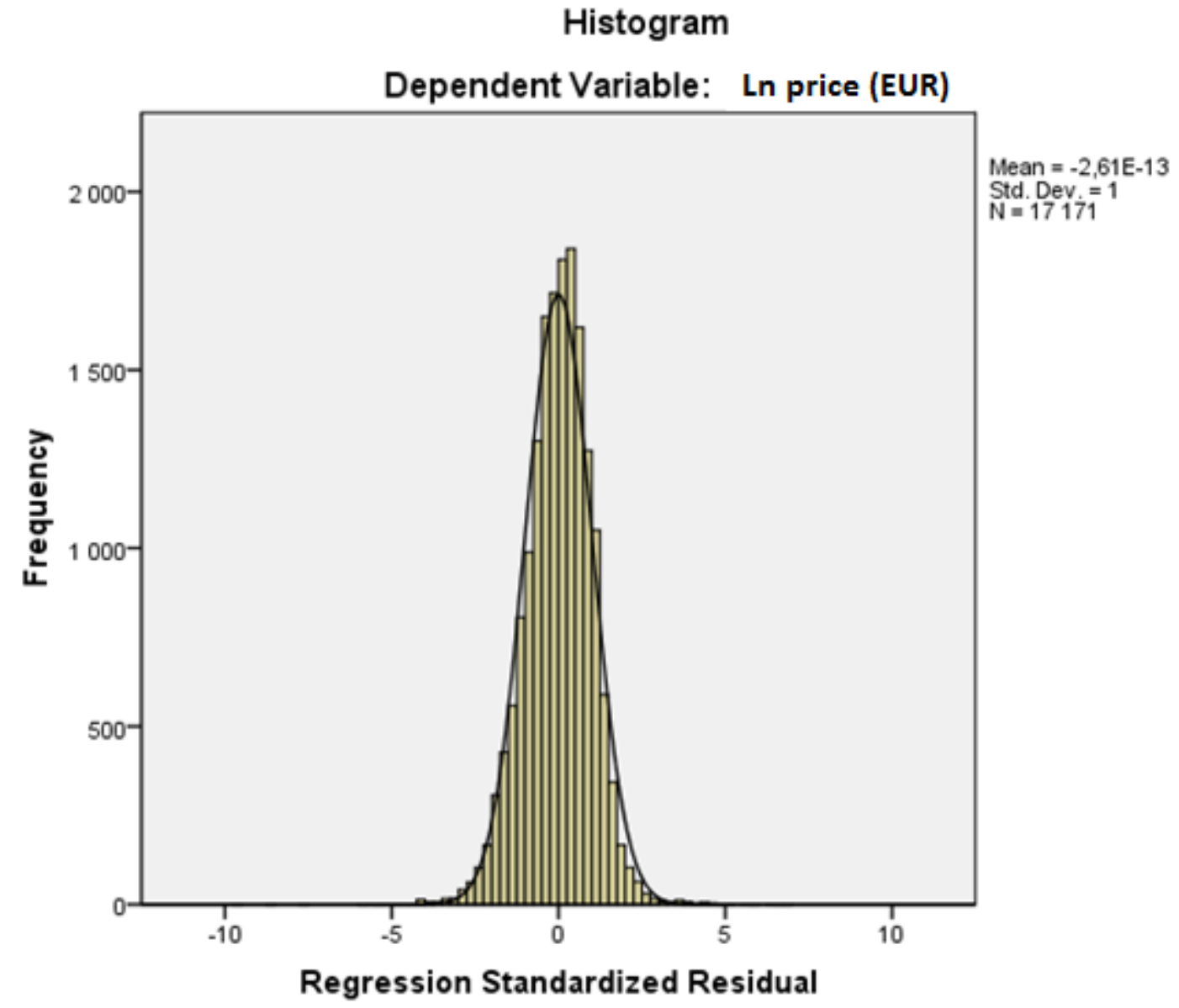




\section{Normal P-P Plot of Regression Standardized Residual}

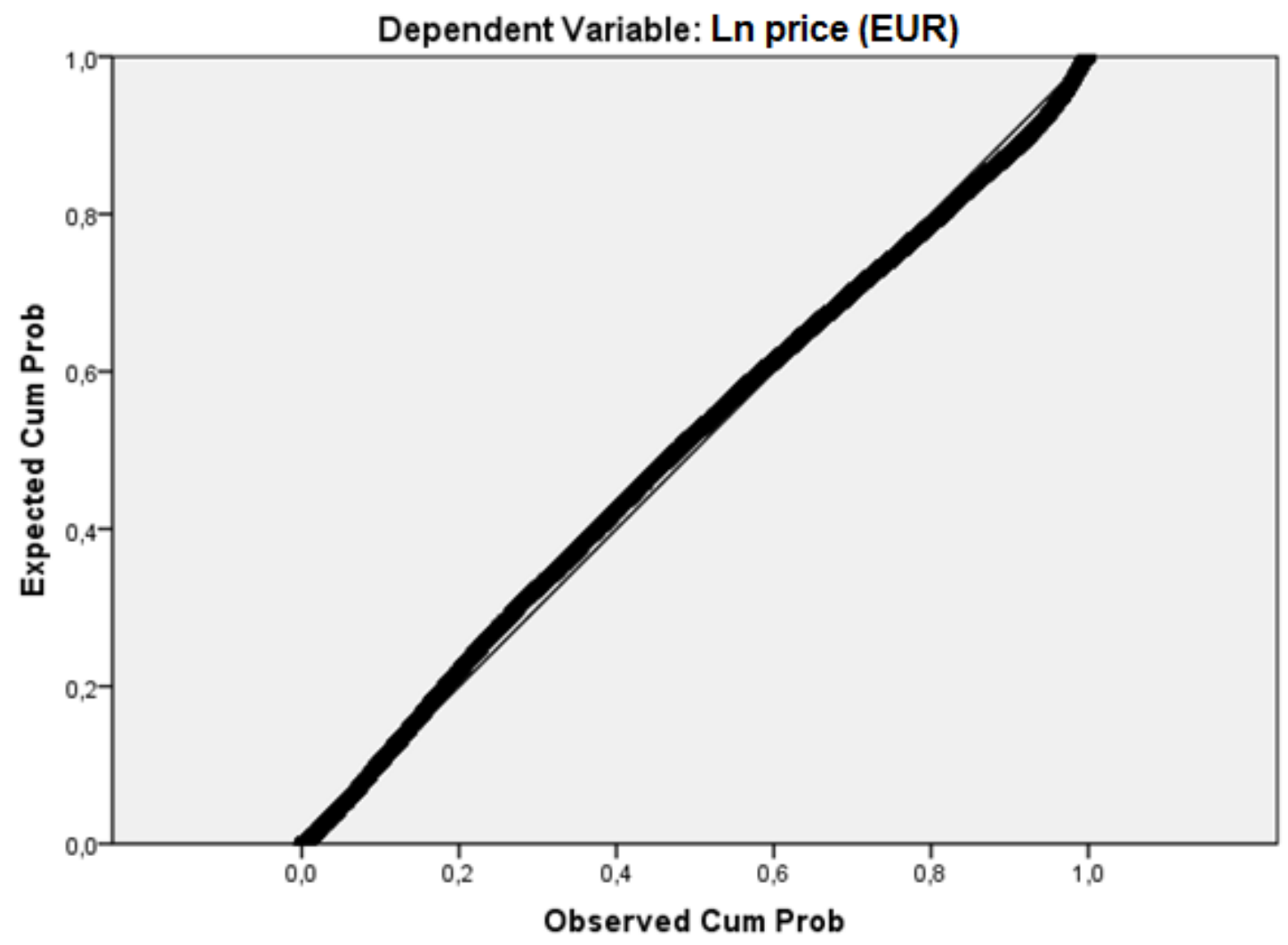

Partial Regression Plot

Dependent Variable: Ln price (EUR)

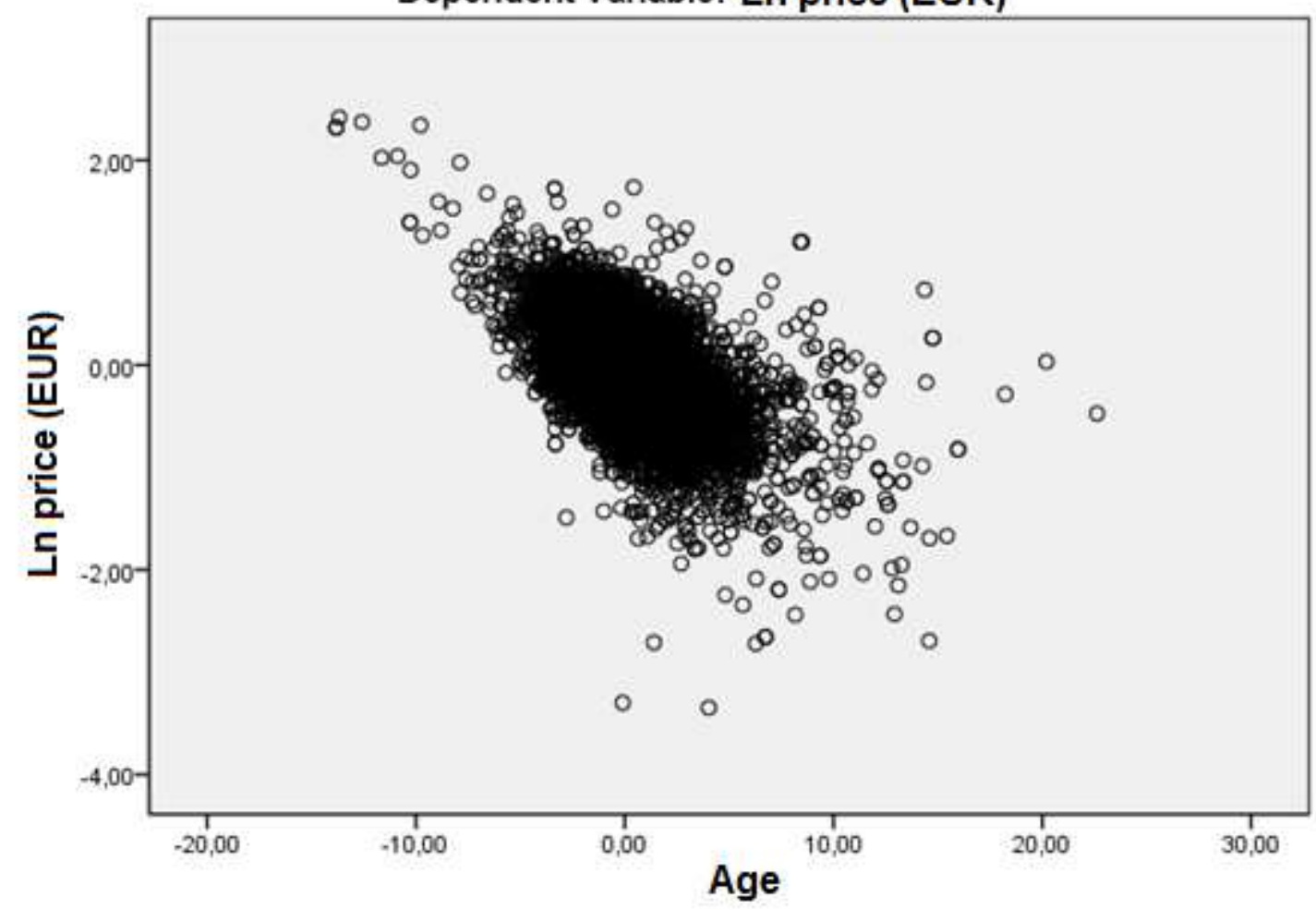




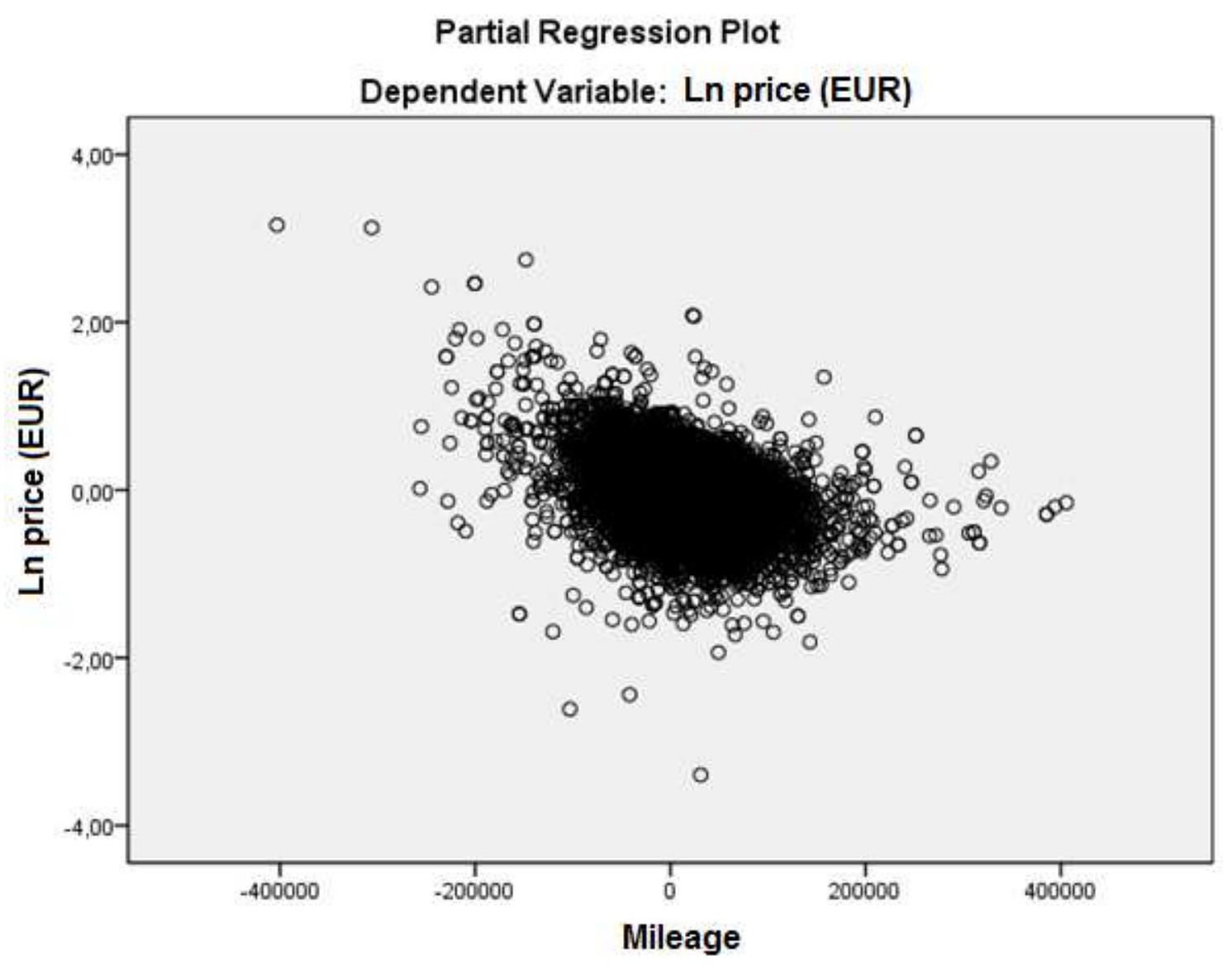




\section{Regression 2}

Descriptive Statistics

\begin{tabular}{|l|r|r|r|}
\hline & \multicolumn{1}{|c|}{ Mean } & Std. Deviation & \multicolumn{1}{l|}{$\mathrm{N}$} \\
\hline Ln price (EUR) & 10,0280 &, 60231 & 2635 \\
Age & 4,8814 & 3,47796 & 2635 \\
Mileage $(\mathrm{Km})$ & 108867,21 & 68886,919 & 2635 \\
\hline
\end{tabular}

\section{Correlations}

\begin{tabular}{|c|c|c|c|c|}
\hline & & $\begin{array}{c}\text { Ln price } \\
\text { (EUR) }\end{array}$ & Age & Mileage $(\mathrm{Km})$ \\
\hline \multirow[t]{3}{*}{ Pearson Correlation } & Ln price (EUR) & 1,000 &,- 725 &,- 665 \\
\hline & Age &,- 725 & 1,000 &, 553 \\
\hline & Mileage $(\mathrm{Km})$ &,- 665 & ,553 & 1,000 \\
\hline \multirow[t]{3}{*}{ Sig. (1-tailed) } & Ln price (EUR) & & ,000 &, 000 \\
\hline & Age &, 000 & & ,000 \\
\hline & Mileage $(\mathrm{Km})$ & ,000 & ,000 & \\
\hline \multirow[t]{3}{*}{$\mathrm{N}$} & Ln price (EUR) & 2635 & 2635 & 2635 \\
\hline & Age & 2635 & 2635 & 2635 \\
\hline & Mileage $(\mathrm{Km})$ & 2635 & 2635 & 2635 \\
\hline
\end{tabular}


Variables Entered/Removed ${ }^{\text {a }}$

\begin{tabular}{|c|c|c|c|}
\hline Model & $\begin{array}{l}\text { Variables } \\
\text { Entered }\end{array}$ & $\begin{array}{l}\text { Variables } \\
\text { Removed }\end{array}$ & Method \\
\hline$\overline{1}$ & Age & & $\begin{array}{l}\text { Stepwise } \\
\text { (Criteria: } \\
\text { Probability-of-F- } \\
\text { to-enter <= } \\
\text {,050, } \\
\text { Probability-of-F- } \\
\text { to-remove >= } \\
, 100) \text {. }\end{array}$ \\
\hline 2 & Mileage $(\mathrm{Km})$ & & $\begin{array}{l}\text { Stepwise } \\
\text { (Criteria: } \\
\text { Probability-of-F- } \\
\text { to-enter <= } \\
, 050, \\
\text { Probability-of-F- } \\
\text { to-remove >= } \\
\text {,100). }\end{array}$ \\
\hline
\end{tabular}

a. Dependent Variable: Ln price (EUR)

Model Summaryc

\begin{tabular}{|l|r|r|r|r|}
\hline Model & $\mathrm{R}$ & $\mathrm{R}$ Square & \multicolumn{1}{c|}{$\begin{array}{c}\text { Adjusted R } \\
\text { Square }\end{array}$} & $\begin{array}{c}\text { Std. Error of the } \\
\text { Estimate }\end{array}$ \\
\hline 1 &, $725^{\mathrm{a}}$ &, 526 &, 526 &, 41478 \\
2 &, $791^{\mathrm{b}}$ &, 626 &, 626 &, 36837 \\
\hline
\end{tabular}
a. Predictors: (Constant), Age
b. Predictors: (Constant), Age, Mileage (Km)
c. Dependent Variable: Ln price (EUR)

Model Summaryc

\begin{tabular}{|l|r|r|r|r|r|r|}
\hline Model & \multicolumn{7}{|c|}{ Change Statistics } & \multirow{2}{*}{ Durbin-Watson } \\
\cline { 2 - 7 } & $\begin{array}{l}\text { R Square } \\
\text { Change }\end{array}$ & F Change & df1 & df2 & Sig. F Change & Durnen \\
\hline 1 &, 526 & 2921,015 & 1 & 2633 &, 000 & \\
2 &, 100 & 706,282 & 1 & 2632 &, 000 &, 764 \\
\hline
\end{tabular}

c. Dependent Variable: Ln price (EUR) 
ANOVA $^{\mathrm{C}}$

\begin{tabular}{|rl|r|r|r|r|r|}
\hline Model & & Sum of Squares & df & Mean Square & F & Sig. \\
\hline 1 & Regression & 502,549 & 1 & 502,549 & 2921,015 &, $000^{\mathrm{a}}$ \\
& Residual & 452,997 & 2633 &, 172 & & \\
& Total & 955,546 & 2634 & & & \\
& Regression & 598,389 & 2 & 299,195 & 2204,864 &, $000^{\circ}$ \\
& Residual & 357,156 & 2632 &, 136 & & \\
& & 955,546 & 2634 & & & \\
& Total & & & & & \\
\end{tabular}
a. Predictors: (Constant), Age
b. Predictors: (Constant), Age, Mileage (Km)
c. Dependent Variable: Ln price (EUR)

\section{Coefficients $^{a}$}

\begin{tabular}{|c|c|c|c|c|c|c|}
\hline Model & & \multicolumn{2}{|c|}{ Unstandardized Coefficients } & \multirow{2}{*}{$\begin{array}{l}\text { Standardized } \\
\text { Coefficients }\end{array}$} & \multirow[b]{2}{*}{$t$} & \multirow[b]{2}{*}{ Sig. } \\
\hline & & $B$ & Std. Error & & & \\
\hline & (Constant) & 10,641 & ,014 & & 764,065 & 000 \\
\hline & Age &,- 126 & ,002 &,- 725 & $-54,046$ & ,000 \\
\hline \multirow[t]{3}{*}{2} & (Constant) & 10,825 & ,014 & & 763,596 &, 000 \\
\hline & Age &,- 089 &, 002 &,- 515 & $-36,004$ & 000 \\
\hline & Mileage $(\mathrm{Km})$ & $-3,324 \mathrm{E}-6$ &, 000 &,- 380 & $-26,576$ &, 000 \\
\hline
\end{tabular}

a. Dependent Variable: Ln price (EUR)

Coefficients $^{\mathrm{a}}$

\begin{tabular}{|ll|r|r|r|r|r|}
\hline Model & \multicolumn{2}{|c|}{$95,0 \%$ Confidence Interval for B } & \multicolumn{2}{|c|}{ Correlations } \\
\cline { 3 - 7 } & & Lower Bound & Upper Bound & Zero-order & Partial & Part \\
\hline 1 & (Constant) & 10,614 & 10,668 & & & \\
& Age &,- 130 &,- 121 &,- 725 &,- 725 &,- 725 \\
\hline 2 & (Constant) & 10,797 & 10,853 & & & \\
& Age &,- 094 &,- 084 &,- 725 &,- 574 &,- 429 \\
& Mileage $(\mathrm{Km})$ &, 000 &, 000 &,- 665 &,- 460 &,- 317 \\
\hline
\end{tabular}

a. Dependent Variable: Ln price (EUR) 
Coefficients $^{\mathrm{a}}$

\begin{tabular}{|ll|r|r|}
\hline \multicolumn{2}{|l|}{ Model } & \multicolumn{2}{|c|}{ Collinearity Statistics } \\
\cline { 3 - 4 } & & Tolerance & \multicolumn{1}{c|}{ VIF } \\
\hline 1 & (Constant) & 1,000 & 1,000 \\
\hline 2 & Age & & \\
& (Constant) &, 694 & 1,441 \\
& Age &, 694 & 1,441 \\
& Mileage $(\mathrm{Km})$ & &
\end{tabular}

a. Dependent Variable: Ln price (EUR)

\section{Excluded Variables $^{\mathrm{b}}$}

\begin{tabular}{|c|c|c|c|c|}
\hline Model & Beta In & $\mathrm{t}$ & Sig. & $\begin{array}{c}\text { Partial } \\
\text { Correlation }\end{array}$ \\
\hline $1 \quad$ Mileage $(\mathrm{Km})$ &,$- 380^{\mathrm{a}}$ & $-26,576$ & ,000 &,- 460 \\
\hline
\end{tabular}

a. Predictors in the Model: (Constant), Age

b. Dependent Variable: Ln price (EUR)

Excluded Variables ${ }^{\text {b }}$

\begin{tabular}{|c|c|c|c|}
\hline \multirow[t]{2}{*}{ Model } & \multicolumn{3}{|c|}{ Collinearity Statistics } \\
\hline & Tolerance & VIF & $\begin{array}{l}\text { Minimum } \\
\text { Tolerance }\end{array}$ \\
\hline Mileage $(\mathrm{Km})$ & ,694 & 1,441 & ,694 \\
\hline
\end{tabular}

b. Dependent Variable: Ln price (EUR)

\section{Coefficient Correlations $^{a}$}

\begin{tabular}{|lll|r|r|}
\hline Model & & \multicolumn{1}{c|}{ Age } & \multicolumn{1}{c|}{ Mileage $(\mathrm{Km})$} \\
\hline 1 & Correlations & Age & 1,000 & \\
\cline { 2 - 5 } & Covariances & Age & $5,400 \mathrm{E}-6$ & \\
\hline 2 & Correlations & Age & 1,000 &,- 553 \\
& & Mileage $(\mathrm{Km})$ &,- 553 & 1,000 \\
\cline { 3 - 5 } & Covariances & Age & $6,136 \mathrm{E}-6$ & $-1,713 \mathrm{E}-10$ \\
& & Mileage $(\mathrm{Km})$ & $-1,713 \mathrm{E}-10$ & $1,564 \mathrm{E}-14$ \\
\hline
\end{tabular}

a. Dependent Variable: Ln price (EUR) 


\section{Collinearity Diagnostics ${ }^{a}$}

\begin{tabular}{|c|c|c|c|c|c|c|}
\hline \multirow[t]{2}{*}{ Model } & \multirow[t]{2}{*}{ Dimension } & \multirow[b]{2}{*}{ Eigenvalue } & \multirow[b]{2}{*}{ Condition Index } & \multicolumn{3}{|c|}{ Variance Proportions } \\
\hline & & & & (Constant) & Age & Mileage (Km) \\
\hline \multirow[t]{2}{*}{1} & 1 & 1,814 & 1,000 & ,09 & ,09 & \\
\hline & 2 & , 186 & 3,127 & ,91 & ,91 & \\
\hline \multirow[t]{3}{*}{2} & 1 & 2,680 & 1,000 & ,03 & ,03 & ,03 \\
\hline & -2 & , 187 & 3,787 & ,80 &, 50 & ,02 \\
\hline & 3 & ,133 & 4,483 & ,17 & ,47 & ,96 \\
\hline
\end{tabular}

a. Dependent Variable: Ln price (EUR) 
Casewise Diagnostics $^{a}$

\begin{tabular}{|c|c|c|c|c|}
\hline Case Number & Std. Residual & $\begin{array}{c}\text { Ln price } \\
\text { (EUR) }\end{array}$ & Predicted Value & Residual \\
\hline 23214 & $-10,036$ & 6,68 & 10,3815 & $-3,69685$ \\
\hline 23216 & $-5,349$ & 7,24 & 9,2146 & $-1,97032$ \\
\hline 23217 & $-5,349$ & 7,24 & 9,2146 & $-1,97032$ \\
\hline 23218 & $-4,696$ & 7,28 & 9,0094 & $-1,73005$ \\
\hline 23219 & $-3,391$ & 7,31 & 8,5625 & $-1,24926$ \\
\hline 23220 & $-3,391$ & 7,31 & 8,5625 & $-1,24926$ \\
\hline 23221 & $-3,753$ & 7,47 & 8,8497 & $-1,38232$ \\
\hline 23222 & $-3,142$ & 7,52 & 8,6802 & $-1,15725$ \\
\hline 23229 & $-3,013$ & 7,82 & 8,9338 & $-1,10975$ \\
\hline 23230 & $-3,013$ & 7,82 & 8,9338 & $-1,10975$ \\
\hline 23231 & $-3,866$ & 7,82 & 9,2481 & $-1,42407$ \\
\hline 23234 & $-3,529$ & 8,07 & 9,3707 & $-1,29981$ \\
\hline 23242 & $-3,347$ & 8,16 & 9,3936 & $-1,23306$ \\
\hline 23243 & $-4,419$ & 8,16 & 9,7882 & $-1,62773$ \\
\hline 23256 & $-3,152$ & 8,34 & 9,5040 & $-1,16119$ \\
\hline 23327 & $-3,014$ & 8,90 & 10,0060 & $-1,11040$ \\
\hline 23386 & 4,710 & 9,10 & 7,3643 & 1,73510 \\
\hline 23412 & $-3,286$ & 9,18 & 10,3882 & $-1,21034$ \\
\hline 23421 & 5,287 & 9,21 & 7,2617 & 1,94764 \\
\hline 23422 & 5,287 & 9,21 & 7,2617 & 1,94764 \\
\hline 23509 & 4,945 & 9,39 & 7,5670 & 1,82151 \\
\hline 23591 & 5,601 & 9,51 & 7,4473 & 2,06314 \\
\hline 23777 & 3,209 & 9,65 & 8,4665 & 1,18209 \\
\hline 23778 & 3,209 & 9,65 & 8,4665 & 1,18209 \\
\hline 23782 & 4,334 & 9,65 & 8,0520 & 1,59656 \\
\hline 25844 & 3,910 & 11,51 & 10,0726 & 1,44031 \\
\hline 25845 & 3,201 & 11,51 & 10,3338 & 1,17914 \\
\hline 25847 & 3,220 & 11,51 & 10,3268 & 1,18615 \\
\hline
\end{tabular}

a. Dependent Variable: Ln price (EUR)

Residuals Statistics ${ }^{a}$

\begin{tabular}{|l|r|r|r|r|r|}
\hline & Minimum & Maximum & Mean & Std. Deviation & N \\
\hline Predicted Value & 7,2007 & 10,8243 & 10,0280 &, 47663 & 2635 \\
Residual & $-3,69685$ & 2,06314 &, 00000 &, 36823 & 2635 \\
Std. Predicted Value & $-5,932$ & 1,671 &, 000 & 1,000 & 2635 \\
Std. Residual & $-10,036$ & 5,601 &, 000 & 1,000 & 2635 \\
\hline
\end{tabular}

a. Dependent Variable: Ln price (EUR) 


\section{Charts}

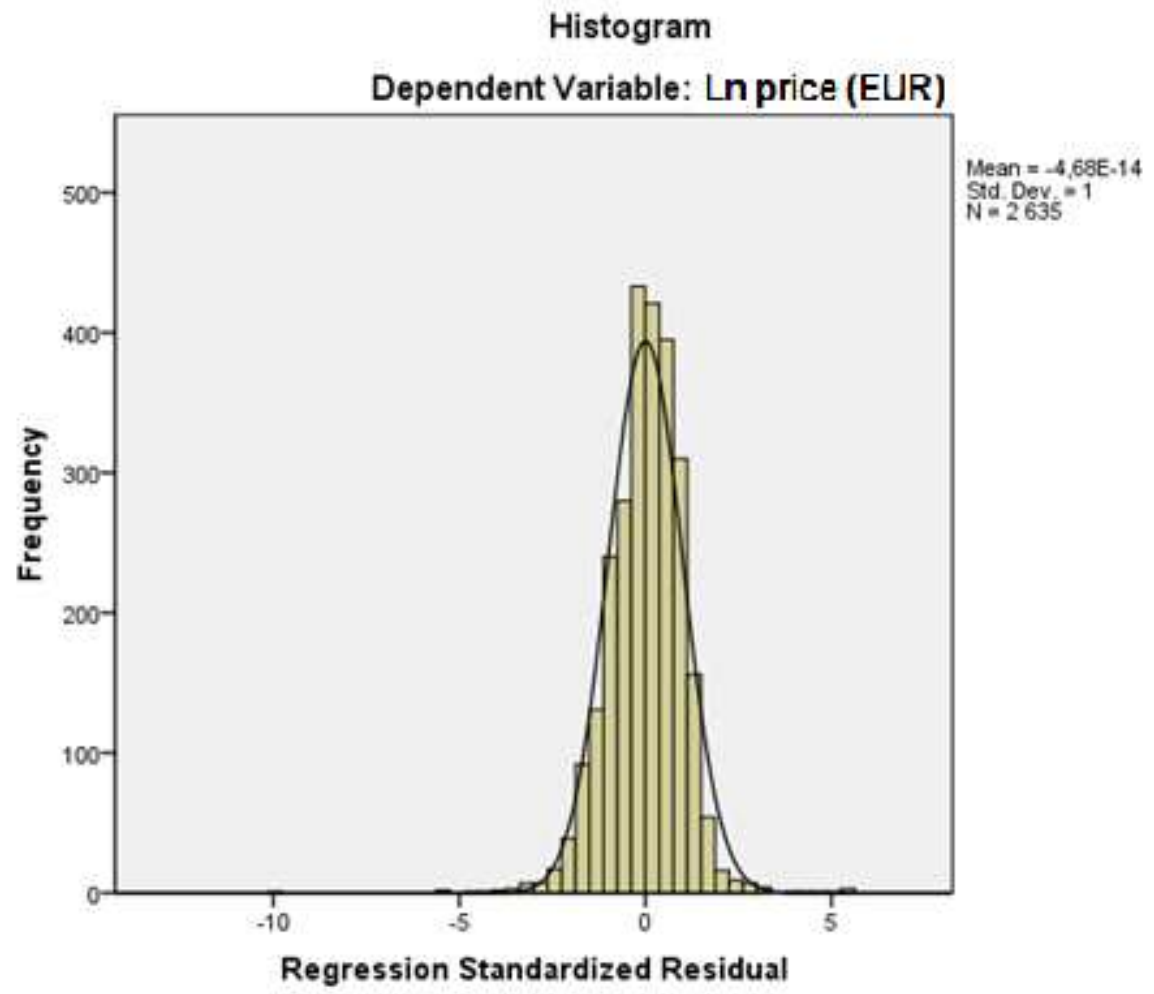

Normal P-P Plot of Regression Standardized Residual

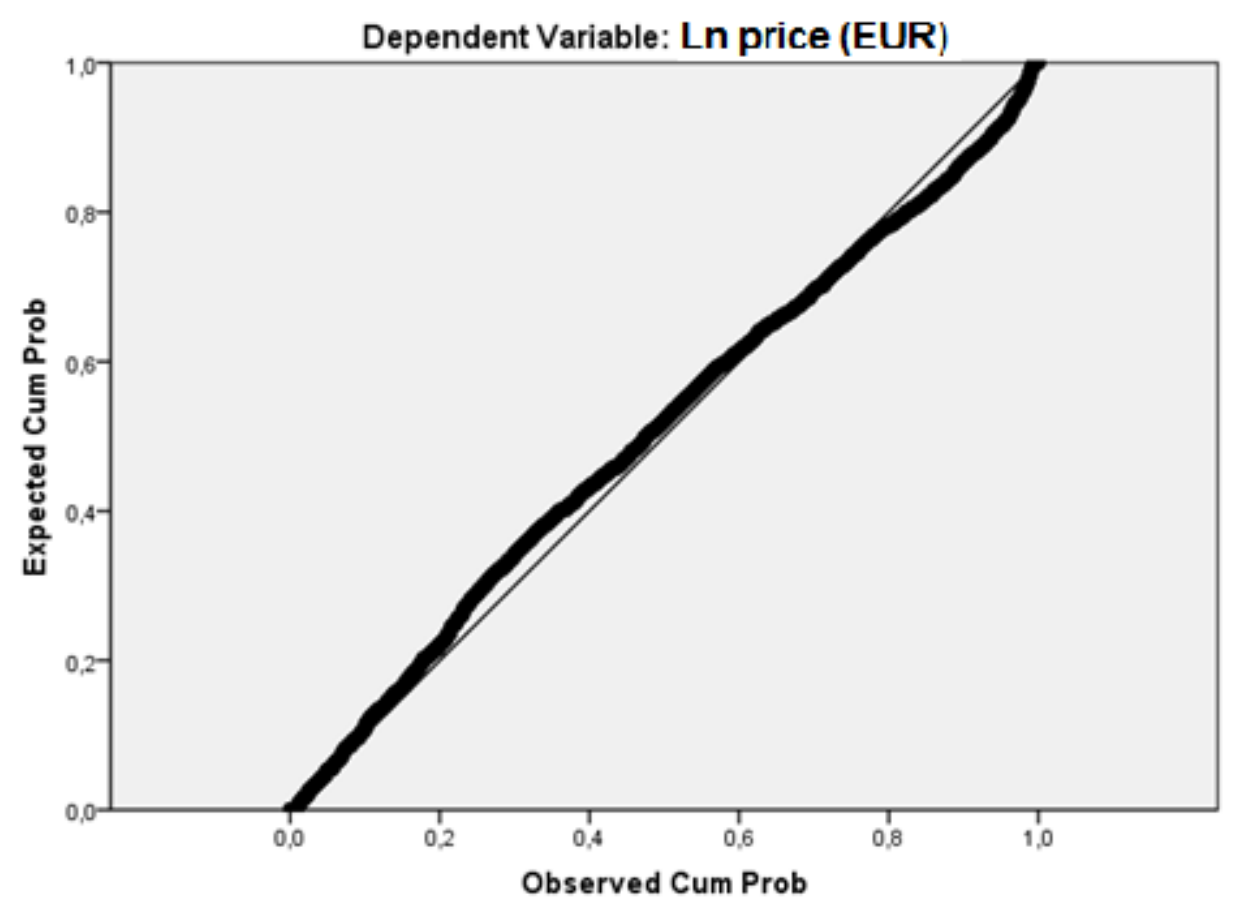



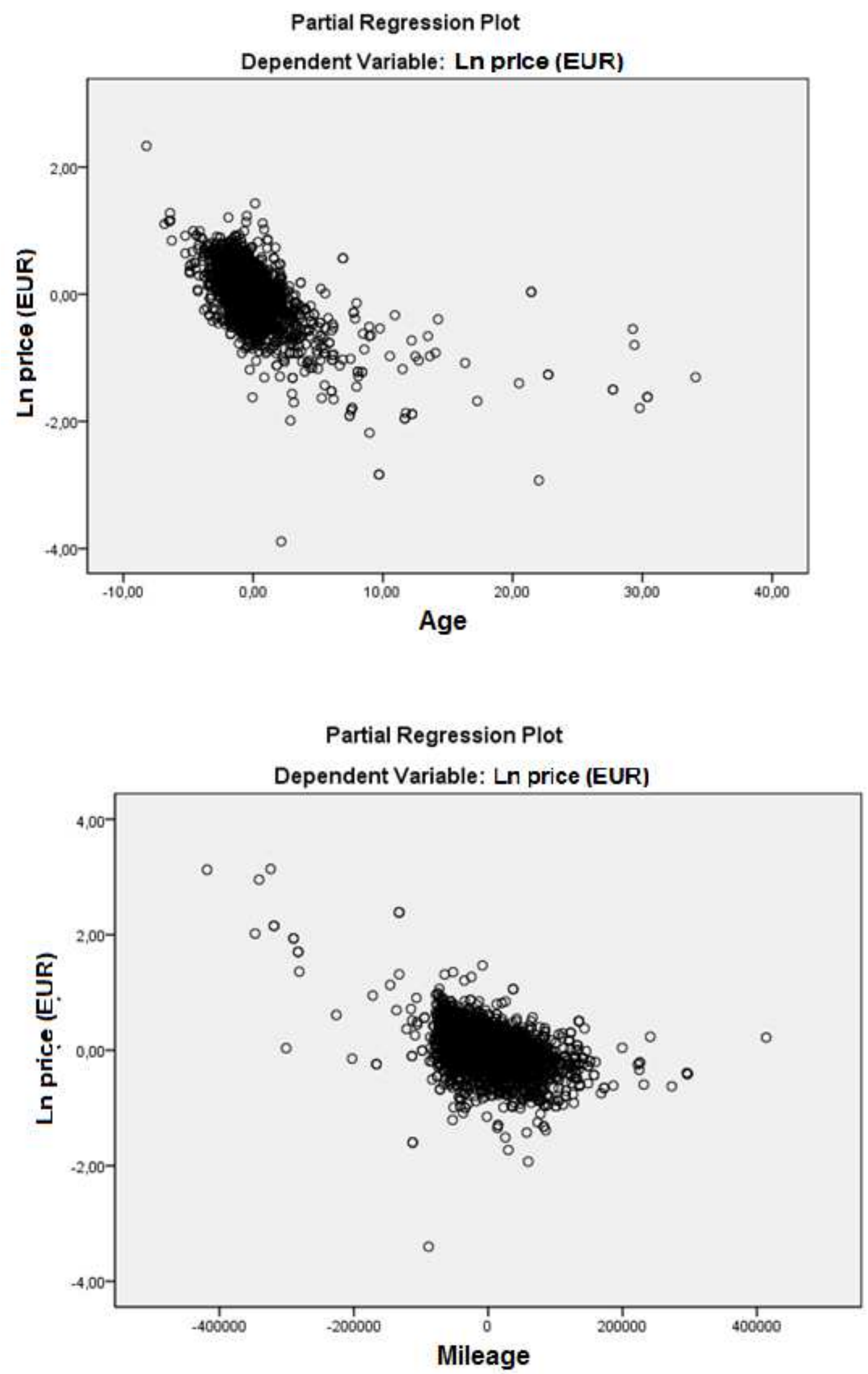


\section{Regression 3}

Descriptive Statistics

\begin{tabular}{|l|r|r|r|}
\hline & \multicolumn{1}{|c|}{ Mean } & Std. Deviation & \multicolumn{1}{|c|}{ N } \\
\hline Ln price (EUR) & 10,2243 &, 68669 & 298 \\
Age & 5,5043 & 4,34789 & 298 \\
Mileage $(\mathrm{Km})$ & 111664,53 & 77100,054 & 298 \\
\hline
\end{tabular}

\section{Correlations}

\begin{tabular}{|c|c|c|c|c|}
\hline & & $\begin{array}{l}\text { Ln price } \\
\text { (EUR) }\end{array}$ & Age & Mileage (Km) \\
\hline \multirow[t]{3}{*}{ Pearson Correlation } & Ln price (EUR) & 1,000 &,- 831 &,- 763 \\
\hline & Age &,- 831 & 1,000 & ,602 \\
\hline & Mileage (Km) &,- 763 & ,602 & 1,000 \\
\hline \multirow[t]{3}{*}{ Sig. (1-tailed) } & Ln price (EUR) & &, 000 &, 000 \\
\hline & Age & ,000 & & ,000 \\
\hline & Mileage $(\mathrm{Km})$ & ,000 & ,000 & \\
\hline \multirow[t]{3}{*}{$\mathrm{N}$} & Ln price (EUR) & 298 & 298 & 298 \\
\hline & Age & 298 & 298 & 298 \\
\hline & Mileage $(\mathrm{Km})$ & 298 & 298 & 298 \\
\hline
\end{tabular}

Variables Entered/Removed $^{\mathrm{a}}$

\begin{tabular}{|c|c|c|c|}
\hline Model & $\begin{array}{l}\text { Variables } \\
\text { Entered }\end{array}$ & $\begin{array}{l}\text { Variables } \\
\text { Removed }\end{array}$ & Method \\
\hline 1 & Age & & $\begin{array}{l}\text { Stepwise } \\
\text { (Criteria: } \\
\text { Probability-of-F- } \\
\text { to-enter <= } \\
\text {,050, } \\
\text { Probability-of-F- } \\
\text { to-remove >= } \\
, 100) \text {. }\end{array}$ \\
\hline 2 & Mileage $(\mathrm{Km})$ & & $\begin{array}{l}\text { Stepwise } \\
\text { (Criteria: } \\
\text { Probability-of-F- } \\
\text { to-enter <= } \\
, 050, \\
\text { Probability-of-F- } \\
\text { to-remove >= } \\
\text {,100). }\end{array}$ \\
\hline
\end{tabular}

a. Dependent Variable: Ln price (EUR) 
Model Summary $^{\mathrm{c}}$

\begin{tabular}{|l|r|r|r|r|}
\hline Model & $\mathrm{R}$ & $\mathrm{R}$ Square & \multicolumn{1}{c|}{$\begin{array}{c}\text { Adjusted R } \\
\text { Square }\end{array}$} & $\begin{array}{c}\text { Std. Error of the } \\
\text { Estimate }\end{array}$ \\
\hline 1 &, $831^{\mathrm{a}}$ &, 690 &, 689 &, 38301 \\
2 &, $893^{\mathrm{D}}$ &, 798 &, 797 &, 30948 \\
\hline
\end{tabular}
a. Predictors: (Constant), Age
b. Predictors: (Constant), Age, Mileage (Km)
c. Dependent Variable: Ln price (EUR)

Model Summary ${ }^{\mathrm{c}}$

\begin{tabular}{|c|c|c|c|c|c|c|}
\hline \multirow[t]{2}{*}{ Model } & \multicolumn{5}{|c|}{ Change Statistics } & \multirow[b]{2}{*}{ Durbin-Watson } \\
\hline & $\begin{array}{l}\text { R Square } \\
\text { Change }\end{array}$ & F Change & df1 & $\mathrm{df2}$ & Sig. F Change & \\
\hline 1 & ,690 & 658,691 & 1 & 296 &, 000 & \\
\hline 2 & 108 & 158,347 & 1 & 295 & ,000 & 1,063 \\
\hline
\end{tabular}

c. Dependent Variable: Ln price (EUR)

ANOVA $^{c}$

\begin{tabular}{|c|c|c|c|c|c|c|}
\hline \multicolumn{2}{|c|}{ Model } & Sum of Squares & $\overline{d f}$ & Mean Square & $F$ & Sig. \\
\hline \multirow[t]{3}{*}{1} & Regression & 96,625 & 1 & 96,625 & 658,691 &, $000^{a}$ \\
\hline & Residual & 43,421 & 296 & ,147 & & \\
\hline & Total & 140,046 & 297 & & & \\
\hline \multirow[t]{3}{*}{2} & Regression & 111,792 & 2 & 55,896 & 583,592 &, $000^{b}$ \\
\hline & Residual & 28,255 & 295 & ,096 & & \\
\hline & Total & 140,046 & 297 & & & \\
\hline
\end{tabular}
a. Predictors: (Constant), Age
b. Predictors: (Constant), Age, Mileage (Km)
c. Dependent Variable: Ln price (EUR)

Coefficients $^{\mathrm{a}}$

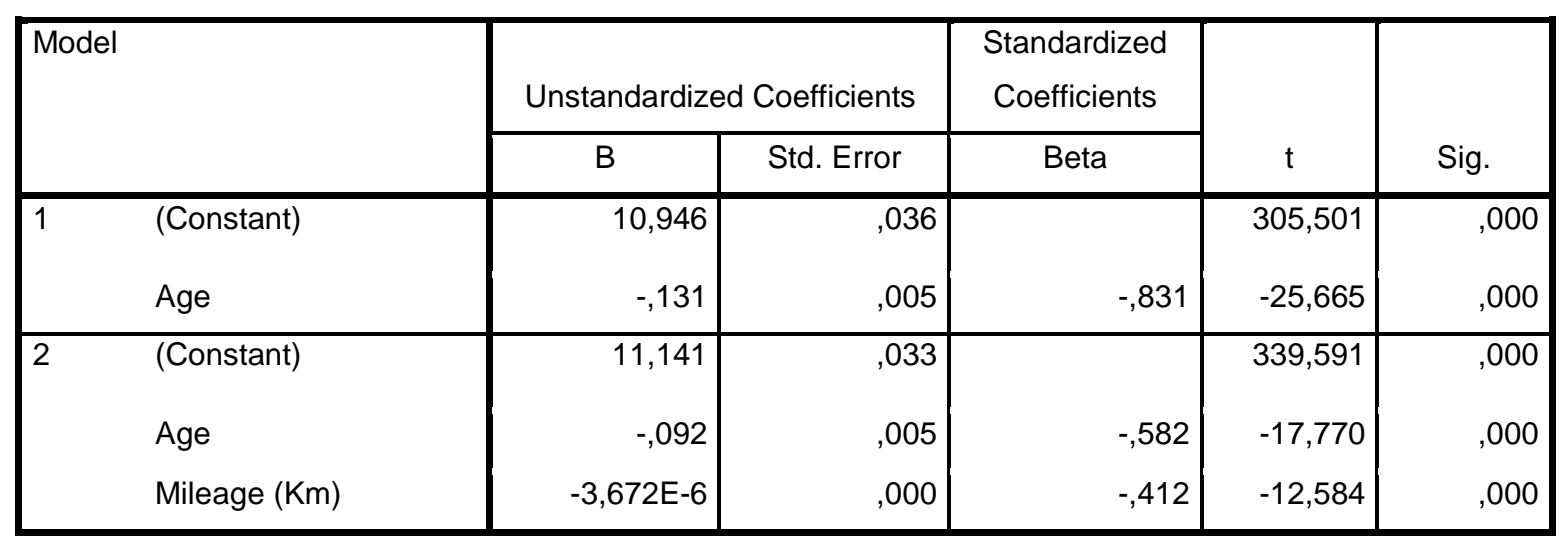




\section{Coefficients $^{\mathrm{a}}$}

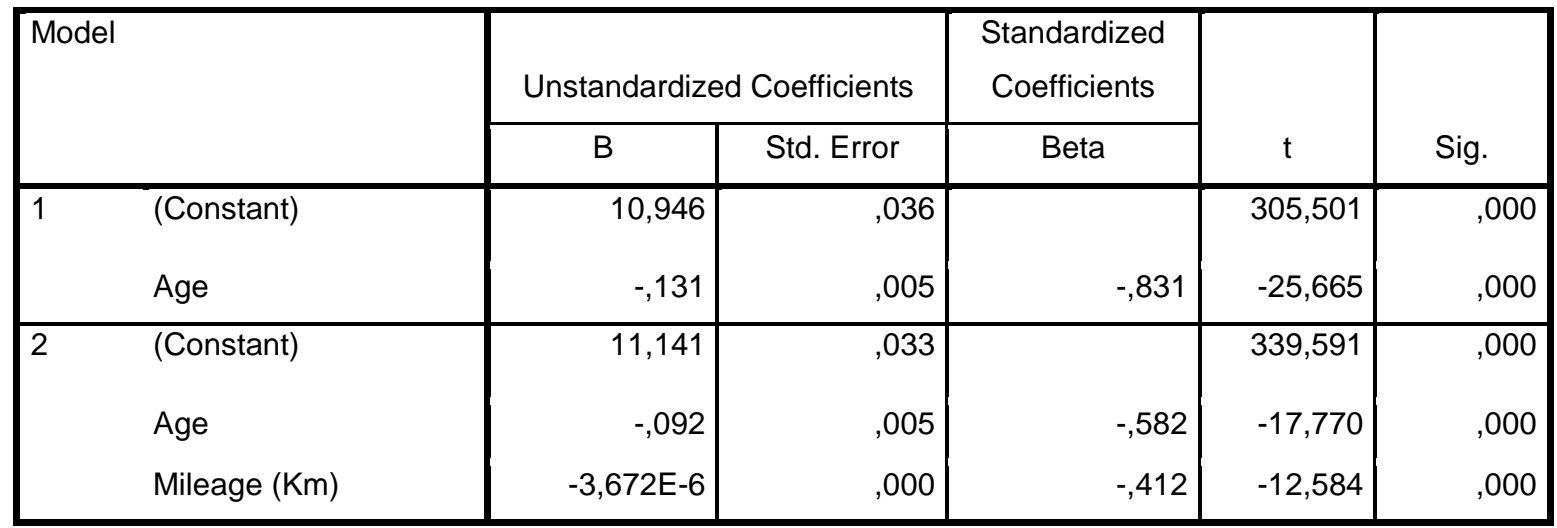

a. Dependent Variable: Ln price (EUR)

\section{Coefficients $^{\mathrm{a}}$}

\begin{tabular}{|ll|r|r|r|r|r|}
\hline Model & \multicolumn{2}{|c|}{$95,0 \%$ Confidence Interval for B } & \multicolumn{3}{|c|}{ Correlations } \\
\cline { 3 - 7 } & Lower Bound & Upper Bound & Zero-order & Partial & Part \\
\hline 1 & (Constant) & 10,876 & 11,017 & & & \\
& Age &,- 141 &,- 121 &,- 831 &,- 831 &,- 831 \\
\hline 2 & (Constant) & 11,076 & 11,205 & & & \\
& Age &,- 102 &,- 082 &,- 831 &,- 719 &,- 465 \\
& Mileage (Km) &, 000 &, 000 &,- 763 &,- 591 &,- 329 \\
\hline
\end{tabular}

a. Dependent Variable: Ln price (EUR)

Coefficients $^{\mathrm{a}}$

\begin{tabular}{|ll|r|r|}
\hline \multicolumn{2}{|l|}{ Model } & \multicolumn{2}{|c|}{ Collinearity Statistics } \\
\cline { 3 - 4 } & & Tolerance & \multicolumn{1}{c|}{ VIF } \\
\hline 1 & (Constant) & 1,000 & 1,000 \\
& Age & & \\
\hline 2 & (Constant) &, 637 & 1,570 \\
& Age &, 637 & 1,570 \\
& Mileage $(\mathrm{Km})$ & & \\
\end{tabular}

a. Dependent Variable: Ln price (EUR)

\section{Excluded Variables $^{\mathrm{D}}$}

\begin{tabular}{|c|c|c|c|c|}
\hline Model & Beta In & $t$ & Sig. & $\begin{array}{c}\text { Partial } \\
\text { Correlation }\end{array}$ \\
\hline $1 \quad$ Mileage $(\mathrm{Km})$ &,$- 412^{a}$ & $-12,584$ & ,000 &,- 591 \\
\hline
\end{tabular}

a. Predictors in the Model: (Constant), Age

b. Dependent Variable: Ln price (EUR) 
Excluded Variables $^{\mathrm{D}}$

\begin{tabular}{|r|r|r|r|}
\hline Model & \multicolumn{3}{|c|}{ Collinearity Statistics } \\
\cline { 2 - 4 } & & \multicolumn{1}{c|}{$\begin{array}{c}\text { Minimum } \\
\text { Tolerance }\end{array}$} \\
\cline { 2 - 5 } & Tolerance & VIF &, 637 \\
\hline
\end{tabular}

b. Dependent Variable: Ln price (EUR)

\section{Coefficient Correlations $^{\mathrm{a}}$}

\begin{tabular}{|lll|r|r|}
\hline Model & & \multicolumn{1}{c|}{ Age } & \multicolumn{1}{c|}{ Mileage $(\mathrm{Km})$} \\
\hline 1 & Correlations & Age & 1,000 & \\
\cline { 2 - 5 } & Covariances & Age & $2,613 \mathrm{E}-5$ & \\
\hline 2 & Correlations & Age & 1,000 &,- 602 \\
& & Mileage $(\mathrm{Km})$ &,- 602 & 1,000 \\
& Covariances & Age & $2,678 \mathrm{E}-5$ & $-9,098 \mathrm{E}-10$ \\
& & Mileage $(\mathrm{Km})$ & $-9,098 \mathrm{E}-10$ & $8,516 \mathrm{E}-14$ \\
\hline
\end{tabular}

a. Dependent Variable: Ln price (EUR)

Collinearity Diagnostics ${ }^{a}$

\begin{tabular}{|c|c|c|c|c|c|c|}
\hline \multirow[t]{2}{*}{ Model } & \multirow[t]{2}{*}{ Dimension } & \multirow[b]{2}{*}{ Eigenvalue } & \multirow[b]{2}{*}{ Condition Index } & \multicolumn{3}{|c|}{ Variance Proportions } \\
\hline & & & & (Constant) & Age & Mileage (Km) \\
\hline 1 & $\begin{array}{r}1 \\
-\quad 2\end{array}$ & $\begin{array}{r}1,785 \\
, 215\end{array}$ & $\begin{array}{l}1,000 \\
2,883\end{array}$ & $\begin{array}{l}, 11 \\
, 89\end{array}$ & $\begin{array}{l}11 \\
, 89\end{array}$ & \\
\hline 2 & $\begin{array}{r}1 \\
-\quad 2 \\
3\end{array}$ & $\begin{array}{r}2,645 \\
, 220 \\
, 135\end{array}$ & $\begin{array}{l}1,000 \\
3,469 \\
4,420\end{array}$ & $\begin{array}{l}, 04 \\
, 85 \\
, 11\end{array}$ & $\begin{array}{r}, 03 \\
, 38 \\
, 59\end{array}$ & $\begin{array}{c}, 03 \\
, 04 \\
, 94\end{array}$ \\
\hline
\end{tabular}

a. Dependent Variable: Ln price (EUR)

Casewise Diagnostics $^{a}$

\begin{tabular}{|r|r|r|r|r|}
\hline Case Number & Std. Residual & $\begin{array}{c}\text { Ln price } \\
\text { (EUR) }\end{array}$ & Predicted Value & Residual \\
\hline 22916 & $-6,823$ & 6,80 & 8,9129 & $-2,11166$ \\
22917 & $-4,815$ & 7,50 & 8,9858 & $-1,49030$ \\
-22924 & 3,339 & 8,85 & 7,8202 & 1,03348 \\
22925 & 3,339 & 8,85 & 7,8202 & 1,03348 \\
\hline
\end{tabular}

a. Dependent Variable: Ln price (EUR)

Residuals Statistics ${ }^{a}$ 


\begin{tabular}{|l|r|r|r|r|r|}
\hline & Minimum & Maximum & Mean & Std. Deviation & N \\
\hline Predicted Value & 7,6786 & 11,1396 & 10,2243 &, 61352 & 298 \\
Residual & $-2,11166$ & 1,03348 &, 00000 &, 30844 & 298 \\
Std. Predicted Value & $-4,149$ & 1,492 &, 000 & 1,000 & 298 \\
Std. Residual & $-6,823$ & 3,339 &, 000 &, 997 & 298 \\
\hline
\end{tabular}

a. Dependent Variable: Ln price (EUR)

\section{Charts}

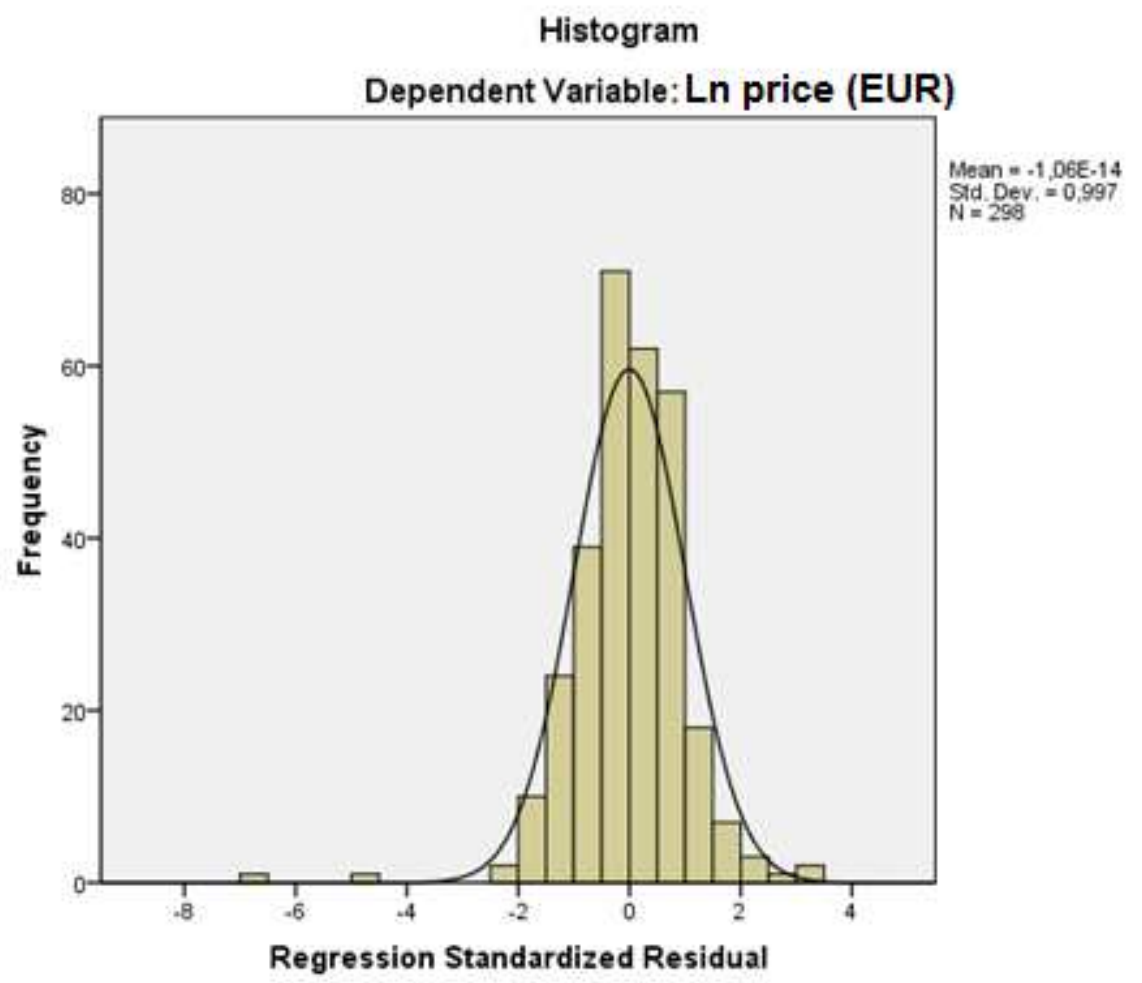


Normal P-P Plot of Regression Standardized Residual

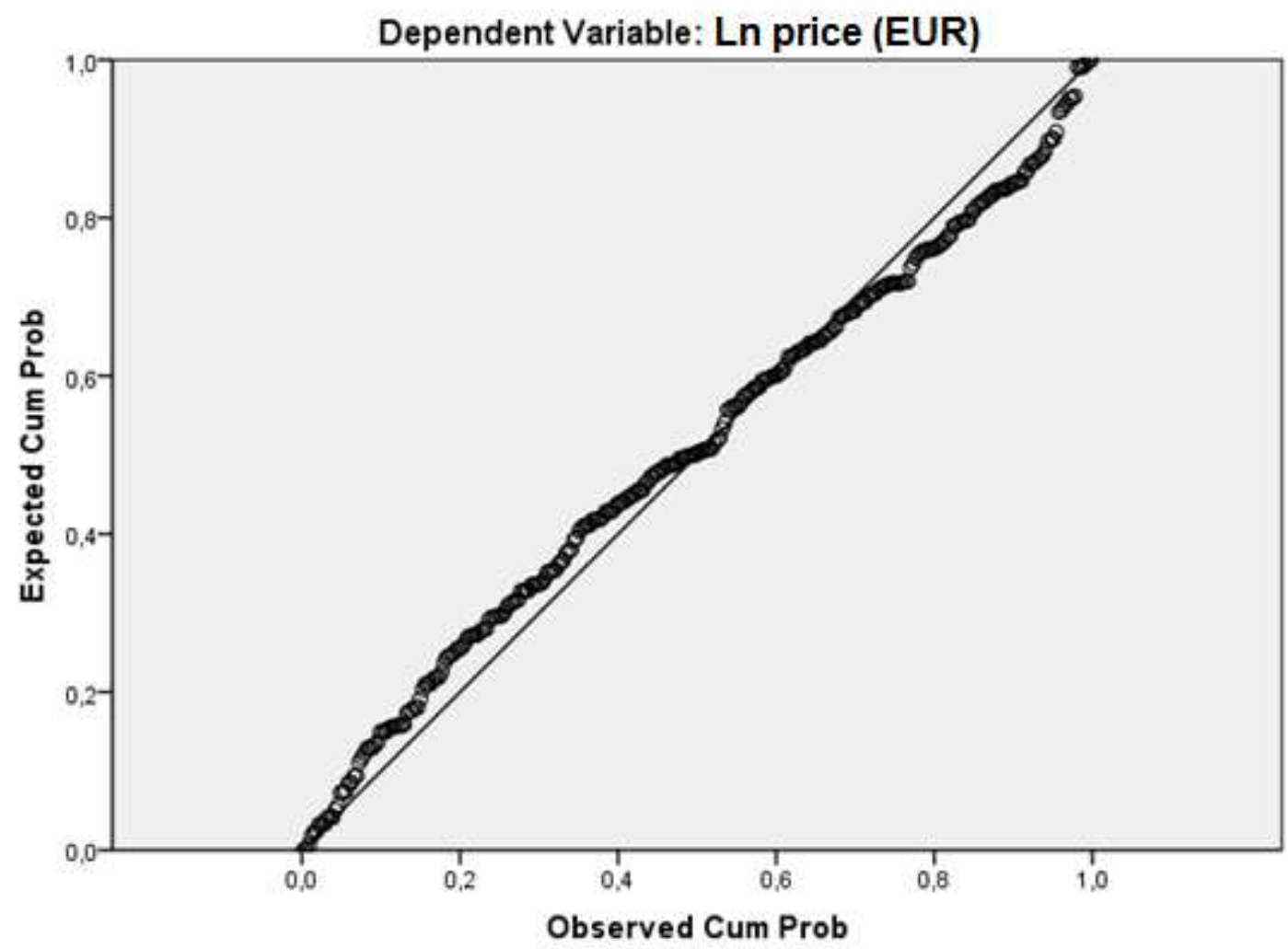

Partial Regression Plot

Dependent Variable: Ln price (EUR)

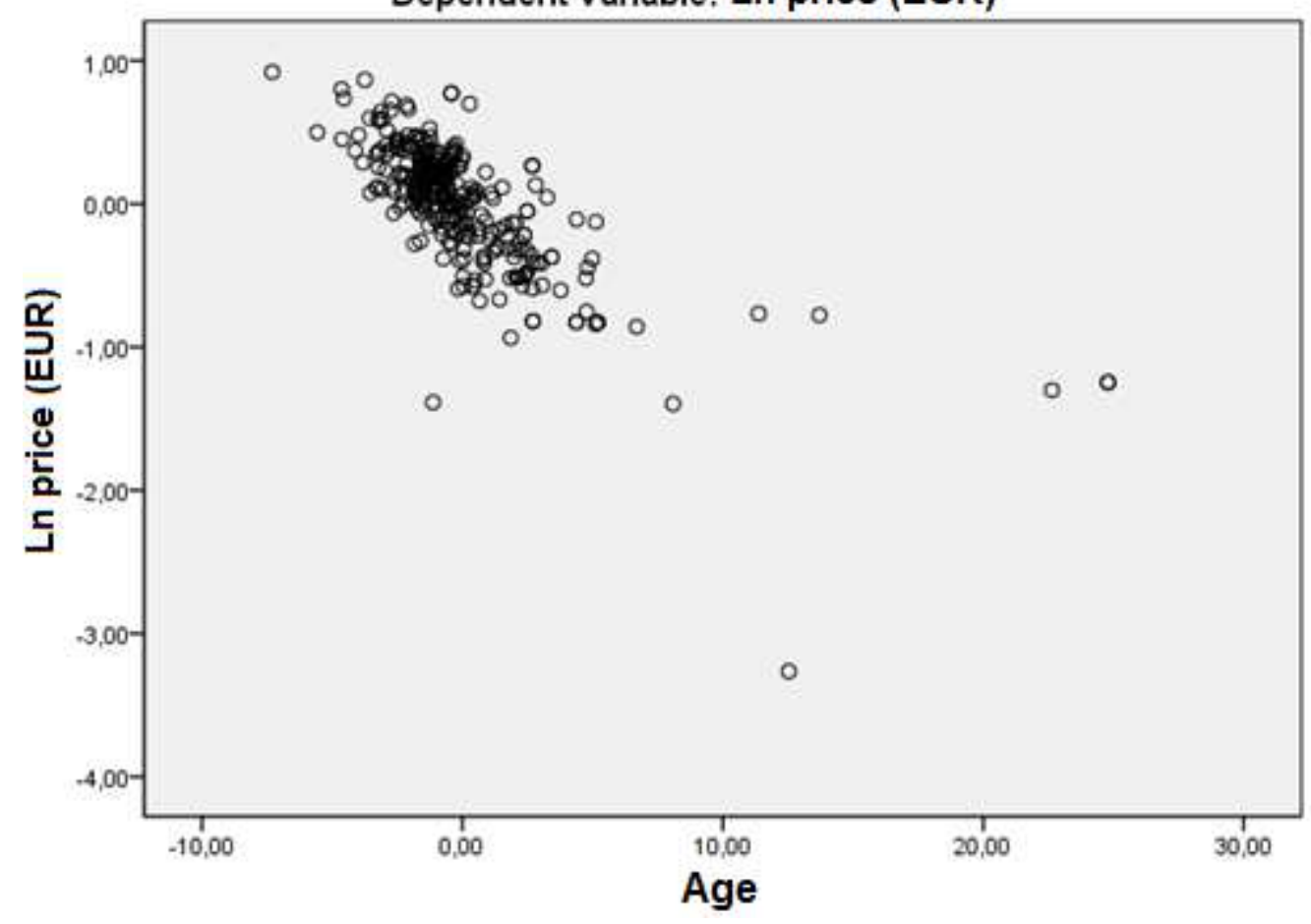




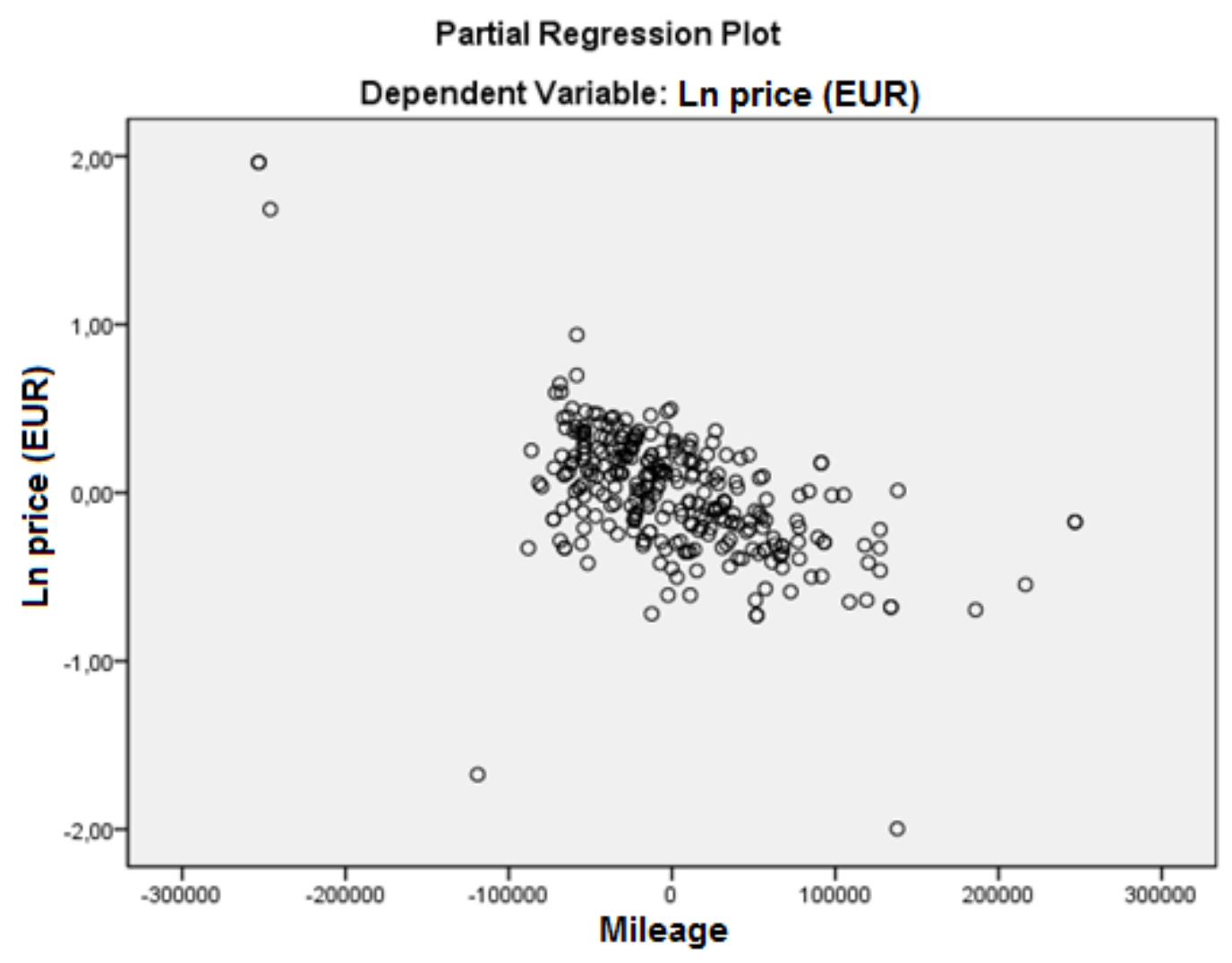


Regression 4

Descriptive Statistics

\begin{tabular}{|l|r|r|r|}
\hline & \multicolumn{1}{|c|}{ Mean } & Std. Deviation & \multicolumn{1}{l|}{$\mathrm{N}$} \\
\hline Ln price (EUR) & 8,7285 &, 71369 & 22915 \\
Age & 6,5523 & 4,09134 & 22915 \\
Mileage $(\mathrm{Km})$ & 120956,38 & 70959,059 & 22915 \\
\hline
\end{tabular}

Correlations

\begin{tabular}{|c|c|c|c|c|}
\hline & & $\begin{array}{l}\text { Ln price } \\
\text { (EUR) }\end{array}$ & Age & Mileage $(\mathrm{Km})$ \\
\hline \multirow[t]{3}{*}{ Pearson Correlation } & Ln price (EUR) & 1,000 &,- 806 &,- 737 \\
\hline & Age &,- 806 & 1,000 & ,740 \\
\hline & Mileage $(\mathrm{Km})$ &,- 737 & ,740 & 1,000 \\
\hline \multirow[t]{3}{*}{ Sig. (1-tailed) } & Ln price (EUR) & &, 000 &, 000 \\
\hline & Age & ,000 & &, 000 \\
\hline & Mileage $(\mathrm{Km})$ & ,000 & ,000 & \\
\hline \multirow[t]{3}{*}{$\mathrm{N}$} & Ln price (EUR) & 22915 & 22915 & 22915 \\
\hline & Age & 22915 & 22915 & 22915 \\
\hline & Mileage $(\mathrm{Km})$ & 22915 & 22915 & 22915 \\
\hline
\end{tabular}

Variables Entered/Removed ${ }^{\mathrm{a}}$

\begin{tabular}{|c|c|c|c|}
\hline Model & $\begin{array}{l}\text { Variables } \\
\text { Entered }\end{array}$ & $\begin{array}{l}\text { Variables } \\
\text { Removed }\end{array}$ & Method \\
\hline 1 & Age & & $\begin{array}{l}\text { Stepwise } \\
\text { (Criteria: } \\
\text { Probability-of-F- } \\
\text { to-enter <= } \\
, 050, \\
\text { Probability-of-F- } \\
\text { to-remove >= } \\
, 100) \text {. }\end{array}$ \\
\hline 2 & Mileage $(\mathrm{Km})$ & & $\begin{array}{l}\text { Stepwise } \\
\text { (Criteria: } \\
\text { Probability-of-F- } \\
\text { to-enter <= } \\
, 050, \\
\text { Probability-of-F- } \\
\text { to-remove >= } \\
, 100) \text {. }\end{array}$ \\
\hline
\end{tabular}

a. Dependent Variable: Ln price (EUR) 
Model Summary $^{\mathrm{c}}$

\begin{tabular}{|l|r|r|r|r|}
\hline Model & $\mathrm{R}$ & $\mathrm{R}$ Square & \multicolumn{1}{c|}{$\begin{array}{c}\text { Adjusted R } \\
\text { Square }\end{array}$} & $\begin{array}{c}\text { Std. Error of the } \\
\text { Estimate }\end{array}$ \\
\hline 1 &, $806^{\mathrm{a}}$ &, 650 &, 650 &, 42212 \\
2 &, $833^{\mathrm{D}}$ &, 694 &, 694 &, 39493 \\
\hline
\end{tabular}

a. Predictors: (Constant), Age

b. Predictors: (Constant), Age, Mileage (Km)

c. Dependent Variable: Ln price (EUR)

Model Summary $^{\mathrm{c}}$

\begin{tabular}{|c|c|c|c|c|c|c|}
\hline \multirow[t]{2}{*}{ Model } & \multicolumn{5}{|c|}{ Change Statistics } & \multirow[b]{2}{*}{ Durbin-Watson } \\
\hline & $\begin{array}{c}\text { R Square } \\
\text { Change }\end{array}$ & F Change & df1 & $\mathrm{df} 2$ & Sig. F Change & \\
\hline 1 & ,650 & 42589,801 & 1 & 22913 & ,000 & \\
\hline 2 & ,044 & 3264,790 & 1 & 22912 &, 000 & ,413 \\
\hline
\end{tabular}

c. Dependent Variable: Ln price (EUR)

ANOVA $^{\mathrm{C}}$

\begin{tabular}{|ll|r|r|r|r|r|}
\hline Model & & Sum of Squares & \multicolumn{1}{c|}{ df } & Mean Square & \multicolumn{1}{c|}{ F } & Sig. \\
\hline 1 & Regression & 7588,767 & 1 & 7588,767 & 42589,801 &, $000^{\text {a }}$ \\
& Residual & 4082,701 & 22913 &, 178 & & \\
& Total & 11671,467 & 22914 & & & \\
& Regression & 8097,964 & 2 & 4048,982 & 25960,599 &, $000^{\circ}$ \\
& Residual & 3573,503 & 22912 &, 156 & & \\
& Total & 11671,467 & 22914 & & & \\
\end{tabular}
a. Predictors: (Constant), Age
b. Predictors: (Constant), Age, Mileage (Km)
c. Dependent Variable: Ln price (EUR) 
Coefficients $^{\mathrm{a}}$

\begin{tabular}{|c|c|c|c|c|c|c|}
\hline Model & & \multicolumn{2}{|c|}{ Unstandardized Coefficients } & \multirow{2}{*}{$\begin{array}{c}\text { Standardized } \\
\text { Coefficients }\end{array}$} & \multirow[b]{2}{*}{$\mathrm{t}$} & \multirow[b]{2}{*}{ Sig. } \\
\hline & & $B$ & Std. Error & & & \\
\hline & (Constant) & 9,650 & ,005 & & 1832,879 &, 000 \\
\hline & Age &,- 141 & ,001 &,- 806 & $-206,373$ &, 000 \\
\hline \multirow[t]{3}{*}{2} & (Constant) & 9,765 & ,005 & & 1835,007 &, 000 \\
\hline & Age &,- 101 & ,001 &,- 576 & $-105,963$ &, 000 \\
\hline & Mileage $(\mathrm{Km})$ & $-3,125 E-6$ & ,000 &,- 311 & $-57,138$ &, 000 \\
\hline
\end{tabular}

a. Dependent Variable: Ln price (EUR)

\section{Coefficients $^{\mathrm{a}}$}

\begin{tabular}{|ll|r|r|r|r|r|}
\hline Model & \multicolumn{2}{|c|}{$95,0 \%$ Confidence Interval for B } & \multicolumn{3}{|c|}{ Correlations } \\
\cline { 3 - 7 } & & Lower Bound & Upper Bound & Zero-order & Partial & Part \\
\hline 1 & (Constant) & 9,640 & 9,660 & & & \\
& Age &,- 142 &,- 139 &,- 806 &,- 806 &,- 806 \\
\hline $2 \quad$ (Constant) & 9,755 & 9,776 & & & \\
& Age &,- 102 &,- 099 &,- 806 &,-- 573 &,- 387 \\
& Mileage $(\mathrm{Km})$ &, 000 &, 000 &,- 737 &,- 353 &,- 209 \\
\hline
\end{tabular}

a. Dependent Variable: Ln price (EUR)

Coefficients $^{\mathrm{a}}$

\begin{tabular}{|ll|r|r|}
\hline \multicolumn{2}{|l|}{ Model } & \multicolumn{2}{|c|}{ Collinearity Statistics } \\
\cline { 3 - 4 } & & Tolerance & \multicolumn{1}{c|}{ VIF } \\
\hline 1 & (Constant) & & \\
& Age & 1,000 & 1,000 \\
\hline $2 \quad$ (Constant) & & \\
& Age &, 452 & 2,213 \\
& Mileage $(\mathrm{Km})$ &, 452 & 2,213 \\
\hline
\end{tabular}

a. Dependent Variable: Ln price (EUR)

\section{Excluded Variables ${ }^{\mathfrak{b}}$}

\begin{tabular}{|c|c|c|c|c|}
\hline Model & Beta In & $t$ & Sig. & $\begin{array}{c}\text { Partial } \\
\text { Correlation }\end{array}$ \\
\hline $1 \quad$ Mileage $(\mathrm{Km})$ &,$- 311^{a}$ & $-57,138$ & ,000 &,- 353 \\
\hline
\end{tabular}

a. Predictors in the Model: (Constant), Age 
Excluded Variables $^{\mathrm{D}}$

\begin{tabular}{|c|c|c|c|c|}
\hline Model & Beta In & $\mathrm{t}$ & Sig. & $\begin{array}{c}\text { Partial } \\
\text { Correlation }\end{array}$ \\
\hline Mileage $(\mathrm{Km})$ &,$- 311^{a}$ & $-57,138$ & ,000 &,- 353 \\
\hline
\end{tabular}

a. Predictors in the Model: (Constant), Age

b. Dependent Variable: Ln price (EUR)

Excluded Variables ${ }^{\mathrm{D}}$

\begin{tabular}{|c|c|c|c|}
\hline \multirow{2}{*}{ Model } & \multicolumn{3}{|c|}{ Collinearity Statistics } \\
\hline & Tolerance & VIF & $\begin{array}{l}\text { Minimum } \\
\text { Tolerance }\end{array}$ \\
\hline $1 \quad$ Mileage $(\mathrm{Km})$ & ,452 & 2,213 & ,452 \\
\hline
\end{tabular}

b. Dependent Variable: Ln price (EUR)

\section{Coefficient Correlations $^{a}$}

\begin{tabular}{|lll|r|r|}
\hline Model & & \multicolumn{1}{c|}{ Age } & \multicolumn{1}{c|}{ Mileage $(\mathrm{Km})$} \\
\hline 1 & Correlations & Age & 1,000 & \\
\cline { 2 - 5 } & Covariances & Age & $4,646 \mathrm{E}-7$ & \\
\hline 2 & Correlations & Age & 1,000 &,- 740 \\
& & Mileage $(\mathrm{Km})$ &,- 740 & 1,000 \\
& Covariances & Age & $9,000 \mathrm{E}-7$ & $-3,842 \mathrm{E}-11$ \\
& & Mileage $(\mathrm{Km})$ & $-3,842 \mathrm{E}-11$ & $2,992 \mathrm{E}-15$ \\
& & & & \\
\end{tabular}

a. Dependent Variable: Ln price (EUR)

\section{Collinearity Diagnostics ${ }^{a}$}

\begin{tabular}{|c|c|c|c|c|c|c|}
\hline \multirow[t]{2}{*}{ Model } & \multirow[t]{2}{*}{ Dimension } & \multirow[b]{2}{*}{ Eigenvalue } & \multirow[b]{2}{*}{ Condition Index } & \multicolumn{3}{|c|}{ Variance Proportions } \\
\hline & & & & (Constant) & Age & Mileage $(\mathrm{Km})$ \\
\hline \multirow[t]{2}{*}{1} & 1 & 1,848 & 1,000 & ,08 & ,08 & \\
\hline & 2 & ,152 & 3,490 & ,92 & ,92 & \\
\hline \multirow[t]{3}{*}{2} & 1 & 2,761 & 1,000 & ,03 & ,02 & 01 \\
\hline & -2 & ,170 & 4,033 & ,96 & ,16 & ,08 \\
\hline & 3 & ,069 & 6,315 & ,02 & ,83 & ,91 \\
\hline
\end{tabular}

a. Dependent Variable: Ln price (EUR) 
Casewise Diagnostics $^{a}$

\begin{tabular}{|c|c|c|c|c|}
\hline Case Number & Std. Residual & $\begin{array}{c}\text { Ln price } \\
\text { (EUR) }\end{array}$ & Predicted Value & Residual \\
\hline 1 & $-4,621$ & 5,30 & 7,1231 & $-1,82483$ \\
\hline 2 & $-6,253$ & 5,30 & 7,7679 & $-2,46956$ \\
\hline 3 & $-5,579$ & 5,52 & 7,7247 & $-2,20327$ \\
\hline 4 & $-4,285$ & 5,52 & 7,2137 & $-1,69222$ \\
\hline 5 & $-5,628$ & 5,52 & 7,7441 & $-2,22267$ \\
\hline 6 & $-5,921$ & 5,52 & 7,8599 & $-2,33846$ \\
\hline 7 & $-5,819$ & 5,52 & 7,8194 & $-2,29796$ \\
\hline 8 & $-4,536$ & 5,70 & 7,4920 & $-1,79153$ \\
\hline 9 & $-4,125$ & 5,70 & 7,3330 & $-1,62923$ \\
\hline 10 & $-3,779$ & 5,70 & 7,1962 & $-1,49237$ \\
\hline 11 & $-5,010$ & 5,70 & 7,6825 & $-1,97871$ \\
\hline 12 & $-5,384$ & 5,70 & 7,8300 & $-2,12625$ \\
\hline 13 & $-4,504$ & 5,70 & 7,4827 & $-1,77894$ \\
\hline 14 & $-5,681$ & 5,70 & 7,9473 & $-2,24352$ \\
\hline 15 & $-6,578$ & 5,70 & 8,3017 & $-2,59795$ \\
\hline 20 & $-4,379$ & 5,86 & 7,5874 & $-1,72951$ \\
\hline 21 & $-3,889$ & 5,86 & 7,3939 & $-1,53597$ \\
\hline 22 & $-4,396$ & 5,86 & 7,5942 & $-1,73628$ \\
\hline-23 & $-4,503$ & 5,86 & 7,6361 & $-1,77816$ \\
\hline 24 & $-4,442$ & 5,86 & 7,6123 & $-1,75441$ \\
\hline 25 & $-3,710$ & 5,86 & 7,3231 & $-1,46513$ \\
\hline 26 & $-4,063$ & 5,86 & 7,4627 & $-1,60478$ \\
\hline 27 & $-4,388$ & 5,86 & 7,5910 & $-1,73305$ \\
\hline 28 & $-4,980$ & 5,86 & 7,8248 & $-1,96687$ \\
\hline 29 & $-4,369$ & 5,86 & 7,5832 & $-1,72531$ \\
\hline 30 & $-5,209$ & 5,86 & 7,9152 & $-2,05725$ \\
\hline 32 & $-4,395$ & 5,94 & 7,6757 & $-1,73556$ \\
\hline 39 & $-3,035$ & 5,99 & 7,1902 & $-1,19876$ \\
\hline 40 & $-3,319$ & 5,99 & 7,3023 & $-1,31083$ \\
\hline 41 & $-3,394$ & 5,99 & 7,3317 & $-1,34021$ \\
\hline 42 & $-4,111$ & 5,99 & 7,6151 & $-1,62362$ \\
\hline 43 & $-3,811$ & 5,99 & 7,4966 & $-1,50512$ \\
\hline 44 & $-4,207$ & 5,99 & 7,6529 & $-1,66139$ \\
\hline 45 & $-3,595$ & 5,99 & 7,4112 & $-1,41973$ \\
\hline 46 & $-3,579$ & 5,99 & 7,4051 & $-1,41361$ \\
\hline 47 & $-3,585$ & 5,99 & 7,4072 & $-1,41573$ \\
\hline 48 & $-3,447$ & 5,99 & 7,3526 & $-1,36111$ \\
\hline
\end{tabular}




\begin{tabular}{|c|c|c|c|c|}
\hline 49 & $-3,447 \mid$ & 5,99 & 7,3526 & $-1,36111$ \\
\hline 50 & $-3,805$ & 5,99 & 7,4944 & $-1,50289$ \\
\hline 51 & $-4,664$ & 5,99 & 7,8333 & $-1,84181$ \\
\hline 52 & $-4,243$ & 5,99 & 7,6670 & $-1,67555$ \\
\hline 53 & $-4,623$ & 5,99 & 7,8172 & $-1,82570$ \\
\hline 54 & $-6,494$ & 5,99 & 8,5563 & $-2,56483$ \\
\hline 58 & $-3,531$ & 6,11 & 7,5037 & $-1,39445$ \\
\hline 59 & $-3,044$ & 6,11 & 7,3114 & $-1,20219$ \\
\hline 60 & $-5,480$ & 6,11 & 8,2735 & $-2,16420$ \\
\hline 61 & $-5,480$ & 6,11 & 8,2735 & $-2,16420$ \\
\hline 62 & $-3,477$ & 6,11 & 7,4822 & $-1,37298$ \\
\hline 63 & $-4,720$ & 6,11 & 7,9734 & $-1,86419$ \\
\hline 64 & $-4,720$ & 6,11 & 7,9734 & $-1,86419$ \\
\hline 65 & $-5,193$ & 6,11 & 8,1601 & $-2,05088$ \\
\hline 66 & $-5,193$ & 6,11 & 8,1601 & $-2,05088$ \\
\hline 76 & $-3,302$ & 6,21 & 7,5187 & $-1,30408$ \\
\hline 78 & $-3,308$ & 6,21 & 7,5211 & $-1,30646$ \\
\hline 80 & $-3,018$ & 6,21 & 7,4067 & $-1,19208$ \\
\hline 83 & $-3,354$ & 6,21 & 7,5391 & $-1,32447$ \\
\hline 86 & $-3,263$ & 6,21 & 7,5031 & $-1,28848$ \\
\hline 87 & $-3,453$ & 6,21 & 7,5781 & $-1,36349$ \\
\hline 88 & $-3,393$ & 6,21 & 7,5546 & $-1,34000$ \\
\hline 89 & $-3,193$ & 6,21 & 7,4755 & $-1,26086$ \\
\hline 90 & $-3,789$ & 6,21 & 7,7110 & $-1,49640$ \\
\hline 91 & $-3,805$ & 6,21 & 7,7173 & $-1,50265$ \\
\hline 92 & $-3,906$ & 6,21 & 7,7571 & $-1,54251$ \\
\hline 93 & $-3,436$ & 6,21 & 7,5715 & $-1,35688$ \\
\hline 94 & $-3,755$ & 6,21 & 7,6976 & $-1,48302$ \\
\hline 95 & $-3,850$ & 6,21 & 7,7351 & $-1,52053$ \\
\hline 96 & $-4,439$ & 6,21 & 7,9678 & $-1,75319$ \\
\hline 97 & $-3,445$ & 6,21 & 7,5751 & $-1,36052$ \\
\hline 98 & $-4,661$ & 6,21 & 8,0554 & $-1,84083$ \\
\hline 99 & $-4,661$ & 6,21 & 8,0554 & $-1,84083$ \\
\hline 100 & $-3,319$ & 6,21 & 7,5252 & $-1,31064$ \\
\hline 101 & $-4,195$ & 6,21 & 7,8713 & $-1,65669$ \\
\hline 102 & $-4,581$ & 6,21 & 8,0239 & $-1,80929$ \\
\hline 103 & $-4,999$ & 6,21 & 8,1887 & $-1,97412$ \\
\hline 104 & $-4,655$ & 6,21 & 8,0529 & $-1,83824$ \\
\hline 105 & $-5,841$ & 6,21 & 8,5212 & $-2,30657$ \\
\hline
\end{tabular}




\begin{tabular}{|c|c|c|c|c|}
\hline 111 & $-3,914$ & 6,31 & 7,8555 & $-1,54560$ \\
\hline 112 & $-3,012$ & 6,31 & 7,4995 & $-1,18956$ \\
\hline 113 & $-3,751$ & 6,31 & 7,7914 & $-1,48147$ \\
\hline 114 & $-4,169$ & 6,31 & 7,9564 & $-1,64651$ \\
\hline 118 & $-3,849$ & 6,40 & 7,9154 & $-1,52017$ \\
\hline 147 & $-3,693$ & 6,40 & 7,8555 & $-1,45859$ \\
\hline 151 & $-3,166$ & 6,40 & 7,6474 & $-1,25044$ \\
\hline 152 & $-4,353$ & 6,40 & 8,1162 & $-1,71925$ \\
\hline 154 & $-3,805$ & 6,40 & 7,8997 & $-1,50273$ \\
\hline 155 & $-3,747$ & 6,40 & 7,8768 & $-1,47985$ \\
\hline 156 & $-3,383$ & 6,40 & 7,7331 & $-1,33621$ \\
\hline 157 & $-3,041$ & 6,40 & 7,5977 & $-1,20082$ \\
\hline 158 & $-3,342$ & 6,40 & 7,7166 & $-1,31971$ \\
\hline 159 & $-3,381$ & 6,40 & 7,7323 & $-1,33534$ \\
\hline 161 & $-3,164$ & 6,40 & 7,6464 & $-1,24946$ \\
\hline 162 & $-4,148$ & 6,40 & 8,0352 & $-1,63827$ \\
\hline 163 & $-3,827$ & 6,40 & 7,9082 & $-1,51126$ \\
\hline 164 & $-4,415$ & 6,40 & 8,1404 & $-1,74343$ \\
\hline 165 & $-4,284$ & 6,40 & 8,0886 & $-1,69168$ \\
\hline 179 & $-3,364$ & 6,48 & 7,8056 & $-1,32866$ \\
\hline 180 & $-3,417$ & 6,48 & 7,8265 & $-1,34954$ \\
\hline 181 & $-3,581$ & 6,48 & 7,8913 & $-1,41431$ \\
\hline 185 & $-3,424$ & 6,48 & 7,8293 & $-1,35231$ \\
\hline 186 & $-3,446$ & 6,48 & 7,8378 & $-1,36081$ \\
\hline 187 & $-3,771$ & 6,48 & 7,9662 & $-1,48921$ \\
\hline 188 & $-3,433$ & 6,48 & 7,8329 & $-1,35595$ \\
\hline 189 & $-3,893$ & 6,48 & 8,0145 & $-1,53756$ \\
\hline 200 & $-3,005$ & 6,55 & 7,7380 & $-1,18687$ \\
\hline 219 & $-3,046$ & 6,55 & 7,7540 & $-1,20294$ \\
\hline 220 & $-3,323$ & 6,55 & 7,8634 & $-1,31233$ \\
\hline 222 & $-3,617$ & 6,55 & 7,9796 & $-1,42848$ \\
\hline 223 & $-3,320$ & 6,55 & 7,8624 & $-1,31135$ \\
\hline 224 & $-3,150$ & 6,55 & 7,7949 & $-1,24385$ \\
\hline 225 & $-3,551$ & 6,55 & 7,9535 & $-1,40237$ \\
\hline 249 & $-3,326$ & 6,62 & 7,9337 & $-1,31363$ \\
\hline 250 & $-3,326$ & 6,62 & 7,9337 & $-1,31363$ \\
\hline 261 & $-3,174$ & 6,62 & 7,8735 & $-1,25345$ \\
\hline 265 & $-3,222$ & 6,62 & 7,8927 & $-1,27259$ \\
\hline 266 & $-3,307$ & 6,62 & 7,9260 & $-1,30597$ \\
\hline
\end{tabular}




\begin{tabular}{|c|c|c|c|c|}
\hline 267 & $-3,020$ & 6,62 & 7,8127 & $-1,19258$ \\
\hline 268 & $-3,633$ & 6,62 & 8,0550 & $-1,43488$ \\
\hline 269 & $-4,168$ & 6,62 & 8,2660 & $-1,64592$ \\
\hline 321 & $-3,300$ & 6,68 & 7,9881 & $-1,30345$ \\
\hline 322 & $-3,257$ & 6,68 & 7,9707 & $-1,28608$ \\
\hline 323 & $-3,257$ & 6,68 & 7,9707 & $-1,28608$ \\
\hline 324 & $-3,634$ & 6,68 & 8,1197 & $-1,43510$ \\
\hline 325 & $-3,399$ & 6,68 & 8,0271 & $-1,34247$ \\
\hline 326 & $-3,399$ & 6,68 & 8,0271 & $-1,34247$ \\
\hline 327 & $-4,492$ & 6,68 & 8,4588 & $-1,77418$ \\
\hline 344 & $-3,050$ & 6,75 & 7,9499 & $-1,20468$ \\
\hline 386 & $-3,010$ & 6,80 & 7,9912 & $-1,18877$ \\
\hline 399 & $-3,250$ & 6,80 & 8,0861 & $-1,28368$ \\
\hline 400 & $-3,250$ & 6,80 & 8,0861 & $-1,28368$ \\
\hline 401 & $-3,684$ & 6,80 & 8,2571 & $-1,45473$ \\
\hline 427 & $-3,049$ & 6,86 & 8,0607 & $-1,20425$ \\
\hline 496 & $-3,079$ & 6,91 & 8,1239 & $-1,21616$ \\
\hline 547 & $-3,135$ & 6,91 & 8,1458 & $-1,23806$ \\
\hline 548 & $-3,135$ & 6,91 & 8,1458 & $-1,23806$ \\
\hline 557 & $-3,315$ & 6,91 & 8,2170 & $-1,30921$ \\
\hline 563 & $-3,129$ & 6,91 & 8,1433 & $-1,23558$ \\
\hline 566 & $-3,298$ & 6,91 & 8,2101 & $-1,30234$ \\
\hline 573 & $-3,242$ & 6,91 & 8,1881 & $-1,28031$ \\
\hline 574 & $-3,364$ & 6,91 & 8,2362 & $-1,32847$ \\
\hline 575 & $-3,364$ & 6,91 & 8,2362 & $-1,32847$ \\
\hline 576 & $-3,500$ & 6,91 & 8,2899 & $-1,38217$ \\
\hline 580 & $-3,206$ & 6,91 & 8,1738 & $-1,26609$ \\
\hline 581 & $-3,427$ & 6,91 & 8,2614 & $-1,35360$ \\
\hline 582 & $-3,522$ & 6,91 & 8,2989 & $-1,39111$ \\
\hline 583 & $-3,602$ & 6,91 & 8,3301 & $-1,42236$ \\
\hline 584 & $-3,602$ & 6,91 & 8,3301 & $-1,42236$ \\
\hline 588 & $-3,039$ & 6,91 & 8,1081 & $-1,20036$ \\
\hline 589 & $-3,150$ & 6,91 & 8,1516 & $-1,24385$ \\
\hline 590 & $-3,150$ & 6,91 & 8,1516 & $-1,24385$ \\
\hline 641 & $-3,009$ & 7,05 & 8,2360 & $-1,18850$ \\
\hline 750 & $-3,148$ & 7,09 & 8,3335 & $-1,24342$ \\
\hline 751 & $-3,526$ & 7,09 & 8,4825 & $-1,39244$ \\
\hline 757 & $-3,499$ & 7,09 & 8,4719 & $-1,38184$ \\
\hline 842 & $-3,034$ & 7,13 & 8,3292 & $-1,19834$ \\
\hline
\end{tabular}




\begin{tabular}{|c|c|c|c|c|}
\hline 849 & $-4,686$ & $7,17 \mid$ & 9,0202 & $-1,85081$ \\
\hline 850 & $-4,686$ & 7,17 & 9,0202 & $-1,85081$ \\
\hline 889 & $-3,515$ & 7,17 & 8,5584 & $-1,38828$ \\
\hline 897 & $-3,423$ & 7,17 & 8,5218 & $-1,35167$ \\
\hline 898 & $-3,051$ & 7,17 & 8,3750 & $-1,20490$ \\
\hline 1215 & $-3,070$ & 7,31 & 8,5256 & $-1,21234$ \\
\hline 1216 & $-3,473$ & 7,31 & 8,6850 & $-1,37173$ \\
\hline 1217 & $-4,002$ & 7,31 & 8,8938 & $-1,58062$ \\
\hline 1655 & 4,251 & 7,55 & 5,8708 & 1,67886 \\
\hline 1715 & $-3,039$ & 7,55 & 8,7498 & $-1,20021$ \\
\hline 1718 & $-3,176$ & 7,55 & 8,8037 & $-1,25413$ \\
\hline 2000 & $-3,006$ & 7,60 & 8,7881 & $-1,18717$ \\
\hline 2012 & $-3,189$ & 7,60 & 8,8601 & $-1,25923$ \\
\hline 2080 & 3,346 & 7,70 & 6,3749 & 1,32127 \\
\hline 2081 & 3,470 & 7,70 & 6,3260 & 1,37023 \\
\hline 2082 & 3,470 & 7,70 & 6,3260 & 1,37023 \\
\hline 2203 & $-3,121$ & 7,70 & 8,9288 & $-1,23255$ \\
\hline 2304 & 3,503 & 7,74 & 6,3571 & 1,38355 \\
\hline 2551 & 6,070 & 7,82 & 5,4267 & 2,39731 \\
\hline 2552 & 6,070 & 7,82 & 5,4267 & 2,39731 \\
\hline 2553 & 4,000 & 7,82 & 6,2445 & 1,57954 \\
\hline 2554 & 4,937 & 7,82 & 5,8744 & 1,94968 \\
\hline 2555 & 4,937 & 7,82 & 5,8744 & 1,94968 \\
\hline 2556 & 3,676 & 7,82 & 6,3724 & 1,45161 \\
\hline 2565 & 3,446 & 7,82 & 6,4631 & 1,36093 \\
\hline 2894 & $-4,022$ & 7,82 & 9,4124 & $-1,58831$ \\
\hline 2895 & $-4,022$ & 7,82 & 9,4124 & $-1,58831$ \\
\hline 2912 & 3,013 & 7,86 & 6,6734 & 1,18990 \\
\hline 2913 & 3,013 & 7,86 & 6,6734 & 1,18990 \\
\hline 3285 & 3,323 & 7,96 & 6,6428 & 1,31232 \\
\hline 3339 & 3,531 & 7,97 & 6,5779 & 1,39460 \\
\hline 3434 & $-3,364$ & 7,97 & 9,3010 & $-1,32850$ \\
\hline 3435 & 3,352 & 7,99 & 6,6656 & 1,32393 \\
\hline 3548 & 3,470 & 8,01 & 6,6355 & 1,37050 \\
\hline 3549 & 3,470 & 8,01 & 6,6355 & 1,37050 \\
\hline 3578 & 5,748 & 8,01 & 5,7364 & 2,26996 \\
\hline 3579 & 3,507 & 8,01 & 6,6215 & 1,38488 \\
\hline 3580 & 3,874 & 8,01 & 6,4765 & 1,52988 \\
\hline 3779 & 3,568 & 8,04 & 6,6300 & 1,40916 \\
\hline
\end{tabular}




\begin{tabular}{|c|c|c|c|c|}
\hline 3820 & 4,855 & 8,07 & 6,1537 & 1,91725 \\
\hline 3821 & 4,855 & 8,07 & 6,1537 & 1,91725 \\
\hline 3970 & 3,158 & 8,09 & 6,8394 & 1,24698 \\
\hline 4199 & 5,294 & 8,13 & 6,0409 & 2,09065 \\
\hline 4254 & 3,259 & 8,15 & 6,8589 & 1,28723 \\
\hline 4333 & 4,095 & 8,16 & 6,5432 & 1,61731 \\
\hline 4655 & 5,747 & 8,19 & 5,9192 & 2,26946 \\
\hline 4656 & 3,785 & 8,19 & 6,6940 & 1,49470 \\
\hline 4740 & 3,410 & 8,20 & 6,8559 & 1,34656 \\
\hline 4855 & 4,954 & 8,23 & 6,2732 & 1,95631 \\
\hline 5177 & 3,790 & 8,28 & 6,7845 & 1,49695 \\
\hline 5178 & 3,769 & 8,28 & 6,7929 & 1,48857 \\
\hline 5179 & 3,844 & 8,28 & 6,7633 & 1,51818 \\
\hline 5408 & 5,267 & 8,29 & 6,2139 & 2,08014 \\
\hline 5409 & 5,267 & 8,29 & 6,2139 & 2,08014 \\
\hline 5411 & 3,139 & 8,29 & 7,0542 & 1,23984 \\
\hline 5731 & 6,531 & 8,35 & 5,7756 & 2,57909 \\
\hline 5940 & 4,239 & 8,39 & 6,7153 & 1,67403 \\
\hline 6051 & 6,635 & 8,41 & 5,7915 & 2,62036 \\
\hline 6052 & 6,635 & 8,41 & 5,7915 & 2,62036 \\
\hline 6053 & 6,214 & 8,41 & 5,9579 & 2,45395 \\
\hline 6062 & 3,387 & 8,41 & 7,0742 & 1,33767 \\
\hline 6063 & 3,387 & 8,41 & 7,0742 & 1,33767 \\
\hline 6353 & $-3,424$ & 8,41 & 9,7642 & $-1,35235$ \\
\hline 6354 & $-3,424$ & 8,41 & 9,7642 & $-1,35235$ \\
\hline 6375 & 3,023 & 8,43 & 7,2401 & 1,19369 \\
\hline 6432 & 3,147 & 8,44 & 7,2016 & 1,24301 \\
\hline 6621 & 4,706 & 8,48 & 6,6177 & 1,85872 \\
\hline 6622 & 3,316 & 8,48 & 7,1666 & 1,30975 \\
\hline 6623 & 3,181 & 8,48 & 7,2200 & 1,25636 \\
\hline 6892 & 3,452 & 8,51 & 7,1439 & 1,36319 \\
\hline 6893 & 4,305 & 8,51 & 6,8071 & 1,70007 \\
\hline 7214 & 6,342 & 8,52 & 6,0127 & 2,50448 \\
\hline 7215 & 4,736 & 8,52 & 6,6468 & 1,87039 \\
\hline 7220 & 3,770 & 8,52 & 7,0284 & 1,48879 \\
\hline 7442 & 4,860 & 8,54 & 6,6177 & 1,91934 \\
\hline 7443 & 4,860 & 8,54 & 6,6177 & 1,91934 \\
\hline 7468 & 3,152 & 8,56 & 7,3116 & 1,24477 \\
\hline 7564 & 3,523 & 8,57 & 7,1746 & 1,39135 \\
\hline
\end{tabular}




\begin{tabular}{|c|c|c|c|c|}
\hline 7565 & 3,523 & 8,57 & 7,1746 & 1,39135 \\
\hline 7708 & 5,032 & 8,58 & 6,5977 & 1,98719 \\
\hline 7792 & 3,489 & 8,60 & 7,2256 & 1,37775 \\
\hline 7793 & 3,489 & 8,60 & 7,2256 & 1,37775 \\
\hline 7912 & 5,739 & 8,61 & 6,3459 & 2,26663 \\
\hline 7913 & 5,739 & 8,61 & 6,3459 & 2,26663 \\
\hline 7914 & 3,680 & 8,61 & 7,1592 & 1,45329 \\
\hline 7915 & 3,680 & 8,61 & 7,1592 & 1,45329 \\
\hline 7916 & 4,172 & 8,61 & 6,9650 & 1,64755 \\
\hline 7917 & 4,172 & 8,61 & 6,9650 & 1,64755 \\
\hline 7918 & 3,271 & 8,61 & 7,3208 & 1,29174 \\
\hline 7919 & 3,271 & 8,61 & 7,3208 & 1,29174 \\
\hline 8214 & 3,556 & 8,62 & 7,2174 & 1,40418 \\
\hline 8215 & 3,086 & 8,62 & 7,4027 & 1,21889 \\
\hline 8323 & 3,107 & 8,65 & 7,4211 & 1,22716 \\
\hline 8577 & 3,904 & 8,67 & 7,1323 & 1,54185 \\
\hline 8611 & 6,619 & 8,68 & 6,0688 & 2,61387 \\
\hline 8800 & 4,145 & 8,69 & 7,0542 & 1,63694 \\
\hline 8801 & 4,145 & 8,69 & 7,0542 & 1,63694 \\
\hline 8802 & 3,104 & 8,69 & 7,4655 & 1,22567 \\
\hline 8803 & 3,104 & 8,69 & 7,4655 & 1,22567 \\
\hline 9128 & 6,106 & 8,70 & 6,2880 & 2,41149 \\
\hline 9129 & 4,965 & 8,70 & 6,7386 & 1,96090 \\
\hline 9130 & 4,965 & 8,70 & 6,7386 & 1,96090 \\
\hline 9315 & 3,843 & 8,72 & 7,1984 & 1,51768 \\
\hline 9428 & 3,281 & 8,74 & 7,4447 & 1,29563 \\
\hline 9594 & 3,290 & 8,76 & 7,4568 & 1,29941 \\
\hline 10281 & 4,300 & 8,81 & 7,1117 & 1,69817 \\
\hline 10779 & 4,380 & 8,85 & 7,1168 & 1,72973 \\
\hline 11152 & 4,888 & 8,85 & 6,9234 & 1,93026 \\
\hline 11153 & 4,716 & 8,85 & 6,9911 & 1,86258 \\
\hline 11460 & 4,348 & 8,89 & 7,1715 & 1,71727 \\
\hline 11667 & 3,232 & 8,91 & 7,6329 & 1,27637 \\
\hline 11884 & 5,974 & 8,92 & 6,5634 & 2,35927 \\
\hline 11885 & 5,018 & 8,92 & 6,9408 & 1,98187 \\
\hline 11886 & 5,018 & 8,92 & 6,9408 & 1,98187 \\
\hline 11887 & 4,313 & 8,92 & 7,2195 & 1,70316 \\
\hline 11888 & 4,463 & 8,92 & 7,1602 & 1,76244 \\
\hline 12350 & 3,761 & 8,94 & 7,4504 & 1,48551 \\
\hline
\end{tabular}




\begin{tabular}{|c|c|c|c|c|}
\hline 12351 & 3,761 & 8,94 & 7,4504 & 1,48551 \\
\hline 12577 & 3,991 & 8,96 & 7,3857 & 1,57615 \\
\hline 13145 & 4,187 & 8,99 & 7,3323 & 1,65368 \\
\hline 13402 & 7,808 & 8,99 & 5,9036 & 3,08355 \\
\hline 13629 & 4,211 & 9,01 & 7,3490 & 1,66287 \\
\hline 14586 & 3,649 & 9,07 & 7,6298 & 1,44124 \\
\hline 15398 & 3,157 & 9,10 & 7,8582 & 1,24663 \\
\hline 16020 & 7,487 & 9,16 & 6,2023 & 2,95672 \\
\hline 16842 & 6,507 & 9,21 & 6,6354 & 2,56998 \\
\hline 17457 & 4,334 & 9,24 & 7,5234 & 1,71163 \\
\hline 17678 & 4,982 & 9,26 & 7,2917 & 1,96747 \\
\hline 17679 & 3,239 & 9,26 & 7,9801 & 1,27906 \\
\hline 18040 & 3,393 & 9,29 & 7,9472 & 1,34010 \\
\hline 19011 & 4,952 & 9,37 & 7,4158 & 1,95583 \\
\hline 19012 & 3,122 & 9,37 & 8,1386 & 1,23296 \\
\hline 19251 & 4,023 & 9,39 & 7,7997 & 1,58878 \\
\hline 19430 & 4,635 & 9,39 & 7,5623 & 1,83035 \\
\hline 19431 & 4,635 & 9,39 & 7,5623 & 1,83035 \\
\hline 20351 & 5,000 & 9,47 & 7,4982 & 1,97451 \\
\hline 20352 & 3,401 & 9,47 & 8,1296 & 1,34310 \\
\hline 20747 & 4,257 & 9,53 & 7,8477 & 1,68107 \\
\hline 21082 & 4,530 & 9,55 & 7,7579 & 1,78893 \\
\hline 21442 & 8,435 & 9,61 & 6,2780 & 3,33112 \\
\hline 21613 & 7,710 & 9,62 & 6,5711 & 3,04473 \\
\hline 21614 & 5,209 & 9,62 & 7,5588 & 2,05700 \\
\hline 22135 & 4,030 & 9,71 & 8,1194 & 1,59168 \\
\hline 22136 & 4,030 & 9,71 & 8,1194 & 1,59168 \\
\hline 22214 & 4,247 & 9,73 & 8,0488 & 1,67735 \\
\hline 22215 & 4,247 & 9,73 & 8,0488 & 1,67735 \\
\hline 22248 & 3,344 & 9,74 & 8,4144 & 1,32067 \\
\hline 22457 & 7,724 & 9,79 & 6,7420 & 3,05056 \\
\hline 22590 & 3,357 & 9,84 & 8,5106 & 1,32568 \\
\hline 22841 & 3,128 & 10,04 & 8,8081 & 1,23515 \\
\hline
\end{tabular}

a. Dependent Variable: Ln price (EUR) 
Residuals Statistics ${ }^{a}$

\begin{tabular}{|l|r|r|r|r|r|}
\hline & Minimum & Maximum & Mean & Std. Deviation & N \\
\hline Predicted Value & 5,4267 & 9,7642 & 8,7285 &, 59448 & 22915 \\
Residual & $-2,59795$ & 3,33112 &, 00000 &, 39491 & 22915 \\
Std. Predicted Value & $-5,554$ & 1,742 &, 000 & 1,000 & 22915 \\
Std. Residual & $-6,578$ & 8,435 &, 000 & 1,000 & 22915 \\
\hline
\end{tabular}

a. Dependent Variable: Ln price (EUR)

\section{Charts}

\section{Histogram}

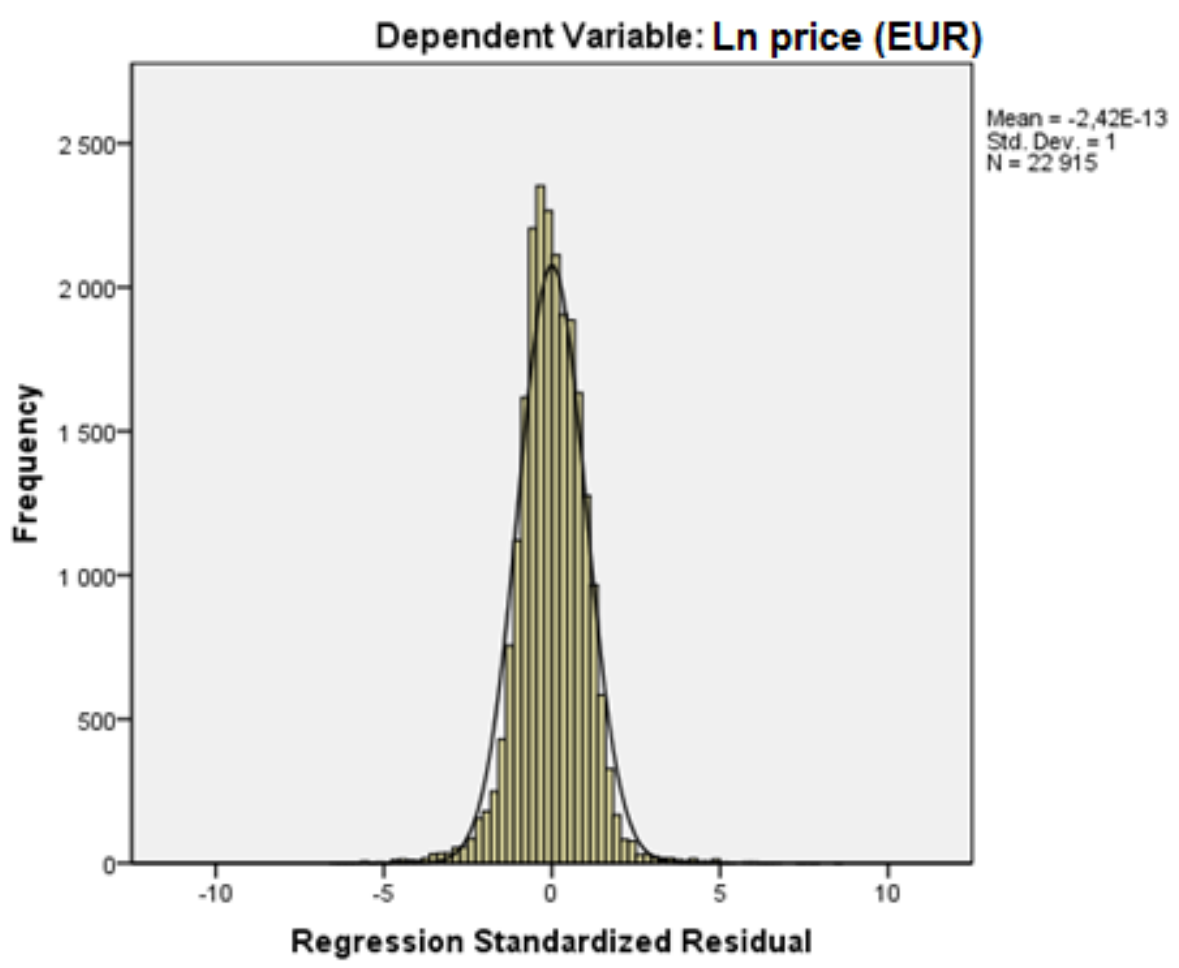



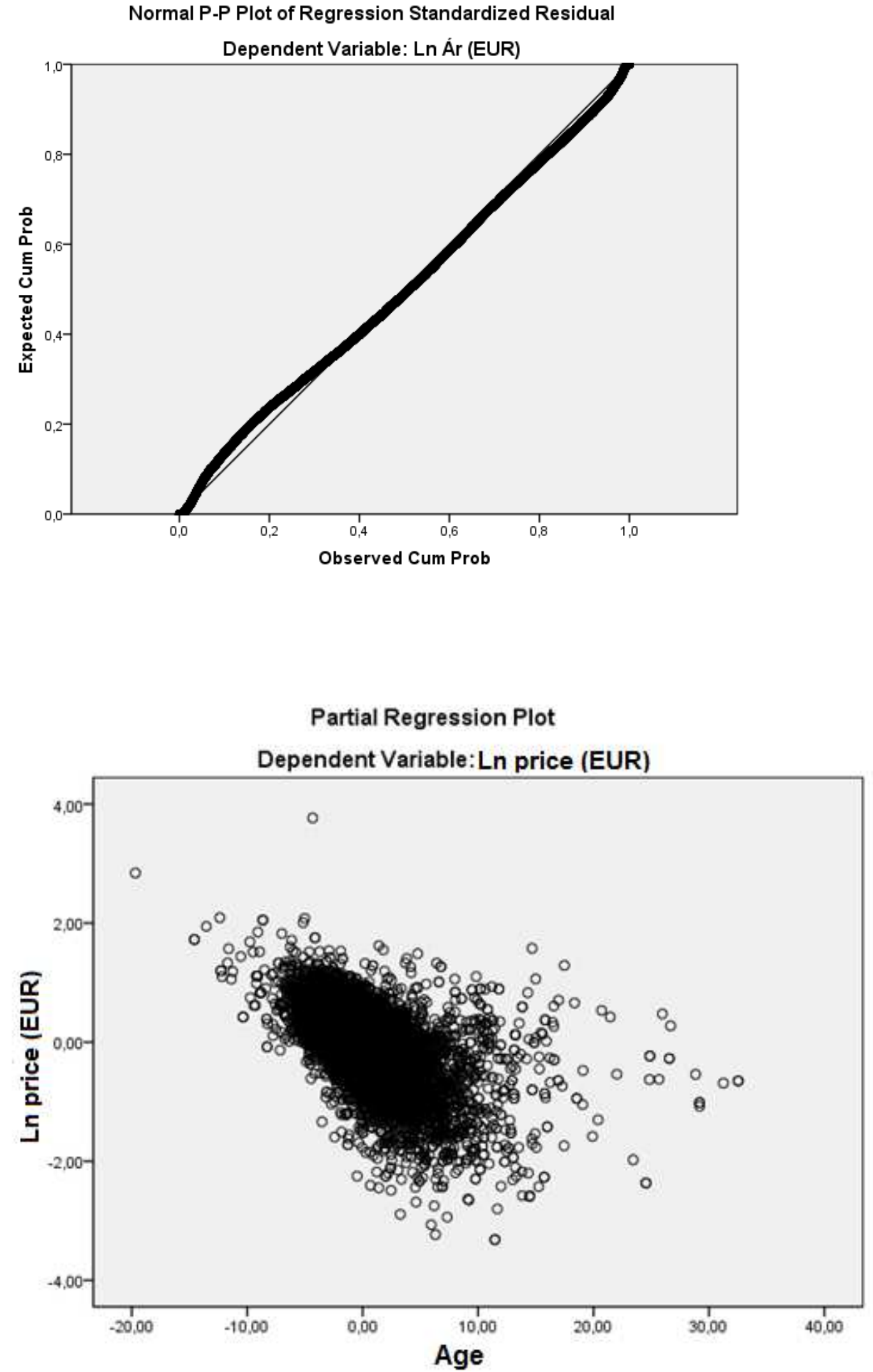


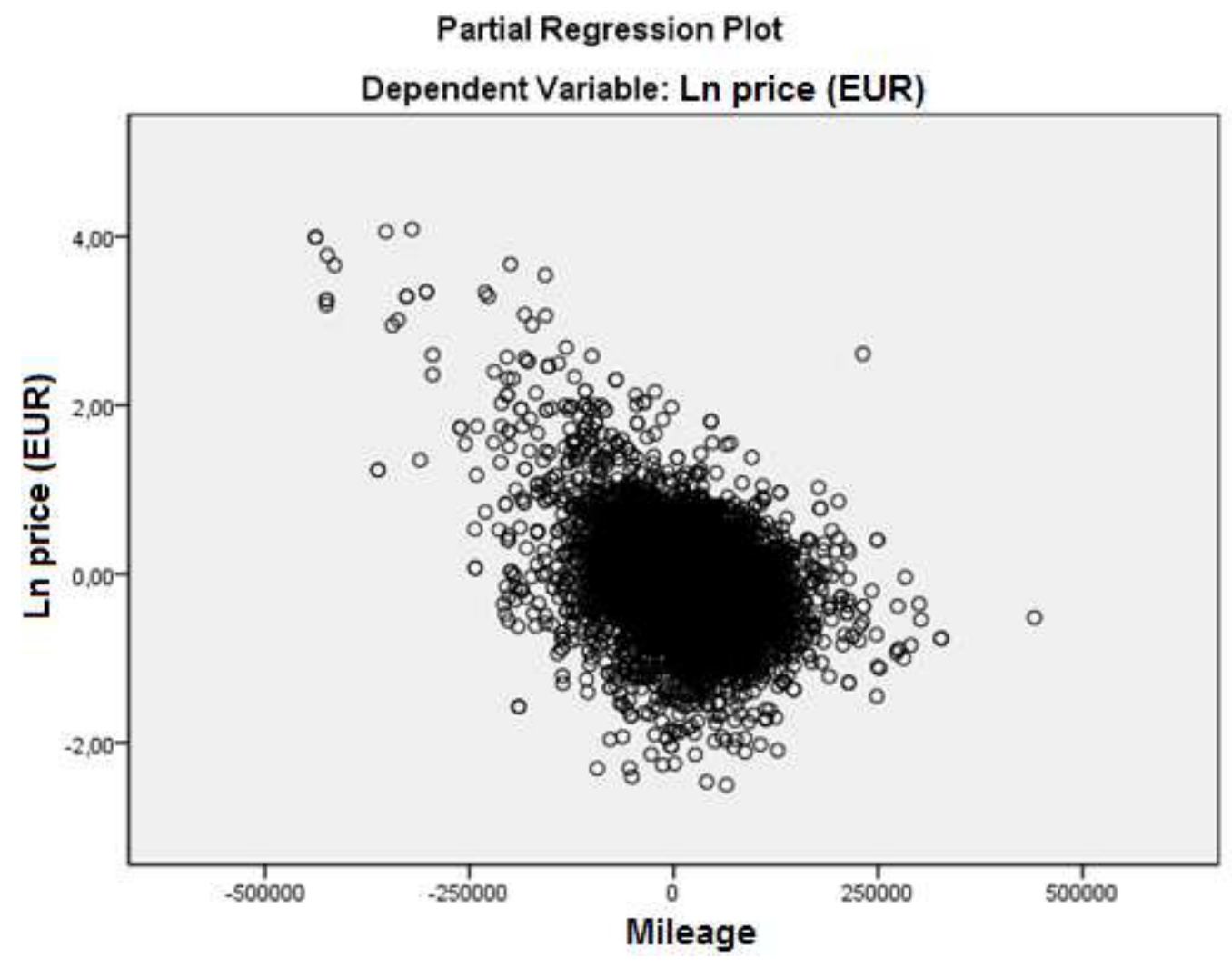


Appendix 2: The results of the pair t-test.

Group Statistics

\begin{tabular}{|cc|c|c|c|c|}
\hline & Percentilis & N & Mean & Std. Deviation & \multicolumn{1}{c|}{$\begin{array}{c}\text { Std. Error } \\
\text { Wean }\end{array}$} \\
\hline Frice & 1,00 & 14339 & 12063,4294 & 7653,03172 & 63,91300 \\
& 3,00 & 14340 & 11775,5462 & 10188,37017 & 85,08052 \\
\hline
\end{tabular}

Independent Samples Test

\begin{tabular}{|c|c|c|c|c|c|c|c|c|c|c|}
\hline & & \multicolumn{2}{|c|}{ Equality of Variances } & \multicolumn{7}{|c|}{ t-test for Equality of Means } \\
\hline & & \multirow[b]{2}{*}{$\mathrm{F}$} & \multirow[b]{2}{*}{ Sig. } & \multirow[b]{2}{*}{$\mathrm{t}$} & \multirow[b]{2}{*}{ df } & \multirow{2}{*}{$\begin{array}{l}\text { Sig. (2- } \\
\text { tailed) }\end{array}$} & \multirow{2}{*}{$\begin{array}{c}\text { Mean } \\
\text { Difference }\end{array}$} & \multirow{2}{*}{$\begin{array}{l}\text { Std. Error } \\
\text { Difference }\end{array}$} & \multicolumn{2}{|c|}{ Interval of the } \\
\hline & & & & & & & & & Lower & Upper \\
\hline Price & $\begin{array}{l}\text { Equal } \\
\text { variances } \\
\text { assumed } \\
\text { Equal } \\
\text { variances } \\
\text { not } \\
\text { assumed }\end{array}$ & 330,425 &, 000 & $\begin{array}{l}2,705 \\
2,705\end{array}$ & $\begin{array}{r}28676 \\
26612,624\end{array}$ &, 007 & $\begin{array}{l}287,88325 \\
287,88325\end{array}$ & $\begin{array}{l}106,41432 \\
106,41225\end{array}$ & $\begin{array}{l}79,30629 \\
79,30966\end{array}$ & $\begin{array}{l}496,46022 \\
496,45685\end{array}$ \\
\hline
\end{tabular}




\section{References}

AKERLOF, G. A. [1970]: The Market for "Lemons": Quality Uncertainty and the Market Mechanism. The Quarterly Journal of Economics, Oxford University Press Vol. 84, No. 3, August, pp. 488-500.

ANDRLE, M. [2003]: Measuring Inflation: Another Stochastic Approach Application to Czech Data. EconWpa http://econpapers.repec.org/ Downloaded: 2011-07-06

BARICZ REZSŐ [1994]: Mérlegtan. Aula Kiadó Budapest.

BÉLYÁCZ IVÁN [1992]: Amortizáció és pótlás. Janus Pannonius Egyetemi Kiadó Pécs.

BÉLYÁCZ IVÁN [1993]: Amortizációelmélet. Janus Pannonius Egyetemi Kiadó Pécs.

BÉLYÁCZ IVÁN [1994a]: A tőke megőrzésének koncepciói. Közgazdasági Szemle, 1994/7-8. 662-669. pp

BÉLYÁCZ IVÁN [1994b]: Az amortizáció költség- és értéktermészetéről. Ipargazdasági Szemle, 3. sz. 51-62. o.

BÉLYÁCZ IVÁN [2002]: Adalékok a gazdaságelméleti amortizáció tartalmának tisztázásához. Közgazdasági Szemle, XLIX. Vol., September (741-759. o.)

BOSNYÁK JÁNOS [2003]: Számviteli értékelési eljárások hatása a vállalkozások vagyoni, jövedelmi és pénzügyi helyzetére. Ph.D értekezés, Budapesti Közgazdaságtudományi és Államigazgatási Egyetem, Gazdálkodástudományi Kar.

BÖHM-BAWERK, E. V. [1891]: The Positive Theory of Capital. London: Macmillan and Co.

BREAK, F. G. [1954]: Capital Maintenace and the Concept of Income. The Journal of Political Economy, Vol. 62, No. 1. February, pp. 48-62 The University of Chicago Press. 
BRIEF, R. P. [1967]: A Late Nineteenth Century Contribution to the Theory of Depreciation. Journal of Accounting Research, Vol. 5, No. 1, Spring, pp. 27-38.

BRÓDY ANDRÁS [1990]: Mennyi az ennyi? Bevezetés a gazdasági mérés elméletébe, Közgazdasági szemle, XXXVII. Vol., No. 5, pp. 521-537.

CANNING, J.B. [1929]: The Economics of Accountancy, New York: The Ronald Press Company.

CHRISTENSEN, L. R. ÉS D. W. JORGENSON [1973]: Measuring the Performance of The Private Sector of The US Economy, 1929-1969. In Measuring Economic and Social Performance, edited by M Moss New York Columbia University Press, pp. 233-351.

DAINES, H.C. [1929]: The Changing Objectives of Accounting. The Accounting Review 4, pp. 94-110.

DANIELS, M.B. [1933]: The Valuation of Fixed Assets", The Accounting Review 8, pp. 302-316.

DIEWERT, W.E. [2005]: Issues in the Measurement of Capital Services, Depreciation, Asset Price Changes and Interest Rates. In Measuring Capital in the New Economy, C. Corrado, J. Haltiwanger and D. Sichel (eds.), Chicago: University of Chicago Press, pp. 479-542.

DIEWERT, E. W. [2001]: The Consumer Price Index and Index Number Theory: A Survey, University of British Columbia Discussion Paper No. 2001-02, pp. 1-105

DIEWERT, W. E. [1996]: The Measurement of Business Capital, Income and Performance. University of British Columbia.

DIEWERT, E. W. [1995]: On the Stochastic Approach to Index Numbers. University of British Columbia Discussion Paper No. 95-31, pp. 1-37 
DIEWERT, W. E. ÉS F. C. WYKOFF [2006]: Depreciation, Deterioration and Obsolescence When There Is Embodied or Disembodied Technical Change. Price and Productivity Measurement Volumes 1 and 2, Erwin W. Diewert, Bert M. Balk, Dennis Fixler, Kevin J. Fox and Alice O. Nakamura (eds.), Trafford Press.

DOOLEY, P. C. [2005]: The Labour theory of value, Routledge Frontiers of political economy. 2 park square, Milton park, Abingdon, Oxon, OX14-4RN.

FELDSTEIN, M. S. ÉS M. ROTHSCHILD [1974]: Towards an Economic Theory of Replacement Investment. Econometrica, May, pp. 393-423.

FISHER, I. [1896]: What is Capital? The Economic Journal, Published by: Blackwell Publishing for the Royal Economic Society Vol. 6, No. 24, December, pp. 509534.

GILMAN, S. [1939]: Accounting Concepts of Profit, New York: The Ronald Press Company.

GRILICHES, Z. [1963]: Capital Stock in Investment Functions Some problems of Concept and measurement. In Measurement in Economics, edited by Carl F. Christ, et al Stanford, California Stanford University Press.

HAAVELMO, T. [1960]: A Study in the Theory of Investment. Chicago: University of Chicago Press.

HALL, R. E. [1968]: Technical Change and Capital from the Point of View of the Dual, The Review of Economic Studies, Published by: Oxford University Press Vol. 35, No. 1, January, pp. 35-46.

HALL, R. E. ÉS D. W. JORGENSON [1967]: Tax Policy and Investment Behavior. American Economic Review, 52, pp. 391-414.

HICKS, J. R. [1942]: Maintaining capital intact: a Further Suggestion. Economica, New Series, Vol. 9, No. 34, May, pp. 174-179.

HICKS, J. R. [1978]: Érték és tőke. Közgazdasági és Jogi Könyvkiadó, Budapest. 
HILL, P. [1999]: Capital Stocks, Capital Service and Depreciation. Paper presented at the third meeting of the Canberra Group on Capital Stock Statistics, Washington, D.C..

HOTELLING, H. [1925]: A General Mathematical Theory of Depreciation. Journal of the American Statistical Association 20, pp. 340-353.

HULTEN, C. R. [1990]: The Measurement of Capital. In Fifty Years of Economic Measurement, Studies in Income and Wealth, edited by Ernst R. Berndt and Jack E. Triplett. Chicago: Chicago University Press for the National Bureau of Economic Research, pp. 119-52.

HULTEN, C. R. ÉS F. C. WYKOFF [1981a] The estimation of economic depreciation using vintage asset prices: An application of the Box-Cox power transformation. Journal of Econometrics, Volume 15, Issue 3, April, pp. 367-396.

HULTEN, C. R. ÉS F. C. WYKOFF [1981b]: The Measurement of Economic Depreciation. In Depreciation Inflation and The Taxation of Income From Capital, Edited by Charles R Hulten, Wasington DC The Urban Institute Press, pp. 81-125.

HULTEN, C.R. ÉS F.C. WYKOFF, [1996]: Issues in the Measurement of Economic Depreciation: Introductory Remarks. Economic Inquiry 34, pp. 10-23.

JORGENSON, D. W. [1966]:The Embodiment Hypothesis. Journal of Political Economy, Published by: The University of Chicago Press Vol. 74, No. 1, February, pp. 1-17.

JORGENSON, D. W. [1971]: Econometric Studies of Investment Behavior: A Survey Source: Journal of Economic Literature, Vol. 9, No. 4, December, pp. 1111-1147.

JORGENSON, D.W. [1973]: The Economic Theory of Replacement and Depreciation, in Econometrics and Economic Theory, W. Sellekaerts (ed.), New York Macmillan, pp. 189-221.

JORGENSON, D. W. [1991]: Productivity and Economic Growth. Fifty Years of Economic Measurement: The Jubilee of the Conference on Research in Income and Wealth University of Chicago Press January. 
JORGENSON D.W. [1996]: Empirical Studies Of Depreciation. Economic Inquiry 34, pp. 24-42.

JORGENSON, D. W., J. HUNTER ÉS M. I. NADIRI [1970]: A Comparison of Alternative Econometric Models of Quarterly Investment Behavior. Econometrica, 38 pp. 187-212.

JORGENSON, D. W., és J. A. STEPHENSON [1967]: The Time Structure of Investment Behavior in United States Manufacturing, 1947-1960," Review of Economics and Statistics, 49, pp. 16-27.

JORGENSON, D. W. [1963]: "Capital Theory and Investment Behavior," American Economic Review, 53 (1963), 247-259.

JUHÁSZ PÉTER [2004]: Az üzleti és könyv szerinti érték eltérésének magyarázata Vállalatok mérlegen kívüli tételeinek értékelési problémái. Ph.D értekezés, Budapesti Corvinus Egyetem, Gazdálkodástudományi Kar.

KALICZKA NÁNDOR [2012]: A tartós eszközök értékcsökkenési mintájának empirikus becslése. Közgazdasági Szemle, LIX. Vol., March, pp. 285-310.

KORNAI JÁNOS [2010]: Innováció és dinamizmus. Kölcsönhatás a rendszerek és a technikai haladás között. Közgazdasági Szemle, LVII. Vol., January, pp. 1-37.

LADELLE, O. G. [1890]: The Calculation of Depretiation. In Richard P. Brief: A Late Nineteenth Century Contribution to the Theory of Depreciation. Journal of Accounting Research,1967, Vol. 5, No. 1, Spring, pp. 27-38.

LEE, T. A. [1986]: Income and Value Measurement Theory and Practice. Van Nostrand Reinhold, P. 180

LUTZ, F. A. ÉS V. LUTZ [1951]: The Theory of Investment of the Firm. Princeton: Princeton University Press.

MORISHIMA, M. [1973]: Marx's Economics The Dual Theory of Value and Growht. Cambridge University Press. 
PREINREICH, G.A.D. [1937]: Valuation and Amortization. The Accounting Review, Vol. 12, No. 3, September, pp. 209-226.

PREINREICH, G.A.D. [1938]: Annual Survey of Economic Theory: The Theory of Depreciation. Econometrica, Vol. 6, No. 3, July, pp. 219-241.

RAMANATHAN, R. [2002]: Bevezetés az Ökonometriába. Panem Kiadó, Budapest

RICARDO, D. [1817]: On the Principles of Political Economy and Taxation. Published: London: John Murray, 1821. Third edition.

SCHMALENBACH, E. [1959]: Dynamic Accounting, translated from the German $12^{\text {th }}$ edition of 1955 (first edition 1919) by G.W. Murphy and K.S. Most, London: Gee and Company.

SOWELL T. [1963]: Marxian Value Reconsidered. Economica New Series, Vol. 30, No. 119, August, pp. 297-308

STORCHMANN, K. [2004] On the Depreciation of Automobiles: an International Comparison. Transportation 31, pp. $371-408$.

TRIPLETT, J. E. [1996]: Depreciation in Production Analysis and Income and Wealth Accounts Resolution of an Old Debate. Economic Inquiry 34, pp. 93-115.

WRIGHT F. K. [1964]: Towards a General Theory of Depreciation. Journal of Accountig Research, Vol. 2, No. 1, Spring, pp. 80-90.

WYKOFF, F. C. [2003]: Obsolescence in Economic Depreciation From the Point of View of The Revaluation Term. Pomona College. Unpublished Manuscript. 


\section{Publications of the author in the topic of the thesis}

\section{Articles}

KALICZKA NÁNDOR [2012]: A tartós eszközök értékcsökkenési mintájának empirikus becslése. Közgazdasági Szemle LIX. Vol., March, pp. 285-310.

KALICZKA NÁNDOR [2012]: Az értékcsökkenés megragadásának elméleti és gyakorlati vizsgálata. Számviteli Tanácsadó, February, pp. 2-12.

KALICZKA NÁNDOR [2011]: A technológiai fejlődés hatása a tartós eszközök gazdasági értékcsökkenésére. Vezetéstudomány különszám, november, pp. 97-105. NAFFA HELENA - KALICZKA NÁNDOR [2011]: Az állami szerepvállalás egy modellje a lejárt követelések piacán. Hitelintézeti Szemle, February, pp. 93-107. KALICZKA NÁNDOR [2010]: Az összevont cash flow kimutatás. Számvitel, Adó, Könyvvizsgálat, March, pp. 137-139.

KALICZKA NÁNDOR - NAFFA HELENA [2010]: Természetes jelzések a megbízóügynök koalíció jövedelmének hitelesítésében. Vezetéstudomány, April, pp. 45-54.

\section{Conference papers}

KALICZKA NÁNDOR [2009]: A konszolidált cash flow kimutatás összeállításának megközelítési módjai. Tavaszi Szél Konferencia. May, 2009, Szeged.

KALICZKA NÁNDOR [2009]: Credibility of earnings from a principal-agent coalition perspective. Fikusz Symposium for young researchers. november, 2009, Budapest.

NAFFA HELENA - KALICZKA NÁNDOR [2009]: Multivariate Analysis of Relative Equity Valuation. Challenges for Analysis of the Economy, the Businesses, and Social Progress. 2009 november, Szeged.

KALICZKA NÁNDOR [2009]: Natural signals in affirming principal-agent coalition earnings. Erdei Ferenc V. Tudományos Konferencia. 2009. September, Kecskemét. KALICZKA NÁNDOR [2009]: Paradigm thinking in a world of accounting. Erdei Ferenc V. Tudományos Konferencia. 2009. September, Kecskemét.

\section{Other}

KALICZKA NÁNDOR [2011]: The Estimation of Economic Depreciation Using the Vintage Asset Model - an Empirical Test on Car Supply Prices. Summer Academy Presentation. European Doctoral Programmes Association in Management and Business Administration (EDAMBA), Soreze-France. 